TARITA SHIRAISHI FURLAN

\title{
ESTUDO DO EFEITO DO TRATAMENTO TÉRMICO E DA ADIÇÃO DE ZIRCÔNIO, VANÁDIO, TITÂNIO E MANGANÊS NAS PROPRIEDADES MECÂNICAS DE UMA LIGA AISi12CuMgNi PARA APLICAÇÃO EM ALTAS TEMPERATURAS
}

Tese apresentada à Escola Politécnica da Universidade de São Paulo para obtenção do título de Doutor em engenharia

São Paulo 
TARITA SHIRAISHI FURLAN

\section{ESTUDO DO EFEITO DO TRATAMENTO TÉRMICO E DA ADIÇÃO DE ZIRCÔNIO, VANÁDIO, TITÂNIO E MANGANÊS NAS PROPRIEDADES MECÂNICAS DE UMA LIGA AISi12CuMgNi PARA APLICAÇÃO EM ALTAS TEMPERATURAS}

Tese apresentada à Escola Politécnica da Universidade de São Paulo para obtenção do título de Doutor em engenharia

Área de concentração:

Engenharia Metalúrgica e de Materiais

Orientador: Prof. Dr. André Paulo Tschiptschin

São Paulo 
Este exemplar foi revisado e corrigido em relação à versão original, sob responsabilidade única do autor e com a anuência de seu orientador.

São Paulo, 15 de maio de 2014.

Assinatura do autor

Assinatura do orientador

Furlan, Tarita Shiraishi

Estudo do efeito do tratamento térmico e da adição de zircônio, vanádio, titânio e manganês nas propriedades mecânicas de uma liga Al12SiCuMgNi para aplicação em altas temperaturas / T.S. Furlan. -- versão corr. -- São Paulo, 2014. $165 \mathrm{p}$.

Tese (Doutorado) - Escola Politécnica da Universidade de São Paulo. Departamento de Engenharia Metalúrgica e de Materiais.

1.Ligas metálicas 2.Tratamento térmico 3.Alta temperatura I.Universidade de São Paulo. Escola Politécnica. Departamento de Engenharia Metalúrgica e de Materiais Il.t. 


\section{AGRADECIMENTOS}

Gostaria de agradecer a todos que de alguma forma participaram da realização deste projeto e, felizmente, não foram poucas pessoas.

Ao meu orientador Professor Doutor André Paulo Tschiptschin.

Ao Doutor Ricardo Fuoco, por toda a orientação informal.

À KSPG Automotive Brazil Ltda. pelo apoio. Em particular ao Carlos Tomaselli e ao Silas Damasceno.

Aos colegas que participaram ativamente da parte operacional deste projeto:

Ao Lourival e Francisco pelas peças.

Aos operadores da fusão, representados pelo Juninho, pela fabricação e tratamento da liga.

Aos operadores da sala de teste, em particular, ao Cidão, pelas amostras.

Aos analistas de laboratório Adenilson, Leandro, Amilton, Valdir, Dracena e Rafael pelos infinitos polimentos e cortes de amostras.

Aos operadores de ferramentaria e manutenção de coquilhas, representados pelo Rafael Mattos, pelos corpos de prova e ferramental de fundição.

Aos operadores de tratamento térmico, representados pelo Robinho, pelos intermináveis tratamentos.

Ao Professor Doutor Waldek Bose Filho, ao Douglas Bon e ao William Naville pelos ensaios mecânicos.

Ao Edward Werninghaus pela interpretação dos dados.

Ao Veríssimo dos Santos pela microscopia eletrônica.

Aos colegas que não participaram ativamente do projeto, mas que sempre apoiaram:

Allan, Thiago, Reinaldo, João, Bruno, Guilherme, Claudiner, Osmar, Paulinho, Murillo, Giba, Jean, David e Fernando.

E por fim, à minha família, por tudo que não é mensurável, mas que não deixa de ser importante. 


\section{RESUMO}

Neste trabalho foram estudados os efeitos do tratamento térmico e da adição de zircônio, vanádio, titânio e manganês nas propriedades mecânicas em alta temperatura de uma liga AlSi12CuMgNi, comumente utilizada em pistões automotivos. Os resultados de tração a $300^{\circ} \mathrm{C}$ mostram que a adição de elementos de liga reduz o alongamento sem aumentar o limite de escoamento. Os ensaios de fadiga a $300^{\circ} \mathrm{C}$ mostram que a aplicação de um tratamento de solubilização a $525^{\circ} \mathrm{C}$ por 15 minutos é duas vezes melhor que a aplicação de um tratamento de solubilização a $500^{\circ} \mathrm{C}$ por uma hora. Estes resultados foram atribuídos ao arredondamento das partículas de silício que, por serem partículas frágeis, quando arredondadas ocupam menor área por volume, reduzindo a velocidade de propagação de trincas. Os ensaios de fadiga a $300^{\circ} \mathrm{C}$ mostram também que a adição de elementos de liga combinados a um tratamento de solubilização a $525^{\circ} \mathrm{C}$ por 15 minutos é cerca de $30 \%$ pior que o mesmo tratamento aplicado a uma liga sem a adição destes elementos de liga. Este fenômeno foi atribuído à fragilização dos intermetálicos que, por consequência, aumentam a velocidade de propagação das trincas de fadiga. 


\section{ABSTRACT}

The effects of heat treatment and the addition of zirconium, vanadium, titanium and manganese on the high temperature properties of an AlSi12CuMgSi alloy, usually applied to cast automotive pistons, were studied. The tensile test results at $300^{\circ} \mathrm{C}$ show that the addition of alloying elements decreases the elongation without significantly increasing the yield strength. The fatigue tests at $300^{\circ} \mathrm{C}$ show that a solution heat treatment at $525^{\circ} \mathrm{C}$ for 15 minutes is two times better than a solution heat treatment at $500^{\circ} \mathrm{C}$ for one hour. These results are due to the spheroidization of the silicone particles that are brittle and, when spheroidized, have a smaller area/volume ratio, slowing the crack propagation speed. The fatigue tests at $300^{\circ} \mathrm{C}$ also show that the addition of alloying elements combined with a solutionizing treatment at $525^{\circ} \mathrm{C}$ for 15 minutes is $30 \%$ worse than the same treatment applied to an alloy without these alloying elements.

This behavior is due to the embrittlement of the intermetallic particles containing these alloying elements, increasing the fatigue crack propagation speed. 


\section{LISTA DE FIGURAS}

Figura 1 - llustração dos quatro tempos de um motor a combustão interna. [Heywood, 1998].

Figura 2 - Gráfico de tendência desenvolvimento de motores: potência específica x ano de início de produção.

Figura 3 - Deformação e principais esforços sobre o pistão sob carregamento e temperatura. [Röhrle, 1995]..

Figura 4 - Distribuição de cargas (figura à direita) e temperaturas (figura à esquerda) em um pistão para motores diesel. [Lehmann et al., 2002].

Figura 5 - Distribuição de temperaturas de trabalho $\left(\mathrm{em}^{\circ} \mathrm{C}\right)$ em um pistão diesel......... 24 Figura 6 - Superfície de fratura por fadiga de um pistão diesel. [Floweday et al., 2011]25 Figura 7 - Dureza de uma liga A319 e uma liga A319 contendo 0,15\%Zr solubilizadas a $505^{\circ} \mathrm{C}$. [Sepehrband et al., 2005]

Figura 8 - DTA de uma liga AISi12Cu5Ni2Mg contendo traços dos elementos que formam diagramas peritéticos com o alumínio (zircônio, vanádio e titânio) com taxa de aquecimento de $4,2^{\circ} \mathrm{C} / \mathrm{min}$.

Figura 9 - DTA de uma liga AISi12Cu5Ni2 contendo traços dos elementos que formam diagramas peritéticos com o alumínio (zircônio, vanádio e titânio) com taxa de aquecimento de $4,2^{\circ} \mathrm{C} / \mathrm{min}$.

Figura 10 - Curvas de DTA de ligas Al-Si-Mg-xCu (x=2\%, 3\%, 4\% e 5\%) a 30K/min [Zeren et al., 2011].

Figura 11 - Diagrama de fases Al-Si [ASM Metals Handbook, 1993].

Figura 12 - Superfície polida de uma liga AISi7Mg0,3 não modificada. [Furlan, 2007].. 34

Figura 13 - Liga AISi7Mg0,3 não modificada após ataque químico profundo do alumínio. [Furlan, 2007].

Figura 14 - Superfície polida de uma liga AISi7Mg0,3 modificada com estrôncio.

[Furlan, 2007].

Figura 15 - Liga AlSi7Mg0,3 modificada após ataque químico profundo do alumínio. [Furlan, 2007]

Figura 16 - Fluidez de ligas binárias de alumínio no teste de espiral. (a) Al-Cu; (b) Al-Si, (c) Al-Mg. [Lang, 1972]. 
Figura 17 - Microestrutura de uma liga Al-12,6\%Si: (a) sem adição de refinador; (b) com adição de 0,8\%Al-3,5P [Yu et al., 2007]. 38

Figura 18 - Análise do núcleo de uma partícula de silício primário em EPMA de uma liga Al-30\%Si. (a) MEV - elétrons retro espalhados. O ponto "B" aponta para o núcleo da particula; (b) imagem de raio-X do alumínio; (c) imagem de raio- $X$ do silício;

(d)Imagem de raio-X do fósforo. [Zuo, 2009].

Figura 19 - Imagem do diagrama de fases AI-P. [Facsage] .................................................... 42

Figura 20 - Imagem da estrutura cúbica do composto Al-P. [Zuo et al., 2009]

Figura 21 - Limite de solubilidade do magnésio e do silício no alumínio em função da temperatura. [Apelian et al., 1989].

Figura 22 - Coeficiente de expansão térmica de ligas Al-Si-Cu-Ni-Mg contendo diferentes teores de cobre. [Yang et al., 2012].

Figura 23 - Limite de resistência a $350^{\circ} \mathrm{C}$ de ligas Al-Si-Cu-Ni-Mg contendo diferentes teores de cobre. Gráfico obtido a partir dos dados de [Yang et al., 2012].

Figura 24 - (a) $\mathrm{Al}_{2} \mathrm{Cu}$ eutético lamelar; (b) $\mathrm{Al}_{2} \mathrm{Cu}$ eutético em formato de bloco [Li et al., 2003]. 48

Figura 25 - Propagação de trincas através de partículas de Fe: (a) plaquetas de $\beta$ $\mathrm{Al}_{5} \mathrm{FeSi}$; (b) escrita chinesa $\alpha-\mathrm{Al}_{15}(\mathrm{Fe}, \mathrm{Mn})_{3} \mathrm{Si}_{2}$. [Taylor, 1995]. 49

Figura 26 - Solubilidade do ferro em ligas AI-Si. [Taylor, 1995] 50

Figura 27 - Micrografias de diversos intermetálicos contendo ferro, mostrando suas morfologias típicas em uma liga Al- $5 \% \mathrm{Si}-1 \% \mathrm{Cu}-0,5 \% \mathrm{Mg}-(\mathrm{Fe})$ : (a) plaquetas de $\beta$ Als $\mathrm{FeSi}$; (b) escrita chinesa de $\alpha-\mathrm{Al}_{8} \mathrm{Fe}{ }_{2} \mathrm{Si}$; (c) fase $\pi$ crescendo de $\beta$; (d) escrita chinesa de $\pi$. [Taylor, 1995]...

Figura 28 - Morfologia das fases: (a) $\varepsilon-\mathrm{Al}_{3} \mathrm{Ni}$; (b) $\delta$-Al7 $\mathrm{Cu}_{4} \mathrm{Ni}$; (c) $\gamma$ - $\mathrm{Al}_{3} \mathrm{CuNi}$. [Li et al., 2010]. 52

Figura 29 - Reconstrução 3D da morfologia do silício na condição bruta de fundição de uma liga AISi12: (a) estrutura do silício com placas interconectadas (cada grupo de placas está identificado com um tom de cinza diferente); (b) detalhe dos nós de conexão [Lasagni et al., 2007].

Figura 30 - Reconstrução 3D da morfologia do silício após solubilização a $540^{\circ} \mathrm{C}$ por 20 minutos de uma liga AISi12. [Lasagni et al., 2007].

Figura 31 - Reconstrução da estrutura 3D do silício (roxo) + intermetálicos contendo níquel (verde) em uma AISi12 através de secções sucessivas em tomografia óptica: (a) bruto de fundição composto por secções de $0,5 \mu \mathrm{m}$ em um volume de $X=51,75 \mu \mathrm{m}$, $\mathrm{Y}=48,80 \mu \mathrm{m}, \mathrm{Z}=14,5 \mu \mathrm{m}$; (b) Após solubilização a $540^{\circ} \mathrm{C}$ por 24 horas em secções de $0,6 \mu \mathrm{m}$ em um volume de $X=51,75 \mu \mathrm{m}, \mathrm{Y}=48,80 \mu \mathrm{m}, Z=16,5 \mu \mathrm{m}$. [Asghar et. al., 2009] ... 56 
Figura 32 - Limite de escoamento em compressão em temperatura ambiente (T.A.) e a $300^{\circ} \mathrm{C}$ para as ligas AlSi12Ni e AlSi12CuMgNi [Asghar et al., 2014]. 58

Figura 33 - Limite de resistência de ligas comumente utilizadas em pistões: (a) condição bruta de fundição; (b) após tratamento de solubilização e envelhecimento. [Zeren, 2007]

Figura 34 - Estrutura (a) LI2 cúbica; (b) DO23 tetragonal [Ryum, 1969] 64

Figura 35 - Dureza de uma liga A319 e uma liga A319 contendo 0,15\%Zr solubilizadas a $505^{\circ} \mathrm{C}$. [Sepehrband et al., 2005].

Figura 36 - Variação da dureza com o tempo de envelhecimento a $195^{\circ} \mathrm{C}$ das ligas A319 e A319Zr solubilizadas a $505^{\circ} \mathrm{C}$ por: (a) 8 horas e; (b) 24 horas. [Sepehrband et al., 2005]

Figura 37 - Curvas de envelhecimento para as ligas A319 e A319Zr solubilizadas a $503^{\circ} \mathrm{C}$ por 24 horas para diferentes temperaturas: (a) $175^{\circ} \mathrm{C}$; (b) $195^{\circ} \mathrm{C}$; (c) $215^{\circ} \mathrm{C}$;

(d) $235^{\circ} \mathrm{C}$. [Mahmudi et al., 2006].

Figura 38 - Curvas de envelhecimento para a liga AISi7Mg0,3 solubilizada a $538^{\circ} \mathrm{C}$ por 8 horas e envelhecidas a $154^{\circ} \mathrm{C}$ contendo: A0 (0\%Zr); A1 (0,1\%Zr); A2 (0,2\%Zr); A3 (0,3\%Zr); [Baradarani; Raiszadeh, 2011] . 68

Figura 39 -Curvas de envelhecimento para a liga AISi7Mg0,3 solubilizada a $538^{\circ} \mathrm{C}$ por 24 horas e envelhecidas a $154^{\circ} \mathrm{C}$ contendo: A0 (0\%Zr); A1 (0,1\%Zr); A2 (0,2\%Zr); A3 (0,3\%Zr). [Baradarani; Raiszadeh, 2011] .

Figura 40 - Solubilidade do Zr e do V em função da temperatura. [Garat, 2011] 71

Figura 41 - Limite de resistência a $300^{\circ} \mathrm{C}$ em função do teor de manganês da liga ZL109. Gráfico plotado a partir de dados obtidos por [Qian et al., 2008]

Figura 42 - Início de uma trinca por fadiga à temperatura ambiente a partir de uma partícula de silício primário. [Joyce et. al, 2003]..

Figura 43 - Início de uma trinca por fadiga à temperatura ambiente a partir de uma partícula de silício primário. [Joyce et. al, 2003]...

-Figura 44 - Crescimento intra-dendrítico em uma liga contendo $7 \% \mathrm{Si} ; \Delta \mathrm{K}=2 \mathrm{MPa} \sqrt{\mathrm{m}}$.

[Moffat et al., 2005]

Figura 45 - Crescimento inter-dendrítico em uma liga contendo $7 \% \mathrm{Si} ; \Delta \mathrm{K}=11 \mathrm{MPa} \sqrt{\mathrm{m}}$. [Moffat et al., 2005]

Figura 46 - De-coesão e fratura de partículas de silício em uma liga contendo 12,5\% $\mathrm{Si}$; $\Delta \mathrm{K}=4,9 \mathrm{MPa} \sqrt{\mathrm{m}}$. [Moffat et al., 2005]

Figura 47 - Partículas de silício fraturadas em uma liga contendo 12,5\%Si; 
Figura 48 - Correlação entre tamanho de óxido e número de ciclos até a falha. [Wang et al., 2001]

Figura 49 - Curva da amplitude máxima de tensão versus a deformação plástica (Pcum). [Guillot et al., 2002].

Figura 50 - Representação esquemática de um galho de fundição de pistões. 83

Figura 50 - Vista lateral. Região onde foi retirado o material para usinagem dos corpos de prova (medidas em $\mathrm{mm}$ ).

Figura 51 - Vista superior (corte na posição $C$ da Figura 50). Região onde foi retirado o material para usinagem dos corpos de prova (medidas em $\mathrm{mm}$ ). 83

Figura 52 - Medição de partículas de silício primário. 85

Figura 53 - Medição de área e perímetro das partículas de silício, realizada pelo software Pax-it.

Figura 54 - Medição de área e perímetro de todas as partículas, realizada pelo software Pax-it. 86

Figura 55 - Medição de área das partículas de silício, realizada pelo software Pax-it... 87 Figura 56 - Medição de área do total de partículas, realizada pelo software Pax-it........ 88

Figura 57 - Sobreposição de 10 linhas paralelas sobre a imagem de uma microestrutura com 200x de aumento.

Figura 58 - Forno tipo mufla utilizado para estabelecer as curvas de tratamento térmico. 90

Figura 59 - Forno de solubilização. 91

Figura 60 - Posicionamento da carga e dos termopares no forno de solubilização........ 91

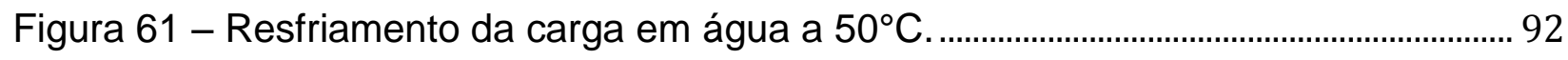

Figura 62 - Curvas de solubilização a $500^{\circ} \mathrm{C}$............................................................................ 93

Figura 63 - Curvas de solubilização a $525^{\circ} \mathrm{C}$......................................................................... 94

Figura 64 - ciclo de tratamento térmico tradicional..................................................................... 95

Figura 65 - ciclo de tratamento térmico proposto. ...................................................................... 95

Figura 66 - Posicionamento do termopar de controle no forno de envelhecimento........ 95

Figura 67 - Posicionamento da carga no forno de envelhecimento. ....................................... 95

Figura 68 - Curvas de envelhecimento a $230^{\circ} \mathrm{C}$. ......................................................................... 96 
Figura 69 - Desenho do corpo de prova.

Figura 70 - Demarcação da região da qual o corpo de prova foi extraído............................. 97

Figura 71 - Corpo de prova sobreposto à região de extração do mesmo. ............................97

Figura 72 - Corpos de prova fraturados na região de concordância.......................................98

Figura 73 - Rugosidade superficial do corpo de prova após usinagem................................. 98

Figura 74 - Rugosidade superficial do corpo de prova após polimento.................................. 99

Figura 75 - Aspecto superficial do corpo de prova antes e após polimento......................... 99

Figura 76 - Equipamento MTS810 com forno MTS653.........................................................100

Figura 77 - Medição da temperatura da superfície do corpo de prova com termopar de contato.

Figura 78 - Equipamento MTS com forno elétrico de resistência...........................................102

Figura 79 - Fixação do termopar ao corpo de prova..................................................................103

Figura 81 - Esforços na borda de câmara de um pistão diesel. [Röhrle, 1995] ................104

Figura 81 - Comparação entre os resultados preliminares de fadiga a quente................107

Figura 82 - Comparação entre os resultados de fadiga a quente $\left(\sigma_{a}=80 \mathrm{MPa}\right)$...............108

Figura 83 - Gráfico boxplot dos resultados de fadiga a quente ( $\left.\sigma_{\mathrm{a}}=80 \mathrm{MPa}\right)$ para as séries de referência, R-ZrVTi, R-ZrVTiMn e R-TT.

Figura 84 - Representação gráfica das retas de expectativa de vida em fadiga paralelas entre si [Lipson; Sheth, 1973].

Figura 85 - Macrografia da liga de referência.

Figura 86 - Macrografia da liga $\mathrm{R}-\mathrm{Zr}$.

Figura 87 - Macrografia da liga R-ZrV.

Figura 88 - Macrografia da liga R-ZrVTi.

Figura 89 - Macrografia da liga R-ZrVTiMn.

Figura 90 - Teste de normalidade dos residuais.

Figura 91 - Teste de normalidade dos residuais, excluindo-se resultados discrepantes.

Figura 92 - Gráfico da vida média em fadiga com amplitude de tensão de $76 \mathrm{MPa}$ e intervalo de confiança de $95 \%$. 
Figura 93 - Gráfico da vida média em fadiga com amplitude de tensão de 80MPa e intervalo de confiança de $95 \%$ para as séries de referência e R-TT.

Figura 94 - Série de Referência (500x).

Figura 95 - R-TT (500x).

Figura 96 - Série de Referência (2000x).

Figura 97 - Série de Referência (2000x).

Figura 98 - Série de R-TT (2000x).

Figura 99 - Série de R-TT (2000x)

Figura 100 - Amostra 1: região de início da fratura (250x - SE).

Figura 101 - Amostra 1: partícula de silício no início da fratura (2500x - BSE).

Figura 102 - Amostra 2: região de início da fratura (250x - SE).

Figura 103 - Amostra 2: partícula de silício no início da fratura (2500x - BSE).

Figura 104 - Amostra 3: região de início da fratura (80x - SE).

Figura 105 - Amostra 3: nenhuma anomalia no início da fratura (500x - BSE).

Figura 106 - Amostra 9: região de início da fratura (250x - SE).

Figura 107 - Amostra 9: partícula de silício no início da fratura (2500x - BSE).

Figura 108 - Amostra 10: região de início da fratura (250x - SE).

Figura 109 - Amostra 10: grão de alumínio no início da fratura (500x - SE).

Figura 110 - Amostra 11: região de início da fratura (500x - SE).

Figura 111 - Amostra 11: nenhuma anomalia no início da fratura (500x - BSE)

Figura 112 - Amostra 13: região de início da fratura (250x - SE).

Figura 113 - Amostra 13: nenhuma anomalia no início da fratura (500x - BSE)

Figura 114 - Amostra 14: superfície de fratura com presença de feather crystals (35x -

$\mathrm{SE})$.

Figura 115 - Amostra 14: detalhe dos feather crystals (500x - SE).

Figura 116 - Amostra 16: região de início da fratura (80x - SE).

Figura 117 - Amostra 16: partícula de silício no início da fratura (2500x - BSE).

Figura 118 - Amostra 17: região de início da fratura (80x - SE). 
Figura 119 - Amostra 17: partícula de silício no início da fratura (2500x - BSE) ............125

Figura 120 - Amostra 18: região de início da fratura (250x - SE)........................................125

Figura 121 - Amostra 18: partículas de silício no início da fratura (2500x - BSE)..........125

Figura 122 - Amostra 19: região de início da fratura (250x - SE).........................................125

Figura 123 - Amostra 19: partícula de silício no início da fratura (2500x - BSE)............125

Figura 124 - Amostra 21: região de início da fratura (250x - SE)........................................126

Figura 125 - Amostra 21: nenhuma anomalia no início da fratura (500x - SE)................126

Figura 126 - Amostra 22: região de início da fratura (250x - SE).......................................126

Figura 127 - Amostra 22: nenhuma anomalia no início da fratura (500x - BSE).............126

Figura 128 - Amostra 23: região de início da fratura (250x - SE).......................................126

Figura 129 - Amostra 23: partícula de silício no início da fratura (2500x - BSE)............126

Figura 130 - Amostra 27: região de início da fratura (80x - SE) ...........................................127

Figura 131 - Amostra 27: nenhuma anomalia no início da fratura (500x - BSE).............127

Figura 132 - Amostra 28: região de início da fratura (250x - SE) ........................................127

Figura 133 - Amostra 28: partícula de silício no início da fratura (2500x - BSE)............127

Figura 134 - Amostra 29: região de início da fratura (250x - SE).........................................127

Figura 135 - Amostra 29: partícula de silício no início da fratura (1500x - SE)...............127

Figura 136 - Amostra 30: região de início da fratura (250x - SE) ..........................................128

Figura 137 - Amostra 30: partícula de silício no início da fratura (2500x - BSE)............128

Figura 138 - Distribuição de tamanho de partículas de silício primário................................129

Figura 139 - Comparação do fator de circularidade das partículas de silício grandes (maiores que 100 $\mu \mathrm{m}^{2}$ ) das séries de Referência e R-TT. ......................................................130

Figura 140 - Série de Referência (Amostra 1): superfície de fratura (200x)....................131

Figura 141 - Série de Referência (Amostra 1): superfície de fratura (500x) .....................131

Figura 142 - Série R-TT (Amostra 32): superfície de fratura (200x)...................................132

Figura 143 - Série R-TT (Amostra 32): superfície de fratura (500x). ..................................132 
Figura 144 - Comparação do fator de circularidade das partículas de silício das séries de referência antes do tratamento térmico (Referência BF) e após o tratamento térmico (Referência e R-TT).

Figura 145 - Fator de circularidade total das séries de Referência e R-TT. .133

Figura 146 - Gráfico da vida média em fadiga com amplitude de tensão de 76MPa e intervalo de confiança de $95 \%$ para as séries R-ZrVTiMn e R-TT.

Figura 147 - Série R-ZrVTiMn (500x). 136

Figura 148 - R-TT (500x). 136

Figura 149 - Série de R-TT (2000x).

Figura 150 - Série de R-TT (2000x).

Figura 151 - Série de R-ZrVTiMn (2000x)

Figura 152 - Série de R-ZrVTiMn (2000x)

Figura 153 - Análise de composição química em EDS das fases presentes na microestrutura da série R-TT. Dados de composição química em peso\%.

Figura 154 - Análise de composição química em EDS das fases presentes na microestrutura da série de R-ZrVTiMn. Dados de composição química em peso\%......141

Figura 155 - Comparação de fator de circularidade das partículas de silício entre as séries R-ZrVTiMn e R-TT.

Figura 156 - Fator de circularidade total das séries de R-ZrVTiMn e R-TT

Figura 157 - Dados de Tensão-Deformação a $300^{\circ} \mathrm{C}$.

Figura 158 - Série R-ZrVTiMn (Amostra 22): superfície de fratura (200x). 144

Figura 159 - Série R-ZrVTiMn (Amostra 22): superfície de fratura (500x). 144

Figura 160 - Série R-TT (Amostra 32): superfície de fratura (200x). 145

Figura 161 - Série R-TT (Amostra 32): superfície de fratura (500x). 145

Figura 162 - Superfície de fratura do corpo de prova de tração a quente da série R-TT. 146

Figura 163 - Superfície de fratura do corpo de prova de tração a quente da série R-TT. 146

Figura 164 - Superfície de fratura do corpo de prova de tração a quente da série R-TT. 
Figura 165 - Superfície de fratura do corpo de prova de tração a quente da série R-TT.

Figura 166 - Superfície de fratura do corpo de prova de tração a quente da série R-TT.

Figura 167 - Superfície de fratura do corpo de prova de tração a quente da série R-TT.

Figura 168 - Superfície de fratura do corpo de prova de tração a quente da série R-TT.

Figura 169 - Superfície de fratura do corpo de prova de tração a quente da série R-TT.

Figura 170 - Superfície de fratura do corpo de prova de tração a quente da série R-TT.

Figura 171 - Superfície de fratura do corpo de prova de tração a quente da série R-TT.

Figura 172 - Superfície de fratura do corpo de prova de tração a quente da série R-TT.

Figura 173 - Superfície de fratura do corpo de prova de tração a quente da série R-TT.

Figura 174 - Superfície de fratura do corpo de prova de tração a quente da série R-TT.

Figura 175 - Superfície de fratura do corpo de prova de tração a quente da série R-TT.

Figura 176 - Superfície de fratura do corpo de prova de tração a quente da série R-TT. 148

Figura 177 - Superfície de fratura do corpo de prova de tração a quente da série R-TT. 148

Figura 178 - Superfície de fratura do corpo de prova de tração a quente da série R-TT. 148

Figura 179 - Superfície de fratura do corpo de prova de tração a quente da série R-TT.

Figura 180 - Superfície de fratura do corpo de prova de tração a quente da série R-TT.

Figura 181 - Superfície de fratura do corpo de prova de tração a quente da série RZrVTiMn. 
Figura 182 - Superfície de fratura do corpo de prova de tração a quente da série RZrVTiMn.

Figura 183 - Superfície de fratura do corpo de prova de tração a quente da série RZrVTiMn.

Figura 184 - Superfície de fratura do corpo de prova de tração a quente da série RZrVTiMn.

Figura 185 - Superfície de fratura do corpo de prova de tração a quente da série RZrVTiMn.

Figura 186 - Superfície de fratura do corpo de prova de tração a quente da série RZrVTiMn.

Figura 187 - Superfície de fratura do corpo de prova de tração a quente da série RZrVTiMn.

Figura 188 - Superfície de fratura do corpo de prova de tração a quente da série RZrVTiMn.

Figura 189 - Superfície de fratura do corpo de prova de tração a quente da série RZrVTiMn.

Figura 190 - Superfície de fratura do corpo de prova de tração a quente da série RZrVTiMn.

Figura 191 - Superfície de fratura do corpo de prova de tração a quente da série RZrVTiMn.

Figura 192 - Superfície de fratura do corpo de prova de tração a quente da série RZrVTiMn.

Figura 193 - Superfície de fratura do corpo de prova de tração a quente da série RZrVTiMn.

Figura 194 - Superfície de fratura do corpo de prova de tração a quente da série RZrVTiMn.

Figura 195 - Superfície de fratura do corpo de prova de tração a quente da série RZrVTiMn.

Figura 196 - Superfície de fratura do corpo de prova de tração a quente da série RZrVTiMn.

Figura 197 - Superfície de fratura do corpo de prova de tração a quente da série RZrVTiMn.

Figura 198 - Superfície de fratura do corpo de prova de tração a quente da série RZrVTiMn. 
Figura 199 - Superfície de fratura do corpo de prova de tração a quente da série R-

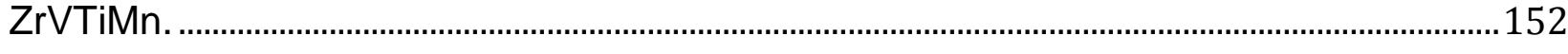

Figura 200 - Superfície de fratura do corpo de prova de tração a quente da série R-

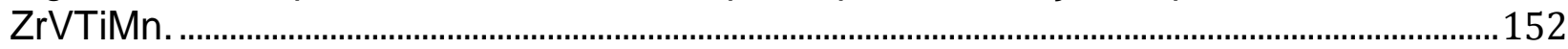




\section{LISTA DE TABELAS}

Tabela 1 - Propriedades mecânicas das ligas estudadas por [Garat; Laslaz, 2002] ...... 26

Tabela 2 - Composição química da liga A390.1 e da liga real utilizada para determinar a seqüência de solidificação. [Backerud, 1990]............................................................................ 38

Tabela 3 - Seqüência de reações durante a solidificação [Backerud, 1990] ...................... 39

Tabela 4 - Resultados obtidos por [Li et al., 2010] para diferentes frações volumétricas das fases $\varepsilon, \delta$ e $\gamma$.

Tabela 5 - Códigos de condições de tratamento em alumínio. [Callister; Rethwisch, 1998].

Tabela 6 - Códigos de tratamentos "T" em alumínio. [Callister; Rethwisch, 1998]............ 54

Tabela 7 - Composições e densidades das fases formadas no sistema

Tabela 8 - Reações invariantes dos sistemas quaternários presentes no sistema Al-Cu-

Fe-Mg-Ni-Si. [Belov et al., 2005]... 62

Tabela 9 - Especificação de composição química da liga de referência. 81

Tabela 10 - Condição inicial das séries para ensaio de tração e fadiga a $230^{\circ} \mathrm{C}$. 96

Tabela 11 - Composição química final das ligas. 105

Tabela 12 - Resultados de dureza das séries após os ensaios de fadiga a quente.....105

Tabela 13 - Resultados preliminares dos ensaios de fadiga a quente. 106

Tabela 14 - Resultados dos ensaios de fadiga a quente $\left(\sigma_{a}=80 \mathrm{MPa}\right)$. 107

Tabela 15 - Resultados dos ensaios de fadiga a quente $\left(\sigma_{a}=100 \mathrm{MPa}, 90 \mathrm{MPa}, 80 \mathrm{MPa}\right.$ e $72 \mathrm{MPa}$ ).

Tabela 16 - Avaliação da presença de anomalias no ponto de início da trinca. 


\section{SUMÁRIO}

FICHA CATALOGRÁFICA. .Error! Bookmark not defined.

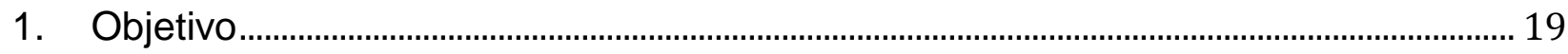

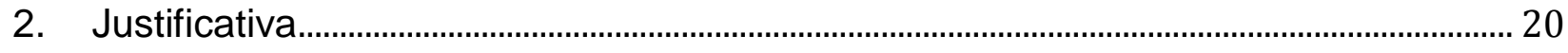

3. Introdução.................................................................................................................. 26

4. Revisão bibliográfica ....................................................................................................... 31

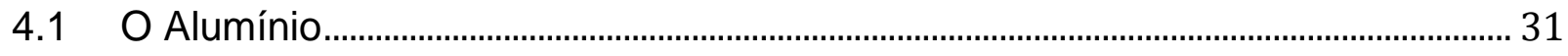

4.2 O sistema Al-Si ......................................................................................................... 31

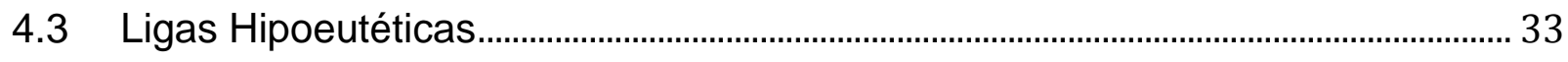

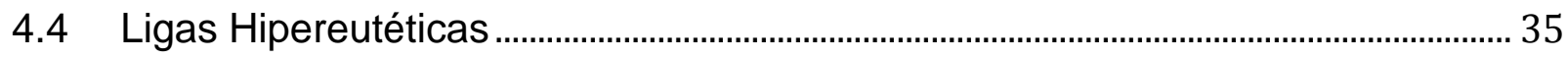

4.4.2 Solidificação de ligas Al-Si hipereutéticas............................................................ 38

4.4.3 Refino de ligas Al-Si hipereutéticas....................................................................... 40

4.5 Principais elementos de liga ................................................................................................. 43

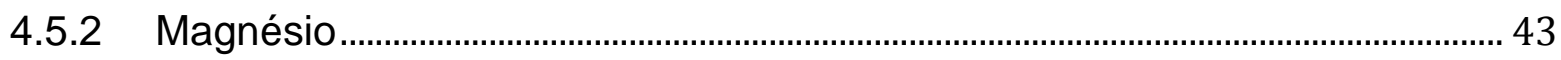

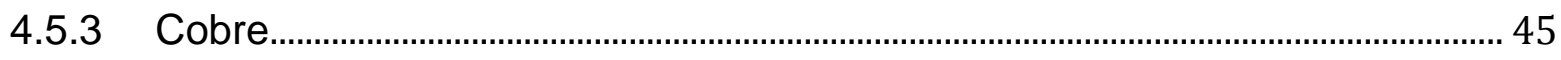

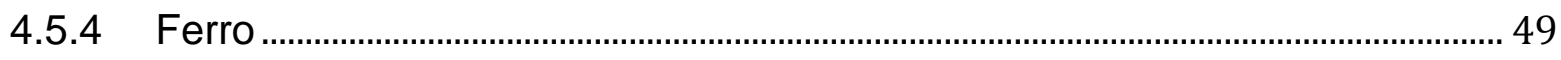

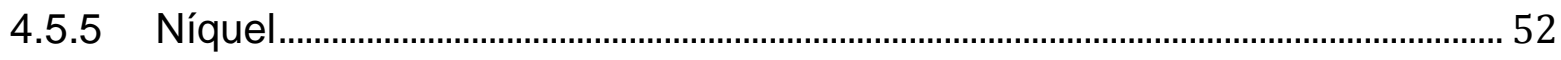

4.6 Tratamento térmico no alumínio e em ligas Al-Si........................................................53

4.6.2 Efeito do tratamento térmico em ensaios de compressão .................................. 58

4.6.3 Efeito do tratamento térmico em ensaios de tração ............................................... 59

4.7 Ligas de alumínio para pistões ....................................................................................... 61

4.8 Ligas de alumínio para altas temperaturas ………………………………………….... 62

4.9 Fadiga

4.9.2 Fadiga em ligas Al-Si........................................................................................ 75

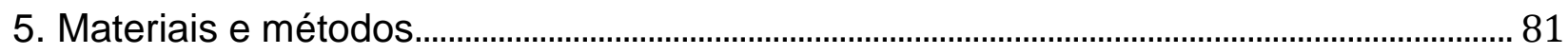


5.1 Preparação da liga e fundição dos pistões para retirada dos corpos de prova. 81

5.2 Caracterização do material e superfícies de fratura ...................................................... 84

5.2.1 Medição do tamanho de partículas de silício primário ........................................... 84

5.2.2 Medição do fator de circularidade de partículas ....................................................... 85

5.2.3 Medição de área de intermetálicos.......................................................................... 87

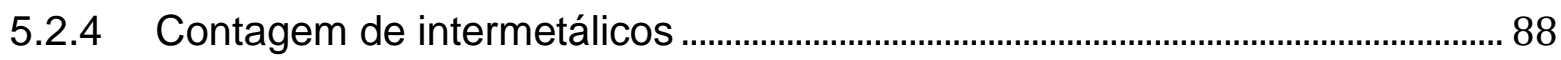

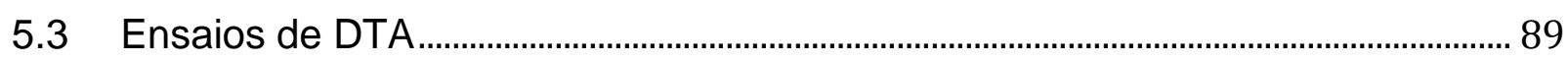

5.4 Curvas de tratamento térmico..................................................................................... 90

5.5 Ensaios de tração e fadiga a quente ………………...................................................... 97

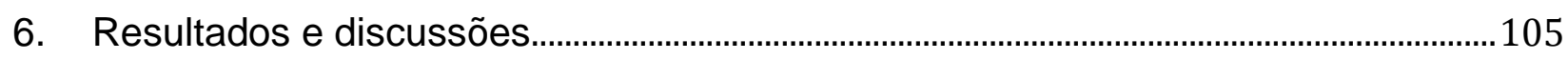

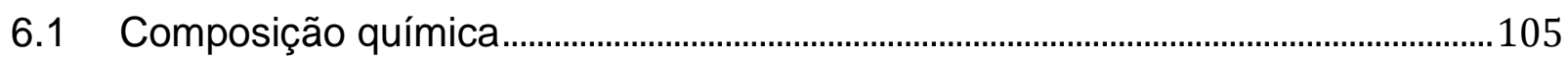

6.2 Ensaios de fadiga a quente......................................................................................105

6.2.1 Modelamento estatístico ......................................................................................109

6.3 Efeito do tratamento térmico …………………............................................................116

6.4 Efeito da adição de elementos de liga ..........................................................................134

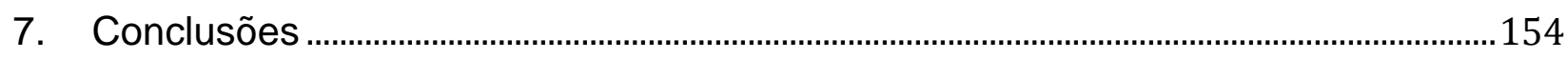

8. Sugestões de trabalhos futuros …………………………………………………….....155

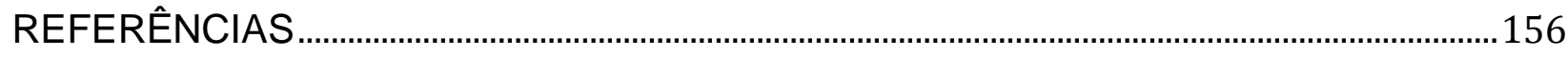




\section{Objetivo}

Este trabalho tem como objetivo a melhoria das propriedades mecânicas de uma liga AISi12CuMgNi tradicionalmente utilizada em pistões automotivos para aplicação em altas temperaturas através de alterações no tratamento térmico e da adição de zircônio, vanádio, titânio e manganês. 


\section{Justificativa}

Motores a combustão interna datam de 1876 quando Otto desenvolveu o motor de ignição por faísca e de 1892 quando Diesel desenvolveu o motor de ignição por compressão. Desde então, os desenvolvimentos em motores continuaram a acontecer, conforme houve aumento no conhecimento em processos de motores, aumento na disponibilidade de novas tecnologias, crescimento da demanda por inovações, assim como das restrições ambientais. [Heywood, 1998]

Nos motores a combustão interna, o pistão se move em um cilindro para baixo e para cima e transmite potência através de um pino conectado a uma biela que está ligada ao virabrequim.

A maior parte dos motores a combustão interna trabalham em quatro tempos: admissão, compressão, expansão e exaustão (Figura 1).

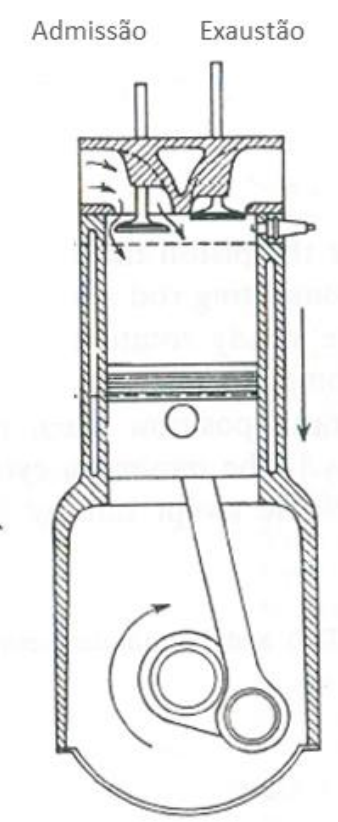

(a) Admissão

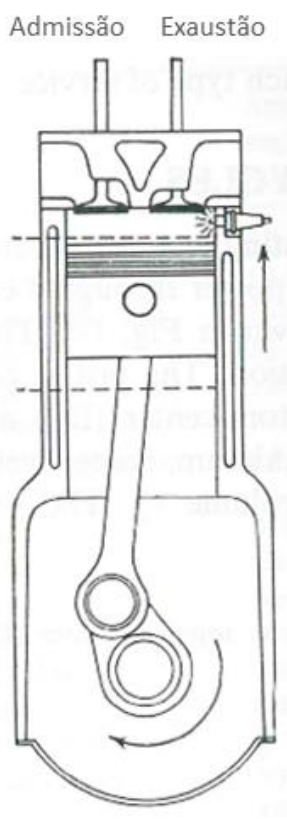

(b) Compressão

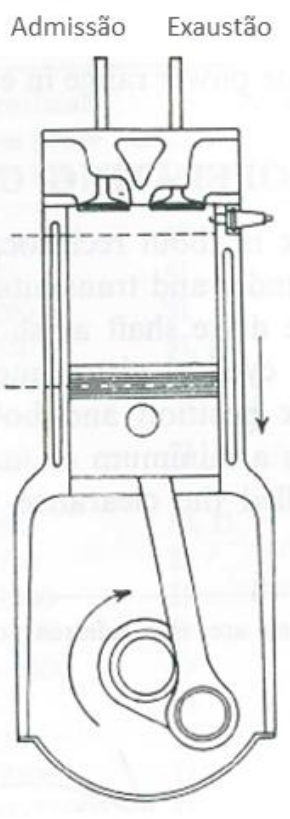

(c) Expansão

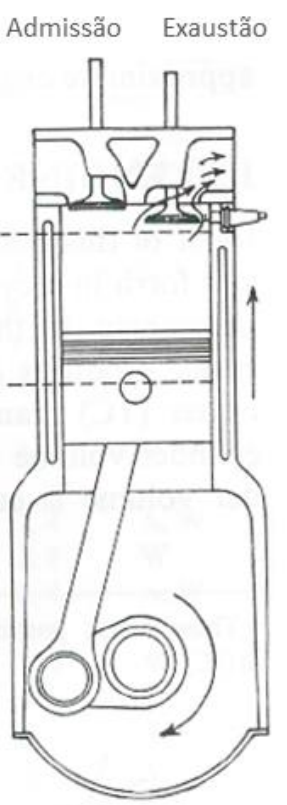

(d) Exaustão

Figura 1 - llustração dos quatro tempos de um motor a combustão interna. [Heywood, 1998] 
Devido a legislações ambientais cada vez mais severas e ao aumento na demanda de melhoria na eficiência, motores automotivos apresentam uma tendência de serem mais leves e de trabalhar em temperaturas cada vez mais elevadas, aumentando as solicitações mecânicas e térmicas impostas aos seus componentes. [Moffat et al., 2005] A Figura 2 mostra a tendência de aumento de potência específica em função do tempo para motores gasolina, turbo gasolina, passeio diesel e caminhão diesel.

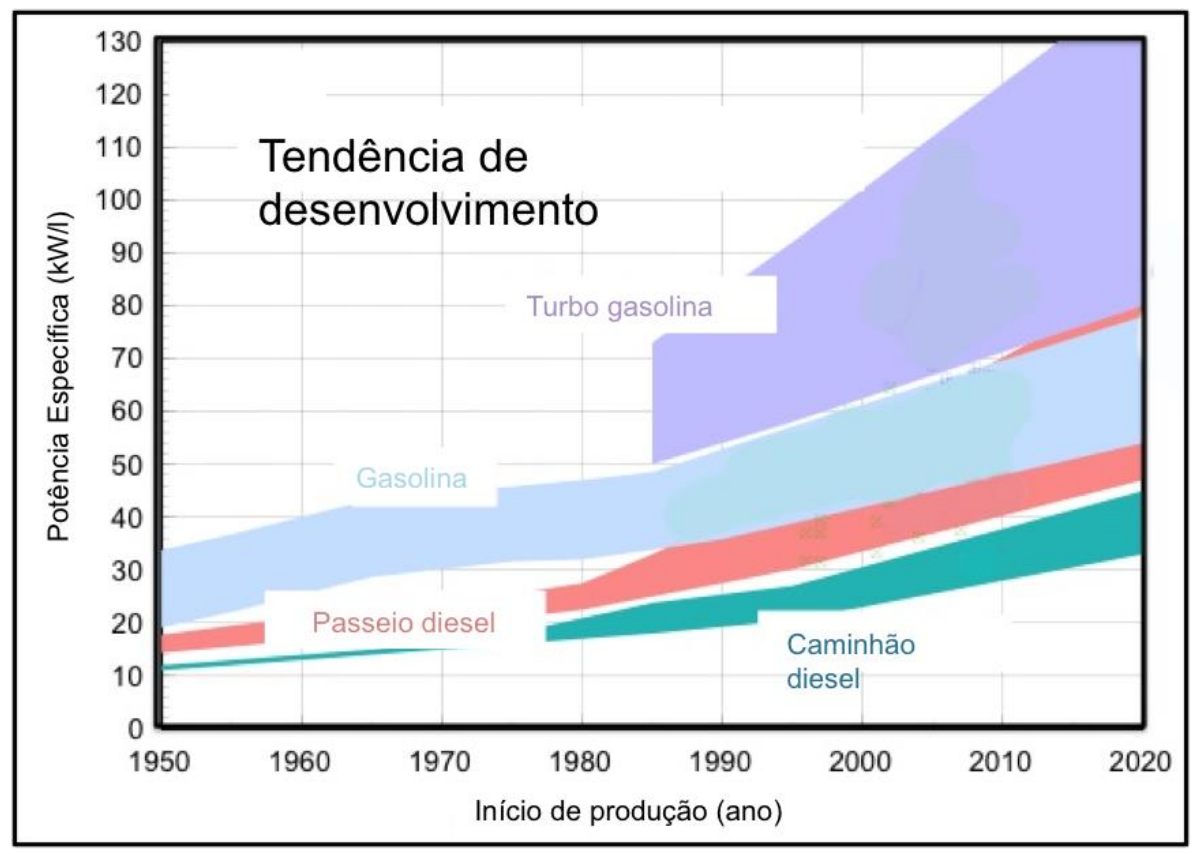

Figura 2 - Gráfico de tendência desenvolvimento de motores: potência específica $x$ ano de início de produção.

Em motores a combustão interna, a função do pistão é de converter energia térmica em trabalho mecânico. [Röhrle, 1995]

Como parte do mecanismo de transmissão, diversas forças atuam sobre o pistão (Figura 3). Externamente, o pistão é carregado pela força do gás, a força de inércia e o momento atuando sobre o centro de gravidade. A força do gás é resultado da pressão na câmara de combustão. A pressão máxima é essencialmente o resultado do sistema de combustão, combustível e taxa de compressão utilizados. [Röhrle, 1995] 

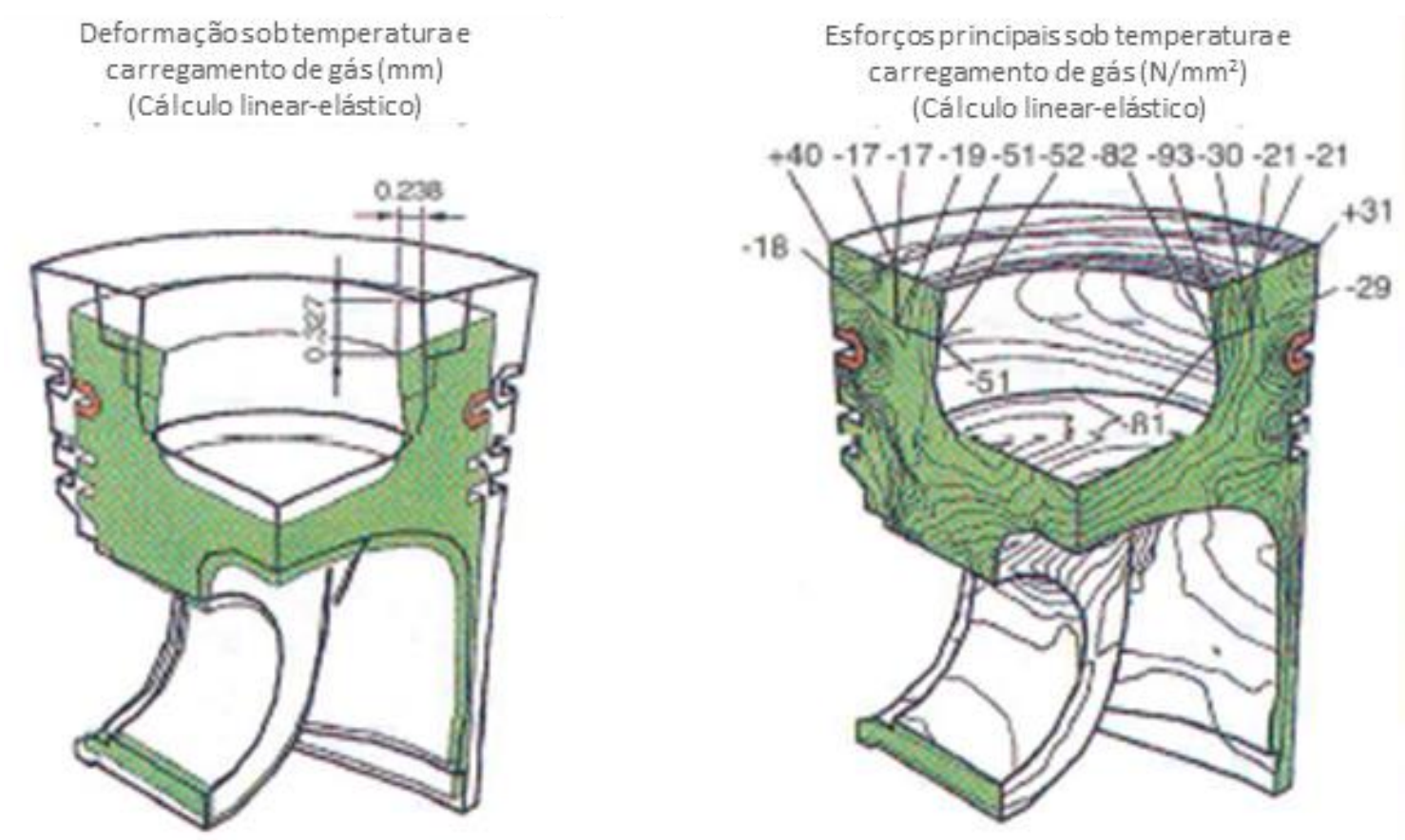

Figura 3 - Deformação e principais esforços sobre o pistão sob carregamento e temperatura.

[Röhrle, 1995]

Poucos componentes de engenharia são submetidos a condições mecânicas e térmicas tão rigorosas quanto os pistões (Figura 4).

As pressões na câmara de combustão de motores gasolina/flex atingem 100 bar, em motores turbo, 130 bar, e em motores diesel, 240 bar.

Durante cada ciclo de trabalho, as pressões e forças de inércia geram sistemas de carregamento complexos que dependem da potência e da velocidade. [Röhrle, 1995]
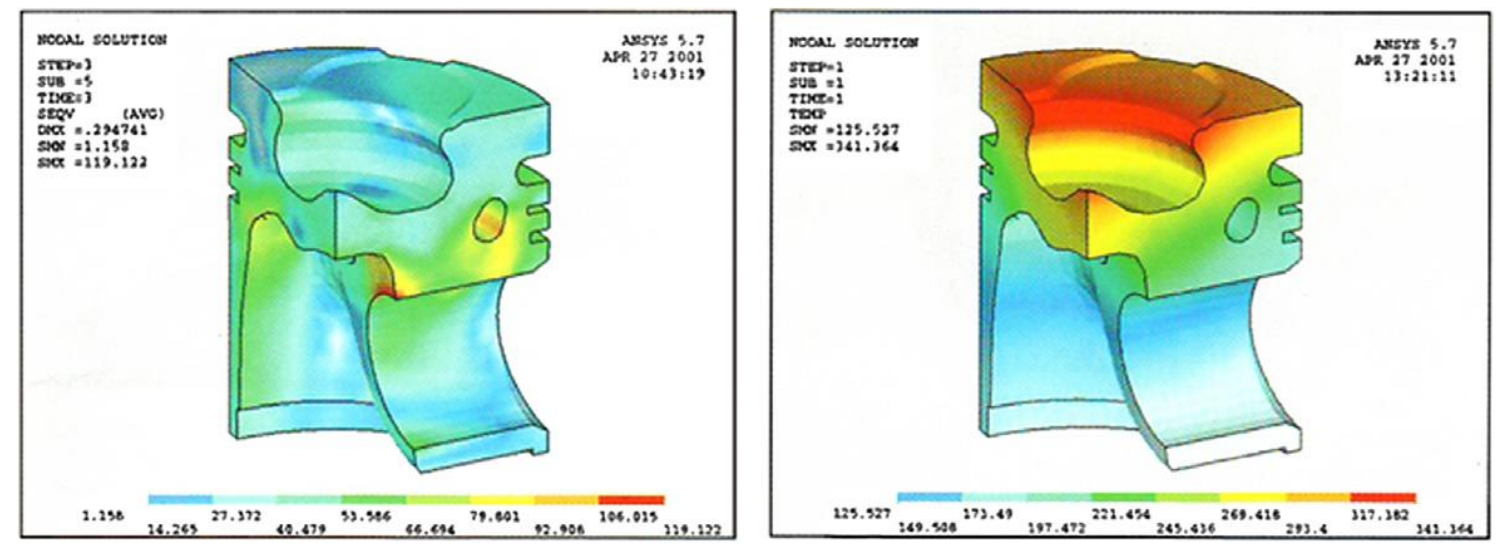

Figura 4 - Distribuição de cargas (figura à direita) e temperaturas (figura à esquerda) em um pistão para motores diesel. [Lehmann et al., 2002] 
Como as forças de inércia mudam proporcionalmente ao quadrado da velocidade do motor, reduzir o peso dos pistões é muito importante e, portanto, o alumínio é utilizado preferencialmente a outros materiais.

No entanto, o alumínio apresenta propriedades mecânicas muito limitadas em altas temperaturas.

Os mecanismos de falha dos pistões e alumínio têm diversas origens normalmente relacionadas ao desgaste, à exposição a altas temperaturas e à fadiga. Para satisfazer todos os requisitos com relação à aplicação bem sucedida dos pistões, em particular a fadiga mecânica, a fadiga mecânica em alta temperatura e a fadiga térmica/termomecânica, existem diversos conceitos que podem ser aplicados como o design, tecnologias de processo e material. [Silva, 2006]

Componentes de motores automotivos são submetidos não só a ciclos de carga mecânicos, mas também a altas temperaturas de trabalho e ciclos térmicos. Os gradientes térmicos induzidos nestes componentes podem levar a tensões e deformações internas que, ao longo do tempo, podem levar a nucleação e propagação de trincas por mecanismo de fadiga térmica. [Santos et al., 2006]

Tanto a Figura 4, quanto a Figura 5 mostram que a borda de câmara de um pistão diesel atinge temperaturas próximas a $350^{\circ} \mathrm{C}$. 


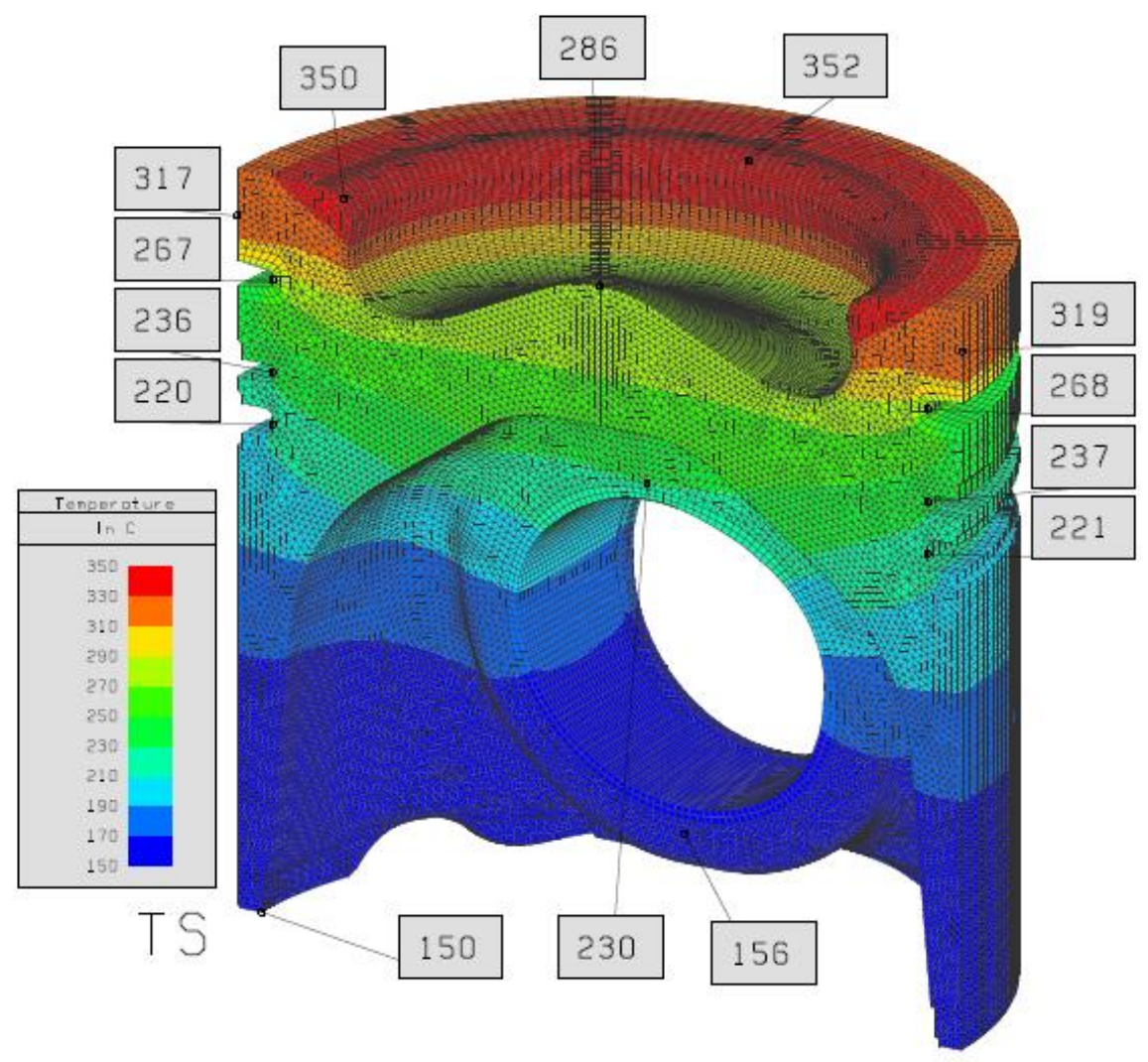

Figura 5 - Distribuição de temperaturas de trabalho $\left(\mathrm{em}^{\circ} \mathrm{C}\right)$ em um pistão diesel.

As trincas por fadiga se desenvolvem a partir de pontos de alta concentração de tensões em peças submetidas a esforços cíclicos e se propagam até atingirem um tamanho crítico que leva o componente à falha. [Hoskin et al., 1988]

A Figura 6 mostra uma superfície de fratura por fadiga em um pistão diesel. A trinca teve início na borda da câmara de combustão e propagou conforme indicações em vermelho de marcas de praia (linhas contínuas) e marcas de Chevron (linhas pontilhadas). [Floweday et al., 2011] 


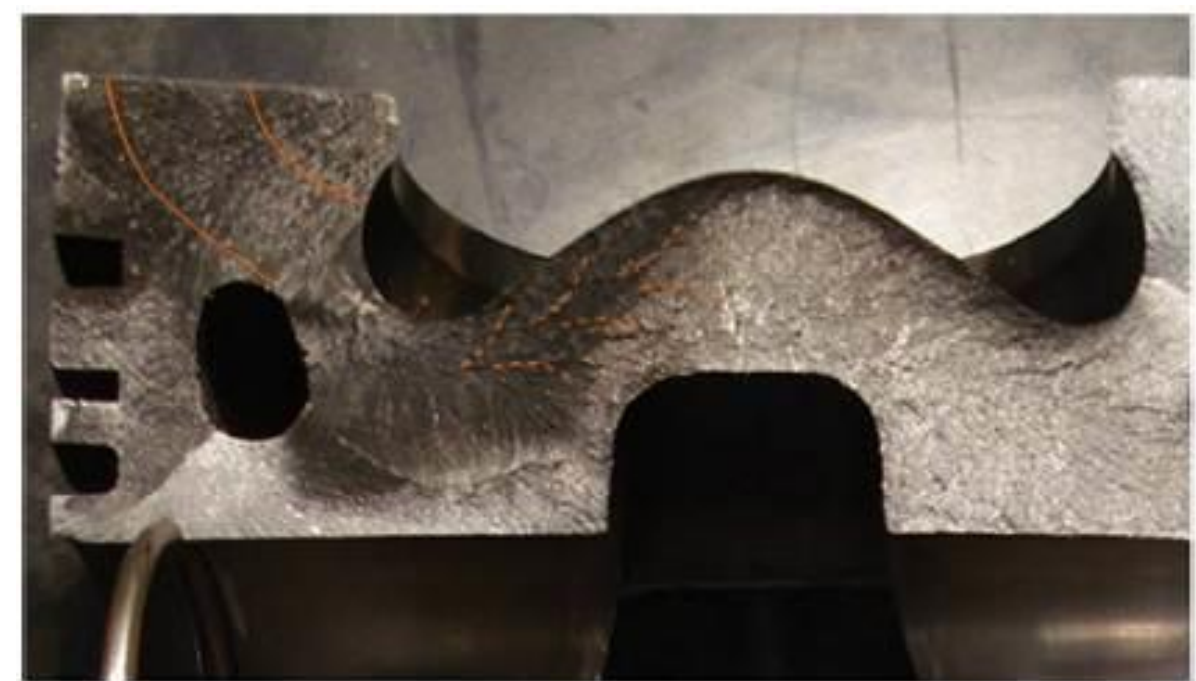

Figura 6 - Superfície de fratura por fadiga de um pistão diesel. [Floweday et al., 2011]

O desenvolvimento de um material resistente à fadiga em altas temperaturas é, portanto, essencial para a aplicação em componentes para motores automotivos, em particular, pistões de motores diesel. 


\section{Introdução}

Esta tese foi motivada inicialmente por dois trabalhos publicados por [Garat; Laslaz, 2002] e [Garat, 2011].

Nestes trabalhos, os autores produziram uma liga do sistema Al-Si-Cu contendo traços de elementos que formam diagramas peritéticos com o alumínio (zircônio, vanádio e titânio) a fim de melhorar as propriedades da liga em altas temperaturas (Tabela 1). A função desses elementos, seu comportamento e mecanismos de atuação serão posteriormente discutidos na revisão bibliográfica.

As ligas utilizadas são hipoeutéticas e para aplicação em cabeçotes de motor.

Tabela 1 - Propriedades mecânicas das ligas estudadas por [Garat; Laslaz, 2002]

\begin{tabular}{|c|c|c|c|c|c|c|c|c|c|c|c|}
\hline & \multicolumn{3}{|c|}{ Temp. Ambiente } & \multicolumn{4}{|c|}{ A $250^{\circ} \mathrm{C}$ (após $100 \mathrm{hs}$ a $250^{\circ} \mathrm{C}$ ) } & \multicolumn{4}{|c|}{$\mathrm{A} 300^{\circ} \mathrm{C}$ (após $100 \mathrm{hs}$ a $300^{\circ} \mathrm{C}$ ) } \\
\hline & $\begin{array}{c}0,2 \% L \\
\text { E } \\
\text { (Mpa) }\end{array}$ & $\begin{array}{c}\text { LR } \\
\text { (Mpa) }\end{array}$ & $\mathrm{E} \%$ & $\begin{array}{c}0,2 \% L \\
E \\
\text { (Mpa) }\end{array}$ & $\begin{array}{l}\text { LR } \\
\text { (Mpa) }\end{array}$ & $\mathrm{E} \%$ & $\begin{array}{c}\text { Fluência } \\
0,1 \%-100 \mathrm{~h}\end{array}$ & $\begin{array}{c}0,2 \% \mathrm{LE} \\
\text { (Mpa) }\end{array}$ & $\begin{array}{l}\text { LR } \\
\text { (Mpa) }\end{array}$ & E\% & $\begin{array}{c}\text { Fluência } \\
0,1 \%-100 h\end{array}$ \\
\hline A356 T7 & 257 & 299 & 9,9 & 55 & 61 & 34,5 & 38,8 & 40 & 43 & 34,5 & 21,7 \\
\hline $\mathrm{A} 356+\mathrm{Cu} 0,5 \% \mathrm{~T} 7$ & 275 & 327 & 9,8 & 66 & 73 & 34,5 & 39,5 & 40 & 44 & 34,6 & 21,8 \\
\hline A356+Cu0,5\%+Zro,14\%+Mn0,15\% T7 & 264 & 319 & 11,3 & 65 & 76 & 37 & 41 & 44 & 51 & 46 & 22,5 \\
\hline AISi7Cu3,3MnZrVTi T7 & 195 & 335 & 8 & 95 & 124 & 19 & & 66 & 75 & 26 & \\
\hline AISi7Cu3,8MnZrVTi T7 & 234 & 368 & 6 & 102 & 133 & 19 & & 63 & 77 & 26 & 31,8 \\
\hline
\end{tabular}

De acordo com os resultados obtidos por [Garat; Laslaz, 2002], a adição 0,5\% de cobre a uma liga A356 não melhora as propriedades mecânicas a $300^{\circ} \mathrm{C}$. No entanto, a adição de zircônio e manganês aumenta o limite de resistência, limite de escoamento e alongamento em cerca de $10 \%$ a $20 \%$.

Ao aumentar o teor de cobre de $0,5 \%$ para $3,3 \%$, na temperatura de $300^{\circ} \mathrm{C}$, os limites de resistência e escoamento aumentam cerca de $50 \%$, enquanto o alongamento é reduzido na mesma proporção.

As ligas utilizadas por [Garat; Laslaz, 2002] e [Garat, 2011] formam compostos com ponto de fusão de $508^{\circ} \mathrm{C}$, o que limitou a temperatura de tratamento térmico. Os próprios autores sugerem medidas para eliminação das fases de baixo ponto de fusão e aumento da temperatura de solubilização. 
Um estudo realizado por [Sepehrband et al., 2005] mostra o efeito do tratamento térmico de solubilização em uma liga contendo zircônio. O tempo ideal para a precipitação do $\mathrm{Al}_{3} \mathrm{Zr}$ em uma liga $\mathrm{AlSi6Cu3}$ contendo $0,15 \% \mathrm{Zr}$ durante o tratamento de solubilização a $505^{\circ} \mathrm{C}$ é de 8 horas (Figura 7). Este tempo de tratamento é considerado longo em um ambiente industrial e aumenta significativamente os custos de produção.

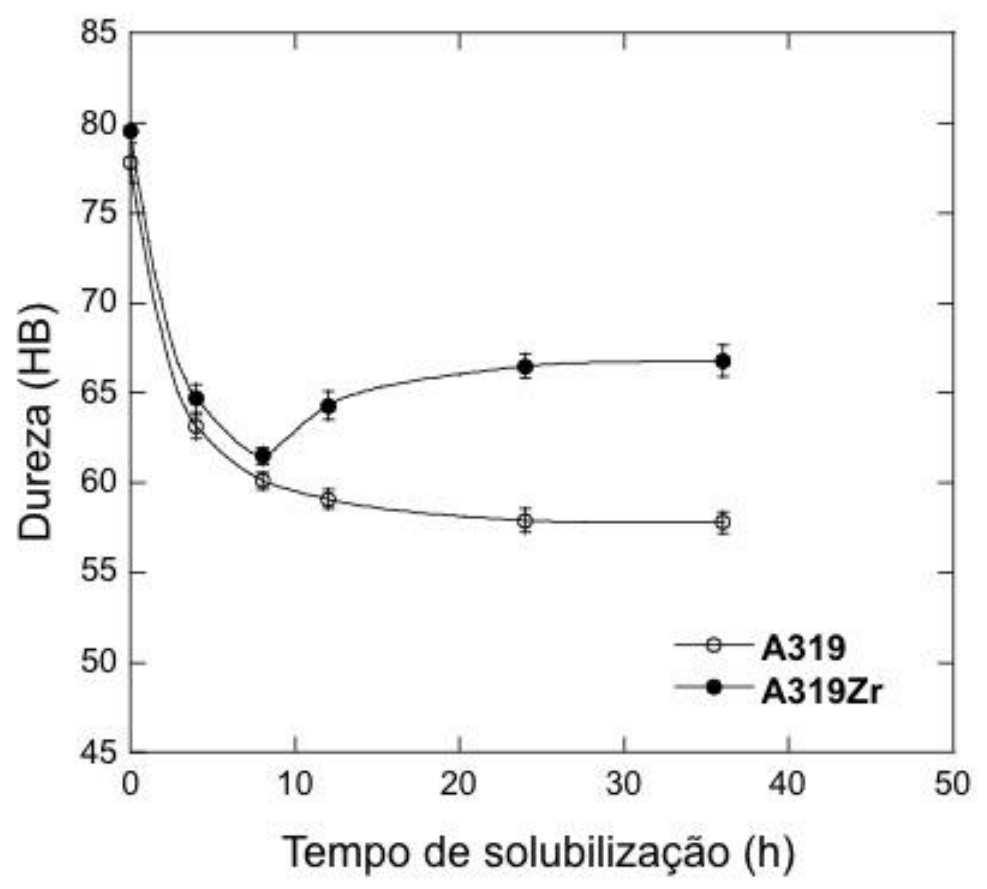

Figura 7 - Dureza de uma liga A319 e uma liga A319 contendo 0,15\%Zr solubilizadas a $505^{\circ} \mathrm{C}$. [Sepehrband et al., 2005]

Ao contrário das ligas utilizadas nos estudos mencionados acima, as ligas comumente utilizadas na fabricação de pistões são hipereutéticas (com presença de partículas de silício primário), No entanto, esta aplicação também requer boas propriedades em altas temperaturas e o uso de elementos que formam diagramas peritéticos com o alumínio é uma tendência nesta aplicação.

No trabalho de [Garat, 2011], sugere-se que seja retirado o magnésio das ligas utilizadas a fim de eliminar a fase de baixo ponto de fusão e possibilitar o aumento da temperatura de solubilização.

A primeira abordagem desta tese foi a tentativa combinada de aumentar a temperatura de tratamento térmico, através da redução do magnésio em uma liga para pistões 
(AlSi12Cu5Ni2Mg) e da adição dos elementos de liga zircônio, vanádio, titânio e manganês.

O aumento na temperatura de solubilização favoreceria a cinética de precipitação de intermetálicos formados pelos elementos que formam diagramas peritéticos com o alumínio e tornaria economicamente viável a solubilização desta liga.

Esta abordagem foi descartada após os primeiros resultados de DTA (Differential Thermal Analysis) na liga fundida sem magnésio porque a eliminação da fase de baixo ponto de fusão não foi possível, conforme Figura 8 e Figura 9.

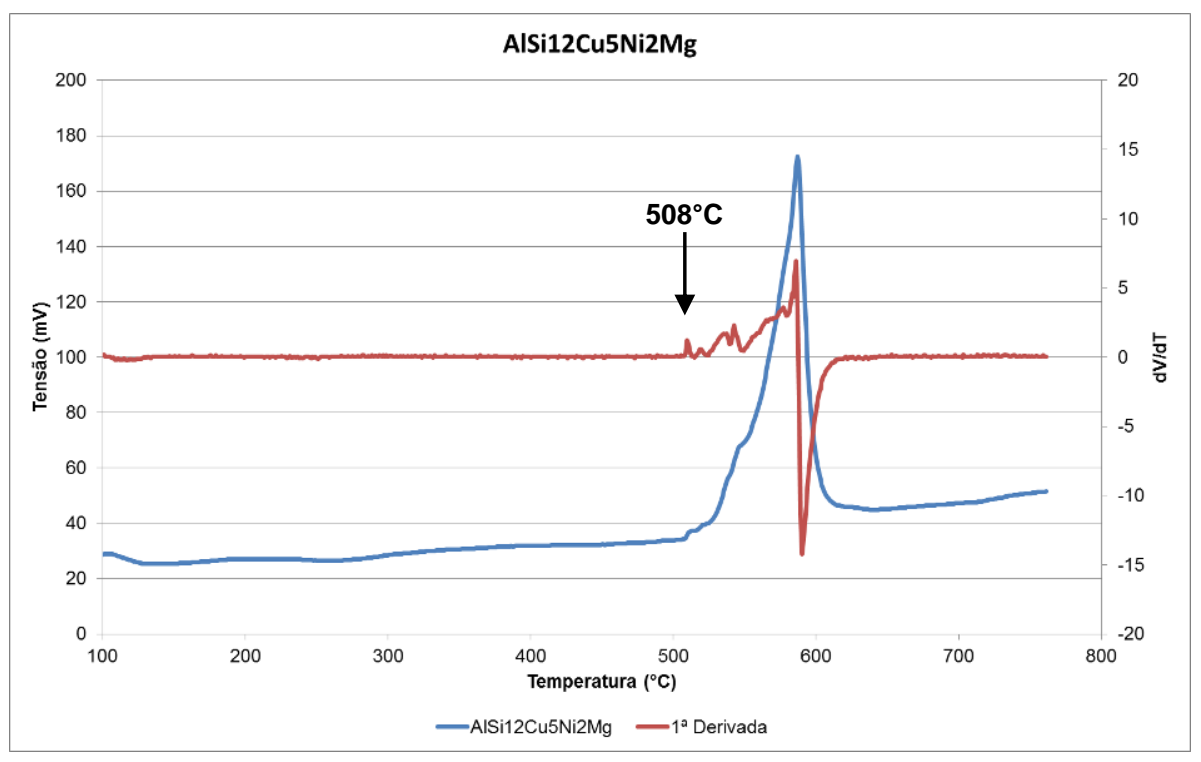

Figura 8 - DTA de uma liga AISi12Cu5Ni2Mg contendo traços dos elementos que formam diagramas peritéticos com o alumínio (zircônio, vanádio e titânio) com taxa de aquecimento de $4,2^{\circ} \mathrm{C} / \mathrm{min}$. 


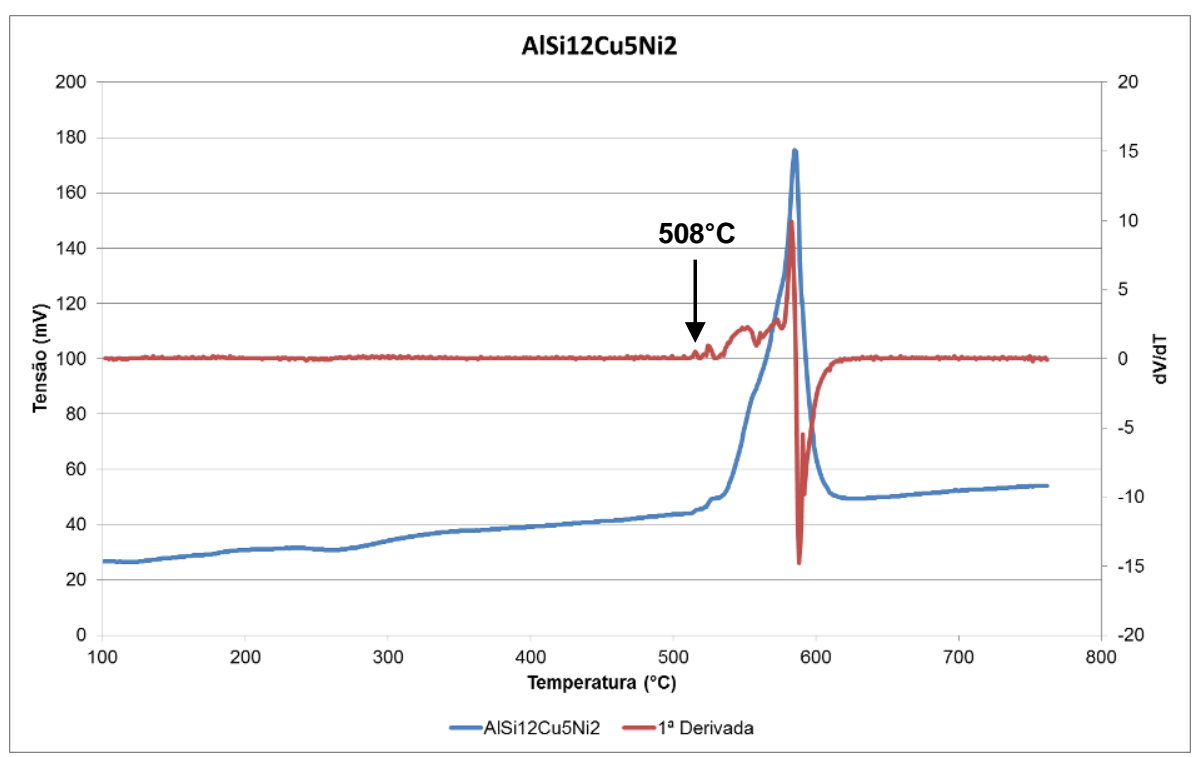

Figura 9 - DTA de uma liga AISi12Cu5Ni2 contendo traços dos elementos que formam diagramas peritéticos com o alumínio (zircônio, vanádio e titânio) com taxa de aquecimento de $4,2^{\circ} \mathrm{C} / \mathrm{min}$.

A ideia de que a ausência de magnésio não elimina a fase de baixo ponto de fusão de uma liga do sistema Al-Si-Cu-Mg é reforçada pelo trabalho de [Zeren et al., 2011]. Neste trabalho, os autores mostram que a fase de baixo ponto é um quaternário Al-SiCu-Mg que se forma quando o teor de cobre ultrapassa $2 \%$ (Figura 10). 


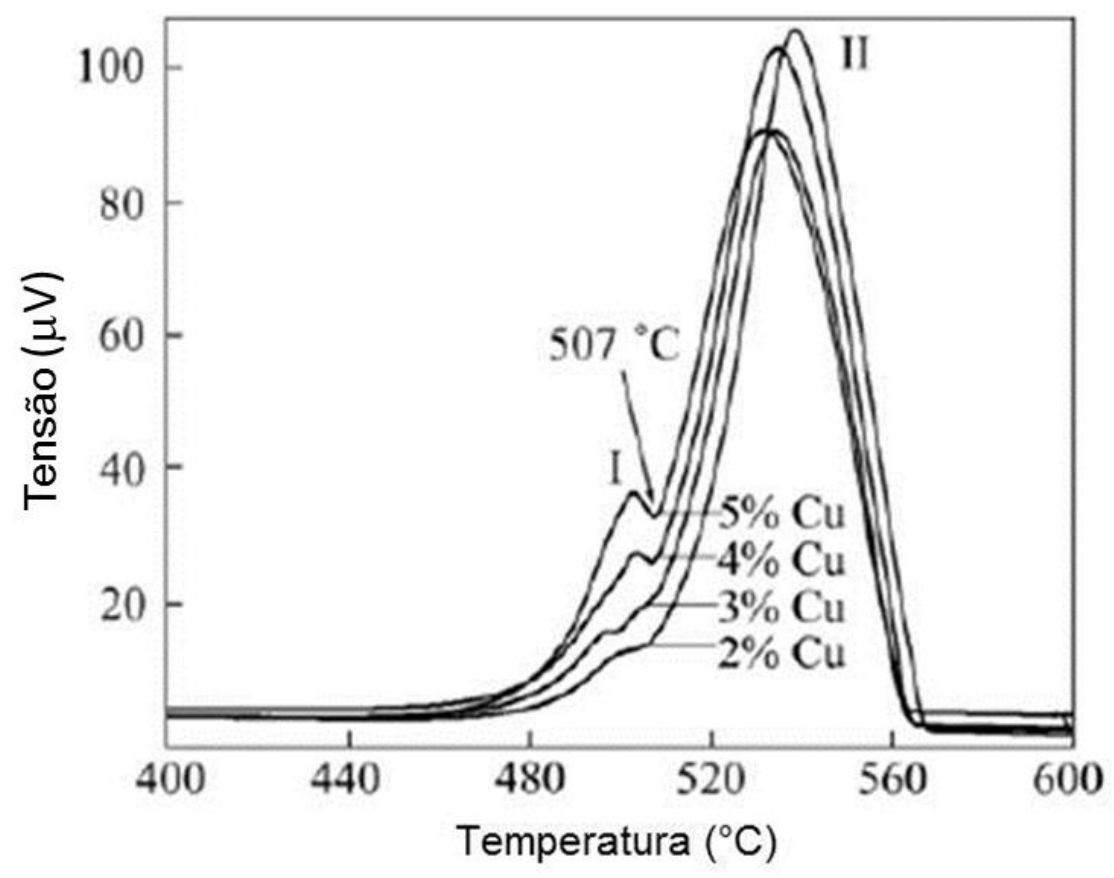

Figura 10 - Curvas de DTA de ligas AI-Si-Mg-xCu (x=2\%, 3\%, 4\% e 5\%) a 30K/min [Zeren et al., 2011].

A impossibilidade de eliminar a fase de baixo ponto de fusão foi atribuída aos altos teores de cobre na liga para pistões.

Em consequência das limitações impostas pela eliminação do magnésio na liga e pela utilização de uma liga contendo alto teor de cobre, neste trabalho será estudada uma liga de baixo teor de cobre (AISi12CuMgNi).

A esta liga, foram adicionados cerca de $0,13 \%$ de zircônio, $0,12 \%$ de vanádio, $0,13 \%$ de titânio e 0,20\% de manganês.

Combinado às adições de elementos químicos, foi testado um tratamento térmico de maior temperatura e menor tempo, a fim de reduzir custos no processo produtivo sem afetar o desempenho dos elementos de liga adicionados. O ciclo de solubilização tradicionalmente utilizada em pistões automotivos é de uma hora a $500^{\circ} \mathrm{C}$ e o ciclo de solubilização testado neste trabalho é de quinze minutos a $525^{\circ} \mathrm{C}$. 


\section{Revisão bibliográfica}

\subsection{O Alumínio}

A utilização do alumínio se tornou economicamente viável somente com a invenção do processo Hall-Heroult de refino do alumínio. Na primeira parte do século 20 , a utilização do alumínio fundido se resumiu a aplicações em objetos de decoração e utensílios de cozinha. [Gruzleski; Closset, 1990]

Como todo metal puro, o alumínio apresenta baixa resistência e não pode ser utilizado em aplicações em que resistência à deformação e fratura são essenciais. Outros elementos são, portanto, adicionados ao alumínio, principalmente para aumentar sua resistência. [Tiryakioglu; Staley, 2003]

Após a segunda guerra mundial, houve uma expansão dramática da indústria do alumínio. Novas ligas surgiram e processos de fundição foram implementados para atender às demandas de engenharia e ampliar as aplicações técnicas e comerciais. A crise de energia dos anos 70 consolidou a utilização do alumínio em escala comercial devido à sua excelente relação peso-resistência. [Gruzleski; Closset, 1990]

\subsection{O sistema Al-Si}

O silício é a segunda impureza mais abundante no alumínio, proveniente da sílica ou de silicatos encontrados na bauxita. É também uma das adições mais comuns em ligas de alumínio, concedendo à liga fluidez durante a fundição e soldagem e altas propriedades mecânicas através da formação de compostos que fazem com que a liga seja termicamente tratável. [Mondolfo, 1976] 
Ligas alumínio-silício representam cerca de $85 \%$ a $90 \%$ do total de peças fundidas em alumínio. [Gruzleski; Closset, 1990]

As ligas Al-Si são conhecidas por serem resistentes ao desgaste, já que o silício, tanto na sua forma primária quanto na sua forma eutética é muito duro, alcançando mais de 1100 na escala Knoop. [Jorstad, 1996]

Essas ligas são muito utilizadas na aplicação para componentes de motores a combustão devido à presença de quantidades elevadas de silício precipitado em sua microestrutura, baixo coeficiente de expansão térmico e alta resistência mecânica quando adicionados outros elementos de liga como cobre, magnésio e níquel. [Manasijevic et al., 2011]

As propriedades mecânicas das ligas binárias dependem menos de sua composição do que da distribuição e forma das partículas de silício. Partículas pequenas, arredondadas e homogeneamente distribuídas, sejam elas eutéticas ou primárias, resultam em alta ductilidade com relativa alta resistência. Cristais de silício facetados e aciculares podem aumentar a resistência, mas diminuem a ductilidade e resistência ao impacto e fadiga. [Mondolfo, 1976]

O sistema Al-Si é um sistema eutético simples (Figura 11) que apresenta um limite de solubilidade na fase sólida em ambos os lados do diagrama e duas fases de solução sólida: alumínio e silício cúbicos de face centrada (CFC). O eutético se forma a $577^{\circ} \mathrm{C}$ e $12,6 \%$ de silício. Na temperatura eutética, o silício apresenta 1,65\% de solubilidade no alumínio e o alumínio apresenta menos de $0,034 \%$ de solubilidade no silício. A $300^{\circ} \mathrm{C}$, a solubilidade do silício no alumínio cai para 0,048\%.[Tenekedjiev, 1989] 


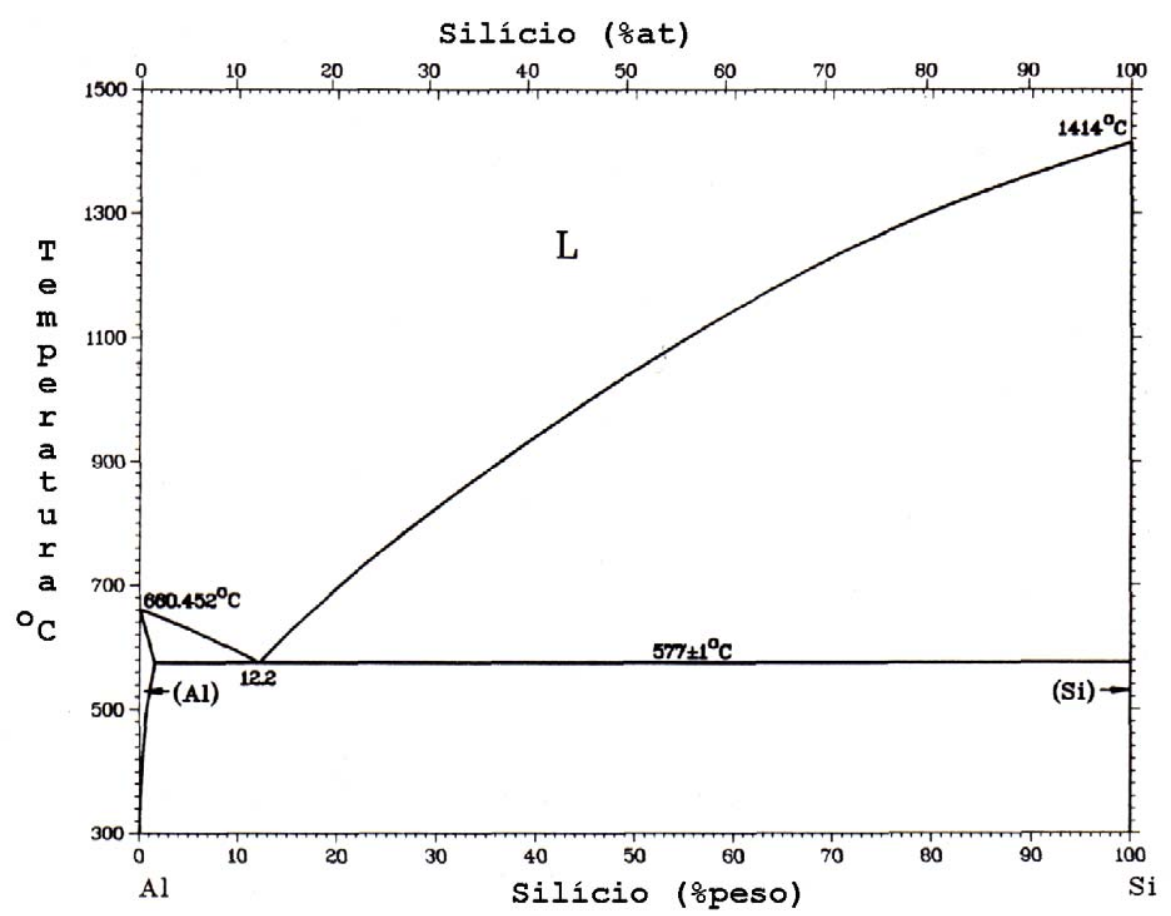

Figura 11 - Diagrama de fases Al-Si [ASM Metals Handbook, 1993].

As ligas alumínio-silício comercialmente importantes podem ser classificadas em três grupos, de acordo com seu teor de silício [Backerud, 1990]:

(1) Ligas hipoeutéticas - contêm 5\% a 10\% de silício

(2) Ligas eutéticas ou quase-eutéticas - contêm $11 \%$ a $13 \%$ de silício

(3) Ligas hipereutéticas - Contêm $14 \%$ a $20 \%$ de silício

Nas ligas eutéticas ou quase-eutéticas, as reações pró-eutéticas não estão presentes.

\subsection{Ligas Hipoeutéticas}

O silício solidifica naturalmente na forma de placas grosseiras (Figura 12 e Figura 13), o que resulta na fragilização da liga. Uma liga não modificada apresenta alongamento baixo e a superfície de fratura frágil. Na presença de alguns elementos como sódio, 
cálcio e estrôncio, o crescimento do silício eutético é modificado e passa a ser fibroso, lembrando uma formação de corais (Figura 14 e Figura 15). Em uma superfície polida, essas fibras parecem partículas individuais pequenas, mas um ataque químico profundo ao alumínio mostra que as partículas são interligadas. [Major, 1989; Loper, 2000; Sigworth, 1983]

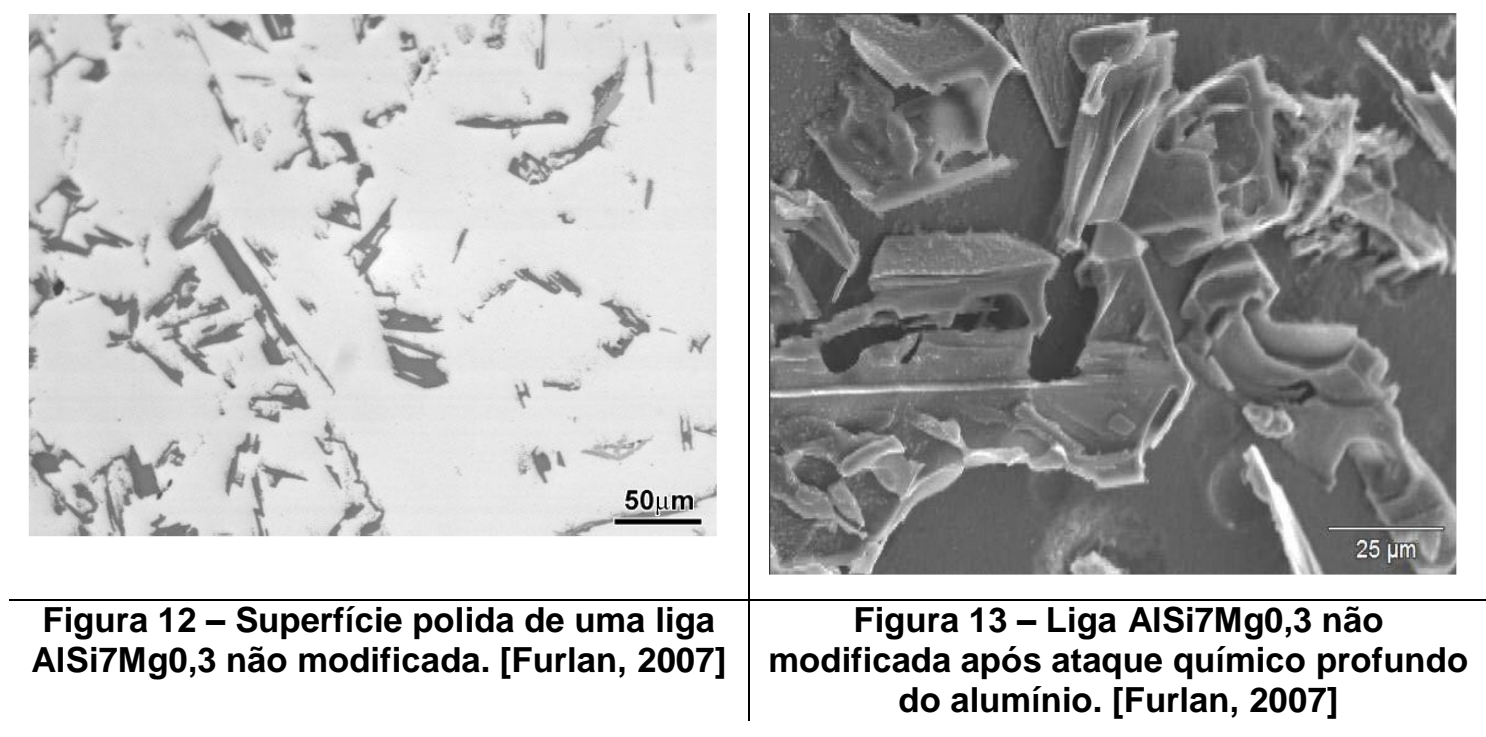

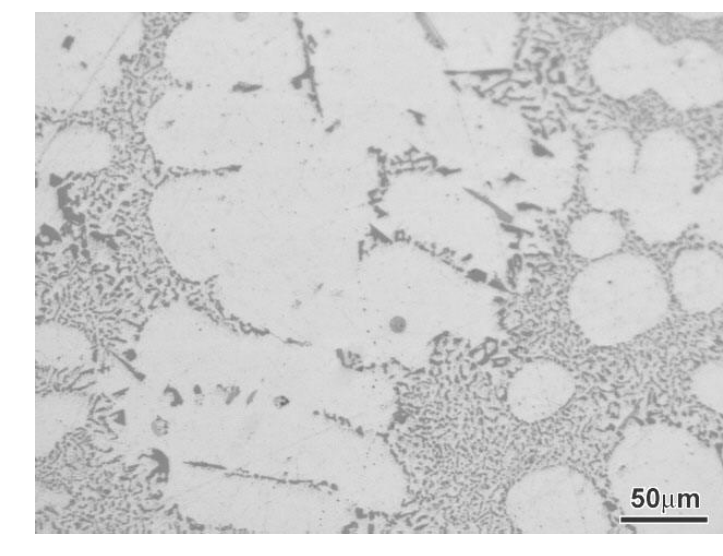

Figura 14 - Superfície polida de uma liga AlSi7Mg0,3 modificada com estrôncio.

[Furlan, 2007]

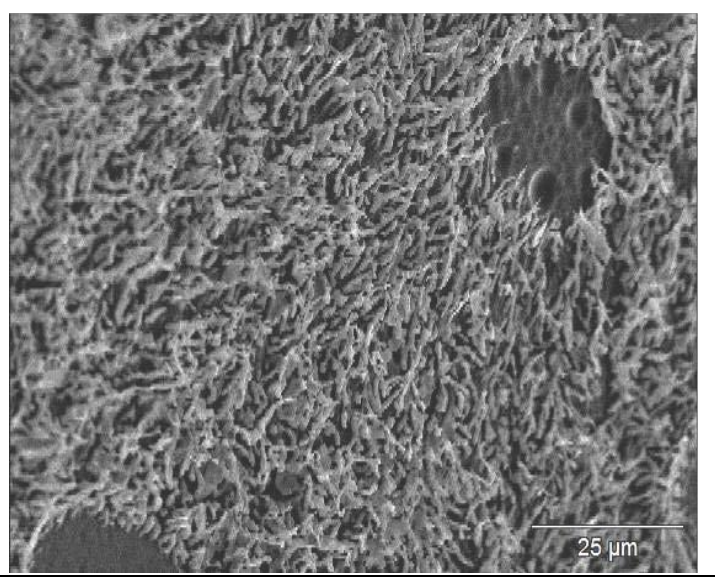

Figura 15 - Liga AISi7Mg0,3 modificada após ataque químico profundo do alumínio. [Furlan, 2007]

O principal efeito dos modificadores se manifesta durante o crescimento do eutético. Em ligas não modificadas, o eutético cresce com o silício liderando o crescimento, 
conseqüentemente, formando esqueletos. Em ligas modificadas, o alumínio precede o silício. [Crosley, Mondolfo, 1966]

As propriedades mecânicas das ligas binárias dependem menos de sua composição do que da distribuição e forma das partículas de silício. Partículas pequenas, arredondadas e homogeneamente distribuídas, sejam elas eutéticas ou primárias, resultam em alta ductilidade com relativa alta resistência. Cristais de silício facetados e aciculares podem aumentar a resistência, mas diminuem a ductilidade e resistência ao impacto e fadiga. [Mondolfo, 1976]

Portanto, a aplicação comercial destas ligas depende da modificação bem sucedida do silício eutético, o que resulta em um aumento da resistência mecânica, ductilidade e usinabilidade das ligas eutéticas e hipoeutéticas. [Sigworth, 1983]

\subsection{Ligas Hipereutéticas}

A utilização das ligas hipereutéticas tem aumentado nas últimas duas décadas. Este grupo de ligas possui excelente resistência à corrosão, baixo coeficiente de expansão térmica, boas propriedades mecânicas em altas temperaturas, boas características de fundição (fluidez, em particular), alta condutividade térmica, boa resistência à corrosão e uma ótima relação peso - resistência mecânica. [Tenekedjiev, 1989]

$\mathrm{O}$ desgaste das ligas Al-Si comumente utilizadas na indústria automotiva ocorre por dois mecanismos: oxidativo e metálico. A presença de silício em ligas de alumínio não influencia na taxa de desgaste oxidativo do alumínio. No entanto, a carga em que o mecanismo de desgaste muda de oxidação para metálico aumenta com o aumento do teor de silício na liga. Em $11 \%$ de silício, as ligas Al-Si apresentam um comportamento anômalo em que há um pico intermediário de desgaste metálico, que pode ser contornado com o uso de ataques químicos que eliminam o alumínio da superfície e deixam expostas as partículas de silício. [Shivanath, 1977] 
Estas propriedades fazem com que essas ligas sejam ideais para aplicações na indústria automotiva em peças como blocos de motor, pistões, cilindros, componentes de bombas, entre outras. [Tenekedjiev,1989; Jorstad, 2009; Heusler et al., 2001] A apresentação das ligas hipereutéticas com ligas funcionais e industrialmente aplicáveis se deu com Jorstad, em seu artigo clássico de utilização da liga 390 para utilização nos blocos de motor Vega da GM. [Jorstad, 1971]

Até então, os fundidores consideravam que o grande intervalo de solidificação destas ligas era sinônimo de baixa fundibilidade. [Jorstad, 1996]

No entanto, ao contrário da maior parte das ligas binárias de alumínio, a fluidez máxima das ligas Al-Si não se encontra no ponto eutético do diagrama de fases, e sim em torno de $18-20 \%$ (Figura 16). Este fato curioso é atribuído ao alto calor latente de fusão do silício que, por tornar necessário que grandes quantidades de calor sejam retiradas da liga para que esta se solidifique, faz com que ela esteja fluida por mais tempo. [Jorstad, 1996; Ravi et al., 2008]

A fluidez das ligas Al-Si começa a diminuir quando o tamanho das partículas de silício se torna tão grande que o metal fica mecanicamente impedido de escoar. [Jorstad, 1996; Ravi et al., 2008] 


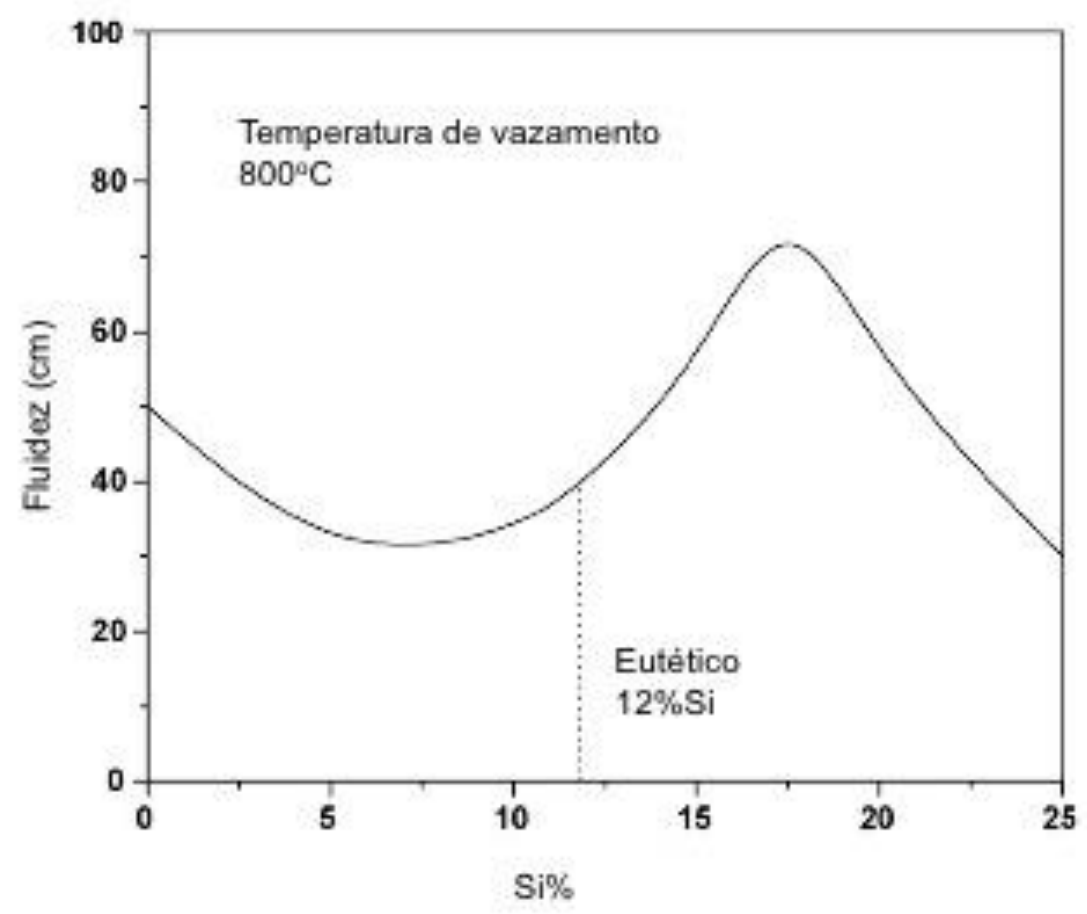

Figura 16 - Fluidez de ligas binárias de alumínio no teste de espiral. (a) Al-Cu; (b) AlSi, (c) Al-Mg. [Lang, 1972].

A característica dominante da microestrutura da liga 390 são as partículas de silício primário: "cubóides" grandes e escuros. Tanto o eutético (partículas na forma de agulhas) quanto em sua forma primária, o silício é extremamente duro, medindo mais de 1100 na escala Knoop. [Jorstad, 1996]

É justamente esta fase dura, principalmente em sua forma primária, que fornece à liga 390 seu excelente desempenho. É também do silício primário que as principais "dificuldades" da liga vêm. O silício primário simplesmente tem que ser controlado, ou seja, refinado a um tamanho razoável para que as propriedades de resistência ao desgaste sejam atingidas. A Figura 17 mostra a microestrutura de uma liga eutética Al12.6\%Si não modificada, com e sem adição de refinador. [Jorstad, 1996] 

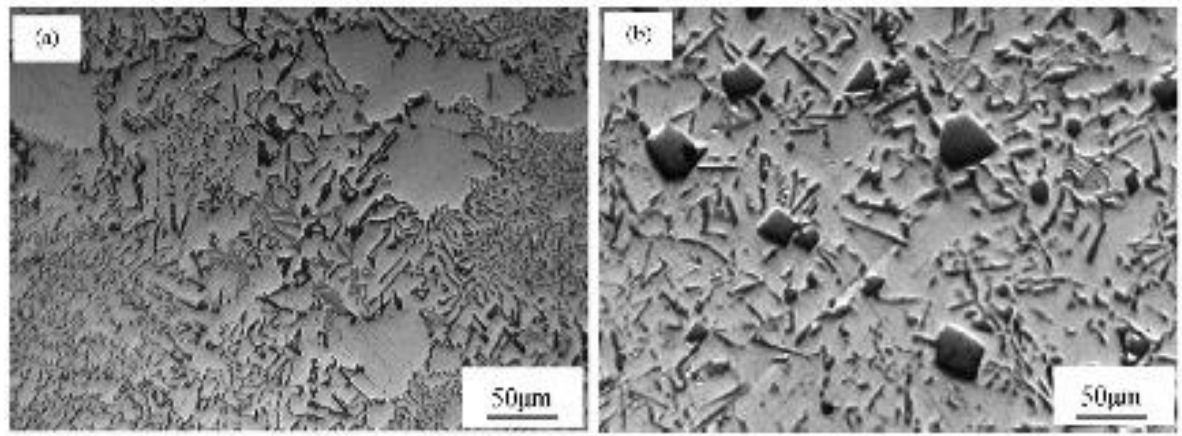

Figura 17 - Microestrutura de uma liga Al-12,6\%Si: (a) sem adição de refinador; (b) com adição de 0,8\%Al-3,5P [Yu et al., 2007].

\subsubsection{Solidificação de ligas Al-Si hipereutéticas}

A seqüência de solidificação de ligas hipereutéticas pode ser generalizada nas seguintes reações: [Backerud, 1990]

1. Precipitação das partículas de silício primário

2. Reação eutética alumínio-silício

3. Precipitação de eutéticos secundários como $\mathrm{Mg}_{2} \mathrm{Si}$ e $\mathrm{Al}_{2} \mathrm{Cu}$

Considerando-se a liga 390 (Tabela 2), utilizada em cabeçotes de motor e compressores, [Backerud, 1990] observou a seguinte seqüência de solidificação (Tabela 3).

Tabela 2 - Composição química da liga A390.1 e da liga real utilizada para determinar a seqüência de solidificação. [Backerud, 1990]

\begin{tabular}{c|c|c|c|c|c|c|c|c}
\hline \multirow{2}{*}{ Liga } & \multirow{2}{*}{ Composição } & \multicolumn{9}{|c}{ Elementos } \\
\cline { 3 - 9 } & & $\mathrm{Si}$ & $\mathrm{Fe}$ & $\mathrm{Cu}$ & $\mathrm{Mn}$ & $\mathrm{Mg}$ & $\mathrm{Zn}$ & $\mathrm{Ti}$ \\
\hline A390.1 & padrão AA & $16.0-18.0$ & 0.4 & $4.0-5.0$ & 0.10 & $0.50-0.65$ & 0.10 & 0.20 \\
\hline 390.0 & Amostra real & 15.0 & 0.3 & 5.5 & 0.1 & 0.65 & 0.065 & 0.01
\end{tabular}


Tabela 3 - Seqüência de reações durante a solidificação [Backerud, 1990]

\begin{tabular}{c|c|c}
\hline Número da reação & Reações & Temperatura sugerida $\left({ }^{\circ} \mathrm{C}\right)$ \\
\hline 1 & Silício primário & 636 \\
\hline 2 & Desenvolvimento da rede de dendritas & 561 \\
\hline 3 & $\mathrm{Liq} \Rightarrow \mathrm{Al}-\mathrm{Si}+\mathrm{Al5FeSi}$ & 575 \\
\hline 4 & $\mathrm{Liq} \Rightarrow \mathrm{Al}-\mathrm{Si}+\mathrm{Mg} 2 \mathrm{Si}$ & 555 \\
\hline 5 & $\mathrm{Liq}+\mathrm{Mg} 2 \mathrm{Si} \Rightarrow \mathrm{Al}+\mathrm{Si}+\mathrm{Al} 2 \mathrm{Cu}+\mathrm{Al} 5 \mathrm{Mg} 8 \mathrm{CuSi6}$ & 512 \\
\hline 6 & $\mathrm{Liq} \Rightarrow \mathrm{Al}+\mathrm{Al} 2 \mathrm{Cu}+\mathrm{Al} 5 \mathrm{Mg} 8 \mathrm{CuSi6}+\mathrm{Si}$ & 507
\end{tabular}

Durante a solidificação das ligas Al-Si hipereutéticas, a primeira fase a se formar é o silício, comumente chamado de silício primário ou silício pró-eutético porque ele aparece na microestrutura antes do silício que faz parte do eutético. [Weiss, 1987]

De acordo com [Gruzleski, Closset, 1990], o silício primário pode ser encontrado como:

- formato estrela, no qual o silício cresce em cinco eixos originários de um mesmo núcleo (diversas variações desta forma são encontradas);

- $\quad$ poliédrico, que pode ser hexagonal ou octaédrico em uma seção polida;

- dendrítico, que lembra uma dendrita, assim como o alumínio primário em ligas hipoeutéticas.

O silício primário de forma facetada cresce normalmente por um mecanismo de crescimento conhecido como "twin plane reentrant edge". Esta forma de crescimento resulta em partículas com diversos formatos poligonais complexos. [Weiss, 1987]

O mecanismo de crescimento de cristais facetados se dá pela propagação de planos de maclas que emergem na superfície dos cristais. O crescimento preferencial ocorre no ângulo reentrante onde os planos de maclas atingem a superfície do cristal. Se só existe um plano de macla, o crescimento cessa. No entanto, se houverem outros planos de maclas presentes na superfície do cristal, o crescimento continua, já que os ângulos reentrantes estão sempre presentes. A maclação do cristal é, portanto, o principal mecanismo envolvido no crescimento do silício primário. [Weiss, 1987]

O silício eutético em ligas Al-Si hipereutéticas assume formato acicular ou fibroso (modificado), exatamente como em ligas hipoeutéticas. Localmente, pode-se encontrar 
regiões com um eutético lamelar geométrico, conhecido como "feathery". [Gruzleski; Closset, 1990]

$\mathrm{Na}$ faixa de temperatura de aproximadamente $540^{\circ} \mathrm{C}$ há a precipitação de $\mathrm{Mg} 2 \mathrm{Si}$. Entre $500^{\circ} \mathrm{C}$ e $520^{\circ} \mathrm{C}$ há a precipitação do $\mathrm{Al}_{2} \mathrm{Cu}$. Outras fases mais complexas contendo o restante do silício, ferro, manganês, cobre e zinco precipitam no intervalo de $480^{\circ} \mathrm{C}$ a $500^{\circ} \mathrm{C}$. [Backerud, 1990]

Fases contendo ferro e manganês são comumente encontradas na estequeometrias AlsFeSi e $\mathrm{Al}_{15}(\mathrm{Mn}, \mathrm{Fe})_{3} \mathrm{Si}_{2}$. A presença de outros elementos de liga pode ter certa influência na temperatura de precipitação desses eutéticos secundários. [Backerud, 1990]

\subsubsection{Refino de ligas Al-Si hipereutéticas}

O silício primário em ligas hipereutéticas não costuma nuclear em nenhuma das impurezas comumente encontradas nas ligas Al-Si. Como resultado disso, é necessário um super-resfriamento considerável para a formação de núcleos e, conseqüentemente, uma quantidade reduzida de núcleos é formada. Os cristais de silício primário crescem bastante e podem a chegar a se separar do banho e flutuar, gerando segregação. Partículas grandes e não homogeneamente distribuídas tendem a causar desgaste acentuado de ferramentas de corte e usinagem. Para minimizar este problema, o refino das partículas de silício costuma ser realizado. [Weiss, 1987; Gruzleski, Closset, 1990] Além disso, o refino das partículas de silício primário resulta em aumento de alongamento. [Zuo et al., 2009]

As partículas de silício primário podem ser refinadas tanto por meio de resfriamento rápido, quanto com a adição de agentes de refino. $O$ agente de refino mais comum é o fósforo que, em pequenas quantidades, produz um silício primário fino, homogeneamente distribuído e de formato poliédrico ou granular (Figura 17). [Weiss, 1987] 
Não existe nenhum composto formado no ternário Al-Si-P. As fases em equilíbrio formadas no canto do alumínio do diagrama ternário formado por estes três elementos são: alumínio, silício e AIP. Cálculos do liquidus indicam que apenas 0,001\%P é suficiente para direcionar as fases para a formação do AIP.[Mondolfo, 1976] Acredita-se que o fósforo seja efetivo na nucleação do silício pela formação do composto AIP (Figura 18). Este composto tem uma estrutura cristalina similar à do silício, um alto ponto de fusão e já foi observado em diversos grãos de silício primário. [Weiss, 1987; Gruzleski, Closset, 1990; Zuo et al., 2009; Arnold, 1961; Tenekedjiev, 1989]
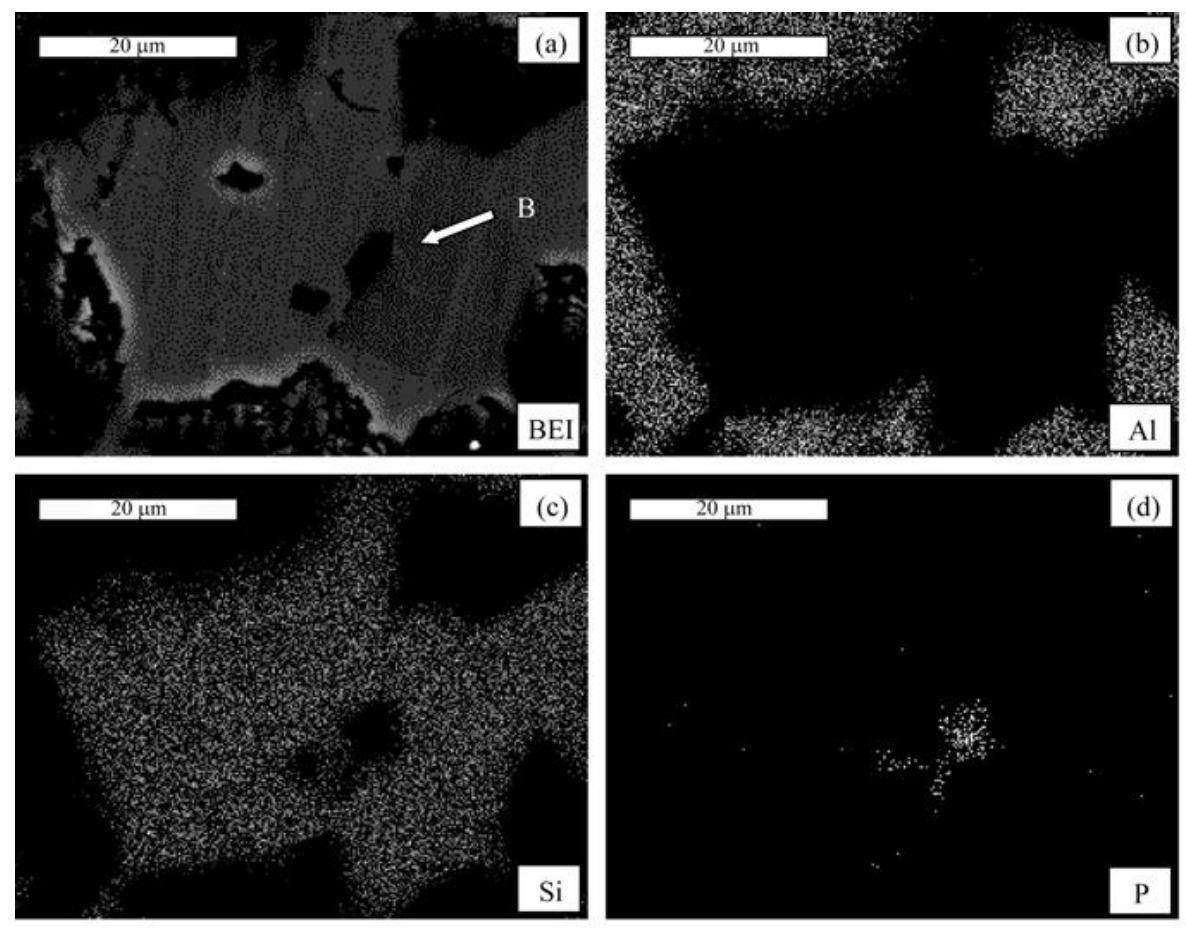

Figura 18 - Análise do núcleo de uma partícula de silício primário em EPMA de uma liga Al-30\%Si. (a) Microscópio Eletrônico de Varredura - elétrons retro espalhados. O ponto "B" aponta para o núcleo da particula; (b) imagem de raio-X do alumínio;

(c) imagem de raio-X do silício; (d)Imagem de raio-X do fósforo. [Zuo, 2009]

Revisando-se o diagrama de fases Al-P (Figura 19), a solubilidade do fósforo no alumínio é da ordem de poucas partes por milhão. O limite superior de solubilidade do fósforo no alumínio- $\alpha$ é de 0,007 at\%. A solubilidade do fósforo no alumínio líquido é de 
0,015 at\% a $660^{\circ} \mathrm{C}$. A característica mais marcante no diagrama Al-P é a formação do composto AIP com ponto de fusão superior a $2400^{\circ} \mathrm{C}$. [Loper, 2000; Mondolfo, 1976]

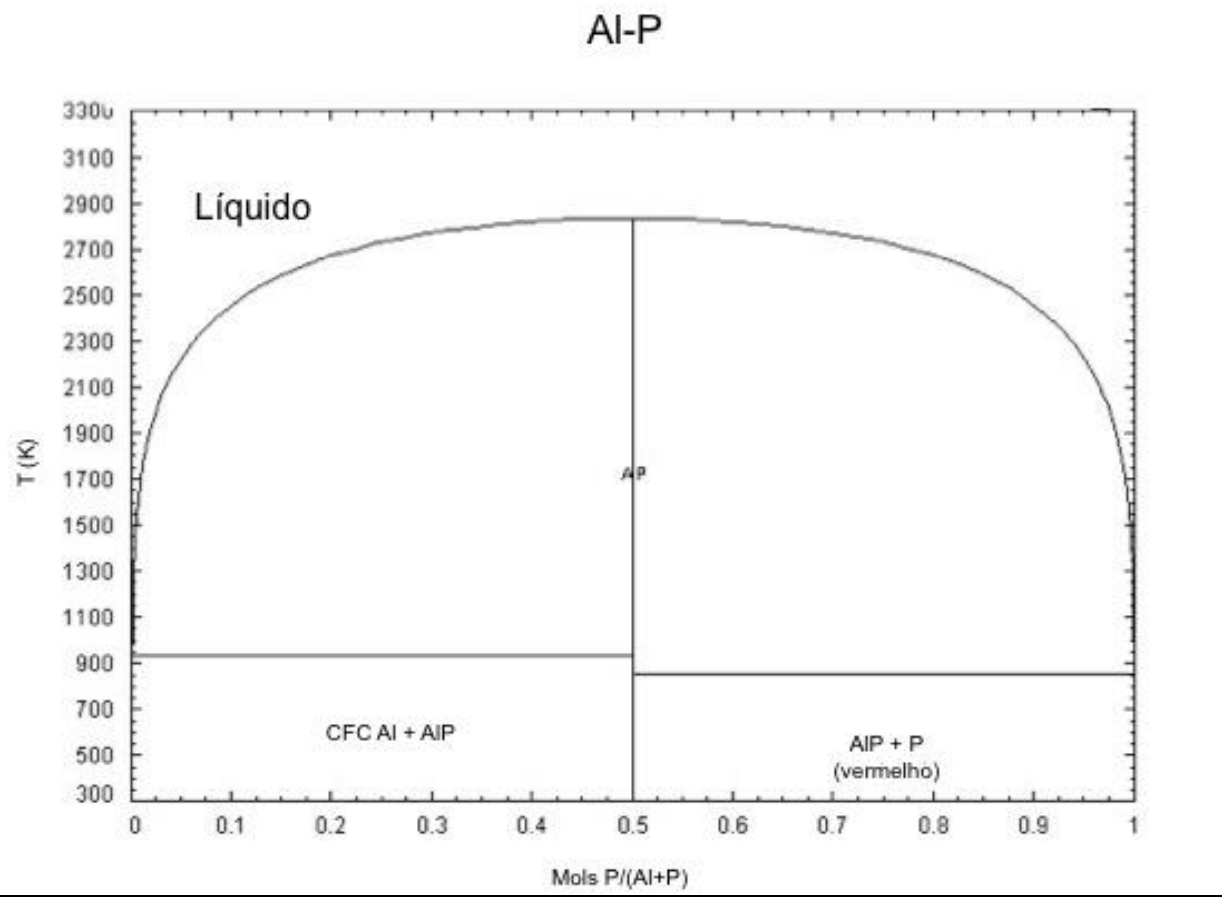

Figura 19 - Imagem do diagrama de fases Al-P. [Facsage]

A estrutura cúbica e a semelhança entre os parâmetros de rede entre as partículas AIP e do silício facilitam sua nucleação (Figura 20). [Zuo et al., 2009]

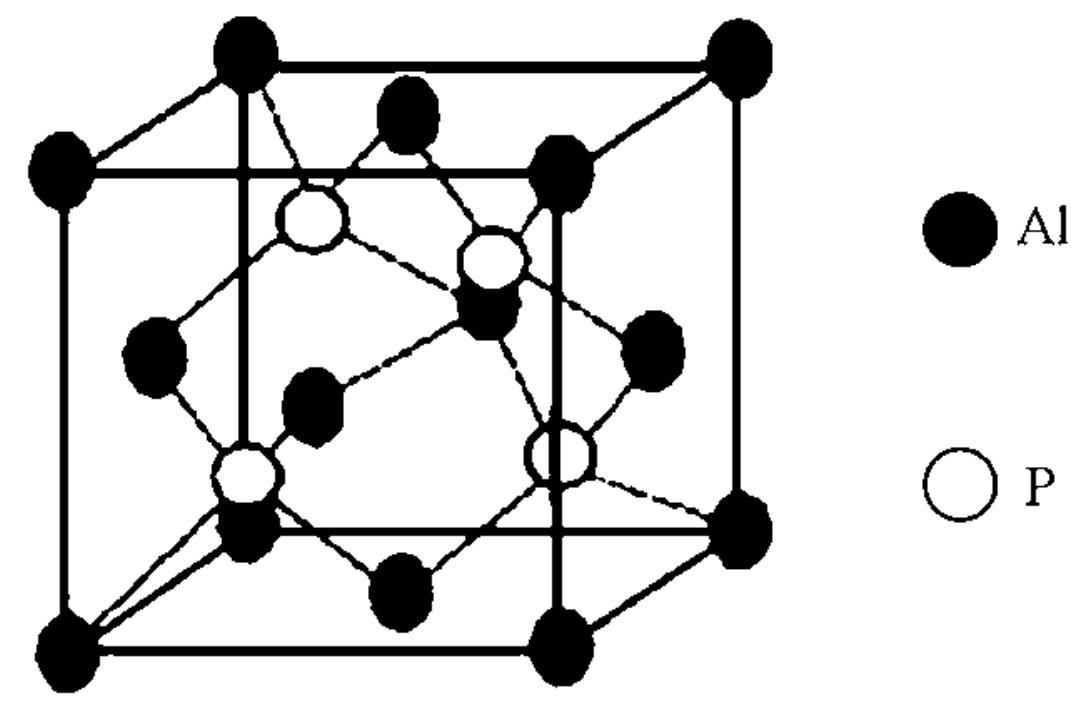

Figura 20 - Imagem da estrutura cúbica do composto Al-P. [Zuo et al., 2009] 
Há, no entanto, algumas restrições quanto ao uso do fósforo como refinador. A baixa solubilidade do fósforo no alumínio e a diferença de densidade causaria a segregação das partículas não dissolvidas. Parâmetros como temperatura de adição do modificador e tempo de espera da liga são, portanto, muito importantes [Zuo et al., 2009].

\subsection{Principais elementos de liga}

\subsubsection{Magnésio}

Pequenas quantidades de magnésio são freqüentemente usadas para melhorar as propriedades mecânicas de ligas Al-Si fundidas. O magnésio aumenta o limite de escoamento ao mesmo tempo em que diminui a ductilidade e a resistência à fratura. [Dons et al., 2005; Closset; Gruzleski, 1982]

Efeitos colaterais da adição de magnésio são a redução da temperatura eutética e da fluidez [Moustafa et al., 2002] e a modificação da composição química e morfologia dos intermetálicos contendo ferro de $\beta$ ( $\left.\mathrm{Al}_{5} \mathrm{FeSi}\right)$ para $\pi\left(\mathrm{Al}_{9} \mathrm{FeMg}_{3} \mathrm{Si}_{5}\right.$ ) [Joenoes; Gruzleski, 1991] ou Als $\mathrm{Mg}_{3} \mathrm{FeSi}_{6}$ na forma de escrita chinesa [Tash et al., 2007], dependendo da composição química da liga e velocidade de resfriamento.

A presença de magnésio nas ligas Al-Si faz com que essas ligas sejam tratáveis termicamente.

Após solubilização seguido de têmpera e envelhecimento, partículas coerentes e semicoerentes de $\mathrm{Mg}_{2} \mathrm{Si}$ precipitam uniformemente na matriz de alumínio em ligas Al-Si contendo magnésio [Joenoes; Gruzleski, 1991]

O limite de solubilidade do magnésio e do silício no alumínio em função da temperatura foi determinado por [Apelian et al., 1989], conforme Figura 21: 


\section{Temperatura $(\mathrm{F})$}

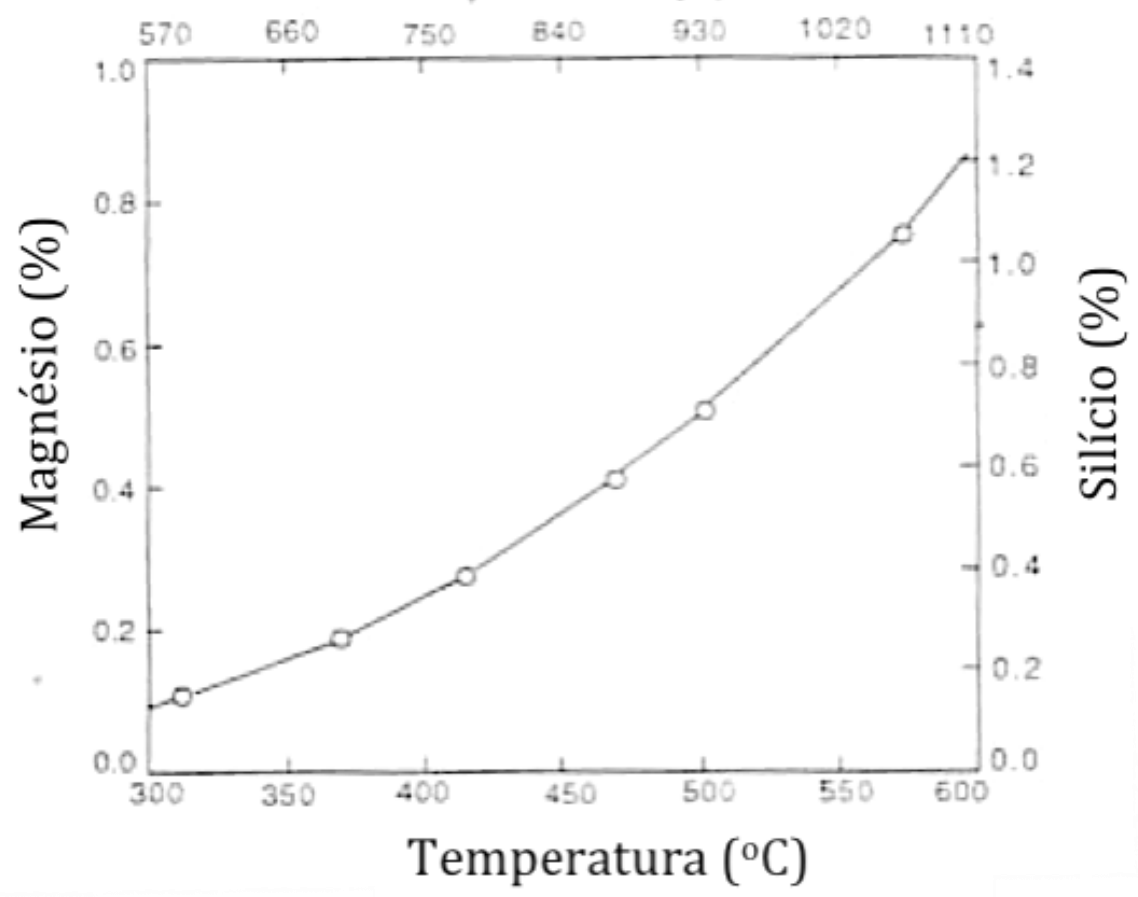

Figura 21 - Limite de solubilidade do magnésio e do silício no alumínio em função da temperatura. [Apelian et al., 1989]

O processo de envelhecimento é caracterizado pela resistência e dureza aumentando a um máximo e posteriormente decrescendo no estado super-envelhecido. $O$ aumento da resistência é normalmente associado à diminuição do alongamento. Sendo assim, ligas susceptíveis ao endurecimento por precipitação, quando envelhecidas ao seu pico de resistência, apresentam valores mínimos de alongamento. [Misra; Oswalt, 1982] Existe muita divergência nos resultados encontrados para a seqüência de reações de precipitação que ocorre nas ligas Al-Si-Mg. Segundo [Edwards et al., 1998] ela ocorre da seguinte forma:

$\Rightarrow \quad$ Formação de aglomerados de átomos de silício e aglomerados de átomos de magnésio

$\Rightarrow \quad$ Dissolução dos aglomerados de magnésio

$\Rightarrow \quad$ Formação de $\mathrm{Mg} / \mathrm{Si}$ co-aglomerados

$\Rightarrow \quad$ Precipitados de $\beta$ " (formato de agulhas)

$\Rightarrow \quad$ Precipitados de $\beta$ ' (formato de varetas) e $\beta$ " 
$\Rightarrow \quad$ Precipitados de $\beta$ (Mg2Si - formato de placas)

A formação de aglomerados de átomos de soluto ocorre durante os primeiros estágios da seqüência de envelhecimento, enquanto a formação de precipitados de $\beta$ "é associada ao pico de envelhecimento. [Edwards et al., 1998]

O efeito de endurecimento, no entanto, é útil até aproximadamente $0,7 \%$. A partir deste teor, o máximo de endurecimento da matriz é atingido e a perda de ductilidade é ainda mais evidente. [Haque et al., 1983]

\subsubsection{Cobre}

Assim como o magnésio, adições de cobre aumentam o limite de resistência e escoamento ao mesmo tempo em que diminuem a ductilidade e a resistência à fratura [Dons et al., 2005; Moustafa et al., 2002].

Um estudo realizado por [Feikus, 1998] compara seis ligas para determinar o efeito do cobre nas propriedades mecânicas das ligas Al-Si: Al-7\%Si-Mg, Al-9\%Si-Mg, a adição de $0,5 \%$ e $1 \%$ de cobre à liga base $\mathrm{Al}-7 \% \mathrm{Si}-\mathrm{Mg}$ e duas ligas secundárias $\mathrm{Al}-10 \% \mathrm{Si}-\mathrm{Mg}$ e Al-9\%Si-3\%Cu.

As duas versões da liga $\mathrm{Al}-7 \% \mathrm{Si}-\mathrm{Mg}$ contendo cobre mostraram aumento resistência à tração em temperaturas de $150^{\circ} \mathrm{C}$ a $200^{\circ} \mathrm{C}$, além de aumento na resistência a fluência, quando comparadas à liga base sem cobre. Houve, no entanto, uma leve redução no alongamento. A comparação entre as versões de ligas secundárias mostra resistência e fluência em níveis parecidos. A presença de altos níveis de impurezas na liga Al-9\%Si$3 \% \mathrm{Cu}$ levou a baixos valores de deformação até a ruptura, embora tenha apresentado os melhores valores de resistência à fluência a $250^{\circ} \mathrm{C}$. A tendência de trincas a quente foi semelhante para as ligas contendo cobre, quando comparadas à liga base. Propriedades físicas importantes como o coeficiente de expansão térmica e a condutividade térmica não foram significativamente afetadas pela adição de cobre. [Feikus, 1998] 
Ao contrário dos resultados obtidos por [Feikus, 1998], um estudo realizado por [Yang et al., 2012] mostra que, em ligas Al-Si-Cu-Ni-Mg, adições crescentes de cobre diminuem o coeficiente de expansão térmica, conforme a Figura 22.

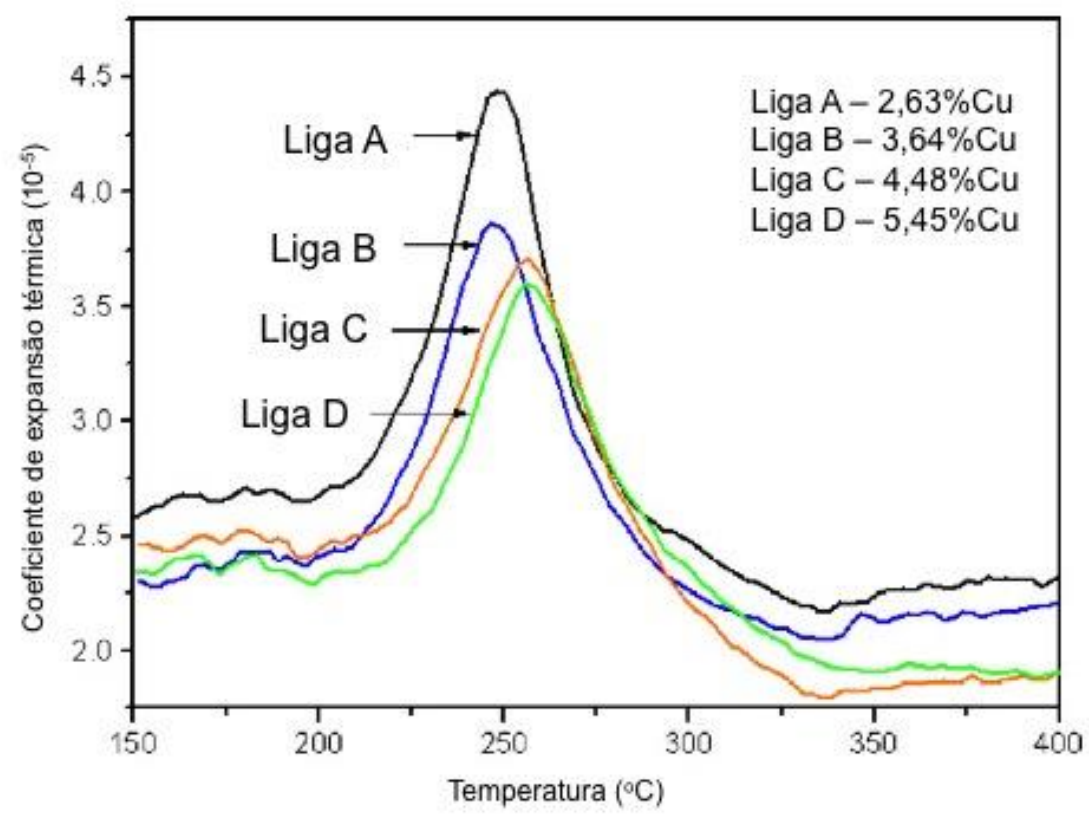

Figura 22 - Coeficiente de expansão térmica de ligas Al-Si-Cu-Ni-Mg contendo diferentes teores de cobre. [Yang et al., 2012]

O trabalho de [Yang et al., 2012] também mostra uma relação entre o aumento do limite de resistência a $350^{\circ} \mathrm{C}$ e o aumento do teor de cobre em ligas Al-Si-Cu-Ni-Mg, conforme a Figura 23. 


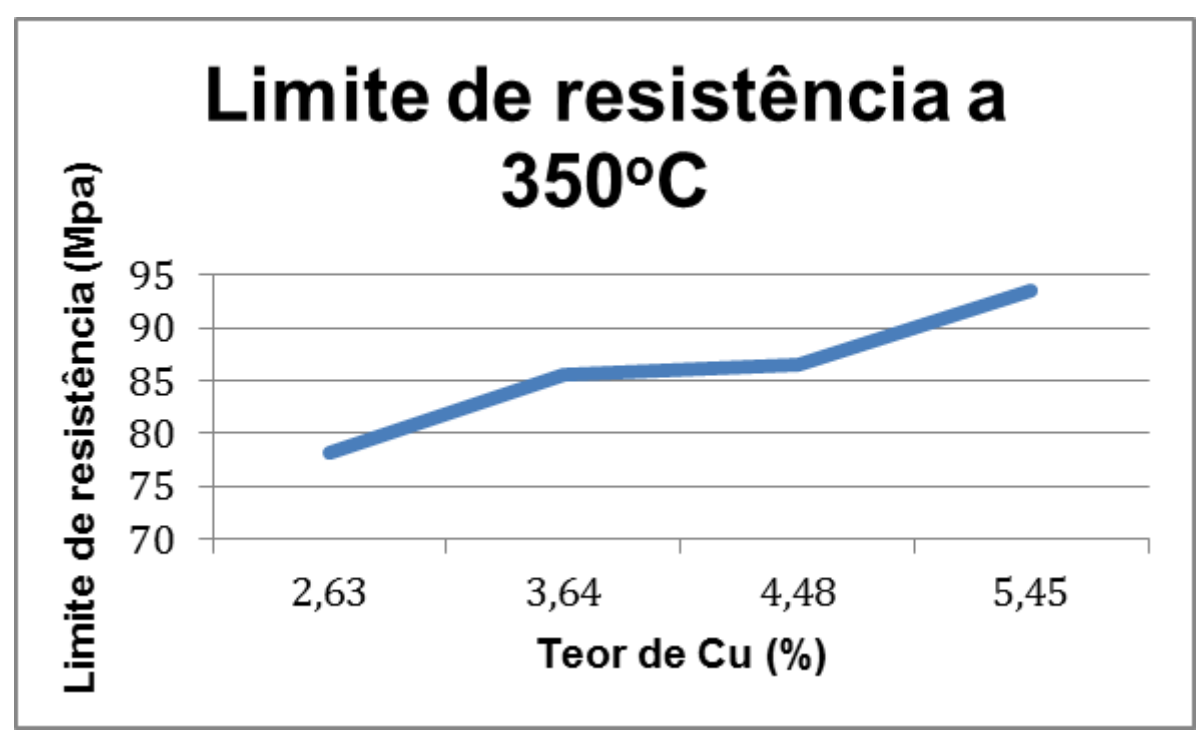

Figura 23 - Limite de resistência a $350^{\circ} \mathrm{C}$ de ligas Al-Si-Cu-Ni-Mg contendo diferentes teores de cobre. Gráfico obtido a partir dos dados de [Yang et al., 2012].

Efeitos colaterais da adição de cobre em ligas Al-Si são: o aumento do intervalo de solidificação da liga (o que levaria à maior propensão a formação de defeitos de fundição como porosidades) [Cárceres et al., 1999a], redução da temperatura eutética (aproximadamente $1,8^{\circ} \mathrm{C}$ para cada $1 \%$ de cobre adicionado) e aumento da fluidez (aproximadamente 4\%) [Moustafa et al., 2002].

A fração volumétrica da fase $\mathrm{Al}_{2} \mathrm{Cu}$ aumenta em aproximadamente $0,76 \%$ a cada $1 \%$ de cobre adicionado [Moustafa et al., 2002].

A fase $\mathrm{Al}_{2} \mathrm{Cu}$ pode solidificar em diferentes morfologias, sendo que altas taxas de solidificação favorecem o aparecimento do $\mathrm{Al}_{2} \mathrm{Cu}$ eutético, enquanto baixas taxas de resfriamento favorecem o aparecimento do $\mathrm{Al}_{2} \mathrm{Cu}$ em formato de bloco (Figura 24) [Sjölander; Seifeddine, 2010]. 
(a)

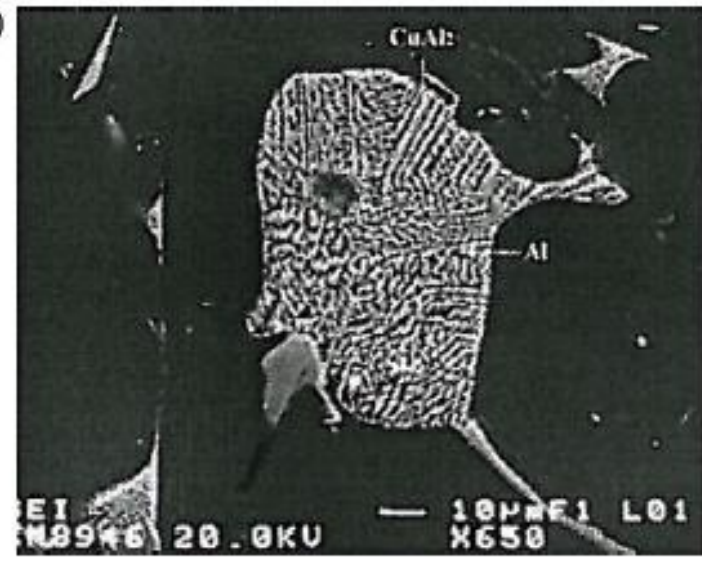

(b)

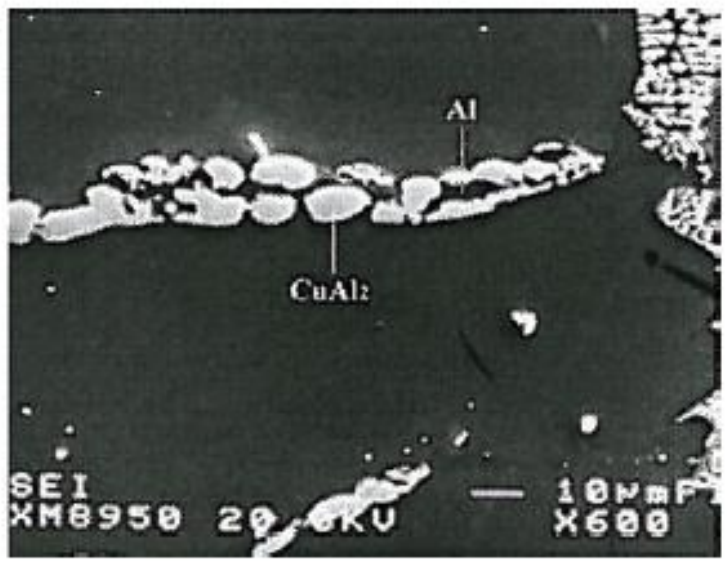

Figura 24 - (a) $\mathrm{Al}_{2} \mathrm{Cu}$ eutético lamelar; (b) $\mathrm{Al}_{2} \mathrm{Cu}$ eutético em formato de bloco [ $\mathrm{Li}$ et al., 2003]

Durante o tratamento de solubilização, nota-se que, na presença de magnésio, há um aumento na taxa de dissolução dos intermetálicos contendo cobre e um aumento na cinética de precipitação da fase $S^{\prime}\left(\mathrm{Al}_{2} \mathrm{CuMg}\right), \beta^{\prime}\left(\mathrm{Mg}_{2} \mathrm{Si}\right)$ e $\theta^{\prime}\left(\mathrm{Al}_{2} \mathrm{Cu}\right)$ que endurecem a liga. Este fenômeno é independente da concentração de cobre na liga [Moustafa et al., 2002].

A transformação do precipitado semi-coerente $\theta^{\prime}\left(\mathrm{Al}_{2} \mathrm{Cu}\right)$ para o precipitado não coerente $\theta\left(\mathrm{Al}_{2} \mathrm{Cu}\right)$ ocorre somente em temperaturas maiores que $200^{\circ} \mathrm{C}$. Para temperaturas menores que $200^{\circ} \mathrm{C}$, somente o efeito de coalescimento das partículas $\theta^{\prime}$ $\left(\mathrm{Al}_{2} \mathrm{Cu}\right)$ é observado. [Guillot et al., 2002]

Segundo [Samuel et al., 1998], a presença combinada de cobre e magnésio na liga AlSi6Cu3 resulta na formação de intermetálicos do tipo $\mathrm{Al}_{8} \mathrm{Mg}_{3} \mathrm{FeSi}{ }_{6}, \mathrm{Mg}_{2} \mathrm{Si}$ e $\mathrm{Al}_{5} \mathrm{Mg}_{8} \mathrm{Si}_{6} \mathrm{Cu}_{2}$. A fase $\mathrm{Al}_{5} \mathrm{Mg}_{8} \mathrm{Cu}_{2} \mathrm{Si}_{6}$ cresce a partir das partículas de $\mathrm{Al}_{2} \mathrm{Cu}$ durante uma reação eutética complexa próxima ao final da solidificação da liga. 


\subsubsection{Ferro}

O ferro é uma impureza comum proveniente de diversas fontes e que é considerada prejudicial para ligas Al-Si por diversos motivos. Infelizmente, ainda não existe um processo economicamente viável para a remoção do ferro. [Taylor, 1995]

O principal motivo pelo qual o ferro é um elemento indesejável em ligas Al-Si é a redução drástica na ductilidade das ligas contendo este elemento. Isso porque, quanto mais ferro, maior o número de intermetálicos formados e consequentemente, mais fácil a propagação de trincas (Figura 25). Além disso, altos teores de ferro podem ser responsáveis pelo aumento no número de porosidades. [Taylor, 1995]

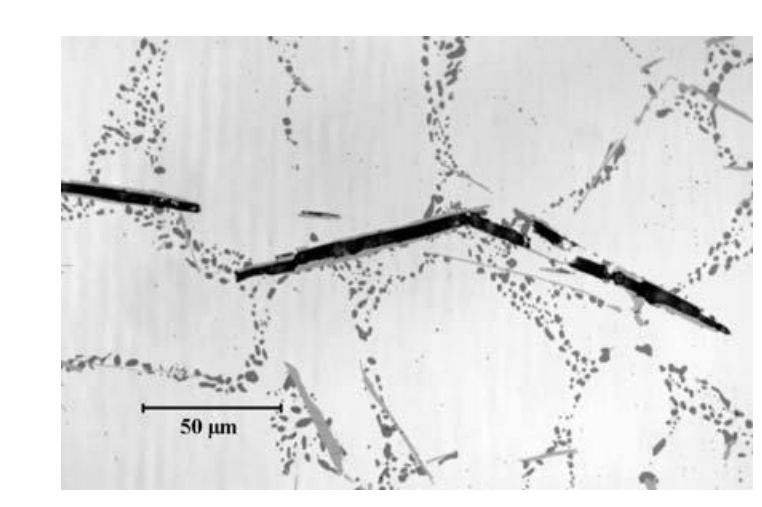

(a)

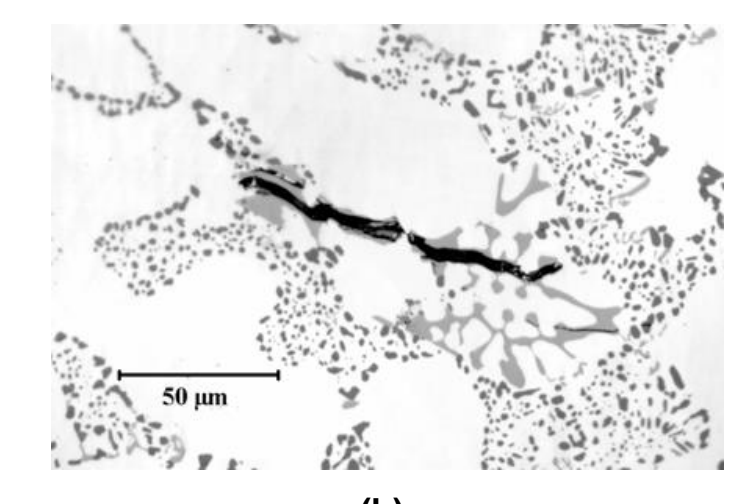

(b)

Figura 25 - Propagação de trincas através de partículas de Fe: (a) plaquetas de $\beta-\mathrm{Al}_{5} \mathrm{FeSi}$;

(b) escrita chinesa $\alpha-\mathrm{Al}_{15}(\mathrm{Fe}, \mathrm{Mn})_{3} \mathrm{Si}_{2 .}$ [Taylor, 1995]

O alumínio líquido é capaz de dissolver o ferro até cerca de $2 \%$ a $700^{\circ} \mathrm{C}$ e até $5 \%$ a $800^{\circ} \mathrm{C}$. O diagrama de fases Al-Fe apresenta um eutético em cerca de $1,9 \% \mathrm{Fe}$ a $655^{\circ} \mathrm{C}$ e, embora a solubilidade do ferro seja alta no estado líquido, ela é muito baixa no estado sólido, tendendo a se combinar com outros elementos e precipitar na forma de diversos intermetálicos (Figura 26). [Taylor, 1995] 


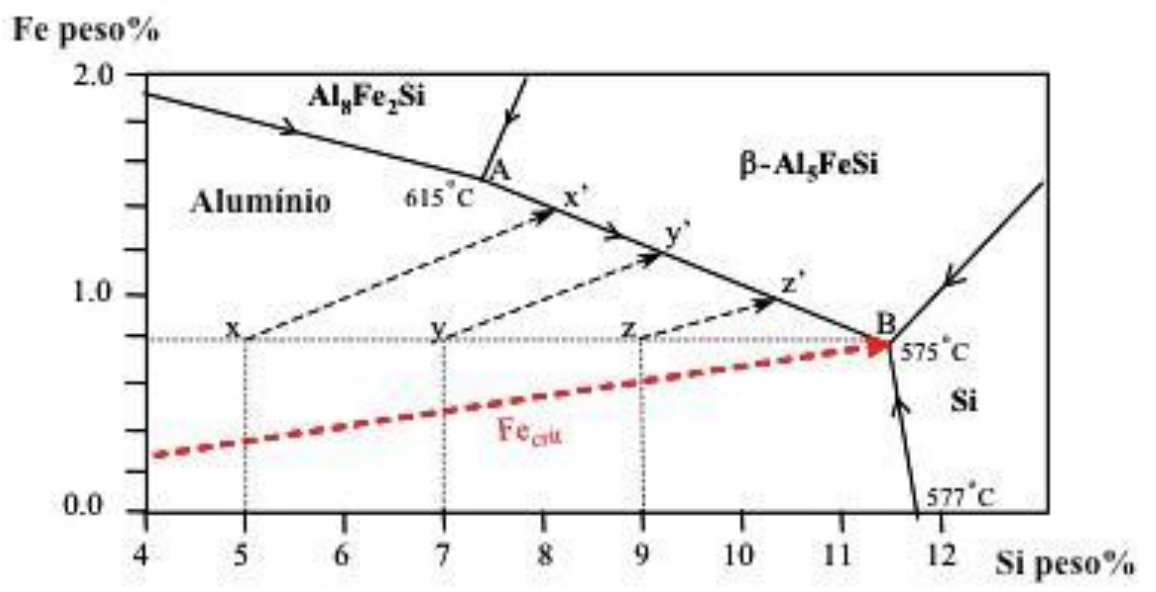

Figura 26 - Solubilidade do ferro em ligas Al-Si. [Taylor, 1995]

Segundo [Closset; Gruzleski, 1982], em uma liga AlSi7Mg0,3, a presença de ferro reduz drasticamente o índice de qualidade (limite de resistência + $150 \log (\%$ alongamento)) da liga. Alongamento, energia absorvida no ensaio Charpy e tenacidade à fratura diminuem com o aumento do teor de ferro na liga.

$\mathrm{Na}$ ausência do silício, as fases dominantes são $\mathrm{Al}_{3} \mathrm{Fe}$ e $\mathrm{Al}_{6} \mathrm{Fe}$. Na presença de silício, $\mathrm{Al}_{8} \mathrm{Fe} 2 \mathrm{Si}$ (conhecida como fase $\alpha$ ) e $\mathrm{Al}_{5} \mathrm{FeSi}$ (conhecida como fase $\beta$ ) são dominantes (Figura 27). [Taylor, 1995]

$\mathrm{Na}$ presença de magnésio, outra fase conhecida como fase $\pi$ ( $\mathrm{Al}_{8} \mathrm{FeMg}_{3} \mathrm{Si}_{6}$ ) também pode se formar. [Taylor, 1995]

Na presença de manganês a fase dominante passa a ser $\mathrm{Al}_{15}(\mathrm{Fe}, \mathrm{Mn})_{3} \mathrm{Si}_{2}$ que também é conhecida como fase $\alpha$. [Taylor, 1995] 


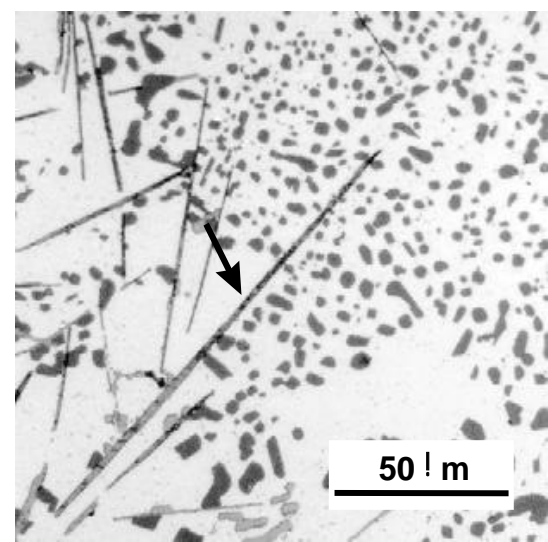

$8 ! 9$

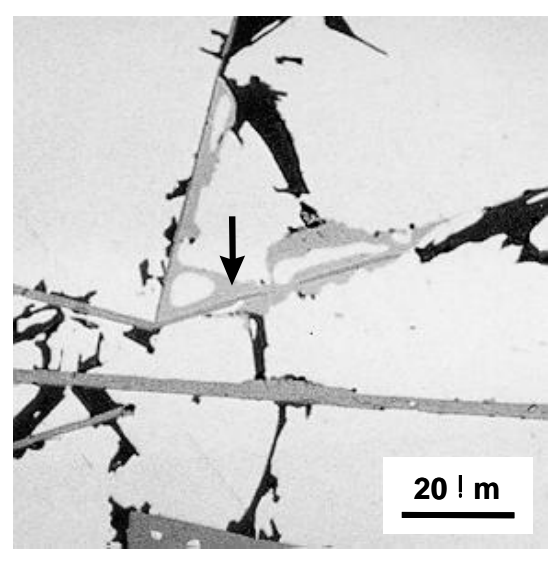

869

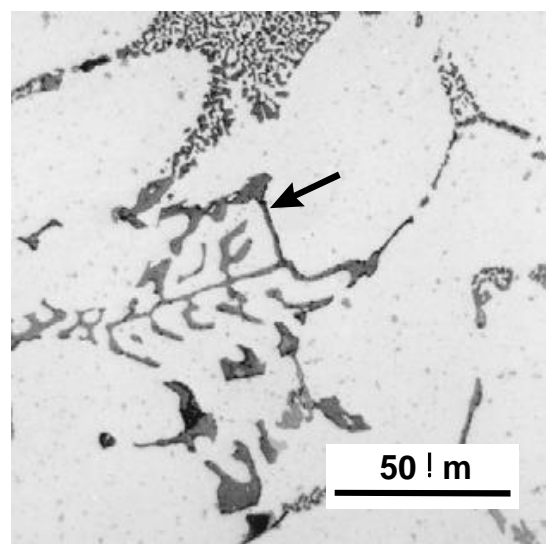

$8(9$

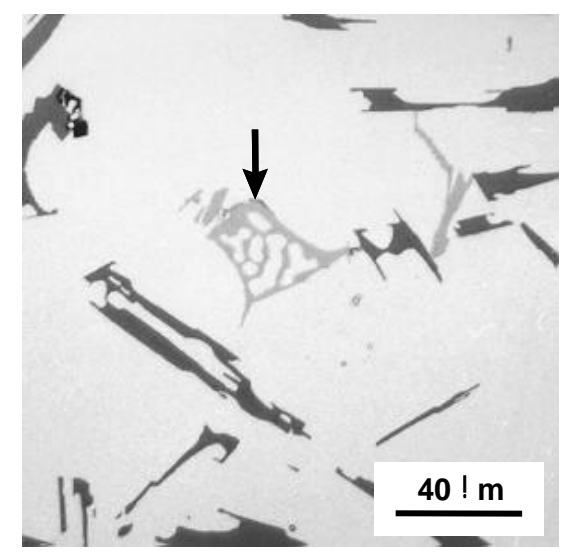

$8+9$

C

Figura 27 - Micrografias de diversos intermetálicos contendo ferro, mostrando suas morfologias típicas em uma liga Al-5\%Si-1\%Cu-0,5\%Mg-(Fe): (a) plaquetas de $\beta-A l_{5} \mathrm{FeSi}$; (b) escrita chinesa de $\alpha-\mathrm{Al}_{8} \mathrm{Fe}_{2} \mathrm{Si}$; (c) fase $\pi$ crescendo de $\beta$; (d) escrita chinesa de $\pi$. [Taylor, 1995]

Outro ponto crítico para os intermetálicos de ferro é o momento em que eles solidificam e isso é influenciado tanto pela concentração dos elementos envolvidos, quanto pelas taxas de resfriamento. Partículas de intermetálicos que precipitam antes ou ao mesmo tempo em que a rede dendrítica tende a crescer muito mais devido à disponibilidade de espaço no líquido. [Taylor, 1995]

O aumento do teor de ferro e manganês tende a antecipar a formação dos intermetálicos e a redução da taxa de resfriamento pode resultar no crescimento dessas partículas em até alguns milímetros. [Taylor, 1995] 


\subsubsection{Níquel}

O níquel é conhecido por melhorar as propriedades mecânicas das ligas Al-Si em altas temperaturas.

Em ligas Al-Si-Cu-Ni-Mg, foram identificadas fases contendo níquel em três composições diferentes: fase $\varepsilon\left(\mathrm{Al}_{3} \mathrm{Ni}\right)$, fase $\delta\left(\mathrm{Al}_{7} \mathrm{Cu}{ }_{4} \mathrm{Ni}\right)$ e fase $\gamma\left(\mathrm{Al}{ }_{3} \mathrm{CuNi}\right)$, dependendo das quantidades de cobre e níquel presentes na liga (Figura 28). [Yang et al., 2012; Li et al., 2010]
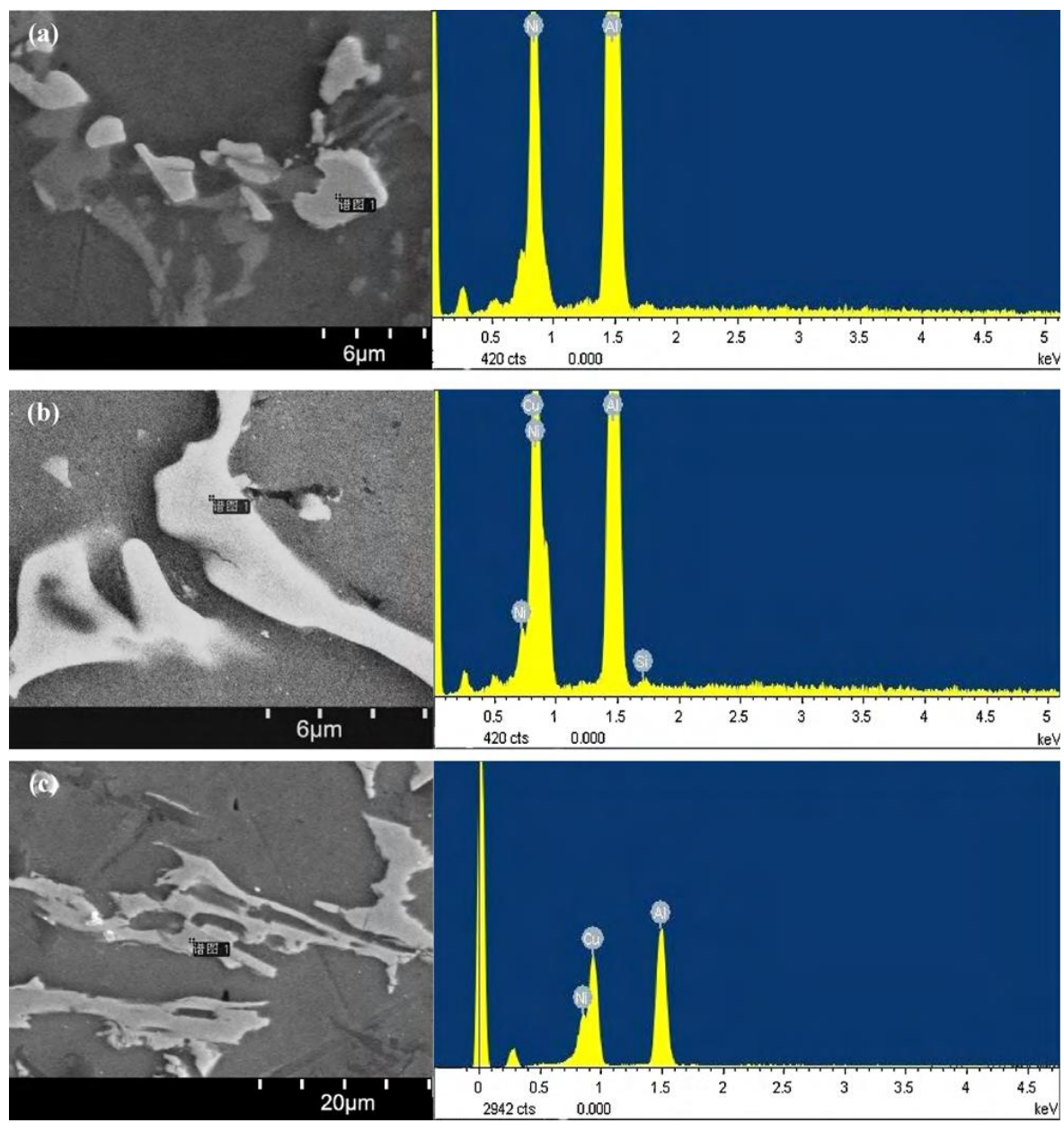

Figura 28 - Morfologia das fases: (a) $\varepsilon-\mathrm{Al}_{3} \mathrm{Ni}$; (b) $\delta-\mathrm{Al}_{7} \mathrm{Cu}_{4} \mathrm{Ni}$; (c) $\gamma-\mathrm{Al}_{3} \mathrm{CuNi}$. [Li et al., 2010] 
Essas fases têm grande contribuição para as propriedades mecânicas em altas temperaturas nas ligas para pistões, conferindo a essas ligas melhor estabilidade térmica, propriedades mecânicas, morfologias e distribuição. [Li et al., 2010]

De acordo com os resultados obtidos por [Li et al., 2010] (Tabela 4), a adição de $1 \%$ de níquel melhora o limite de resistência $(\mathrm{LR})$ a $350^{\circ} \mathrm{C}$ quando comparada a uma liga sem níquel. Adições crescentes de cobre alteram a composição química, estrutura cristalina e morfologia da fase contendo níquel de $\varepsilon$ para $\delta$ com a adição de $1,08 \%$ de cobre e de $\delta$ para $\gamma$ com a adição de $3,23 \%$ de cobre. A fase $\delta$ se mostrou a mais eficiente na melhoria das propriedades mecânicas a $350^{\circ} \mathrm{C}$.

Tabela 4 - Resultados obtidos por [Li et al., 2010] para diferentes frações volumétricas das fases $\varepsilon, \delta$ e $\gamma$.

\begin{tabular}{|c|cc|ccc|c|c|c|c|}
\hline & \multicolumn{5}{|c|}{ Composição Química (\%) } & \multicolumn{3}{|c|}{ Fração volumétrica (\%) } & \multicolumn{2}{|c|}{ LR a 350oC } \\
& $\mathrm{Si}$ & $\mathrm{Mg}$ & $\mathrm{Fe}$ & $\mathrm{Ni}$ & $\mathrm{Cu}$ & Fase $\varepsilon$ & Fase $\delta$ & Fase $\gamma$ & (MPa) \\
\hline Liga A & 13.1 & 1.10 & 0.29 & 0.0 & $<0.1$ & & & & 42.74 \\
Liga B & 13.1 & 1.03 & 0.30 & 1.0 & $<0.1$ & 1.60 & & & 49.51 \\
\hline Liga C & 13.0 & 1.05 & 0.30 & 1.0 & 1.08 & & 1.95 & & 61.63 \\
\hline Liga D & 12.8 & 1.01 & 0.31 & 1.0 & 3.23 & & & 4.31 & 61.71 \\
\hline
\end{tabular}

\subsection{Tratamento térmico no alumínio e em ligas Al-Si}

As propriedades mecânicas das ligas do sistema Al-Si dependem principalmente da composição química da liga e dos parâmetros de fundição. A aplicação de tratamentos térmicos pode ainda influenciar essas propriedades. [Sjölander; Seifeddine, 2010] As têmperas são classificadas conforme a NBR 6835 de acordo com os processos aos quais são submetidas, como apresenta a Tabela 5. 
Tabela 5 - Códigos de condições de tratamento em alumínio. [Callister; Rethwisch, 1998]

\begin{tabular}{c|l}
\hline Código & \multicolumn{1}{c}{ Definição } \\
\hline $\mathbf{F}$ & $\begin{array}{l}\text { Como fabricada: Aplica-se aos produtos obtidos através de processos de conformação em } \\
\text { que não se emprega qualquer controle especial sobre as condições térmicas ou de } \\
\text { encruamento. }\end{array}$ \\
\hline $\mathbf{O}$ & $\begin{array}{l}\text { Recozida: Aplica-se aos produtos acabados, no estado em que apresentam o menor valor } \\
\text { de resistência mecânica. }\end{array}$ \\
\hline $\mathbf{H}$ & $\begin{array}{l}\text { Encruada: Aplica-se aos produtos em que a resistência mecânica foi aumentada por } \\
\text { deformação plástica a frio e, que podem ou não, ser submetidos a um recozimento } \\
\text { complementar para produzir amolecimento parcial ou a um processo de estabilização. É } \\
\text { utilizado para as ligas nãotratáveis termicamente. A letra "H" deverá sempre ser } \\
\text { seguida de dois ou mais dígitos. }\end{array}$ \\
\hline $\mathbf{T}$ & $\begin{array}{l}\text { Tratada termicamente: Aplica-se aos produtos que sofrem tratamento térmico com ou sem } \\
\text { deformação plástica complementar. A letra "T" deve ser seguida de dígitos que indicam a } \\
\text { seqüência dos processos básicos realizados: tratamentos térmicos ou deformações } \\
\text { plásticas. }\end{array}$
\end{tabular}

Os tratamentos do tipo "T" foram divididos conforme Tabela 6 (NBR 6835).

Tabela 6 - Códigos de tratamentos "T” em alumínio. [Callister; Rethwisch, 1998]

\begin{tabular}{c|l}
\hline Código & \multicolumn{1}{c}{ Definição } \\
\hline T1 & $\begin{array}{l}\text { Resfriado de um processo de conformação em alta temperatura e envelhecido naturalmente } \\
\text { até uma condição estável. }\end{array}$ \\
\hline T2 & $\begin{array}{l}\text { Resfriado de um processo de conformação em alta temperatura, trabalhado a frio e } \\
\text { envelhecido naturalmente até uma condição estável. }\end{array}$ \\
\hline T3 & Solubilizado, trabalhado a frio e envelhecido naturalmente até uma condição estável. \\
\hline T4 & Solubilizado, envelhecido naturalmente até uma condição estável. \\
\hline T5 & Resfriado de um processo de conformação em alta temperatura e envelhecido artificialmente. \\
\hline T6 & Solubilizado e envelhecido artificialmente. \\
\hline T8 & Solubilizado e super-envelhecido. \\
\hline T9 & Solubilizado, trabalhado a frio e envelhecido artificialmente. \\
\hline T10 & $\begin{array}{l}\text { Resfriado de um processo de conformação em alta temperatura, trabalhado a frio e } \\
\text { envelhecido artificialmente. }\end{array}$
\end{tabular}


Tratamentos de solubilização são realizados em altas temperaturas e têm a função de [Sjölander; Seifeddine, 2010]:

- Dissolver as fases contendo cobre e magnésio formadas durante a solidificação;

- Homogeneizar os elementos de liga;

- Esferoidizar as partículas de silício.

Ligas de Al-Si com teor de silício maior que 7\% apresentam estrutura de silício eutético interconectada na condição bruta de fundição (Figura 29) [Lasagni et al., 2007].
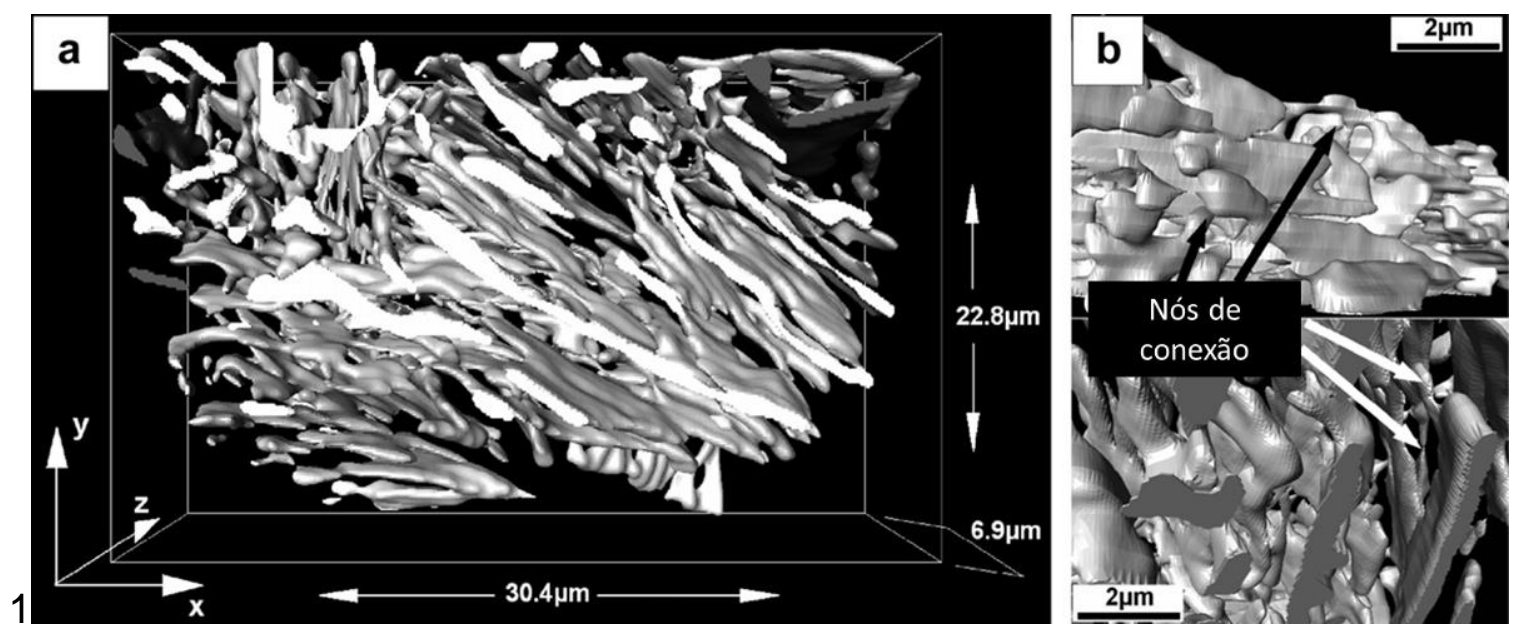

Figura 29 - Reconstrução 3D da morfologia do silício na condição bruta de fundição de uma liga AISi12: (a) estrutura do silício com placas interconectadas (cada grupo de placas está identificado com um tom de cinza diferente); (b) detalhe dos nós de conexão [Lasagni et al., 2007].

Tratamentos térmicos em temperaturas maiores que $400^{\circ} \mathrm{C}$ causam rápida esferoidização desta estrutura (Figura 30) [Lasagni et al., 2007]. 

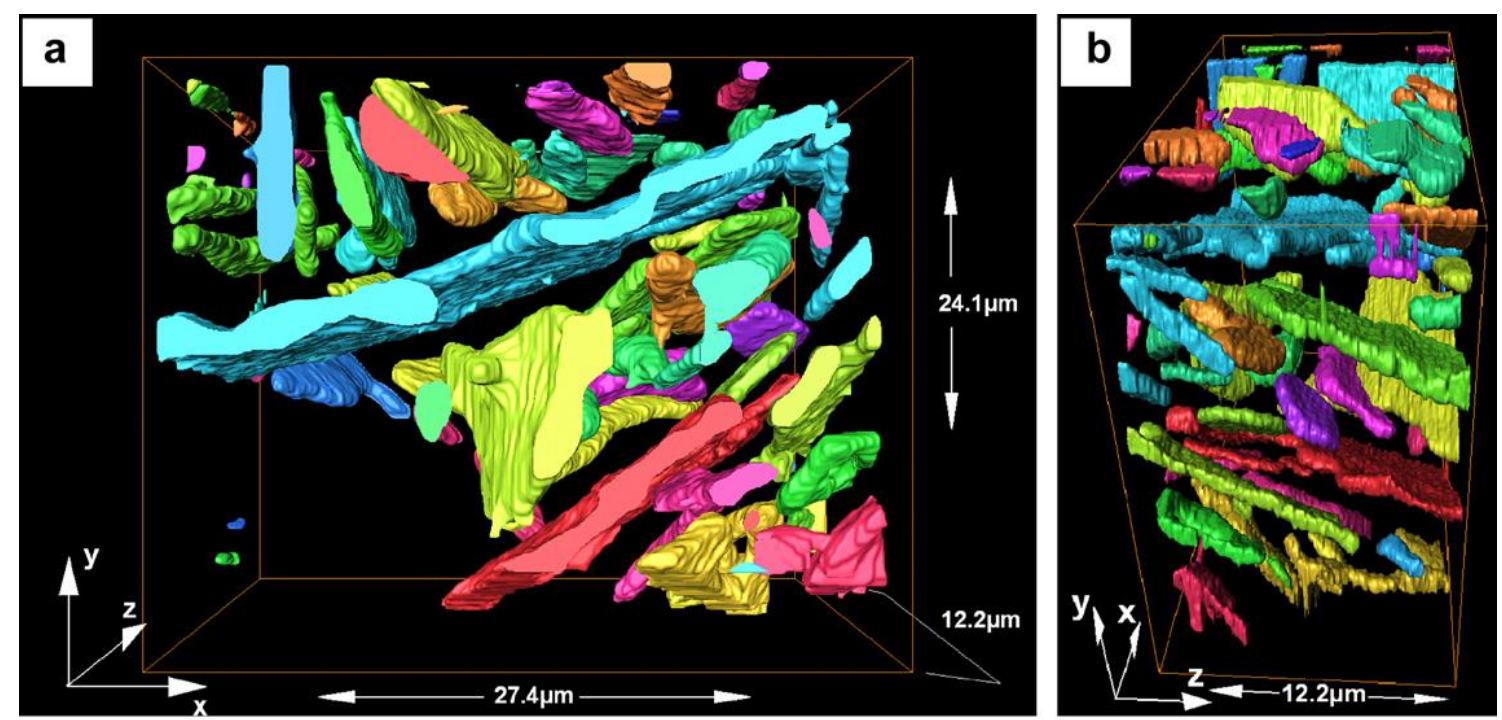

Figura 30 - Reconstrução 3D da morfologia do silício após solubilização a $540^{\circ} \mathrm{C}$ por 20 minutos de uma liga AlSi12. [Lasagni et al., 2007]

Em ligas Al-Si eutéticas contendo 1\%Ni, na condição bruta de fundição, além de uma rede de lamelas de silício conectadas, são encontradas formas complexas de intermetálicos contendo níquel (Figura 31). [Asghar et al., 2009]

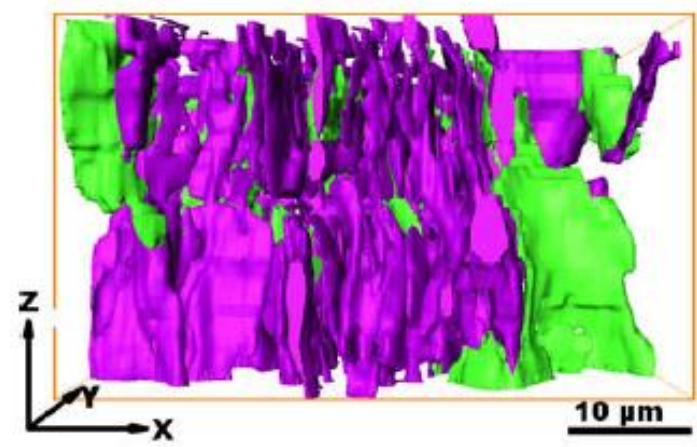

(a)

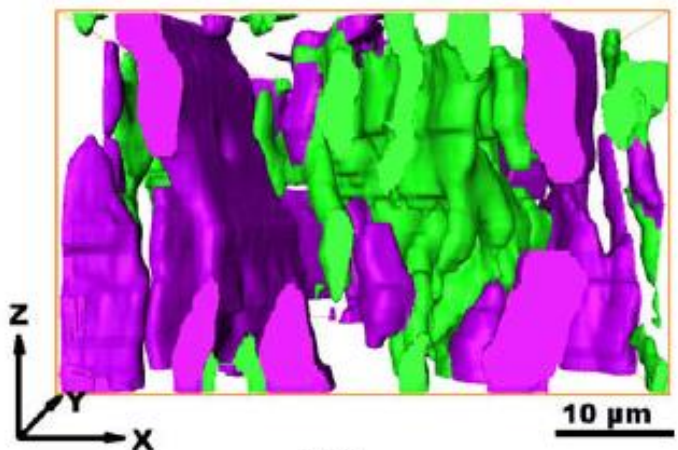

(b)

Figura 31 - Reconstrução da estrutura 3D do silício (roxo) + intermetálicos contendo níquel (verde) em uma AISi12 através de secções sucessivas em tomografia óptica: (a) bruto de fundição composto por secções de $0,5 \mu \mathrm{m}$ em um volume de $X=51,75 \mu \mathrm{m}, Y=48,80 \mu \mathrm{m}, Z=14,5 \mu \mathrm{m}$; (b) Após solubilização a $540^{\circ} \mathrm{C}$ por 24 horas em secções de $0,6 \mu \mathrm{m}$ em um volume de $X=51,75 \mu \mathrm{m}$, $\mathrm{Y}=48,80 \mu \mathrm{m}, \mathrm{Z}=16,5 \mu \mathrm{m}$. [Asghar et. al., 2009]

O tratamento térmico de solubilização, realizado em temperaturas próximas à temperatura de fusão dessas ligas causa a desintegração desta rede de silício eutético interconectada e esferoidização das partículas de silício. [Asghar et al., 2014] 
O processo de esferoidização das partículas de silício depende da difusão do silício na interface Al-Si. Existem duas possibilidades para um átomo de silício migrar na interface Al-Si: 1) auto-difusão na superfície e 2) inter-difusão do silício no alumínio. O coeficiente de para o silício na interface Al-Si pode ser descrito pela equação:

$$
D s=D o \cdot \exp \left(-\frac{E_{A \text { inter }}-E_{A, V}}{R \cdot T}\right)
$$

Onde $E_{A \text {,inter }}$ é a energia de ativação para a inter-difusão do silício, $E_{A, v}$ é a energia de ativação para a formação de lacunas no alumínio e $D_{0}$ é o fator de frequência. [Ogris et al., 2002]

De acordo com a equação apresentada, a temperatura tem relação exponencial com a velocidade de esferoidização do silício.

Nem todas as fases formadas durante a solidificação dissolvem durante o tratamento térmico. Por exemplo, $\beta-\mathrm{Mg}_{2} \mathrm{Si}$ e $\theta-\mathrm{Al}{ }_{2} \mathrm{Cu}$ são relativamente fáceis de dissolver,

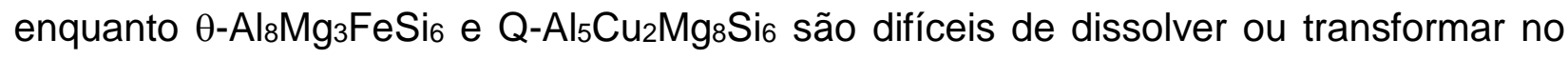
estado sólido. Fases contendo ferro são difíceis de dissolver. A fase $\alpha-\mathrm{Al}_{15}(\mathrm{Fe}, \mathrm{Mn})_{3} \mathrm{Si}_{2}$ é virtualmente não afetada pelo tratamento de solubilização, enquanto plaquetas de $\beta$ $\mathrm{Al}_{5} \mathrm{FeSi}$ se fragmentam e passam por uma dissolução lenta após longos tempos em alas temperaturas. [Sjölander; Seifeddine, 2010]

$\mathrm{O}$ tratamento de envelhecimento pode ocorrer de forma natural (em temperatura ambiente) ou de forma artificial (em temperaturas mais elevadas). [Sjölander; Seifeddine, 2010]

Ligas contendo magnésio envelhecem rapidamente em temperatura ambiente, enquanto ligas contendo cobre passam por um envelhecimento natural mais lento e menos efetivo. [Sjölander; Seifeddine, 2010]

O envelhecimento em temperaturas elevadas aumenta a cinética de movimentação atômica, gerando precipitados muito maiores do que as zonas de Guinier-Preston observadas após envelhecimento em temperatura ambiente. [Sjölander; Seifeddine, 2010] 


\subsubsection{Efeito do tratamento térmico em ensaios de compressão}

Em ensaios de compressão realizados em uma liga AlSi12CuMgNi, tanto em temperatura ambiente, quanto a $300^{\circ} \mathrm{C}$, notou-se queda da resistência mecânica após tratamento de solubilização a $490^{\circ} \mathrm{C}$ (Figura 32). [Asghar et al., 2014]

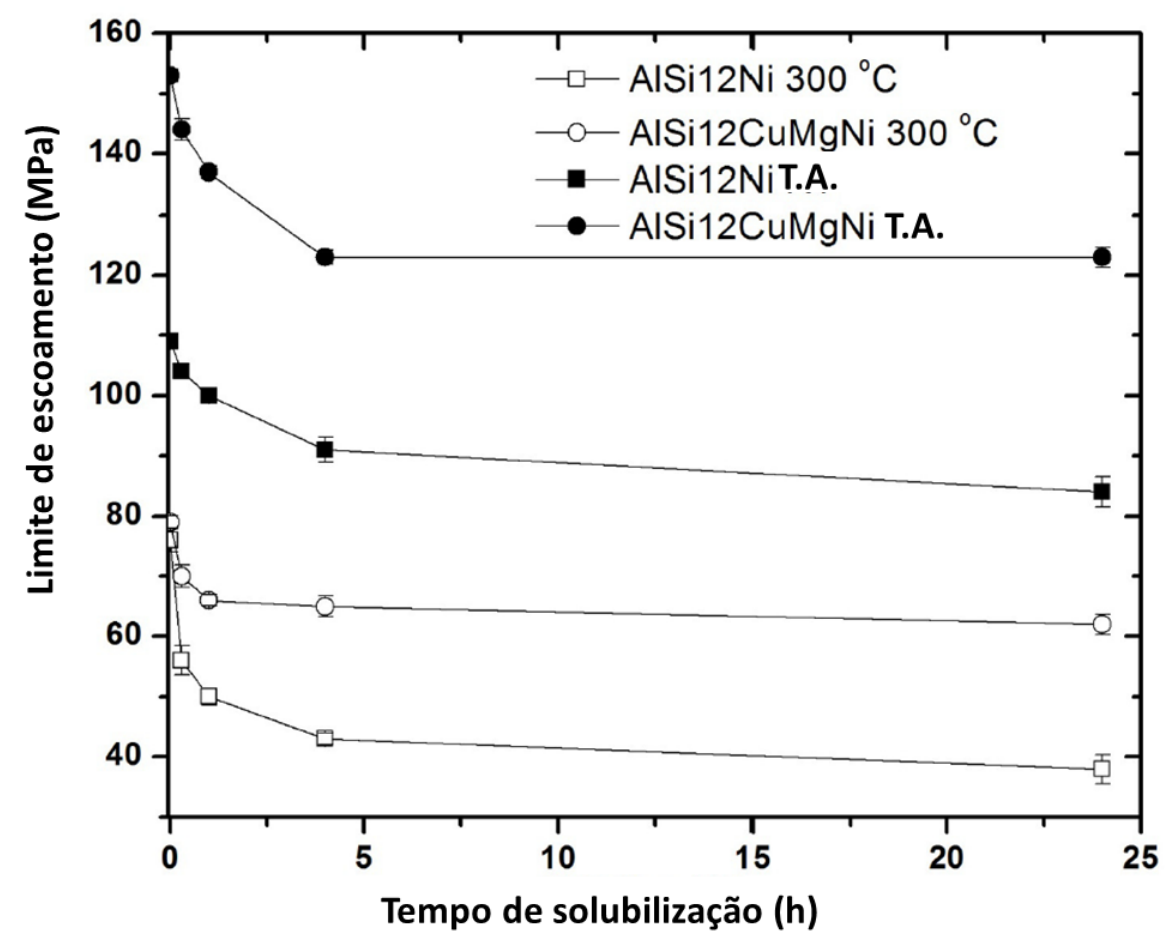

Figura 32 - Limite de escoamento em compressão em temperatura ambiente (T.A.) e a $300^{\circ} \mathrm{C}$ para as ligas AISi12Ni e AlSi12CuMgNi [Asghar et al., 2014].

Estes resultados foram atribuídos à estrutura do material que, quando bruta de fundição é contínua e após tratamento térmico perde a continuidade e se torna esferoidizada.

De acordo com os autores, a estrutura contínua é capaz de suportar cargas mais altas devido às redes rígidas de silício eutético e intermetálicos contendo níquel. 


\subsubsection{Efeito do tratamento térmico em ensaios de tração}

Em ensaios de tração realizados em ligas para pistões, o resultado difere dos resultados de ensaios de compressão.

Um estudo realizado com cinco tipos de ligas comumente utilizadas em pistões revela que, após o tratamento de solubilização $\left(500^{\circ} \mathrm{C}\right.$ por 5 horas) e envelhecimento $\left(180^{\circ} \mathrm{C}\right.$ por 9 horas), há um aumento no limite de resistência e na dureza das ligas, e uma redução no alongamento (Figura 33). [Zeren, 2007] 

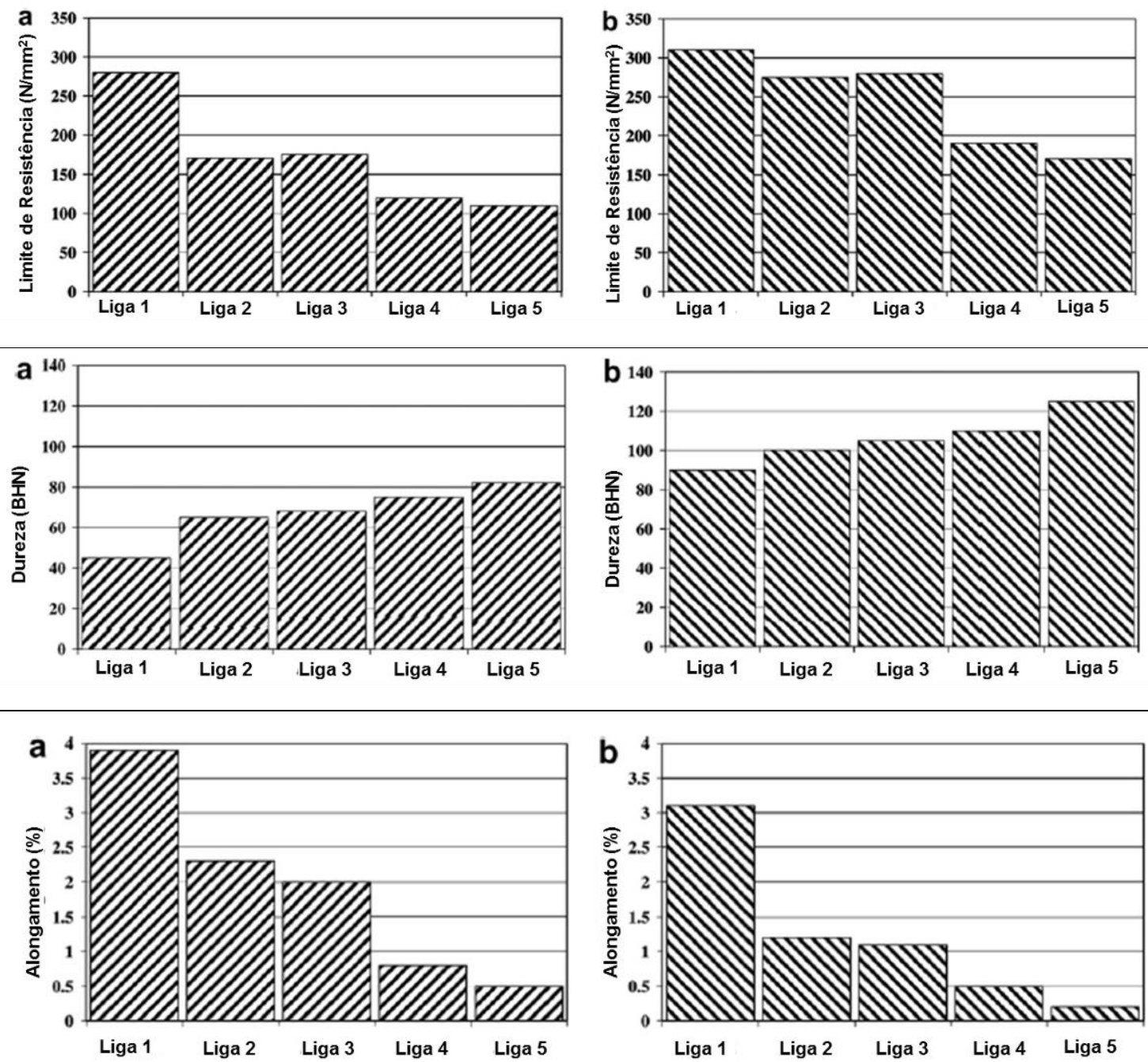

\begin{tabular}{|c|c|c|c|c|c|c|}
\hline & $\mathrm{Cu}$ & Si & Mg & $\mathbf{N i}$ & $\mathrm{Fe}$ & Al \\
\hline Liga 1 & 4,0 & 0,6 & 1,5 & 1,8 & 0,6 & Restante \\
\hline Liga 2 & 0,9 & 10,5 & 1,0 & 0,9 & 0,6 & Restante \\
\hline Liga 3 & 1,0 & 12,0 & 0,8 & 1,0 & 0,5 & Restante \\
\hline Liga 4 & 0,9 & 18,1 & 0,9 & 0,9 & 0,5 & Restante \\
\hline Liga 5 & 1,1 & 24,0 & 0,8 & 1,2 & 0,6 & Restante \\
\hline
\end{tabular}

Figura 33 - Limite de resistência de ligas comumente utilizadas em pistões: (a) condição bruta de fundição; (b) após tratamento de solubilização e envelhecimento. [Zeren, 2007] 


\subsection{Ligas de alumínio para pistões}

Ligas de alumínio contendo níquel e silício são amplamente utilizadas na indústria automotiva para a fabricação de pistões. Essas ligas contêm diversos outros elementos, formando fases de composição complexa. [Belov et al., 2005]

Diversas classes de ligas para pistões contêm $11-23 \% \mathrm{Si}, 0.5-3 \% \mathrm{Ni}, 0.5-5.5 \% \mathrm{Cu}$, 0.6$1.3 \% \mathrm{Mg}$, até $1.3 \% \mathrm{Fe}$ e até $1 \% \mathrm{Mn}$. O manganês é encontrado em baixas concentrações e pode ser desconsiderado para efeitos de composição de fases e reações de solidificação. [Belov et al., 2005]

A identificação de fases em ligas Al-Si multi-componentes não é fácil devido à diversidade de fases intermetálicas complexas que se formam. [Chen et al., 2006]

A Tabela 7 mostra as composições e densidade das fases que podem se formar em ligas Al-Si para pistões. [Belov et al., 2005]

Tabela 7 - Composições e densidades das fases formadas no sistema Al-Cu-Fe-Mg-Ni-Si. [Belov et al., 2005]

\begin{tabular}{c|c|c|c}
\hline Fase & Designação & $\begin{array}{c}\text { Composição } \\
\text { (peso\%) }\end{array}$ & $\begin{array}{c}\text { Densidade } \\
\left(\mathbf{g} / \mathbf{c m}^{3} \text { ) }\right.\end{array}$ \\
\hline $\mathrm{Al}_{3} \mathrm{Ni}$ & $\varepsilon$ & $42 \mathrm{Ni}$ & 3.95 \\
\hline $\mathrm{Al}_{2} \mathrm{Cu}$ & $\theta$ & $52.5 \mathrm{Cu}$ & 4.34 \\
\hline $\mathrm{Mg}{ }_{2} \mathrm{Si}$ & $\mathrm{M}$ & $63.2 \mathrm{Mg} ; 36.8 \mathrm{Si}$ & 1.98 \\
\hline $\mathrm{Al}_{3} \mathrm{CuNi}\left(\mathrm{Al}{ }_{3} \mathrm{Ni}\right)$ & $\delta$ & $\sim 30 \mathrm{Ni} ; 31 \mathrm{Cu}$ & 4.76 \\
\hline $\mathrm{Al}{ }_{7} \mathrm{Cu} 4 \mathrm{Ni}$ & $\gamma$ & $38.7-50.7 \mathrm{Cu} ; 11.8-22.2 \mathrm{Ni}$ & 5.48 \\
\hline $\mathrm{Al} 9 \mathrm{FeSi}$ & $\mathrm{T}$ & $4.5-14 \mathrm{Fe} ; 18-28 \mathrm{Ni}$ & 3.4 \\
\hline $\mathrm{Al}_{5} \mathrm{FeSi}$ & $\beta$ & $25-30 \mathrm{Fe} ; 12-15 \mathrm{Si}$ & 3.45 \\
\hline $\mathrm{Al}_{8} \mathrm{FeMg}_{3} \mathrm{Si}_{6}$ & $\pi$ & $10.9 \mathrm{Fe} ; 14.1 \mathrm{Mg} ; 32.9 \mathrm{Si}$ & 2.82 \\
\hline $\mathrm{Al}_{4} \mathrm{Cu}_{2} \mathrm{Mg}_{8} \mathrm{Si}_{6}$ & $\Theta$ & $20.3 \mathrm{Cu} ; 31.1 \mathrm{Mg} ; 27 \mathrm{Si}$ & 2.79
\end{tabular}

A Tabela 8 mostra as reações invariantes dos sistemas quaternários presentes no sistema Al-Cu-Fe-Mg-Ni-Si. [Belov et al., 2005] 
Tabela 8 - Reações invariantes dos sistemas quaternários presentes no sistema Al-Cu-Fe-Mg-Ni-Si. [Belov et al., 2005]

\begin{tabular}{c|c|c|c}
\hline Sistema & Fases & Reação invariante & $\begin{array}{c}\text { Temperatura } \\
\left({ }^{\circ} \mathrm{C}\right)\end{array}$ \\
\hline Al-Cu-Fe-Si & $\theta, \beta$ & $\mathrm{L} \rightarrow(\mathrm{Al})+(\mathrm{Si})+\theta+\beta$ & $\sim 520$ \\
\hline $\mathrm{Al}-\mathrm{Cu}-\mathrm{Mg}-\mathrm{Si}$ & $\theta, \mathrm{M}, \Theta$ & $\mathrm{L}+(\mathrm{Si})+\mathrm{M} \rightarrow(\mathrm{Al})+\mathrm{Q}$ & 529 \\
& & $\mathrm{~L} \rightarrow(\mathrm{Al})+(\mathrm{Si})+\theta+\mathrm{Q}$ & $503-507$ \\
\hline Al-Cu-Ni-Si & $\delta, \gamma, \theta$ & $\mathrm{L}+\varepsilon \rightarrow(\mathrm{Al})+(\mathrm{Si})+\theta+\delta$ & $\sim 540$ \\
& & $\mathrm{~L}+\delta \rightarrow(\mathrm{Al})+(\mathrm{Si})+\gamma$ & $\sim 530$ \\
& & $\mathrm{~L} \rightarrow(\mathrm{Al})+(\mathrm{Si})+\theta+\gamma$ & $\sim 520$ \\
\hline Al-Fe-Mg-Si & $\beta, \mathrm{M}, \pi$ & $\mathrm{L}+\beta \rightarrow(\mathrm{Al})+(\mathrm{Si})+\pi$ & 567 \\
& & $\mathrm{~L} \rightarrow(\mathrm{Al})+(\mathrm{Si})+\mathrm{M}+\pi$ & 554 \\
\hline Al-Fe-Ni-Si & $\mathrm{T}, \beta, \varepsilon$ & $\mathrm{L} \rightarrow(\mathrm{Al})+(\mathrm{Si})+\varepsilon+\mathrm{T}$ & $\sim 556$ \\
& & $\mathrm{~L}+\beta \rightarrow(\mathrm{Al})+(\mathrm{Si})+\mathrm{T}$ & $573-576$ \\
\hline Al-Mg-Ni-Si & $\mathrm{M}, \varepsilon$ & $\mathrm{L} \rightarrow(\mathrm{Al})+\mathrm{M}+(\mathrm{Si})+\varepsilon$ & $\sim 550$
\end{tabular}

\subsection{Ligas de alumínio para altas temperaturas}

Diversas ligas de alumínio são reconhecidas por suas propriedades mecânicas e físicas atraentes para aplicações envolvendo trabalho em altas temperaturas. Muitas dessas ligas são resultantes dos esforços de algumas décadas atrás para atingir um desempenho satisfatório em pistões. A maior parte dos desenvolvimentos de ligas de alumínio para altas temperaturas foram baseados em tentativa e erro. [Granger et al., 1986]

De acordo com [Knipling et al., 2006], existem quatro critérios que devem ser atendidos para se produzir uma liga de alumínio com estabilidade e resistência em altas temperaturas apresentando boa fundibilidade e endurecimento por precipitação:

- $\quad$ ser capaz de formar uma fase endurecedora adequada;

- $\quad$ apresentar baixa solubilidade no alumínio sólido;

- $\quad$ apresentar baixa difusividade no alumínio;

- $\quad$ manter a habilidade da liga de solidificar de forma convencional. 
Alguns elementos como o cobre, o níquel e o ferro, são reconhecidos por impactarem favoravelmente o desempenho de ligas de alumínio em altas temperaturas. Relações entre concentração de elementos e a propriedade mecânica foram estabelecidos para diferentes temperaturas de exposição. [Granger et al., 1986]

No entanto, nem essas relações de concentração nem os efeitos de endurecimento da matriz podem ser definidos como meio de prever o desempenho da liga em diferentes temperaturas. [Granger et al., 1986]

Em ligas complexas contendo diversas fases, a adição de elementos é feita de forma a produzir um efeito benéfico (formação de uma alta fração volumétrica de partículas que se mantêm estáveis em altas temperaturas) e minimizar os efeitos adversos nas características do material. [Granger et al., 1986]

O estudo da adição de zircônio em ligas de alumínio iniciou devido à observação de que a presença zircônio aumentava a temperatura de recristalização do alumínio consideravelmente. A estabilidade dos precipitados $\mathrm{Al}_{3} \mathrm{Zr}$ chamou a atenção e foi atribuída à baixa solubilidade desta fase nas temperaturas de recristalização. [Ryum, 1969]

Um segundo motivo para a estabilidade dessas partículas foi levantado: além da baixa solubilidade, as partículas de $\mathrm{Al}_{3} \mathrm{Zr}$ têm uma cinética de coalescimento muito lenta. [Ryum, 1969]

Segundo [Ryum, 1969], uma partícula será resistente ao coalescimento se a energia de sua interface com a matriz for baixa e se a taxa de difusividade e solubilidade de um dos elementos for pequena. Dentre os metais de transição, o zircônio apresenta o menor fluxo de difusão no alumínio e sua adição à ligas de alumínio resulta na formação da fase $\mathrm{Al}_{3} Z \mathrm{r}$.

Em ligas $\mathrm{Al}-\mathrm{Zr}$ binárias, a fase $\mathrm{Al}_{3} \mathrm{Zr}$ pode se formar, tanto como uma fase de equilíbrio tetragonal semi-coerente, quanto como uma fase cúbica coerente (Figura 34). Ambas as formas são de baixa energia de interface com a matriz, em especial a fase cúbica. [Robson; Prangnell, 2001]

A seqüência de precipitação estabelecida por [Ryum, 1969] foi:

Solução sólida $\rightarrow \mathrm{Al}_{3} \mathrm{Zr}$ cúbico $\rightarrow \mathrm{Al}_{3} \mathrm{Zr}$ tetragonal 


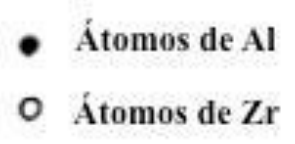

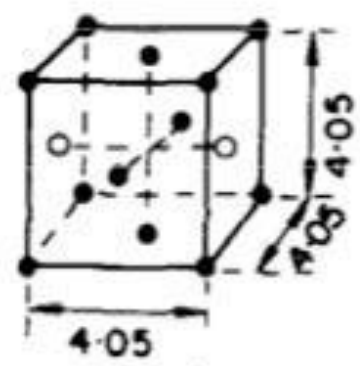

(a)

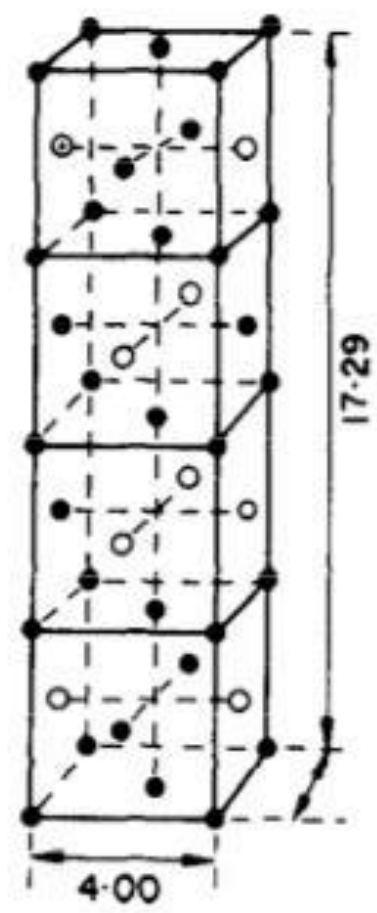

(b)

Figura 34 - Estrutura (a) LI2 cúbica; (b) DO23 tetragonal [Ryum, 1969]

Estas partículas coerentes são muito estáveis durante o aquecimento, devido à baixa solubilidade e difusividade do zircônio na matriz de alumínio e à baixa energia de interface entre as partículas de $\mathrm{Al}_{3} \mathrm{Zr}$ e o metal base.

De acordo com o diagrama de fases $\mathrm{Al}-\mathrm{Zr}$, a precipitação do dispersóide só será possível em concentrações maiores que $0,01 \%$ a $305^{\circ} \mathrm{C}$ e $0,08 \%$ a $500^{\circ} \mathrm{C}$. Considerando que elementos com coeficiente de segregação $k>1$ segregam em direção oposta à maioria dos elementos de liga, a maior concentração de zircônio é encontrada no centro das dendritas, diminuindo sua concentração próxima às bordas. [Sepehrband et al., 2005; Robson; Pangnell, 2001]

Um estudo conduzido por [Sepehrband et al., 2005] apresenta o efeito do tempo de solubilização a $505^{\circ} \mathrm{C}$ na dureza de uma liga A319 (AlSi6Cu3) contendo 0,15\%Zr. De acordo com os autores, a temperatura de $495^{\circ} \mathrm{C}$ a $530^{\circ} \mathrm{C}$ é ideal para a precipitação do $\mathrm{Al}_{3} \mathrm{Zr}$, o que resulta em um aumento de dureza a partir de cerca de 8 horas de 
tratamento. A queda de dureza inicial é atribuída à dissolução de precipitados formados durante a solidificação, conforme a Figura 35.

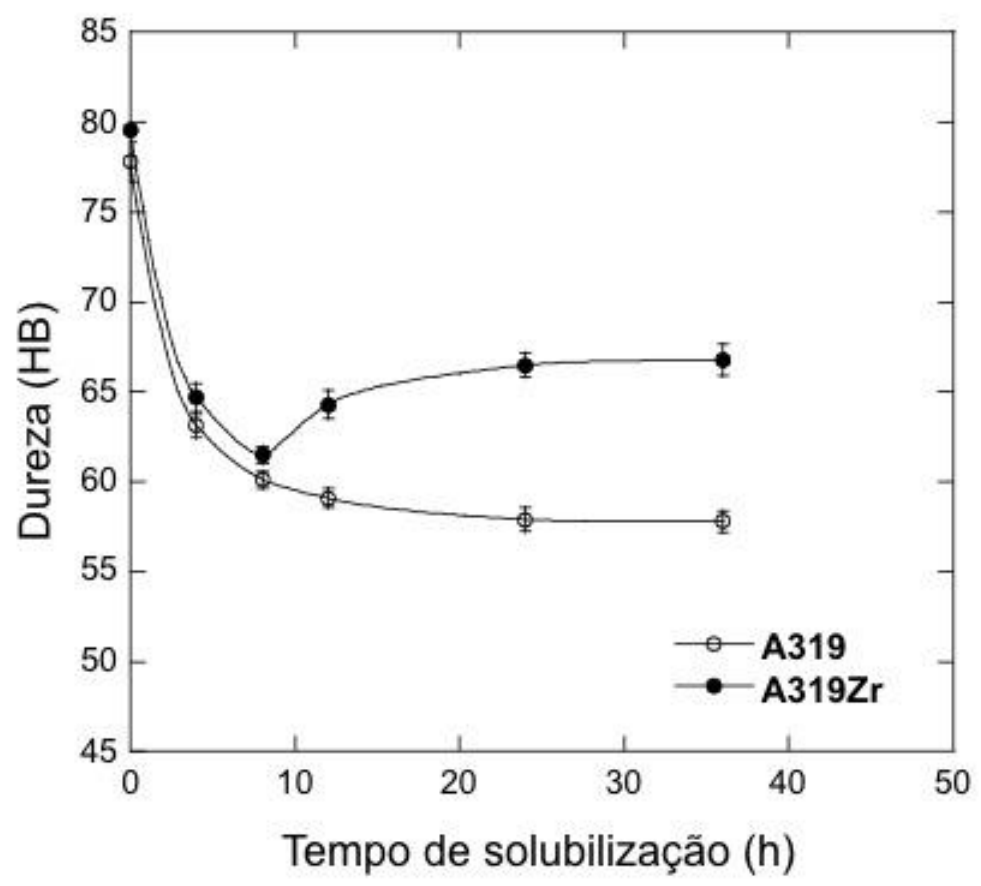

Figura 35 - Dureza de uma liga A319 e uma liga A319 contendo 0,15\%Zr solubilizadas a $505^{\circ} \mathrm{C}$. [Sepehrband et al., 2005]

[Sepehrband et al., 2005] realizaram tratamentos de envelhecimento a $195^{\circ} \mathrm{C}$ nas ligas A319 e A319 contendo $0,15 \% Z r$ solubilizadas a $505^{\circ} \mathrm{C}$ por 8 horas e por 24 horas (Figura 36). As ligas solubilizadas por 8 horas apresentaram comportamentos similares até cerca de 10 horas de tratamento, tempo que, segundo os autores, foi necessário para o início da precipitação das partículas $\mathrm{Al}_{3} Z \mathrm{Zr}$. As ligas solubilizadas por 24 horas já apresentaram comportamentos distintos desde o início do envelhecimento, devido à precipitação de $\mathrm{Al}_{3} \mathrm{Zr}$ durante a solubilização. Apesar de trazerem benefícios para as propriedades mecânicas do material, tratamentos térmicos superiores a 8 horas são economicamente inviáveis em ambientes industriais. 

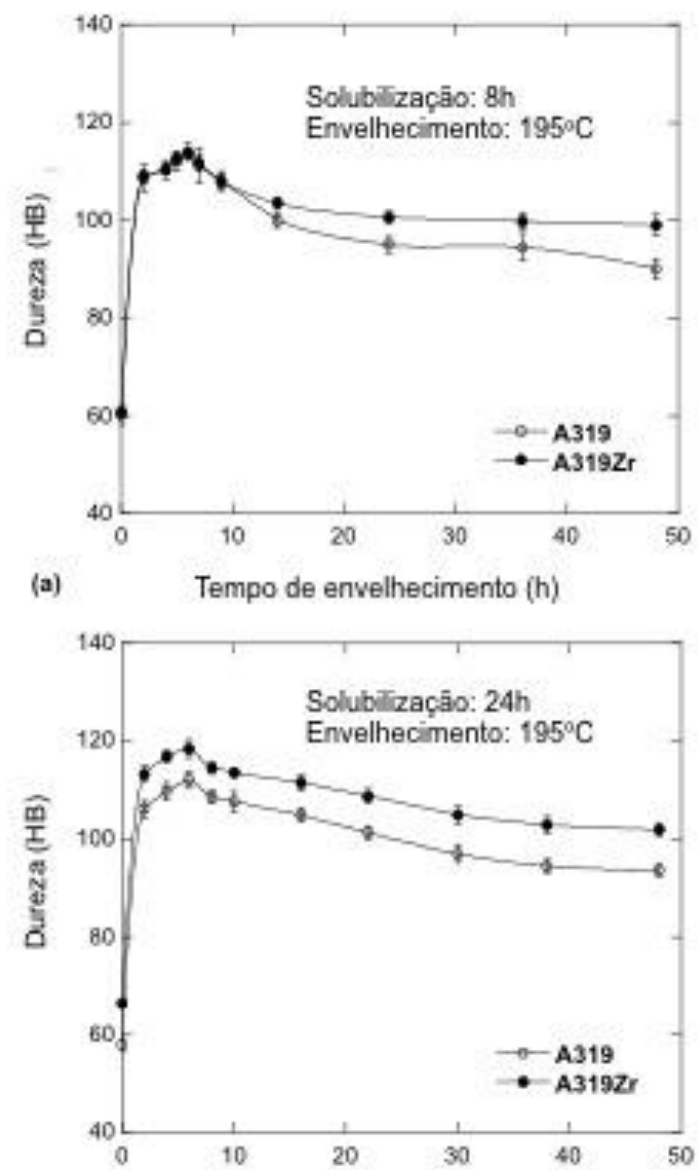

(b)

Tempo de envelhecimento (h)

Figura 36 - Variação da dureza com o tempo de envelhecimento a $195^{\circ} \mathrm{C}$ das ligas A319 e A319Zr solubilizadas a $505^{\circ} \mathrm{C}$ por: (a) 8 horas e; (b) 24 horas. [Sepehrband et al., 2005]

Outro estudo conduzido por [Mahmudi et al., 2006] com ligas A319 (solubilizadas a $503^{\circ} \mathrm{C}$ por 24 horas e envelhecidas em um intervalo de $175^{\circ} \mathrm{C}$ a $235^{\circ} \mathrm{C}$ por períodos de até 48 horas) mostra que adições de 0,15\%Zr levam a um aumento de dureza de $8 \%$ a $10 \%$ nos tratamentos de envelhecimento (Figura 37). Esses autores afirmam que seja a formação de compostos $\mathrm{Al}_{3} \mathrm{Zr}$ é responsável por este efeito. 

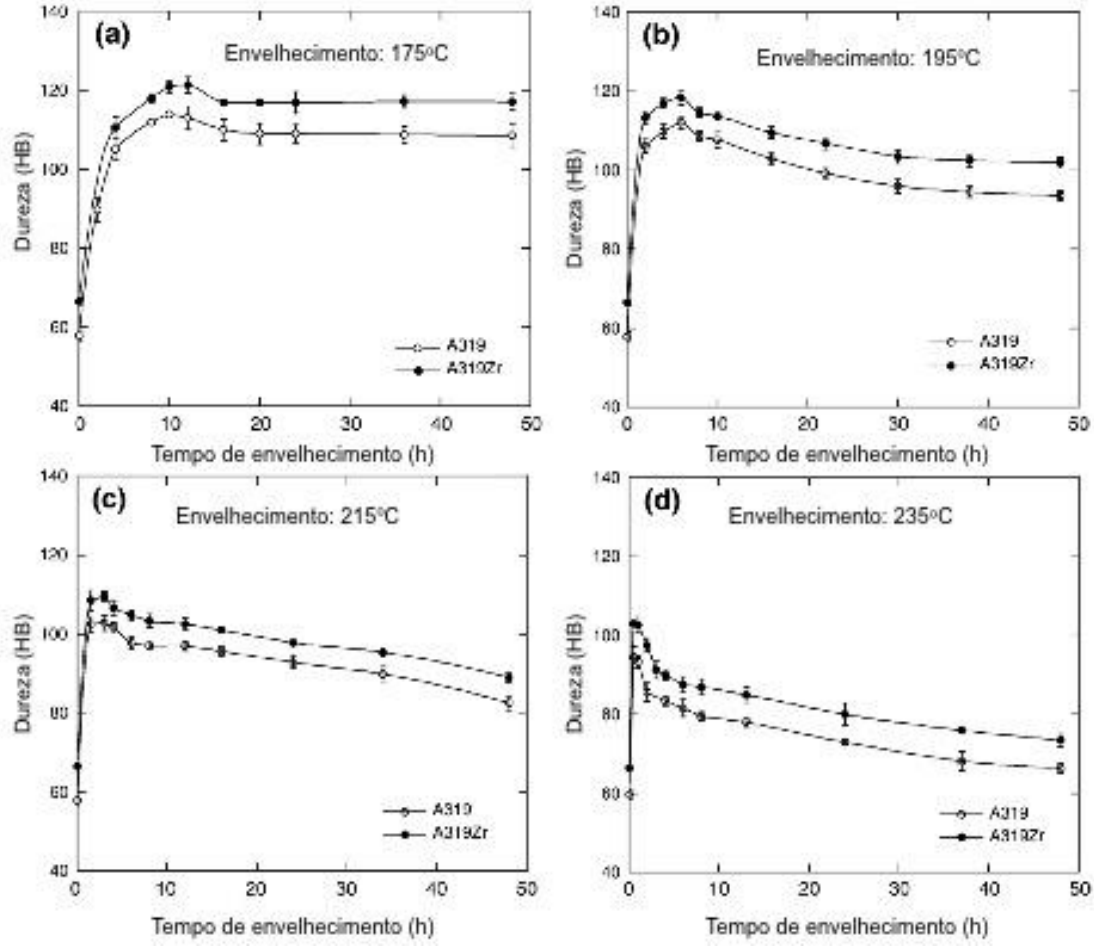

Figura 37 - Curvas de envelhecimento para as ligas A319 e A319Zr solubilizadas a $503^{\circ} \mathrm{C}$ por 24 horas para diferentes temperaturas: (a) $175^{\circ} \mathrm{C}$; (b) $195^{\circ} \mathrm{C}$; (c) $215^{\circ} \mathrm{C}$;

(d) $235^{\circ} \mathrm{C}$. [Mahmudi et al., 2006]

[Baradarani; Raiszadeh, 2011] também atribuem a estabilidade da dureza em altas temperaturas de ligas AISi7Mg0,3 contendo zircônio (solubilizadas a $538^{\circ} \mathrm{C}$ por 8 ou 24 horas e envelhecidas a $154^{\circ} \mathrm{C}$ por períodos entre 8 e 48 horas) à formação de compostos $\mathrm{Al}_{3} Z \mathrm{Zr}$. Segundo os autores, durante a solidificação, a precipitação de partículas $\mathrm{Al}_{3} \mathrm{Zr}$ grosseiras e incoerentes seria responsável pelo refino de grão observado na liga. Após o tratamento de solubilização, houve dissolução e reprecipitação dessas partículas, dessa vez em tamanho menor e coerentes com a matriz e, devido à baixa cinética de difusão do zircônio no alumínio, essas partículas seriam responsáveis pela manutenção da dureza da liga em altas temperaturas por longos períodos de tempo (Figura 38 e Figura 39).

Não foi notada nenhuma diferença de endurecimento entre as adições de $0,1 \%, 0,2 \% \mathrm{e}$ 0,3\% de zircônio na liga AISi7Mg0,3. A diferença de solubilização de 8 horas e 24 horas também não resultou em nenhuma diferença significativa de dureza durante 0 envelhecimento (Figura 38 e Figura 39). 


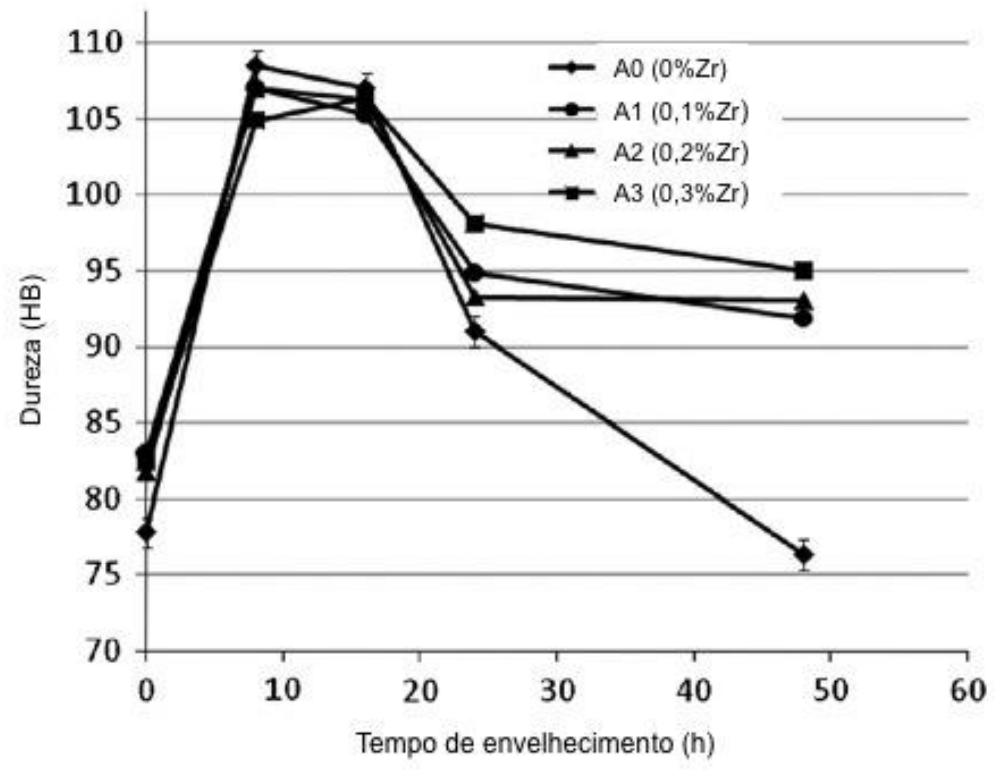

Figura 38 - Curvas de envelhecimento para a liga AISi7Mg0,3 solubilizada a $538^{\circ} \mathrm{C}$ por 8 horas e envelhecidas a $154^{\circ} \mathrm{C}$ contendo: $\mathrm{A0}(0 \% \mathrm{Zr})$; $\mathrm{A} 1(0,1 \% \mathrm{Zr})$; $\mathrm{A} 2(0,2 \% \mathrm{Zr}) ; \mathrm{A} 3(0,3 \% \mathrm{Zr})$;

[Baradarani; Raiszadeh, 2011]

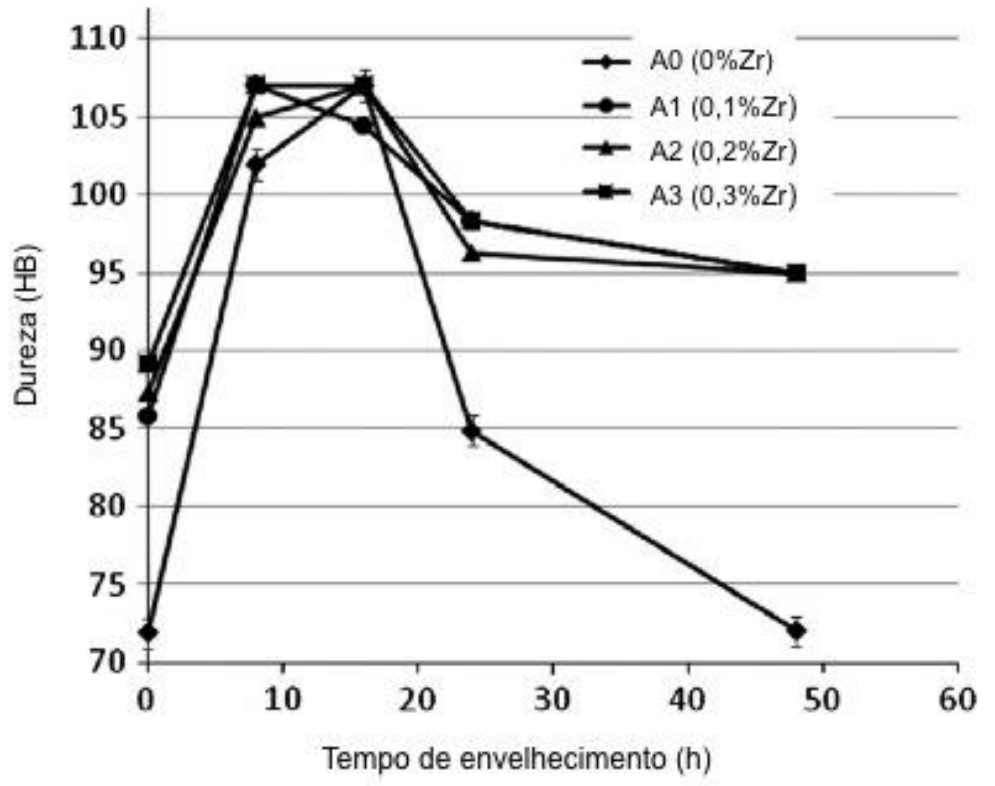

Figura 39 -Curvas de envelhecimento para a liga AISi7Mg0,3 solubilizada a $538^{\circ} \mathrm{C}$ por 24 horas e envelhecidas a $154^{\circ} \mathrm{C}$ contendo: A0 (0\%Zr); A1 (0,1\%Zr); A2 (0,2\%Zr); A3 (0,3\%Zr).

[Baradarani; Raiszadeh, 2011] 
Ao contrário de [Baradaran; Raiszadeh, 2011], nos experimentos de [Spehrband et al.; 2005] e [Mahmudi et al., 2006], a estrutura bruta de fundição não apresentou $\mathrm{Al}_{3} \mathrm{Zr}$, sugerindo que a formação destes precipitados ocorreu durante o tratamento de solubilização.

Como não foi notada uma convergência entre as curvas de dureza ao longo do envelhecimento entre as ligas com e sem zircônio, [Mahmudi et al., 2006] acreditam que não esteja ocorrendo coalescimento entre as partículas. Os autores atribuem esse fato à baixa solubilidade do zircônio na matriz de alumínio e à baixa difusividade do zircônio no alumínio, assim como [Baradarani; Raiszadeh, 2011].

Apesar dos resultados de dureza da liga contendo zircônio terem mostrado apenas $10 \%$ de aumento com relação à liga sem zircônio, os resultados de desgaste mostraram um aumento de $60 \%$ em um ensaio pino contra disco de contato contra um disco de ferro fundido.

Assim como o zircônio, a presença de titânio aumenta a temperatura de recristalização de ligas de alumínio. [Mondolfo, 1976]

A adição de titânio em ligas AI-Si é normalmente feita na forma de ante-ligas contendo boro com o objetivo de refinar a estrutura.

Durante a solidificação, a presença de $\mathrm{TiB}_{2}$ diminui a segregação da fase $\mathrm{Al}_{2} \mathrm{Cu}$, resultando em uma melhor distribuição destas partículas. [Tash et al., 2007]

[Misra e Oswalt, 1982] estudaram o efeito do titânio no envelhecimento de ligas AlSi7Mg0,3 e AlSi7Mg0,6. Foi observado que existia um pico secundário de alongamento para tempos mais longos de tratamento que os que são normalmente praticados pela indústria (até 4 horas). Através de microscopia eletrônica de transmissão foi possível determinar a seqüência de precipitação e a microestrutura durante o envelhecimento. A microestrutura consiste de dois precipitados distintos: $\mathrm{TiAl}_{3}$ acicular e $\mathrm{Mg}_{2} \mathrm{Si}$ em plaquetas. A distribuição relativa destes dois precipitados é uma função do tempo de envelhecimento. O pico secundário combinado ao máximo de resistência foi observado quando a microestrutura consiste exclusivamente de precipitados $\mathrm{Mg}_{2} \mathrm{Si}$. 
Precipitados de $\mathrm{TiAl}_{3}$ têm o efeito de atrasar a cinética de precipitação da fase de equilíbrio $\mathrm{Mg}_{2} \mathrm{Si}$, afetando a ductilidade da liga.

Da mesma forma que o titânio e o zircônio, a presença de vanádio aumenta a temperatura de recristalização de ligas de alumínio, mas não tem a mesma eficiência como refinador de grãos. O envelhecimento de ligas de alumínio contendo vanádio só ocorre em altas temperaturas [Mondolfo, 1976].

Elementos que aumentam a temperatura de recristalização formam dispersóides estáveis em altas temperaturas que dificultam a movimentação das discordâncias, atrasando a formação de novos contornos de grãos [Forbord et al., 2008]. Esta teoria pode ser aplicada à outras propriedades do material, já que dispersóides estáveis em altas temperaturas também são benéficos para o aumento da resistência à fluência e para o atraso na nucleação de trincas de fadiga.

[Garat; Laslaz, 2002] realizaram adições de zircônio, vanádio e titânio a uma liga AlSi7Mg0,3 contendo $0,5 \% \mathrm{Cu}$ (tratada por HIP por 2 horas a $485^{\circ} \mathrm{C}$ e 1000 bar , solubilizada a $500^{\circ} \mathrm{C}$ por 4 horas seguido de 10 horas a $540^{\circ} \mathrm{C}$ com resfriamento em água, pré-envelhecida em temperatura ambiente por 24 horas e envelhecida a $200^{\circ} \mathrm{C}$ por 5 horas) e concluíram que houve aumento da fluência terciária a $300^{\circ} \mathrm{C}$ sem perda de ductilidade.

Uma liga AISi7Cu3Mn, sem magnésio, também foi testada por [Garat; Laslaz, 2002] com pequenas adições dos elementos que formam diagramas peritéticos com 0 alumínio $\mathrm{Ti}, \mathrm{Zr}$ e V. A liga foi solubilizada a $515^{\circ} \mathrm{C}$ por 10 horas, resfriada em água, préenvelhecida a temperatura ambiente por 24 horas e envelhecida a $220^{\circ} \mathrm{C}$ por 5 horas. Esta liga apresentou uma combinação de resistência à tração e fluência e ductilidade na faixa de $250^{\circ} \mathrm{C}$ a $300^{\circ} \mathrm{C}$, se mostrando superior às ligas tradicionalmente utilizadas na fabricação de cabeçotes de cilindro na temperatura de $300^{\circ} \mathrm{C}$.

Em um estudo posterior, [Garat, 2011] descobriu que esta liga sem magnésio apresentava baixa resistência à fadiga de baixo ciclo e propôs uma nova formulação contendo $0,15 \% \mathrm{Mg}$, embora uma redução na temperatura de solubilização tenha sido necessária. 
Outro problema apresentado pela liga proposta por [Garat; Laslaz, 2002] foi o risco de precipitação e sedimentação de vanádio em longos tempos de espera. Medições de solubilidade de vanádio e zircônio foram realizadas utilizando duas metodologias diferentes: filtragem isotérmica e sedimentação natural. Ambos os métodos apresentaram resultados similares e estão representados na Figura 40. [Garat, 2011]

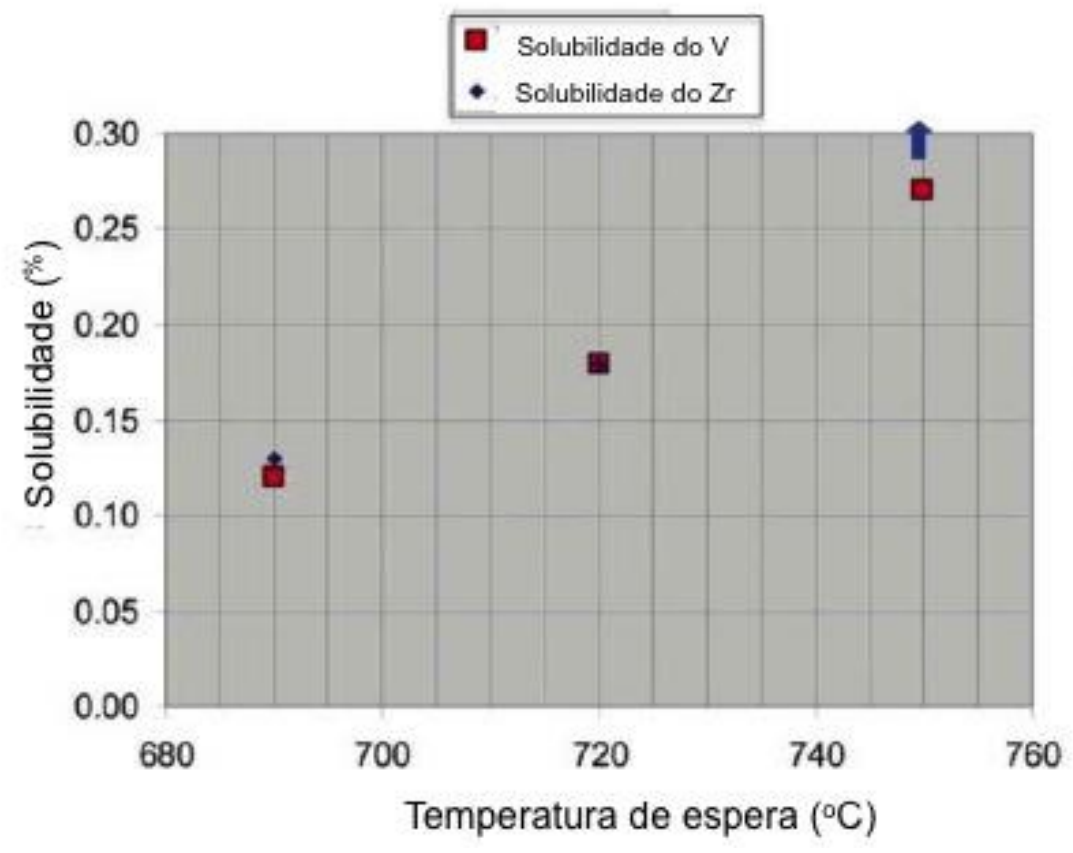

Figura 40 - Solubilidade do Zr e do V em função da temperatura. [Garat, 2011]

O melhor desempenho de ligas contendo $0,15 \% Z r$ é atribuída à formação de dispersóides Al-Zr-Si semi-coerentes com a matriz de alumínio e extremamente estáveis. Segundo [Garat; Laslaz, 2002], em ligas AISi7, o zircônio não forma o binário $\mathrm{Al}_{3} \mathrm{Zr}$ e sim um composto com silício, comportamento similar ao titânio. Este resultado difere dos resultados obtidos por outros autores.

[Garat; Laslaz, 2002] citam a adição combinada de zircônio e manganês como responsáveis por retardar o efeito de fluência terciária a $300^{\circ} \mathrm{C}$ e $22 \mathrm{MPa}$.

O manganês é um elemento de liga comumente adicionado à ligas Al-Si para modificar as fases contendo ferro e minimizar seu efeito deletério.

No entanto, de acordo com os resultados obtidos por [Qian et al., 2008], em ligas contendo baixos teores de ferro, o manganês age como elemento de liga, alterando as 
propriedades mecânicas da liga para pistões ZL109. Os resultados obtidos por [Qian et al., 2008] mostram que o limite de resistência (LR) a $300^{\circ} \mathrm{C}$ varia com a adição crescente de manganês (Figura 41). A elevação inicial do limite de resistência é atribuída à presença de manganês na fase dendrítica $\mathrm{Al}{ }_{9} \mathrm{FeSi}$. A redução posterior do limite de resistência é atribuída à formação de fases contendo manganês na forma de plaquetas que diminuem a resistência da liga.

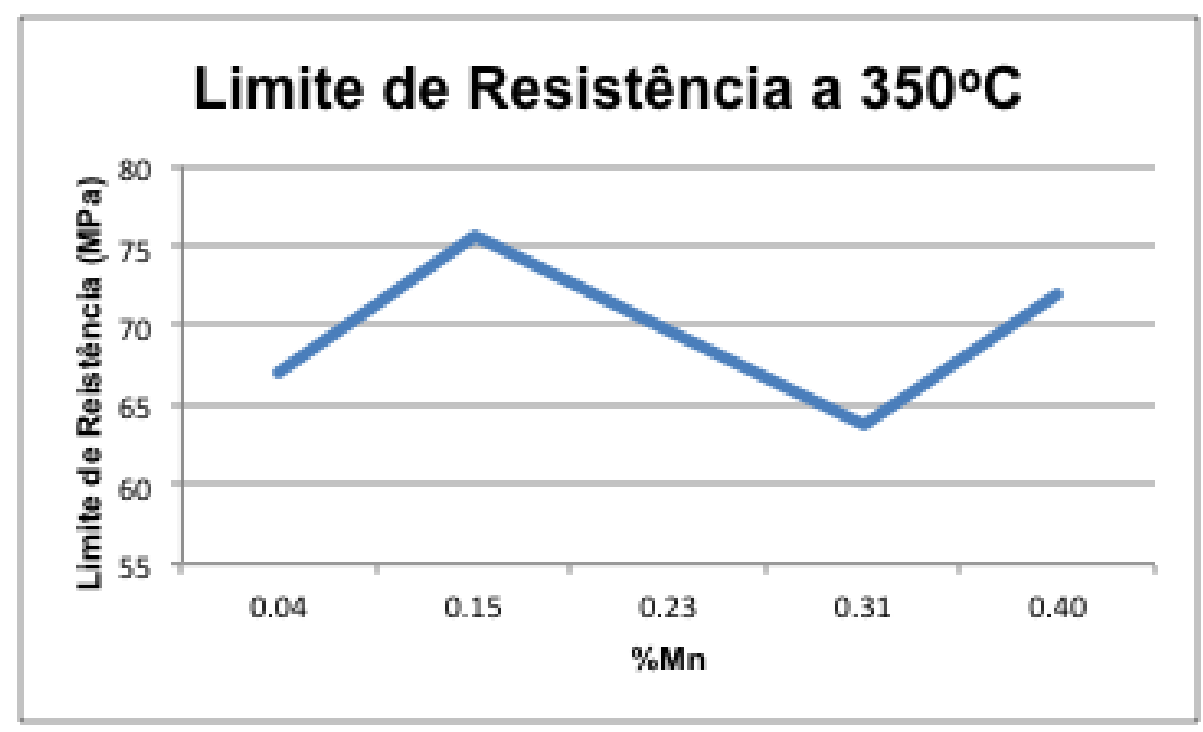

Figura 41 - Limite de resistência a $300^{\circ} \mathrm{C}$ em função do teor de manganês da liga ZL109. Gráfico plotado a partir de dados obtidos por [Qian et al., 2008]

Uma pesquisa realizada por [Kim et al., 2006] mostrou que pequenas adições de cromo $(0,13 \%)$ associadas ao manganês $(0,13 \%)$ em uma liga AISi7Mg0,3 contendo $0,20 \% \mathrm{Fe}$ também alteram a morfologia e composição dos precipitados contendo ferro, resultando em um aumento do alongamento com relação à adição simples de manganês $(0,20 \%)$, com valores similares de limite de resistência, embora com uma redução no limite de escoamento e na dureza. 


\subsection{Fadiga}

Fadiga é um mecanismo de falha que ocorre em estruturas submetidas a tensões cíclicas. Diversos sistemas são afetados por este modo de falha: automóveis, aviões, pontes, navios, reatores nucleares, turbinas, etc. [Meyers; Chawla, 1982]

Nestas circunstâncias é possível que uma falha ocorra em tensões consideravelmente mais baixas que o limite de resistência ou de escoamento de um material para um carregamento estático. [Callister; Rethwisch, 1998]

Quando o número de ciclos é alto (na casa de milhões), o fenômeno é chamado de fadiga de alto ciclo. Quando o número de ciclos é baixo (na casa de dezenas, centenas ou milhares), o fenômeno é chamado de fadiga de baixo ciclo. [Dowling, 1998]

A fadiga de baixo ciclo é normalmente acompanhada de quantidades significativas de deformação plástica, enquanto a fadiga de alto ciclo é comumente associada à pequenas deformações, em geral, de natureza elástica. [Dowling, 1998]

Há ainda a fadiga de ultra-alto ciclo, com $10^{9}-10^{10}$ ciclos.

Em geral, a nucleação de trincas por fadiga de alto ciclo estão associadas à fenômenos superficiais como PSBs (persistent slipbands), contornos de grãos, poros e inclusões de partículas não metálicas, enquanto as trincas por fadiga de ultra-alto ciclo estão associadas a fenômenos sub-superficiais. [Chan, 2010]

Em geral, a resistência à fadiga dos materiais diminui com o aumento da temperatura. Em temperaturas superiores a cerca de $30 \%$ a $60 \%$ da temperatura absoluta de fusão de um material, a fluência passa a ser importante, tornando-se a principal causa das falhas. [Dieter,1988; Dowling,1998]

Fluência é um modo de deformação termicamente ativado que depende do tempo e do carregamento e tem como principal mecanismo o aumento da movimentação de átomos, lacunas, discordâncias ou moléculas em um material sólido com o aumento da temperatura. [Dowling, 1998] 
A transição entre uma falha por fadiga e uma falha por fluência com o aumento da temperatura resulta em uma mudança no modo de propagação da trinca de transgranular para intergranular. [Dieter,1988]

Os efeitos térmicos e mecânicos podem aparecer de forma combinada quando há carregamentos em alta temperatura, havendo combinação de fadiga, fluência e corrosão. [Dowling, 1998]

Os mecanismos responsáveis pela nucleação de uma trinca de fadiga em altas temperaturas podem ser agrupados nas seguintes categorias [Surresh, 1998]:

(a) Deslizamento cíclico: em temperaturas maiores ou iguais à metade da temperatura homóloga, os materiais tendem a apresentar mais deslizamentos, com ativação de mecanismos de movimentações de discordâncias decorrentes do aumento da energia de falha de empilhamento. Alterações microestruturais termicamente ativadas como solubilização, recuperação e precipitação também são potencializadas e podem influenciar a resistência à fadiga tanto positivamente quanto negativamente.

(b) Cavitação de contornos de gãos: em temperaturas de um terço a dois terços da temperatura de fusão com baixa imposição de cargas, a maior parte dos metais e cerâmicas apresenta fluência por cavitação de contornos de grãos.

(c) Deslizamento de contornos de grãos: é um mecanismo importante para a nucleação de cavidades intergranulares no processo de fadiga-fluência. No entanto, para deformações de tração-compressão abaixo do valor crítico e curvas de carregamento proporcionais, não há danos, já que os deslizamentos ocorrerão igualmente nos dois sentidos.

(d) Inclusões e precipitados: a nucleação de trincas de fadiga sub-superficiais em altas temperaturas pode ocorrer devido à decoesão de inclusões e partículas de segunda fase. Além disso, o aumento da taxa de precipitação proporciona um aumento na quantidade de vazios.

(e) Oxidação e corrosão: a presença de um ambiente agressivo pode influenciar a nucleação de trincas de fadiga em altas temperaturas de diversas formas. Em altas temperaturas, o ambiente pode proporcionar a sinterização ou fechamento 
de cavidades. A oxidação superficial pode também evitar a difusão de elementos para o interior do material, fragilizando contornos de grãos ou nucleando cavidades. Carregamentos cíclicos podem levar à fadiga do óxido superficial que tanto pode levar à falha catastrófica do material, quanto pode permitir um ataque à superfície desprotegida do material. A oxidação de superfícies de escorregamento pode tornar o processo de escorregamento cíclico irreversível, levando à nucleação de trincas. Além disso, a oxidação preferencial de determinadas regiões microestruturais pode causar concentrações de tensão microscópicas que podem ocasionar a nucleação de trincas.

O modelamento mais simples para previsão de vida em fluência-fadiga é um modelo de soma linear de danos:

$$
\zeta_{\mathrm{f}+}+\zeta_{\mathrm{c}}=1
$$

Onde $\zeta_{f}$ corresponde à fração de danos devido à fadiga e $\zeta_{c}$ corresponde à fração de danos devido à fluência.

\subsubsection{Fadiga em ligas Al-Si}

Ligas Al-Si apresentam microestrutura formada por, no mínimo, duas fases. De acordo com [Hoskin et al., 1988], [Joyce et. al, 2003] e [Styles; Reed, 2000], o estágio de nucleação da trinca em temperatura ambiente é particularmente sensível à presença de partículas de silício primário (Figura 42 e Figura 43).

No estudo realizado por [Styles; Reed, 2000], de doze trincas observadas, dez iniciaram em partículas de silício e duas em aglomerados de intermetálicos AlıFeNi.

[Joyce et al., 2003] realizaram um trabalho interessante de interrupção de ensaios de fadiga para monitoramento das trincas. De acordo com este trabalho, diversas trincas nucleiam e nem todas levam à falha do material. De onze trincas secundárias observadas, nove partiram de partículas de silício e duas de aglomerados de intermetálicos $\mathrm{Al}_{3}(\mathrm{Cu}, \mathrm{Ni})_{2}$. Os autores notaram também que tanto as partículas de silício 
no início da trinca, quanto as partículas de silício encontradas no caminho da trinca apresentam tamanho maior que a média, o que indica que o tamanho do silício exerce um papel importante não só na nucleação quanto também na propagação das trincas por fadiga (Figura 42 e Figura 43).

[Styles; Reed, 2000] também observaram que as partículas de silício no início da trinca eram primárias e não eutéticas. Isso mostra a importância do controle do tamanho das partículas de silício primário.

Ao contrário dos ensaios realizados em altas temperaturas, ensaios realizados em temperatura ambiente e/ou em ligas hipoutéticas revelam resultados opostos. A maior parte das trincas parte de intermetálicos e não de partículas de silício. [Moffat et al., 2006] e [Mbuya et al., 2011]

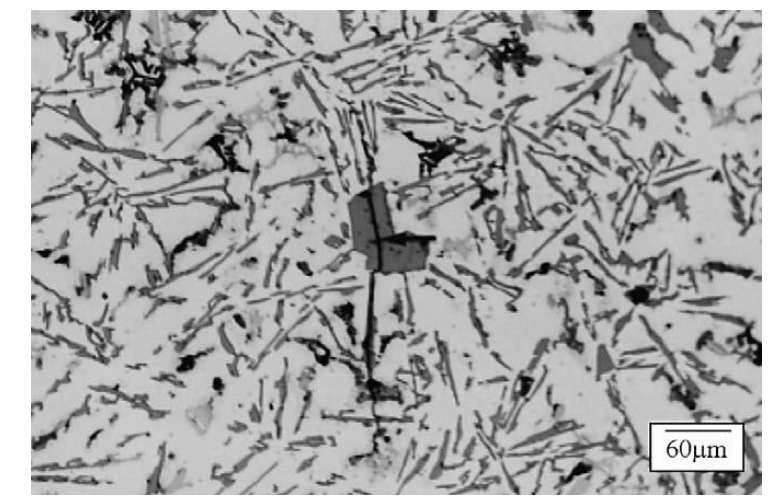

Figura 42 - Início de uma trinca por fadiga à temperatura ambiente a partir de uma partícula de silício primário. [Joyce et. al, 2003]

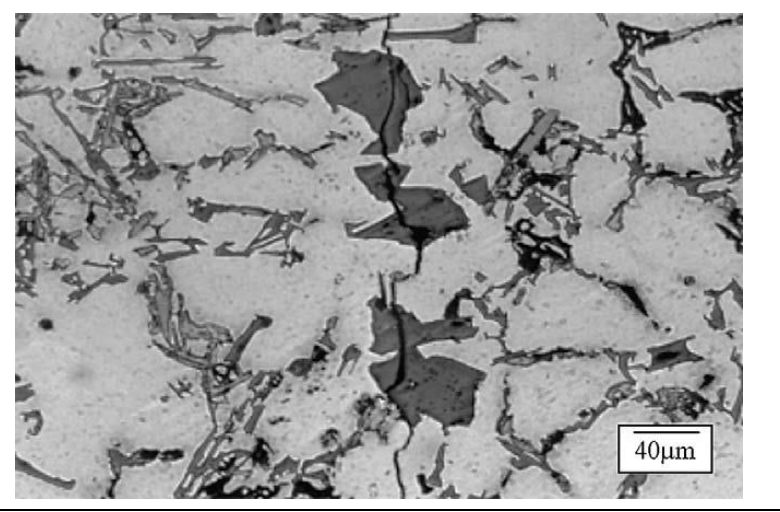

Figura 43 - Início de uma trinca por fadiga à temperatura ambiente a partir de uma partícula de silício primário. [Joyce et. al, 2003]

De acordo com [Hoskin et al., 1988] durante o estágio de crescimento, a trinca cresce de forma plana, através das dendritas de alumínio primário e das partículas de silício de forma mais ou menos igualitária, sem fazer grandes desvios para privilegiar as partículas de silício. Durante o estágio de ruptura final, o caminho da trinca foi principalmente através da interface entre alumínio e silício.

Um estudo posterior, realizado por [Moffat et al., 2005], mostrou que a intensidade de carga aplicada e o teor se silício da liga determinam por onde a trinca se propagará. 
Para ligas hipoeutéticas, valores de $\Delta \mathrm{K}$ baixos resultam em fraturas intra-dendríticas, enquanto valores de $\Delta \mathrm{K}$ altos resultam em fraturas inter-dendríticas, conforme Figura 44 e a Figura 45. [Moffat et al., 2005]

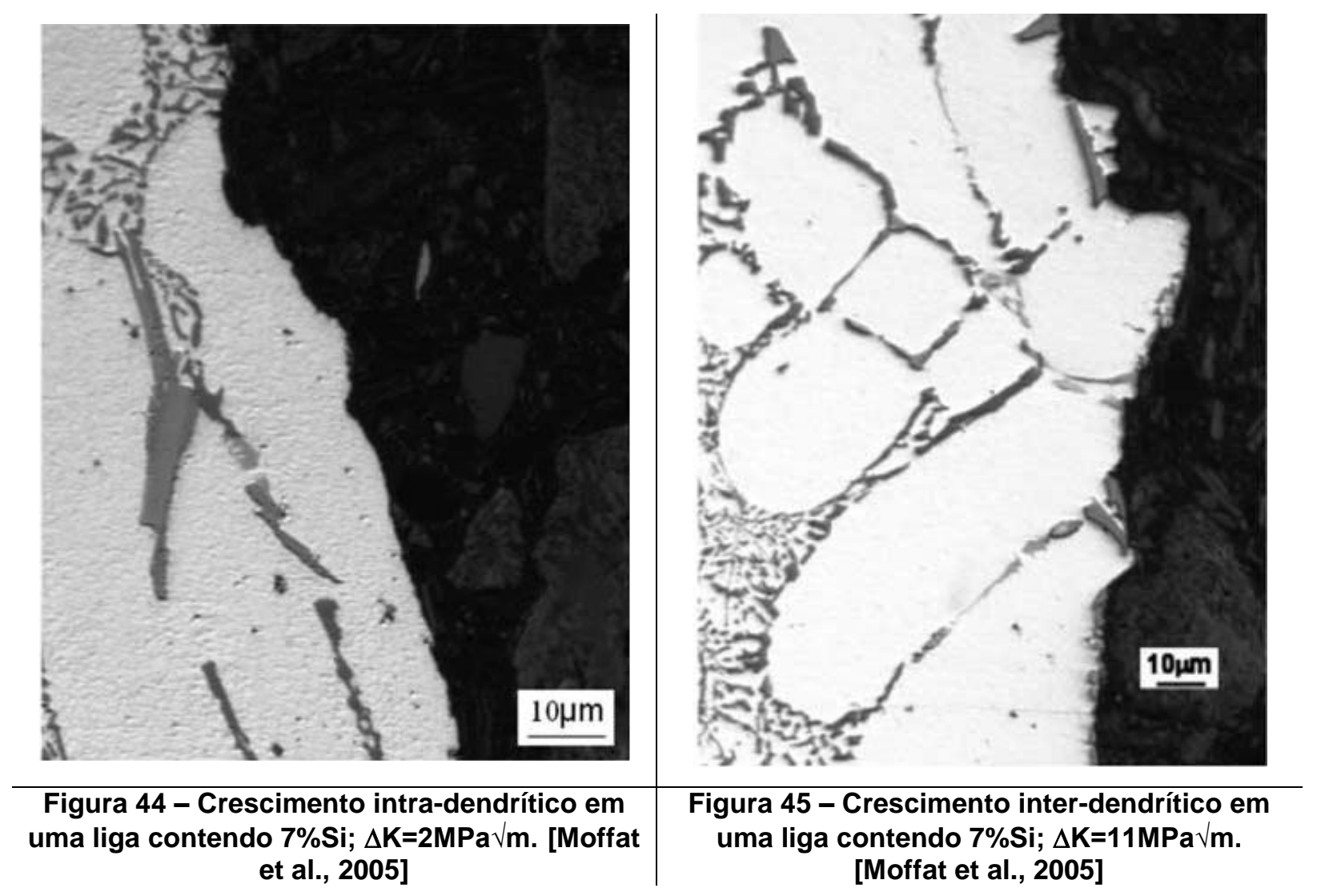

Em ligas quase-eutéticas, para baixos valores de $\Delta \mathrm{K}$ a trinca se propaga tanto através de partículas de silício trincadas, quanto pela interface alumínio-silício. Para altos valores de $\square \mathrm{K}$, a trinca se propaga através de partículas de silício primário trincadas (Figura 47). [Moffat et al., 2005] 


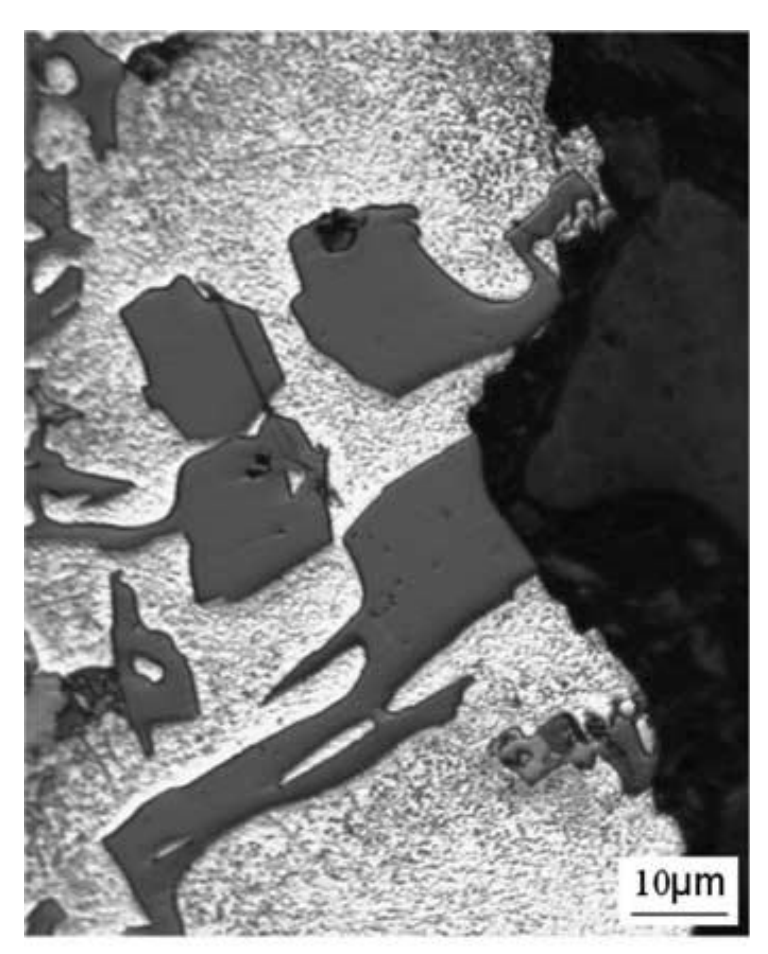

Figura 46 - De-coesão e fratura de partículas de silício em uma liga contendo $12,5 \% \mathrm{Si}$; $\Delta \mathrm{K}=4,9 \mathrm{MPa} \vee \mathrm{m}$. [Moffat et al., 2005]

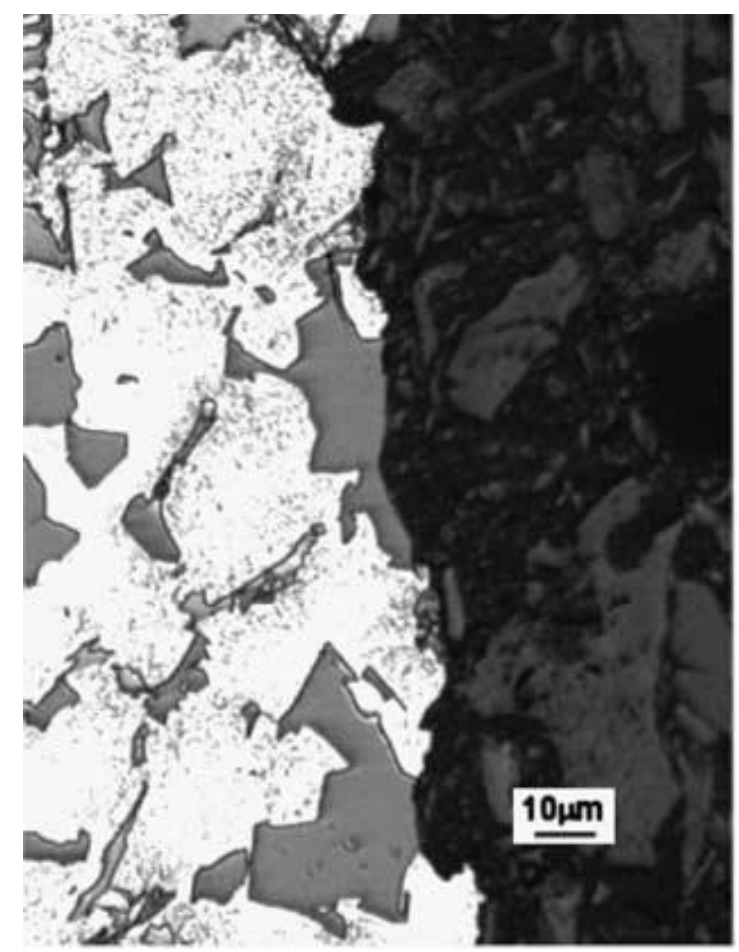

Figura 47 - Partículas de silício fraturadas em uma liga contendo $12,5 \% \mathrm{Si} ; \Delta \mathrm{K}=10 \mathrm{MPa} \sqrt{\mathrm{m}}$.

[Moffat et al., 2005]

[Joyce et. al, 2003] observaram este efeito de de-coesão também no ponto de início das trincas em ensaios de fadiga em altas temperaturas (Figura 46). Este efeito foi atribuído à maior susceptibilidade à formação de vazios.

A velocidade de resfriamento também tem influência na vida em fadiga de componentes fundidos. Os resultados obtidos por [Wang et al., 2001] e [Wang et al., 2001b] para diferentes SDAS em uma liga AlSi7Mg0,3 mostram que quanto mais rápido o resfriamento, maior a vida em fadiga.

As propriedades de fadiga de componentes de alumínio fundidos dependem tanto da microestrutura quanto da presença de defeitos de fundição. [Wang et al., 2001] A presença de defeitos de fundição (porosidade de gás, inclusões de óxido, rechupes, soldas frias, etc.) tem efeito deletério tanto para a nucleação quanto para a propagação de trincas de fadiga de um componente fundido. No estudo realizado por [Wang et al., 2001], foram comparados corpos de prova com diferentes tamanhos de óxidos e porosidades e nota-se uma correlação direta entre tamanho do defeito e redução da 
vida em fadiga (Figura 48). Componentes contendo defeitos de fundição apresentam vida em fadiga de pelo menos uma ordem de magnitude menor que componentes livres de defeitos. Este estudo também mostrou que porosidade são mais deletérias que óxidos para a vida em fadiga.

De acordo com os autores, existe um tamanho crítico de defeito em que há nucleação de uma trinca de fadiga. Para as condições usadas no estudo, o tamanho crítico encontrado foi de $25 \mu \mathrm{m}-50 \mu \mathrm{m}$.

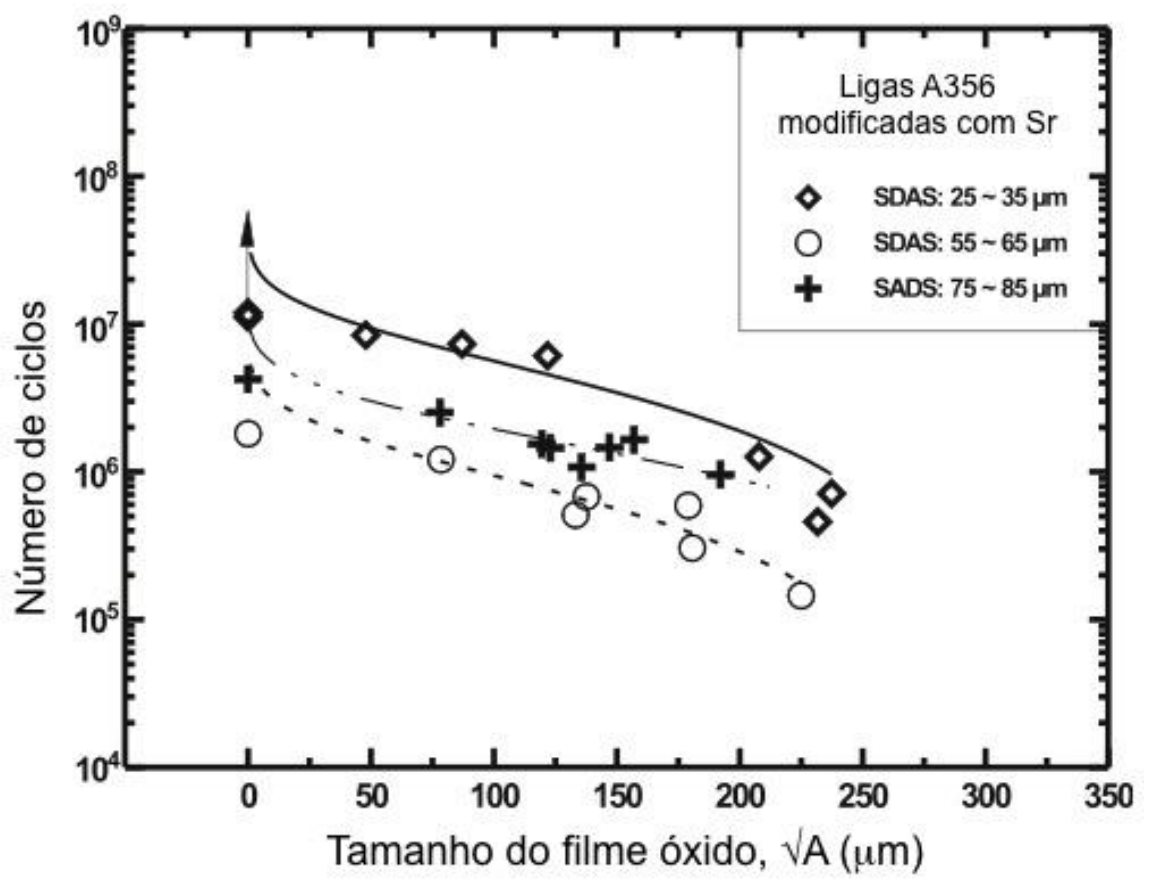

Figura 48 - Correlação entre tamanho de óxido e número de ciclos até a

falha. [Wang et al., 2001]

O efeito do teor de magnésio e do ferro em ligas AISi7Mg0,3 e AISi7Mg0,6 também foi estudado por [Wang et al., 2001b]. Segundo este estudo, o aumento no teor de magnésio de $0,4 \%$ para $0,7 \%$ diminuiu consideravelmente a vida em fadiga. Este efeito é atribuído à redução do limite de escoamento da liga. O aumento do teor de ferro também reduziu a vida em fadiga, o que leva os autores a recomendar um tratamento de solubilização adequado para fracionar os precipitados de ferro.

O efeito da temperatura de trabalho foi estudado por [Guillot et al., 2002]. Corpos de prova da liga 319 fundidos em coquilha com tratamento T5 (24 horas em temperatura 
ambiente e 5 horas a $210^{\circ} \mathrm{C}$ ) foram superenvelhecidos a diversas temperaturas por 100 horas para simular o funcionamento da peça em um motor. A curva de fadiga em temperatura ambiente é apresentada na Figura 49.

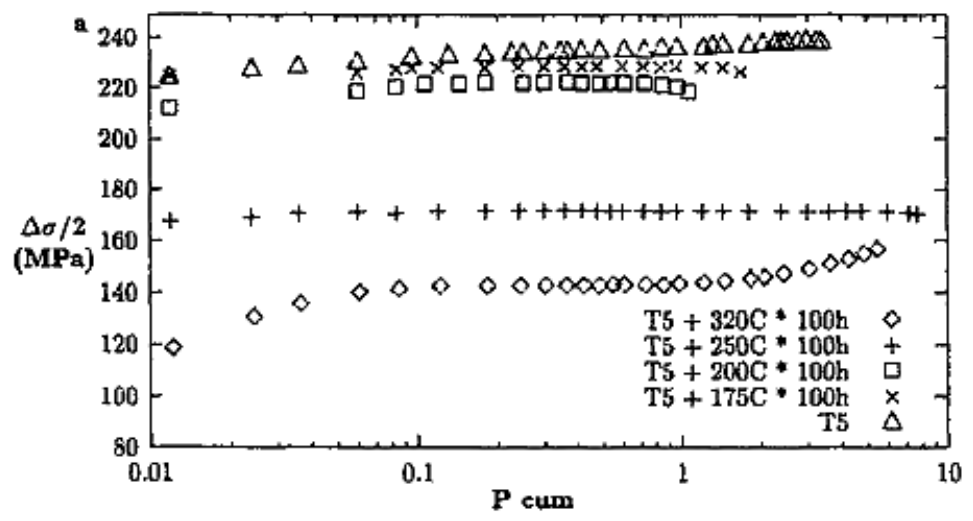

Figura 49 - Curva da amplitude máxima de tensão versus a deformação plástica (Pcum). [Guillot et al., 2002]

De acordo com [Davies; Bakken, 1966], a frequência em que o ensaio de fadiga é realizado não influencia seu resultado. 


\section{Materiais e métodos}

A revisão bibliográfica foi escrita de forma a introduzir conceitos sobre ligas de alumínio fundidas, utilização dessas ligas em altas temperaturas e aplicação do alumínio em pistões automotivos.

Cabe agora lembrar que todos estes conceitos foram apresentados para que se possa entender este trabalho que tem como objetivo o desenvolvimento de um processo mais resistente à fadiga em altas temperaturas quando comparada à uma liga AISi12CuMgNi (solubilizada a $500^{\circ} \mathrm{C}$ ) tradicionalmente utilizada em pistões automotivos através da alteração do tratamento térmico e da utilização de zircônio, vanádio, titânio e manganês.

\subsection{Preparação da liga e fundição dos pistões para retirada dos corpos de prova}

Foram fundidas as séries de ligas: Referência, R-Zr, R-ZrV, R-ZrVTi e R-ZrVTiMn. As ligas foram fabricadas em forno de indução a partir de alumínio primário de pureza comercial.

Todas as ligas foram fundidas a partir da liga de referência, com adição progressiva dos outros elementos.

A especificação de composição química da liga de referência está apresentada na Tabela 9.

Tabela 9 - Especificação de composição química da liga de referência.

\begin{tabular}{|c|c|c|c|c|c|c|c|c|c|c|c|c|}
\hline & \multicolumn{2}{|c|}{ Si } & \multicolumn{2}{|c|}{$\mathrm{Cu}$} & \multicolumn{2}{|c|}{$\mathrm{Ni}$} & \multicolumn{2}{|c|}{ Mg } & \multicolumn{2}{|c|}{$\mathrm{Fe}$} & \multicolumn{2}{|c|}{ Mn } \\
\hline & $\min$ & $\max$ & $\min$ & $\max$ & $\min$ & $\max$ & $\min$ & $\max$ & $\min$ & $\max$ & $\min$ & $\max$ \\
\hline Referência & 11,0 & 13,5 & 0,8 & 1,5 & 0,7 & 1,3 & 0,7 & 1,2 & - & 0,7 & - & 0,35 \\
\hline
\end{tabular}


Os outros elementos de liga foram adicionados de forma a atingir:

- $0,12 \%-0,14 \% Z r$ na forma de anteliga Al-10\%Zr nas ligas R-Zr, R-ZrV, R-ZrVTi e R-ZrVTiMn;

- 0,10\%-0,13\%V na forma de anteliga Al-10\%V nas ligas R-ZrV, R-ZrVTi e RZrVTiMn;

- 0,12\%-0,14\%Ti na forma de titânio metálico nas ligas R-ZrVTi e R-ZrVTiMn;

- 0,19\%-0,23\%Mn na forma de manganês metálico na liga R-ZrVTiMn.

Foi realizada a adição de fósforo (de 40ppm a 120ppm) para refino das partículas de silício primário na forma de $\mathrm{Cu}-7,5 \% \mathrm{P}$ à temperatura de $820^{\circ} \mathrm{C}$. Aguardou-se 15 minutos para a completa dissolução do material.

Após a preparação, a liga foi transferida para um forno de espera, onde foi realizado um tratamento de desgaseificação com um equipamento FDU (Foundry Degassing Unit Foseco), rotor Foseco XSR por 20 minutos com injeção de nitrogênio e cloro na proporção de 9:1. Este tratamento foi realizado para evitar porosidades provenientes de hidrogênio dissolvido na liga, filmes óxidos e possíveis inclusões.

Foram fundidos pistões com cada uma das ligas para reproduzir as condições de enchimento e velocidade de solidificação reais. O material para usinagem de todos os corpos de prova foi retirado sempre da mesma região do pistão, conforme Figura 51 e Figura 52.

Os pistões foram fundidos por gravidade em coquilha de aço $\mathrm{H} 13$ com refrigeração a água. A cada ciclo de vazamento, é produzido um galho com dois pistões.

A altura do canal de descida (h) é de $150 \mathrm{~mm}$ (Figura 50).

O ciclo de solidificação da peça foi de 75 segundos. 


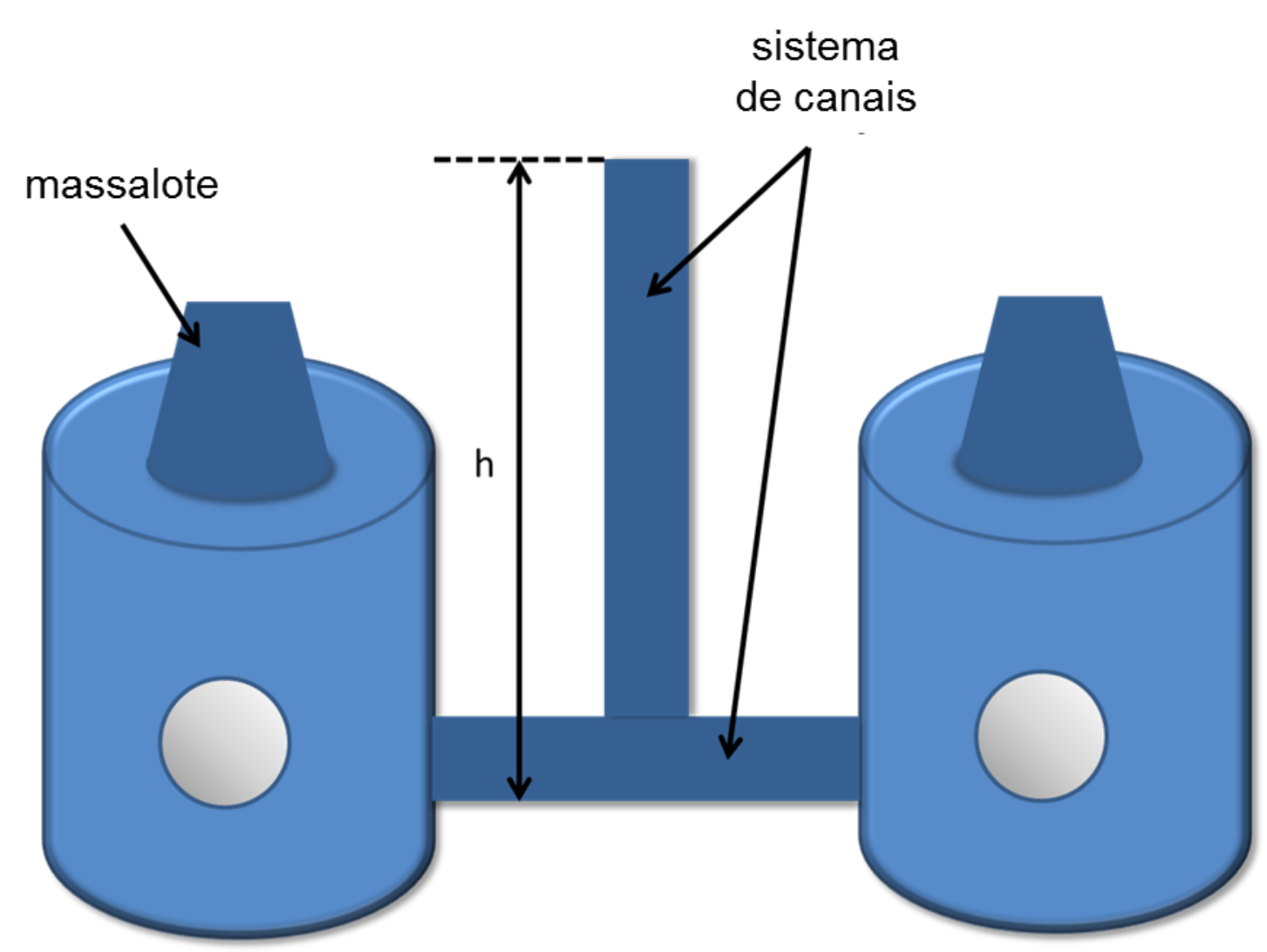

Figura 50 - Representação esquemática de um galho de fundição de pistões.
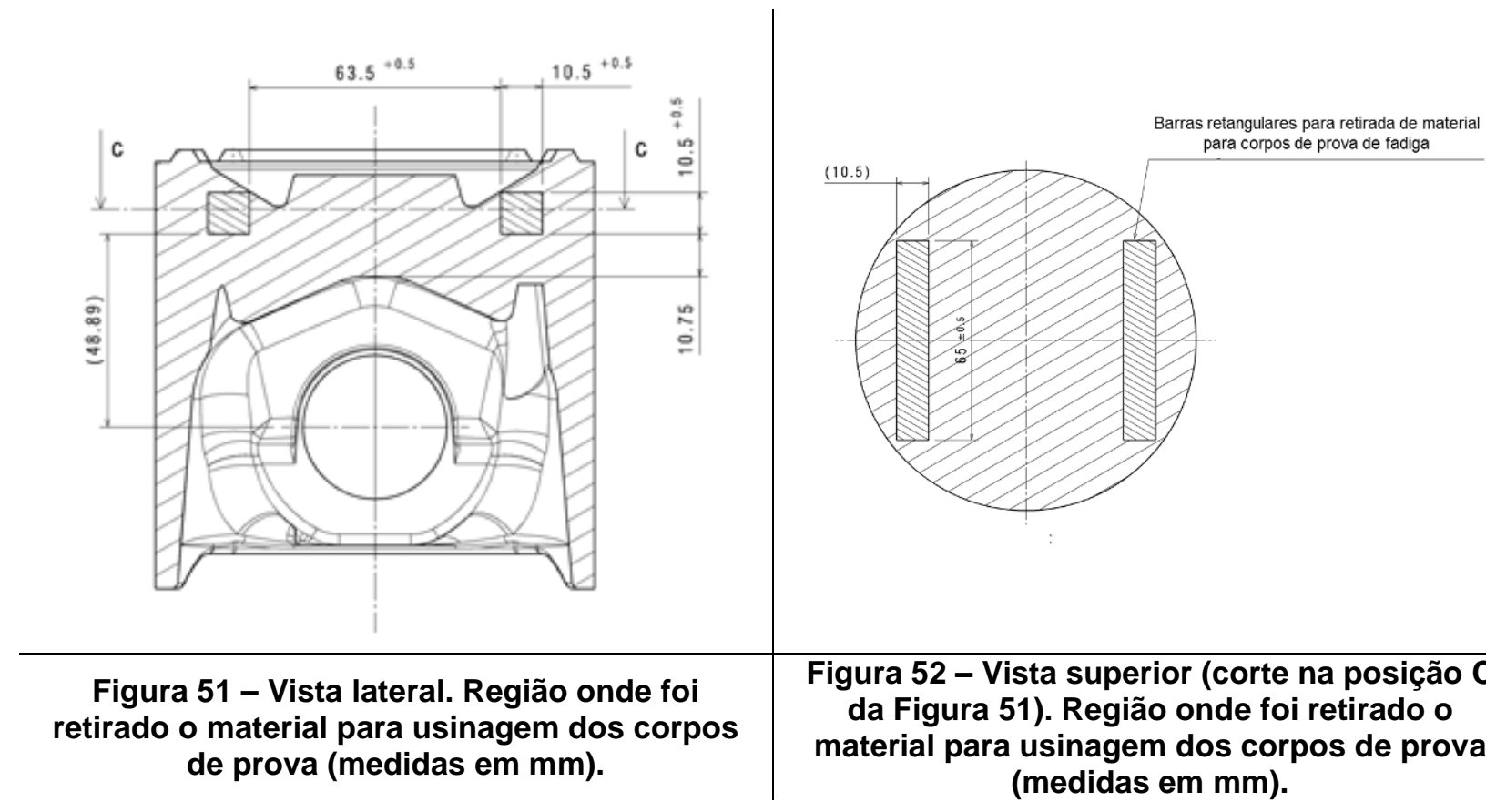

Figura 52 - Vista superior (corte na posição C da Figura 51). Região onde foi retirado o material para usinagem dos corpos de prova (medidas em $\mathrm{mm}$ ). 


\subsection{Caracterização do material e superfícies de fratura}

A preparação das micrografias foi feita com lixa 180, 400 e 1200, polimento com pasta de diamante $6 \mu \mathrm{m}$ e acabamento com sílica coloidal $0,04 \mu \mathrm{m}$. Não foi realizado ataque químico.

A caracterização das microestruturas foi realizada em microscópio óptico e microscópio eletrônico de varredura Phillips XL-30.

A caracterização das fraturas foi realizada em estereoscópio e microscópio eletrônico de varredura Phillips XL-30.

As macrografias foram feitas com ataque em HF $10 \%$ por cerca de 10 segundos.

\subsubsection{Medição do tamanho de partículas de silício primário}

A medição do tamanho de partículas de silício primário foi realizada de forma manual nas amostras brutas de fundição, na região central do corpo de prova de fadiga.

Cerca de 300 partículas foram medidas em cada amostra para se obter a distribuição. Em todos os casos, mediu-se a maior dimensão da partícula e, em caso de aglomerados de partículas de silício, considerou-se uma partícula única.

A Figura 53 mostra um exemplo de medição de partículas de silício primário contendo partículas pequenas $(8 \mu \mathrm{m})$, partículas grandes $(30 \mu \mathrm{m})$ e aglomerados $(42 \mu \mathrm{m})$. 


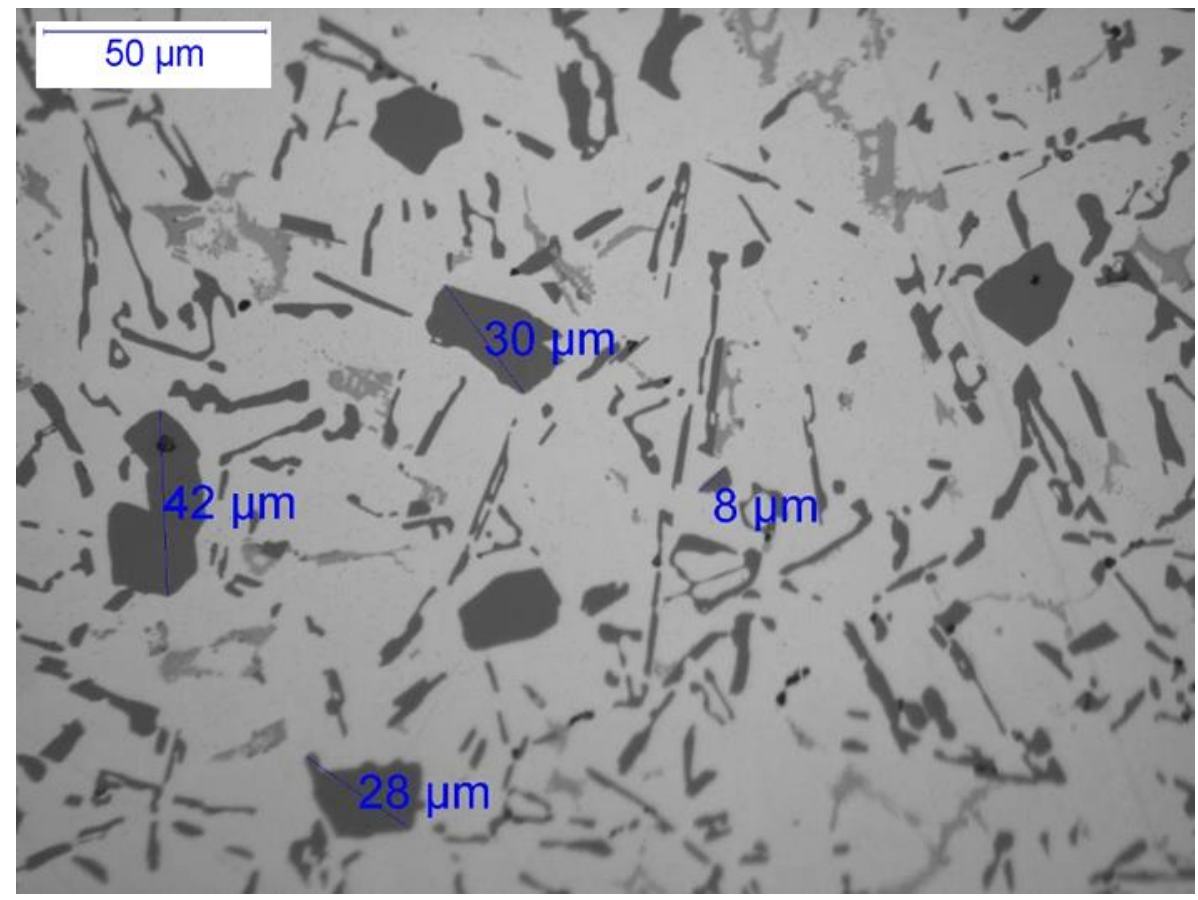

Figura 53 - Medição de partículas de silício primário.

\subsubsection{Medição do fator de circularidade de partículas}

O fator de circularidade é um número adimensional calculado a partir do valor da área e do perímetro das partículas, conforme equação abaixo:

$$
\text { Fator de circularidade }=\frac{4 . \pi \text {.Área }}{(\text { Perímetro })^{2}}
$$

A área e o perímetro das partículas foram medidos de forma automática com a utilização de um software de análise de imagens chamado Pax-it, conforme Figura 54 e Figura 55.

Áreas menores que $10 \mu \mathrm{m}^{2}$ foram descartadas.

A medição de partículas foi realizada de duas formas: somente partículas de silício (Figura 54) e todas as partículas (Figura 55). 


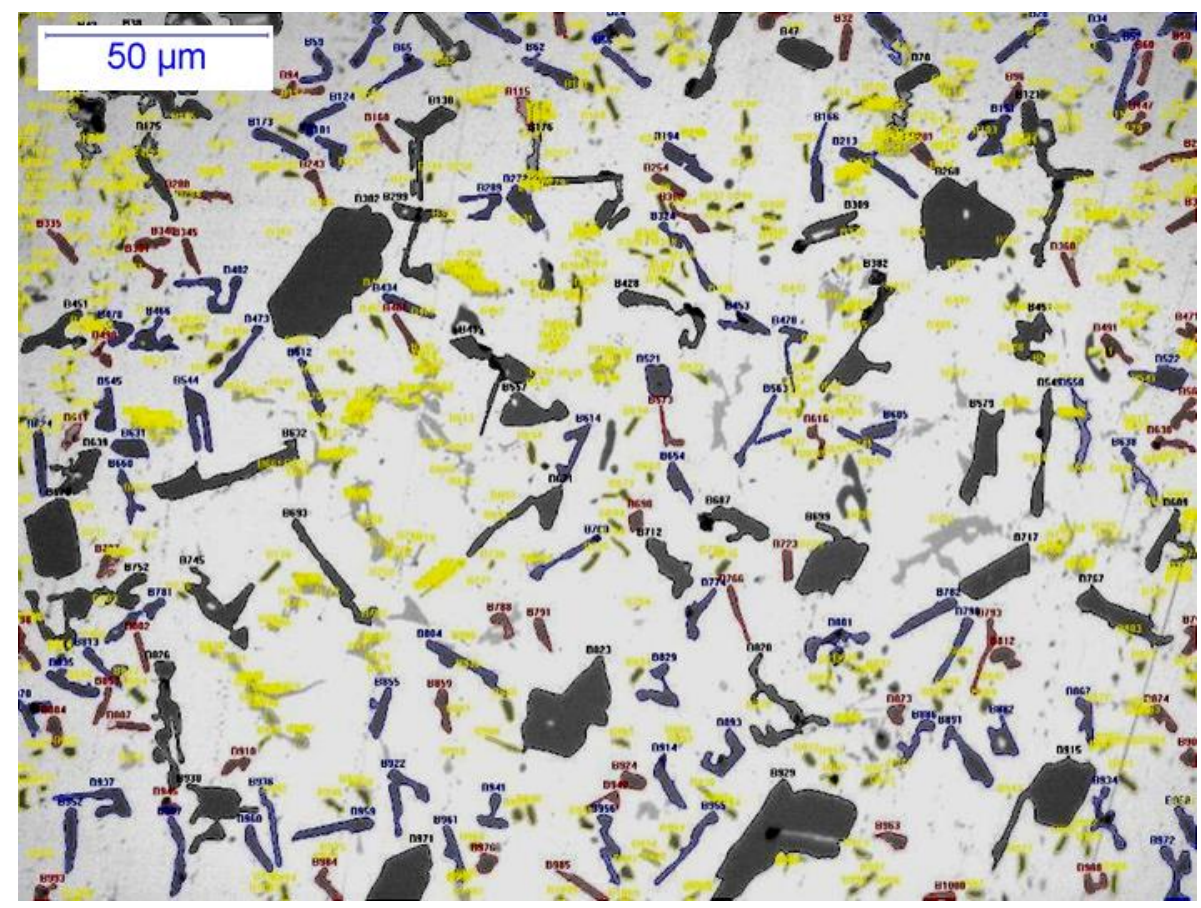

Figura 54 - Medição de área e perímetro das partículas de silício, realizada pelo software Pax-it.

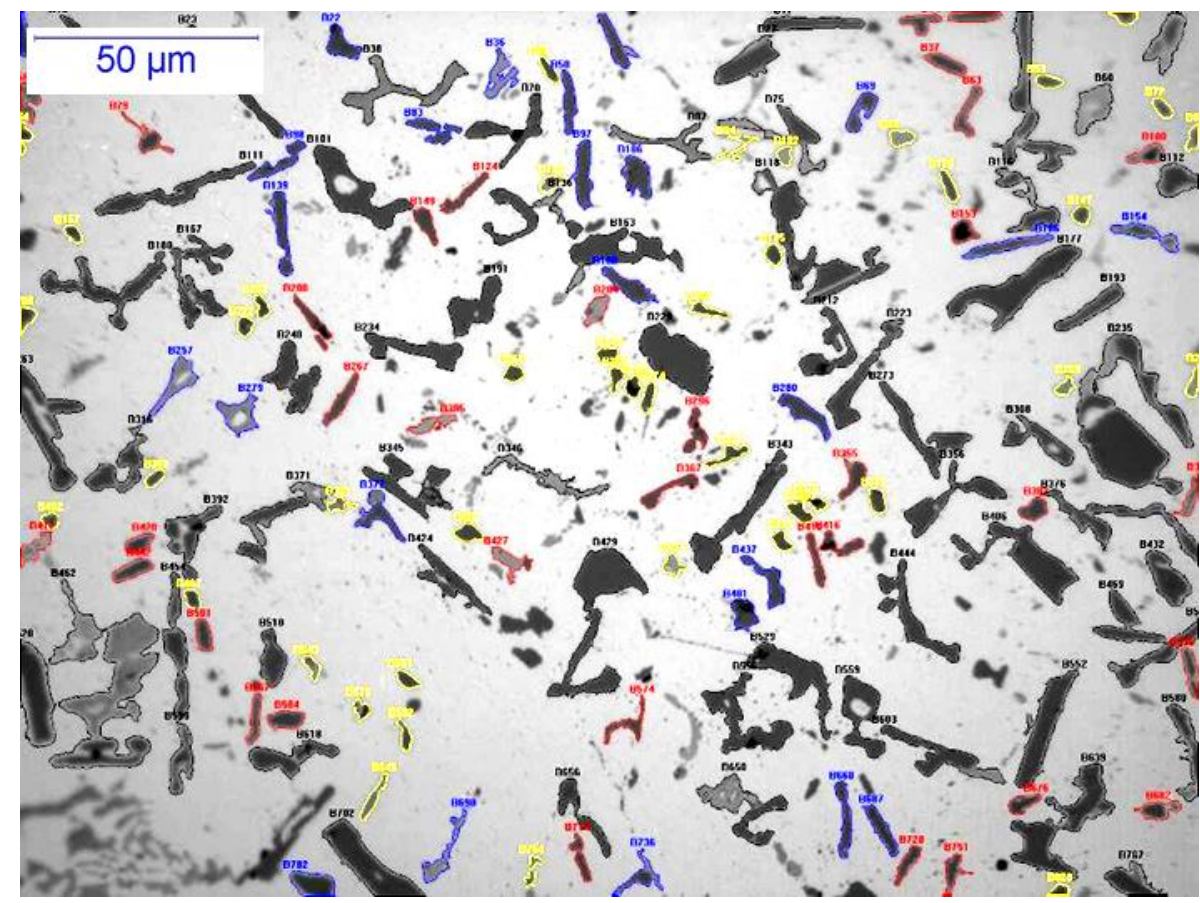

Figura 55 - Medição de área e perímetro de todas as partículas, realizada pelo software Pax-it. 


\subsubsection{Medição de área de intermetálicos}

A área dos intermetálicos também foi medida de forma automática através do software Pax-it.

Para a medição da área, foi realizada a subtração das áreas do total de partículas (Figura 57) e das partículas de silício (Figura 56).

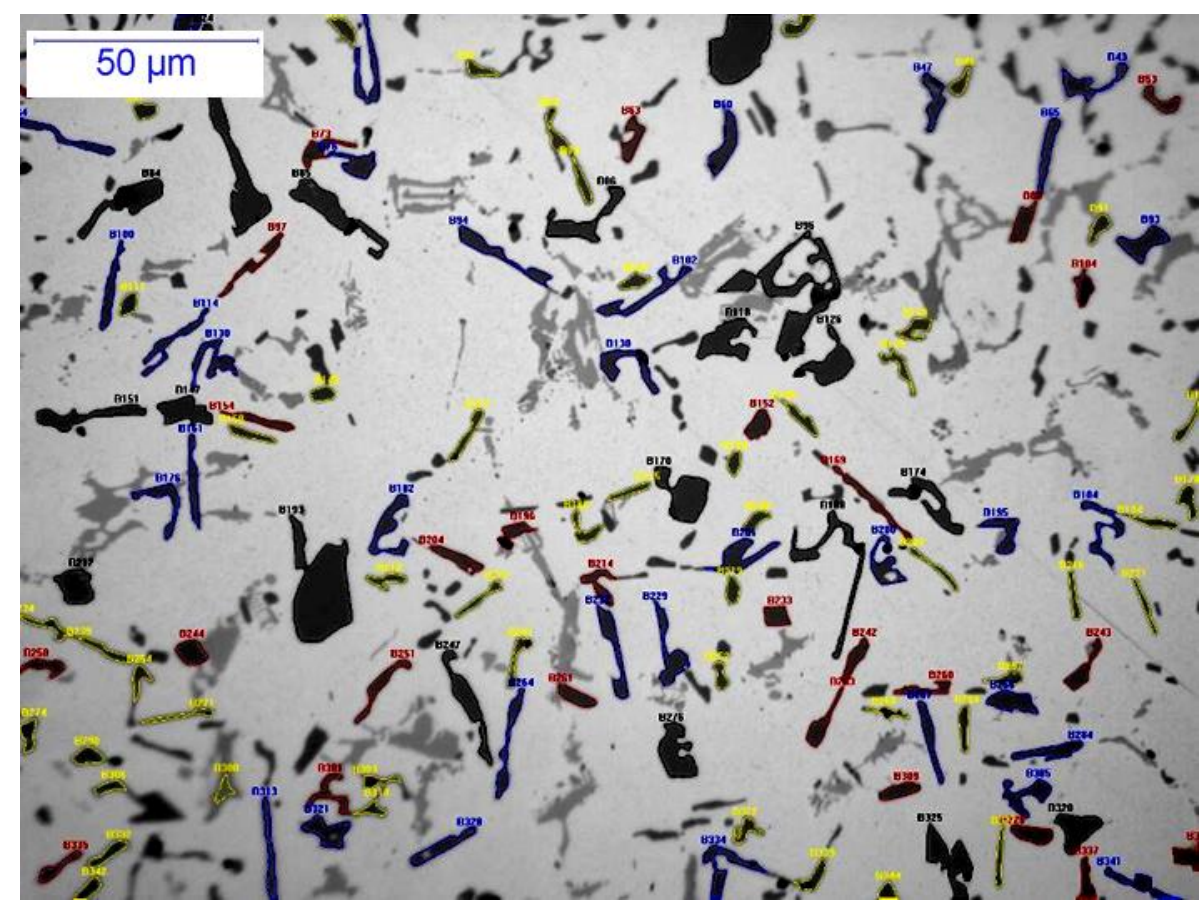

Figura 56 - Medição de área das partículas de silício, realizada pelo software Pax-it. 


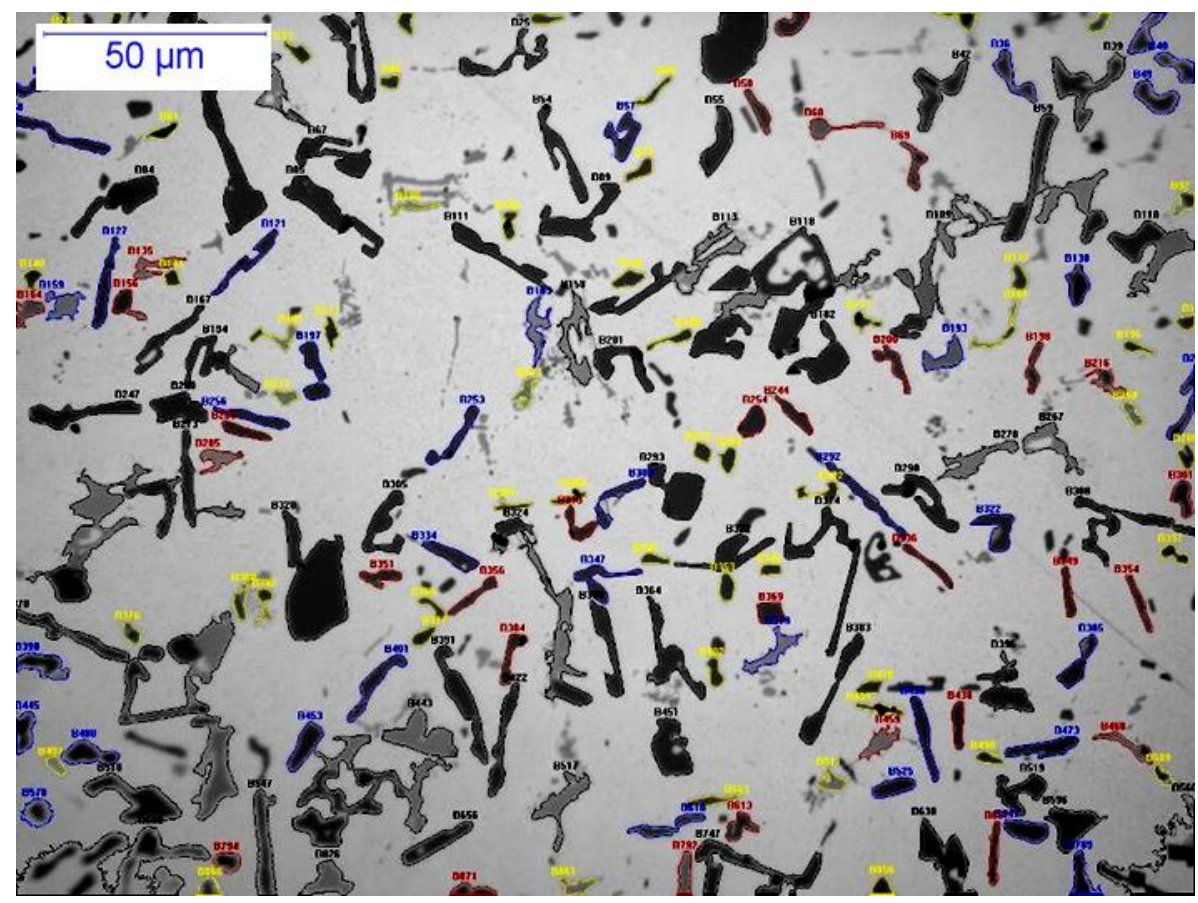

Figura 57 - Medição de área do total de partículas, realizada pelo software Pax-it.

\subsubsection{Contagem de intermetálicos}

A contagem de intermetálicos foi realizada através da sobreposição de 10 linhas paralelas sobre as imagens de microestruturas com 200x de aumento (Figura 58) e posterior contagem do número de intersecções dessas linhas com partículas intermetálicas. 


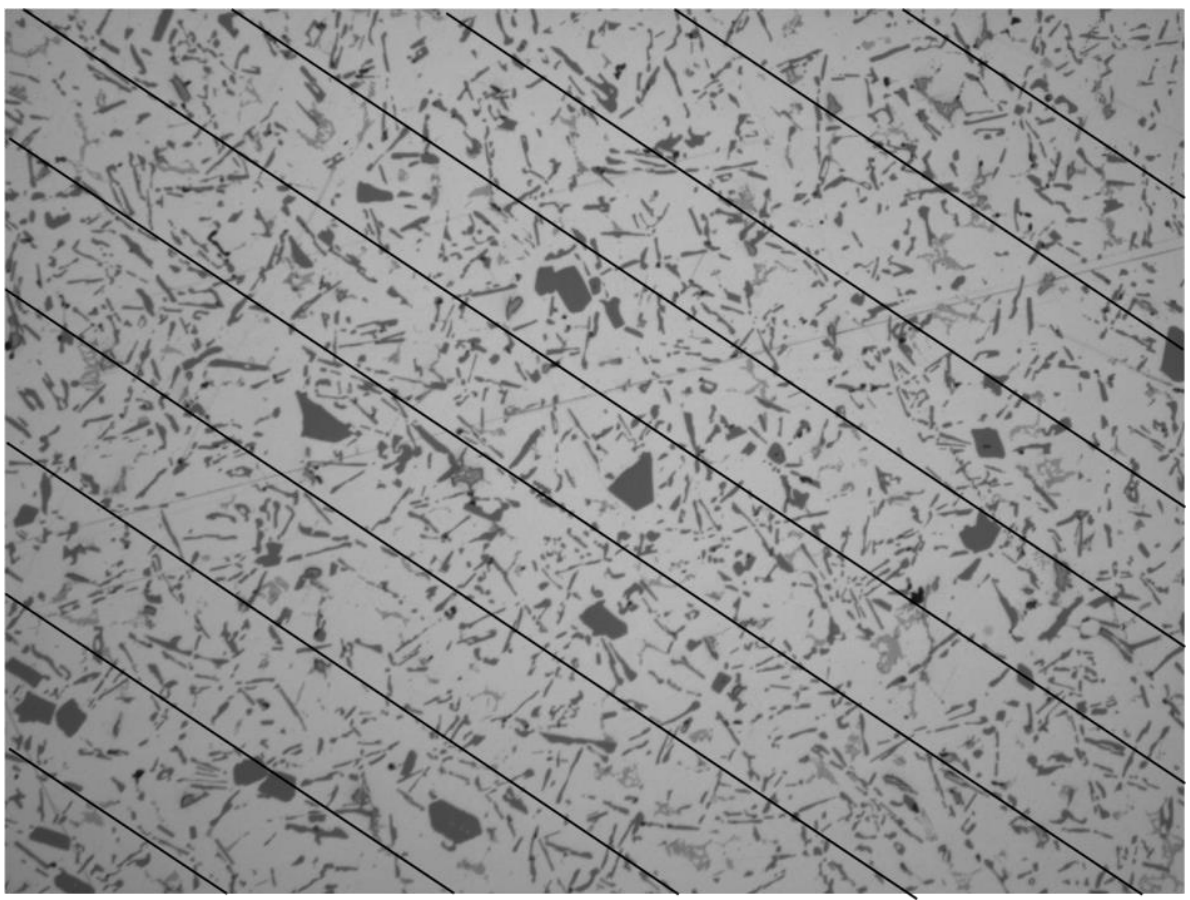

Figura 58 - Sobreposição de 10 linhas paralelas sobre a imagem de uma microestrutura com 200x de aumento.

\subsection{Ensaios de DTA}

Os ensaios de DTA foram realizados em um equipamento Netzsch modelo $404 \mathrm{~S}$, com controlador TASC 414/2.

Foi utilizada atmosfera de argônio para evitar a oxidação da liga.

A velocidade de aquecimento foi de $5.5^{\circ} \mathrm{C} / \mathrm{min}$, simulando o aquecimento real dos pistões durante o tratamento de solubilização. 


\subsection{Curvas de tratamento térmico}

Os tratamentos térmicos para estabelecer as curvas de solubilização e envelhecimento foram realizados em um forno tipo mufla da fabricante Quimis (Figura 59).

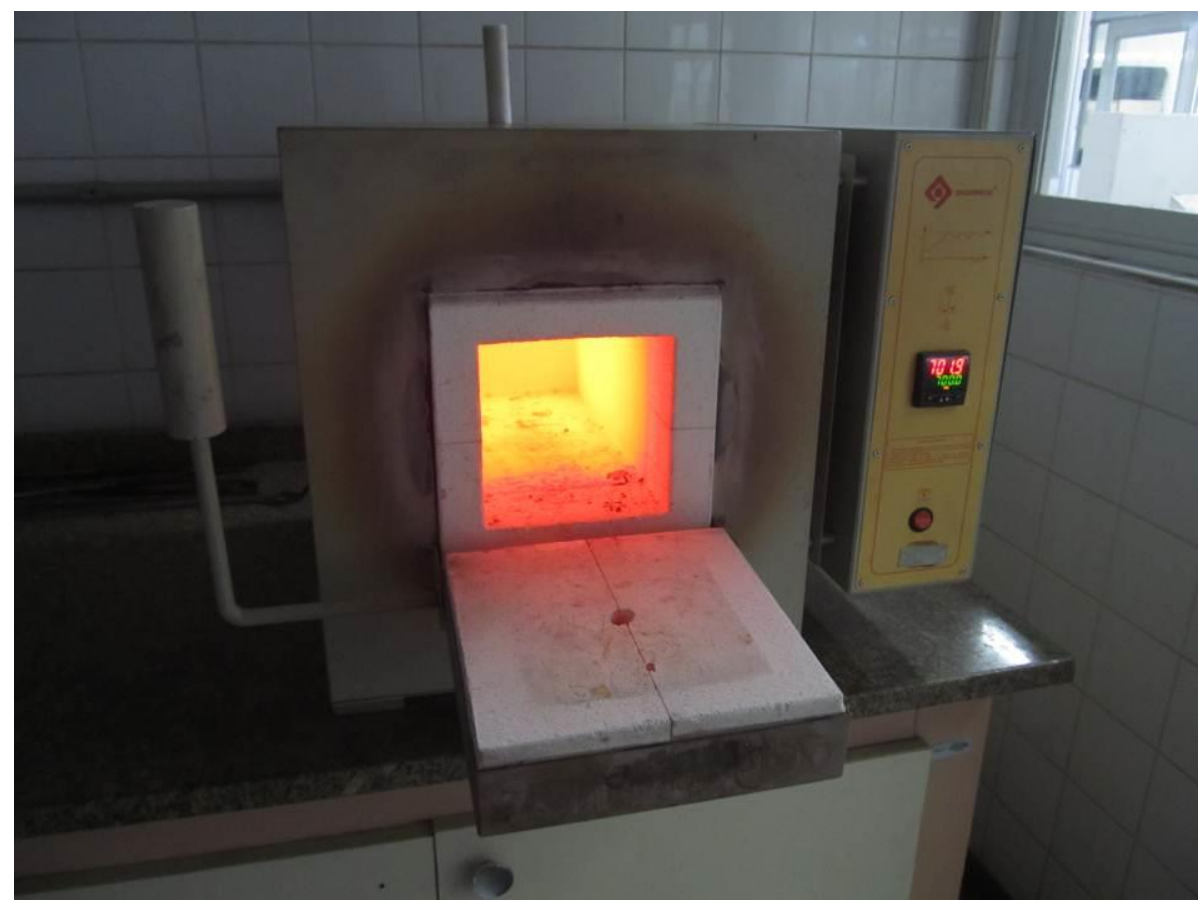

Figura 59 - Forno tipo mufla utilizado para estabelecer as curvas de tratamento térmico.

A solubilização dos corpos de prova de fadiga foi realizada em um forno Brasimet com circulação de ar (Figura 60). O controle de temperatura foi feito através de um termopar embutido em uma peça de alumínio para simular o aquecimento real da peça (Figura $61)$. 


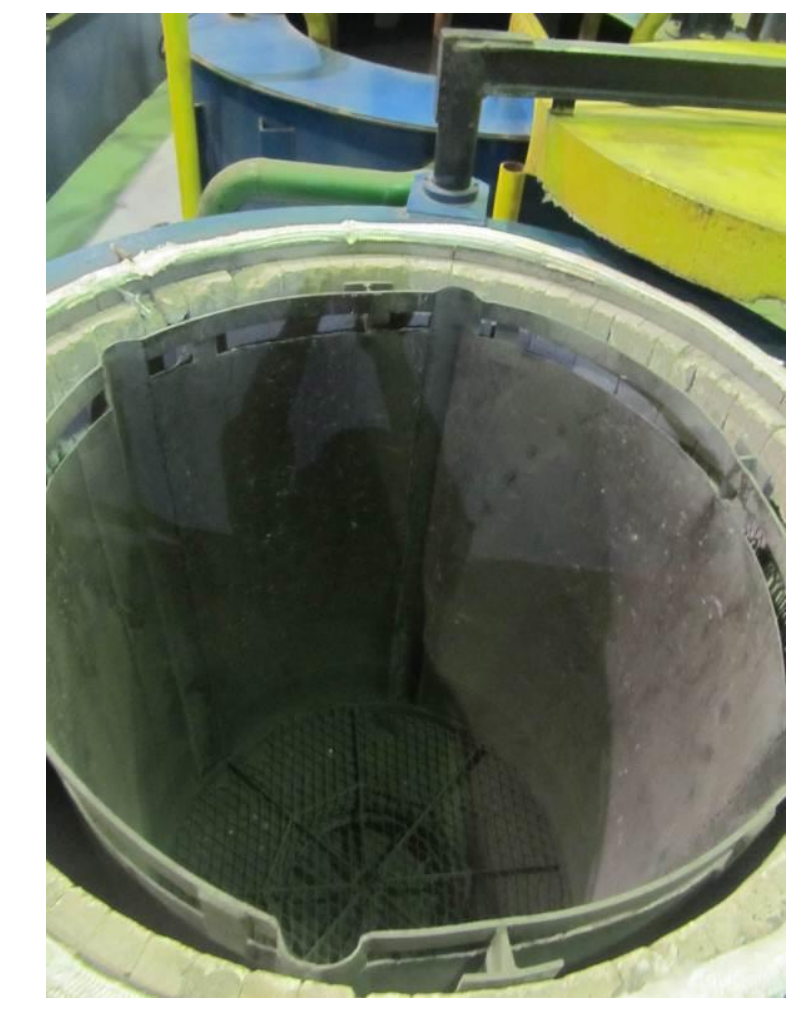

Figura 60 - Forno de solubilização.

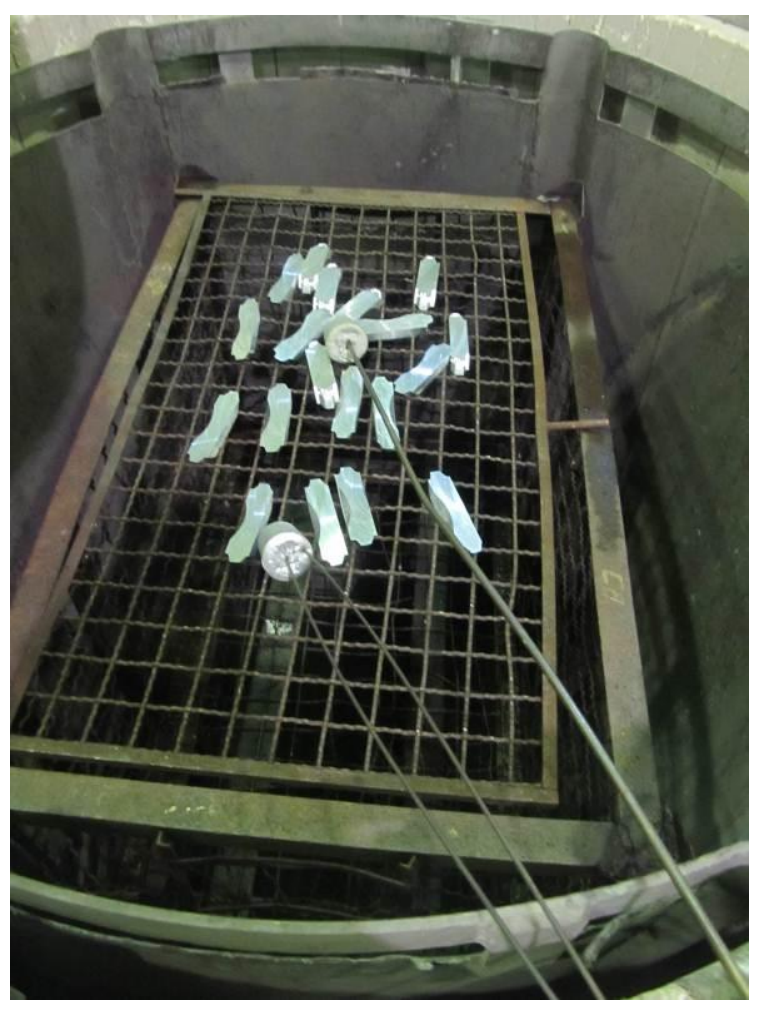

Figura 61 - Posicionamento da carga e dos termopares no forno de solubilização.

As curvas de solubilização foram levantadas para as temperaturas de $500^{\circ} \mathrm{C}$ e $525^{\circ} \mathrm{C}$. O resfriamento das peças após solubilização foi feito em água a $50^{\circ} \mathrm{C}$ (Figura 62). 


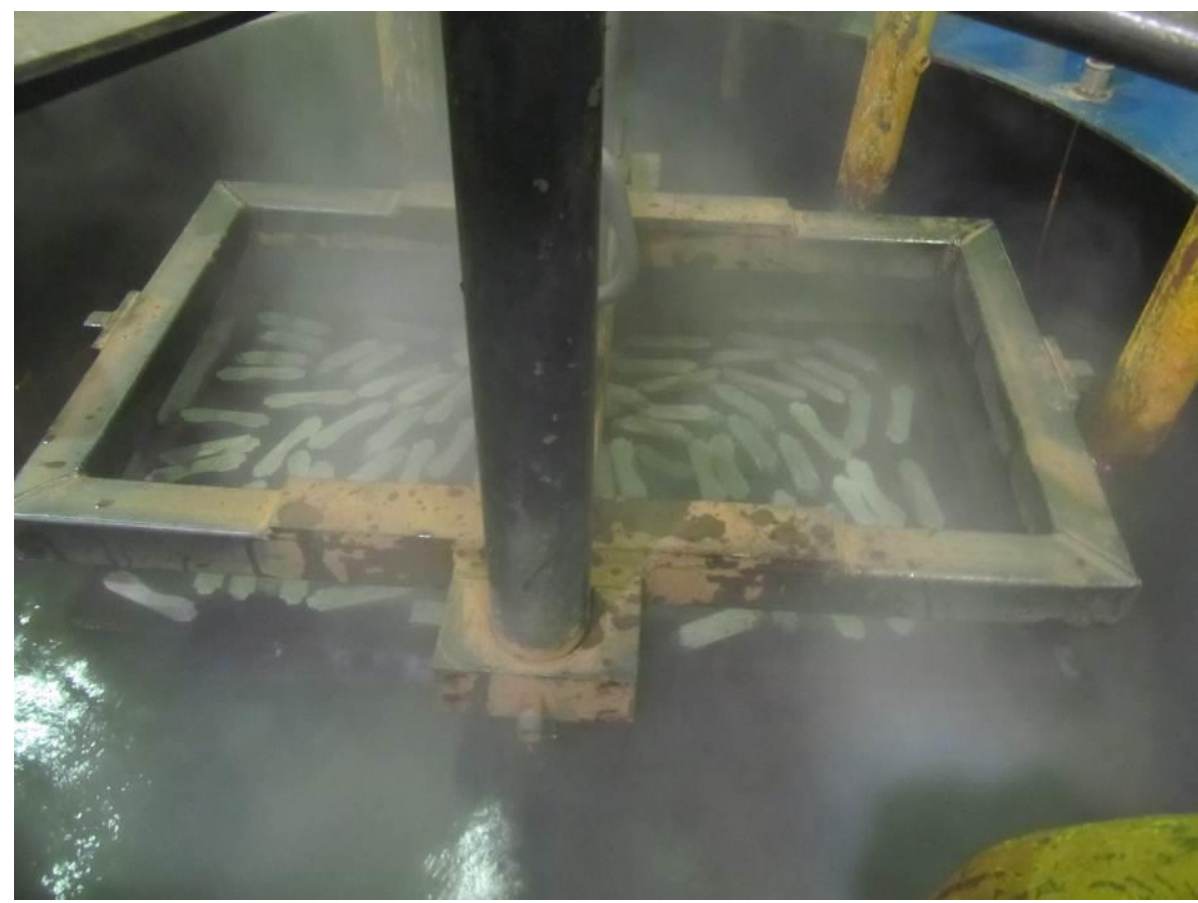

Figura 62 - Resfriamento da carga em água a $50^{\circ} \mathrm{C}$.

A Figura 63 mostra a curva de solubilização das ligas a $500^{\circ} \mathrm{C}$. As durezas foram medidas após 24 horas do término do tratamento. As amostras não passaram por tratamento de envelhecimento artificial. 


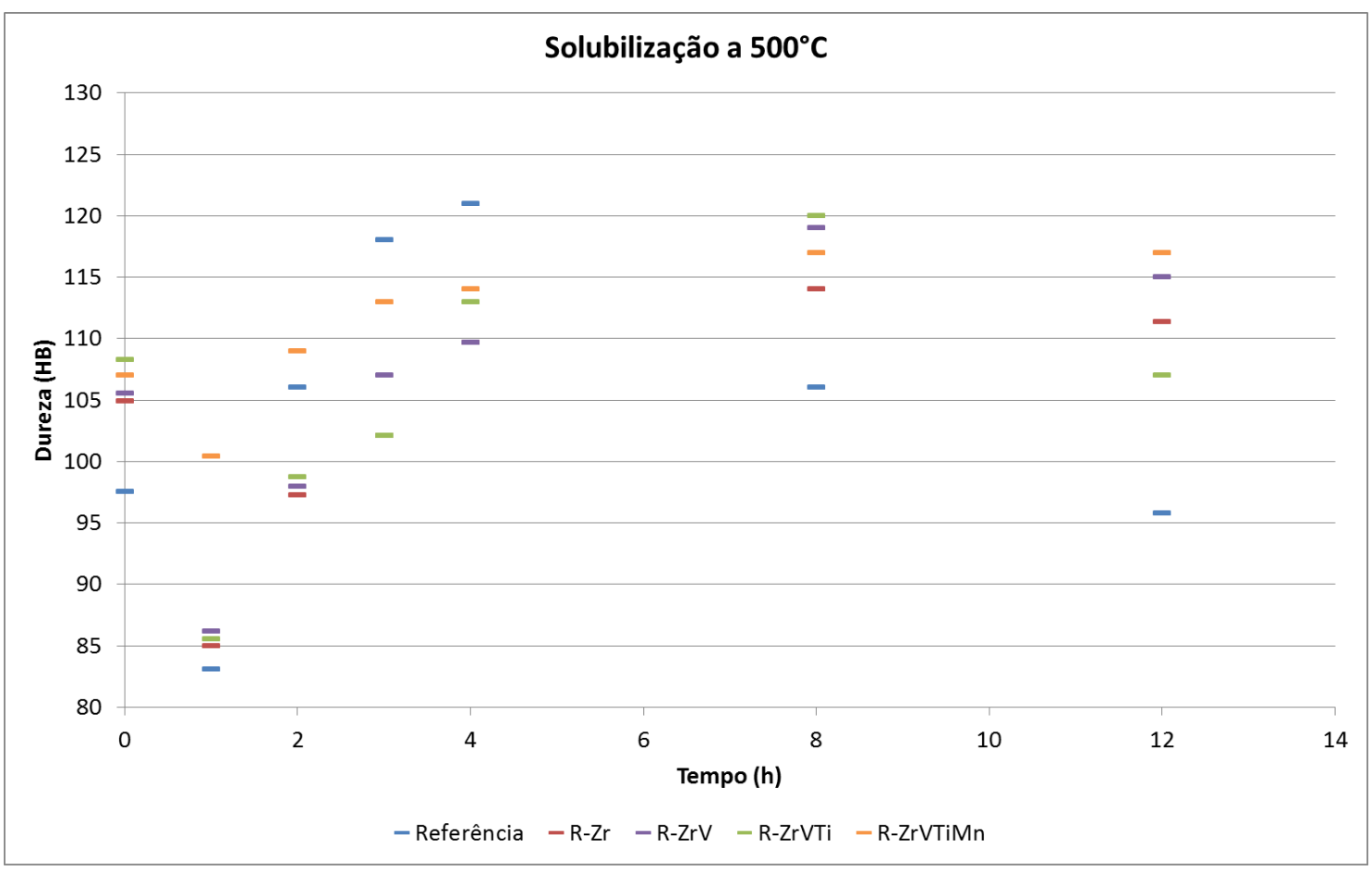

Figura 63 - Curvas de solubilização a $500^{\circ} \mathrm{C}$.

A Figura 64 mostra a curva de solubilização das ligas a $525^{\circ} \mathrm{C}$. As durezas foram medidas após 24 horas do término do tratamento. As amostras não passaram por tratamento de envelhecimento artificial. 


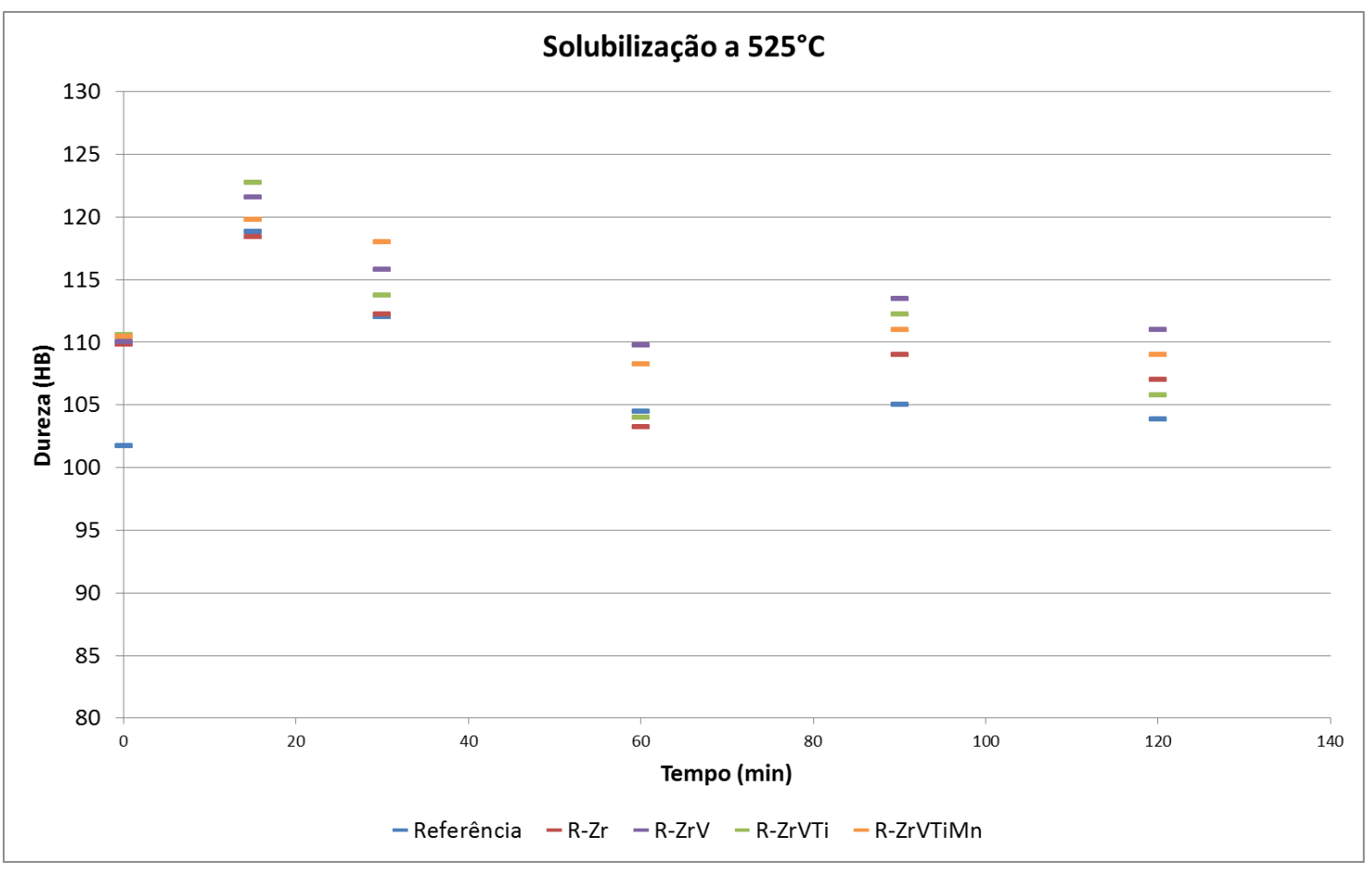

Figura 64 - Curvas de solubilização a $525^{\circ} \mathrm{C}$.

De acordo com a Figura 63, a liga de referência atinge o pico de dureza após cerca de quatro horas de tratamento, enquanto as outras ligas atingem seu pico após cerca de oito horas de tratamento. Quando a temperatura é aumentada em $25^{\circ} \mathrm{C}$, todas as ligas atingem o pico de dureza após 15 minutos de tratamento, conforme a Figura 64 .

A série de Referência passou pelo ciclo de tratamento térmico duplo tradicionalmente utilizado na fabricação de pistões (solubilização a $500^{\circ} \mathrm{C}$ por 1 hora + envelhecimento a $230^{\circ} \mathrm{C}$ ), enquanto as outras séries passaram pelo ciclo de tratamento térmico proposto (solubilização a $525^{\circ} \mathrm{C}$ por 15 minutos + envelhecimento a $230^{\circ} \mathrm{C}$ ), conforme Figura 65 e Figura 66. 


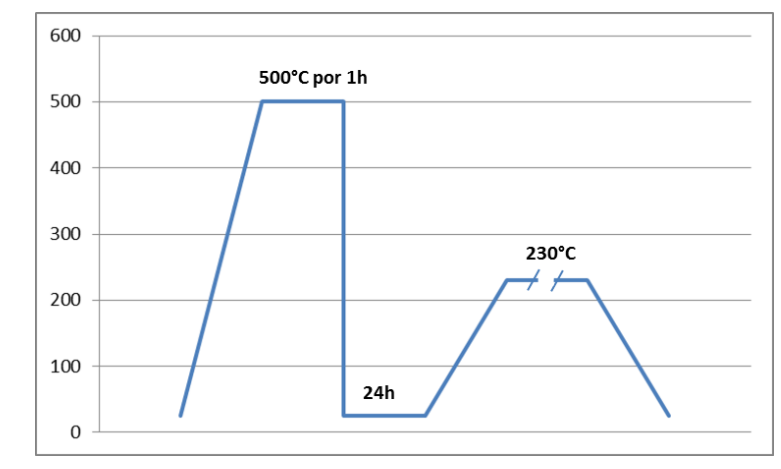

Figura 65 - ciclo de tratamento térmico tradicional.

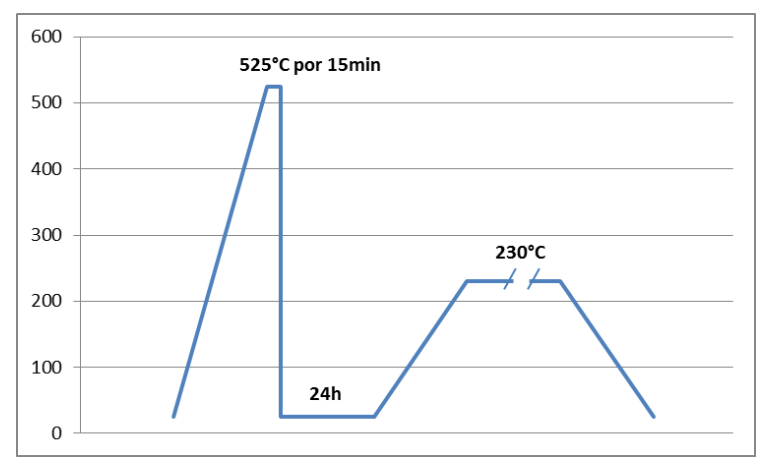

Figura 66 - ciclo de tratamento térmico proposto.

As medições de dureza foram realizadas em um durômetro Brinnel com carga de $62,5 \mathrm{~kg}$ e esfera de $2,5 \mathrm{~mm}$.

O envelhecimento das ligas foi realizado em um forno Brasimet com circulação de ar (Figura 67 e Figura 68). O controle de temperatura foi feito através de um termopar embutido em uma peça de alumínio para simular o aquecimento real da peça (Figura $67)$.

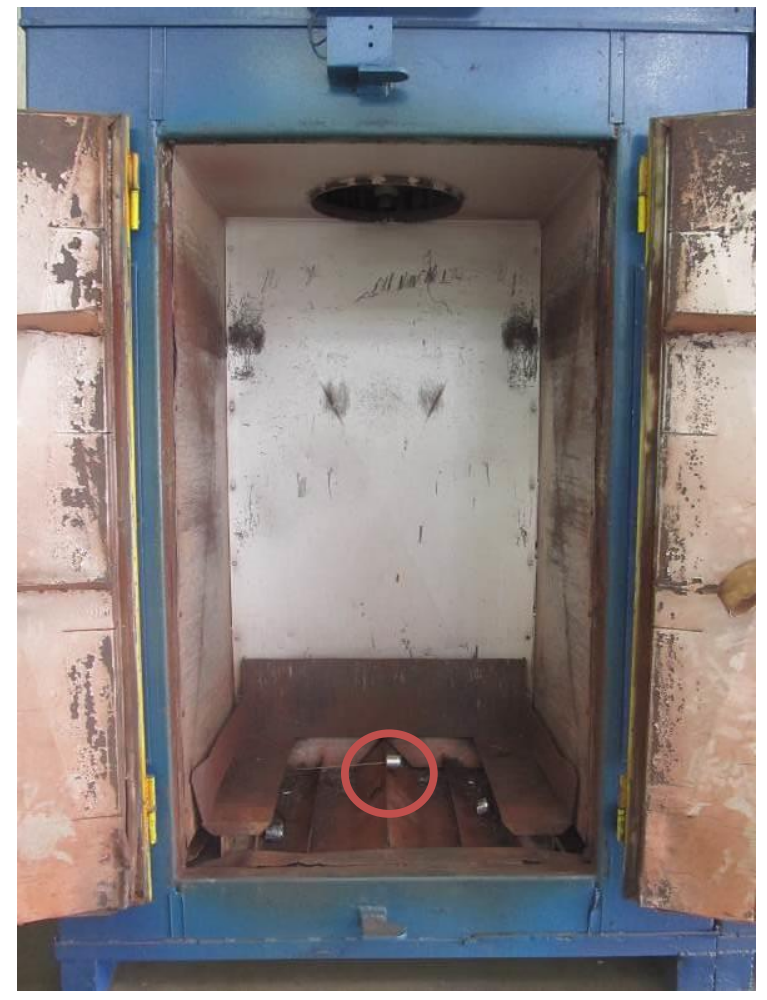

Figura 67 - Posicionamento do termopar de controle no forno de envelhecimento.

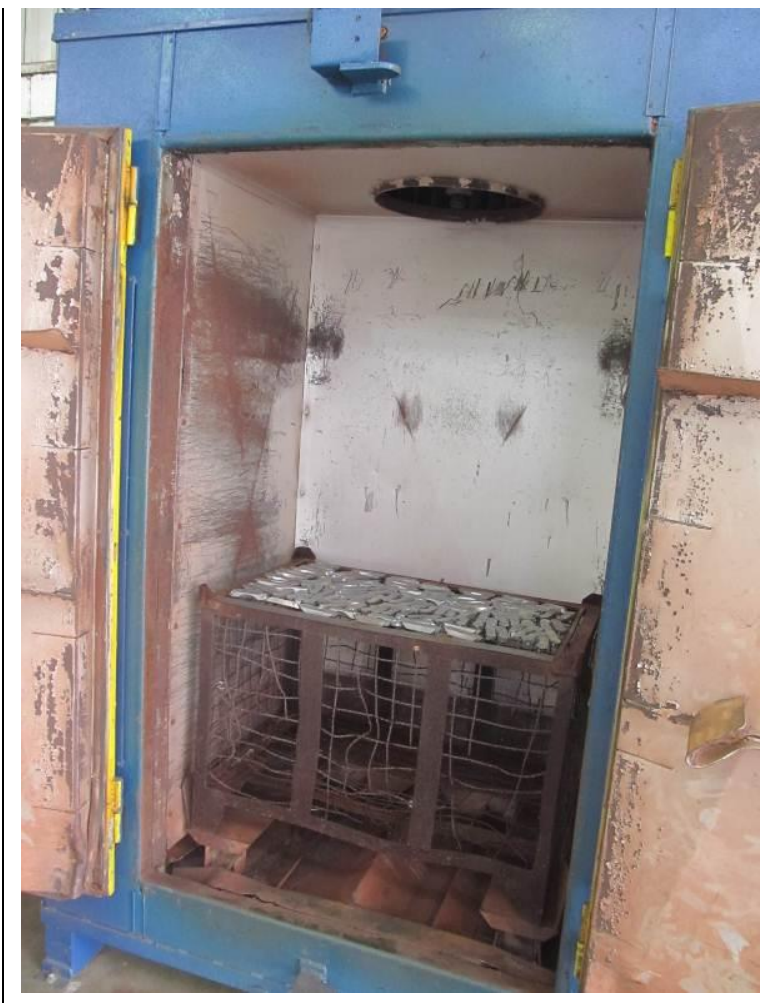

Figura 68 - Posicionamento da carga no forno de envelhecimento. 
A Figura 69 mostra as curvas de envelhecimento das ligas a $230^{\circ} \mathrm{C}$.

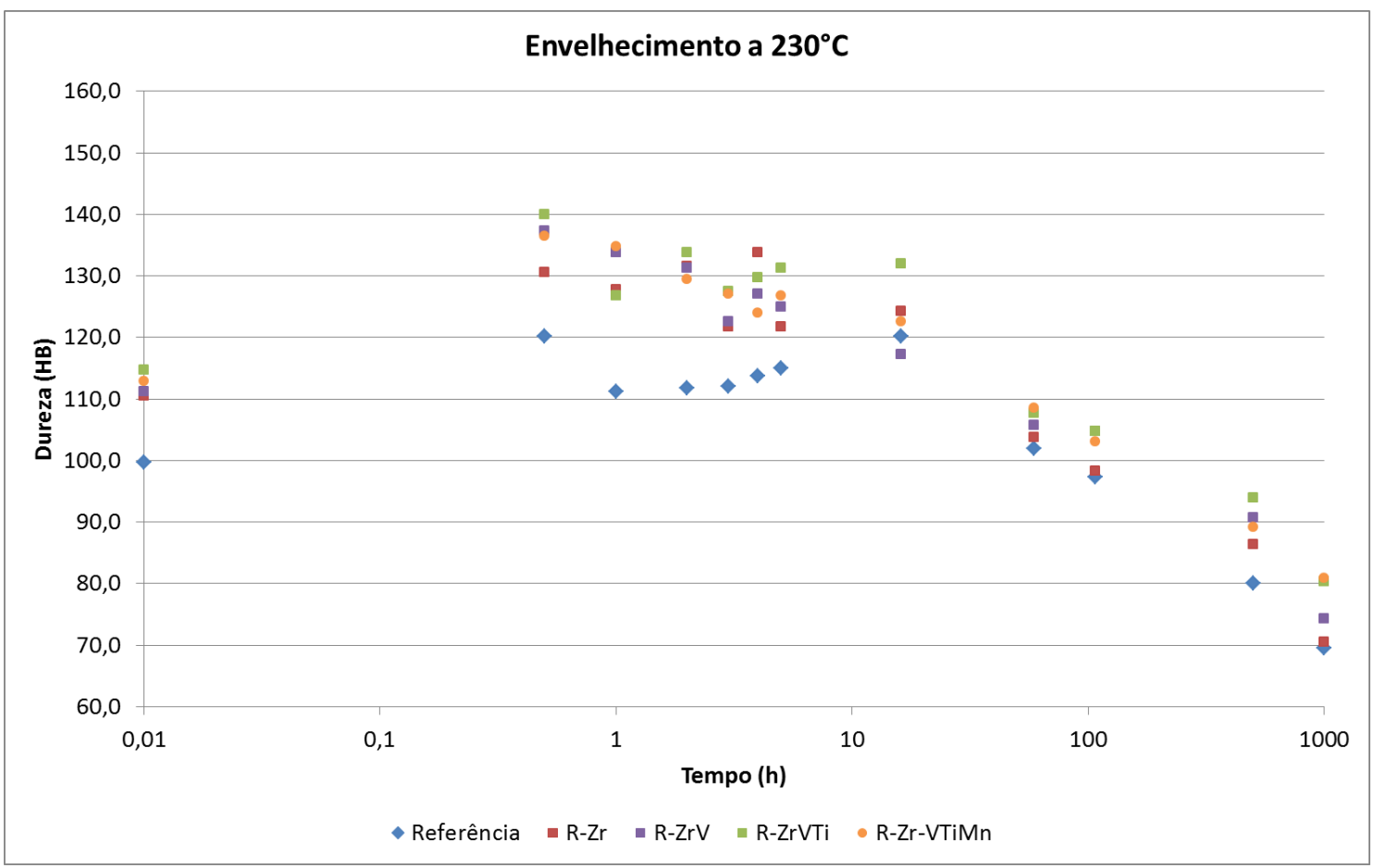

Figura 69 - Curvas de envelhecimento a $230^{\circ} \mathrm{C}$.

Série de Referência: solubilização a $500^{\circ} \mathrm{C}$ por 1 hora + envelhecimento a $230^{\circ} \mathrm{C}$. Séries R-Zr, R-ZrV, R-ZrVTi e R-ZrVTiMn: solubilização a $525^{\circ} \mathrm{C}$ por 15 minutos + envelhecimento a $230^{\circ} \mathrm{C}$.

Todos os corpos de prova passaram por um tratamento de 100 horas a $230^{\circ} \mathrm{C}$ (soaking) para simular a condição de serviço de um pistão.

A Tabela 10 apresenta as condições de tratamento térmico de cada uma das séries.

Tabela 10 - Condição inicial das séries para ensaio de tração e fadiga a $230^{\circ} \mathrm{C}$.

\begin{tabular}{c|c|c|c|c}
\hline \multirow{2}{*}{ Série } & \multicolumn{2}{|c|}{ Solubilização } & \multicolumn{2}{c}{ Envelhecimento/Soaking } \\
\cline { 2 - 5 } & $\begin{array}{c}\text { Temperatura } \\
\left({ }^{\circ} \mathrm{C}\right)\end{array}$ & $\begin{array}{c}\text { Tempo } \\
(\min )\end{array}$ & $\begin{array}{c}\text { Temperatura } \\
\left({ }^{\circ} \mathrm{C}\right)\end{array}$ & $\begin{array}{c}\text { Tempo } \\
(\mathrm{h})\end{array}$ \\
\hline Referência & 500 & 60 & 230 & 100 \\
\hline R-Zr & 525 & 15 & 230 & 100 \\
\hline R-ZrV & 525 & 15 & 230 & 100 \\
\hline R-ZrVTi & 525 & 15 & 230 & 100 \\
\hline R-ZrVTiMn & 525 & 15 & 230 & 100 \\
\hline R-TT & 525 & 15 & 230 & 100
\end{tabular}




\subsection{Ensaios de tração e fadiga a quente}

Os corpos de prova utilizados foram usinados conforme a Figura 70, a partir do material extraído do topo do pistão (Figura 52, Figura 71 e Figura 72).

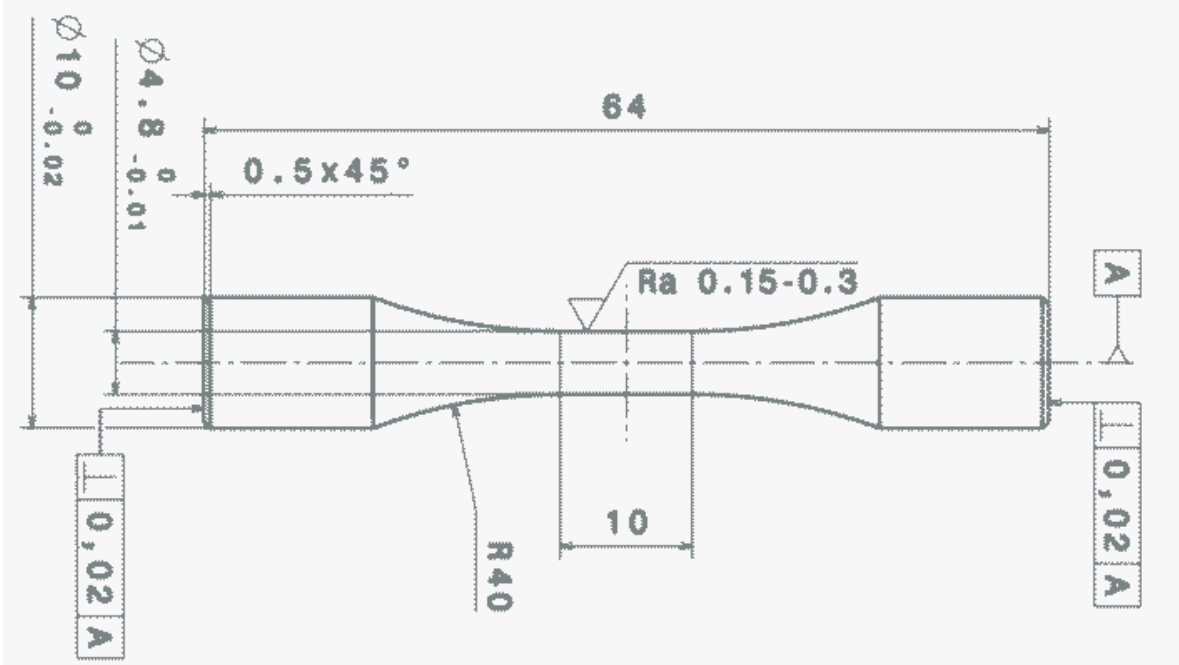

Figura 70 - Desenho do corpo de prova.

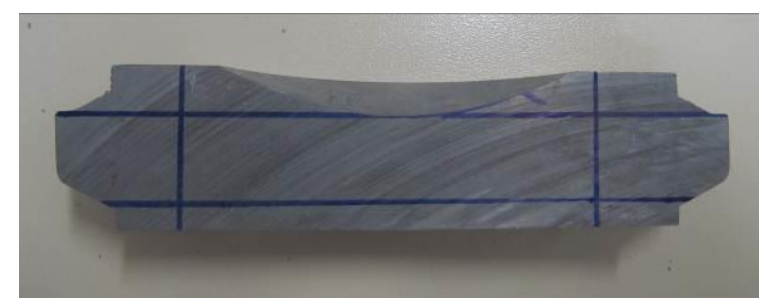

Figura 71 - Demarcação da região da qual o corpo de prova foi extraído.

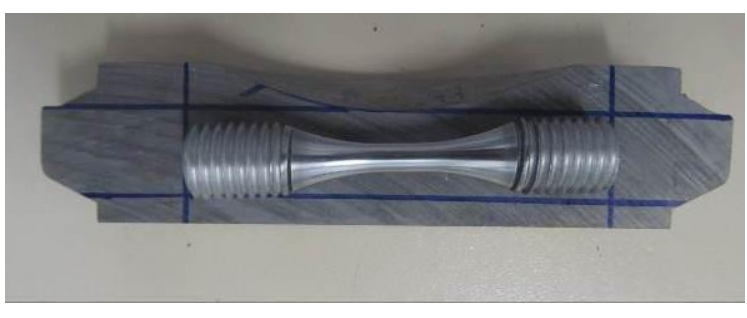

Figura 72 - Corpo de prova sobreposto à região de extração do mesmo.

Os primeiros ensaios de fadiga a quente foram descartados devido a uma redução de área na região de concordância e todas as fraturas ocorreram na mesma região do corpo de prova (Figura 73). 

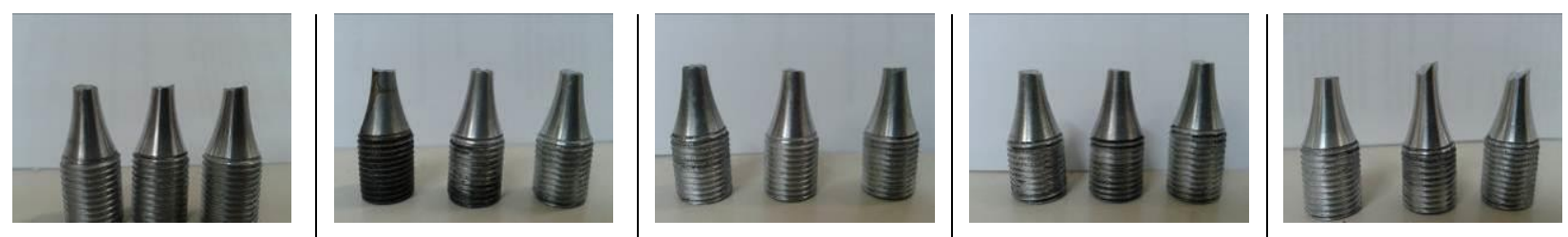

Figura 73 - Corpos de prova fraturados na região de concordância.

Para evitar este efeito, todos os corpos de prova foram lixados com lixas 400, 600, 1200 e posteriormente polidos com pasta de diamante de $6 \mu \mathrm{m}$.

A rugosidade superficial dos corpos de prova foi medida antes e após o polimento (Figura 74, Figura 75 e Figura 76).

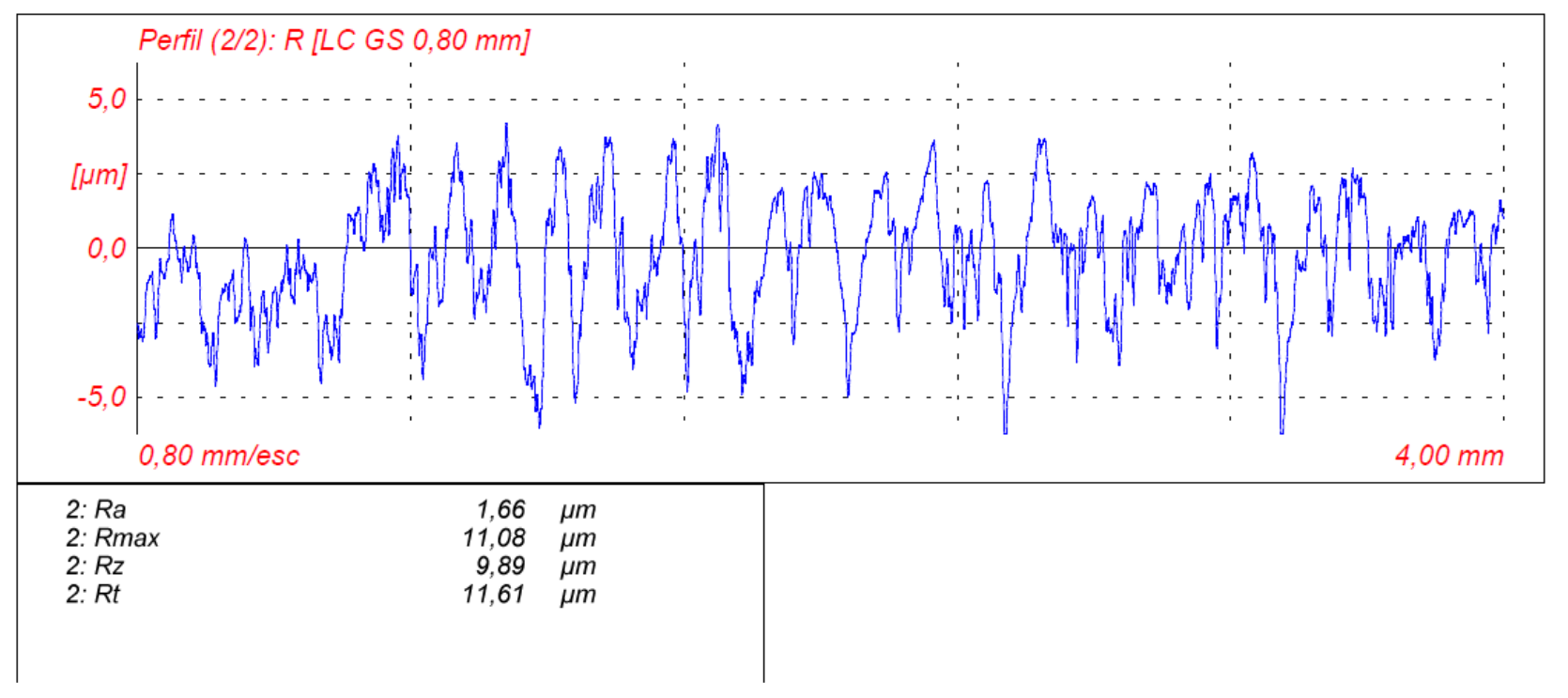

Figura 74 - Rugosidade superficial do corpo de prova após usinagem. 


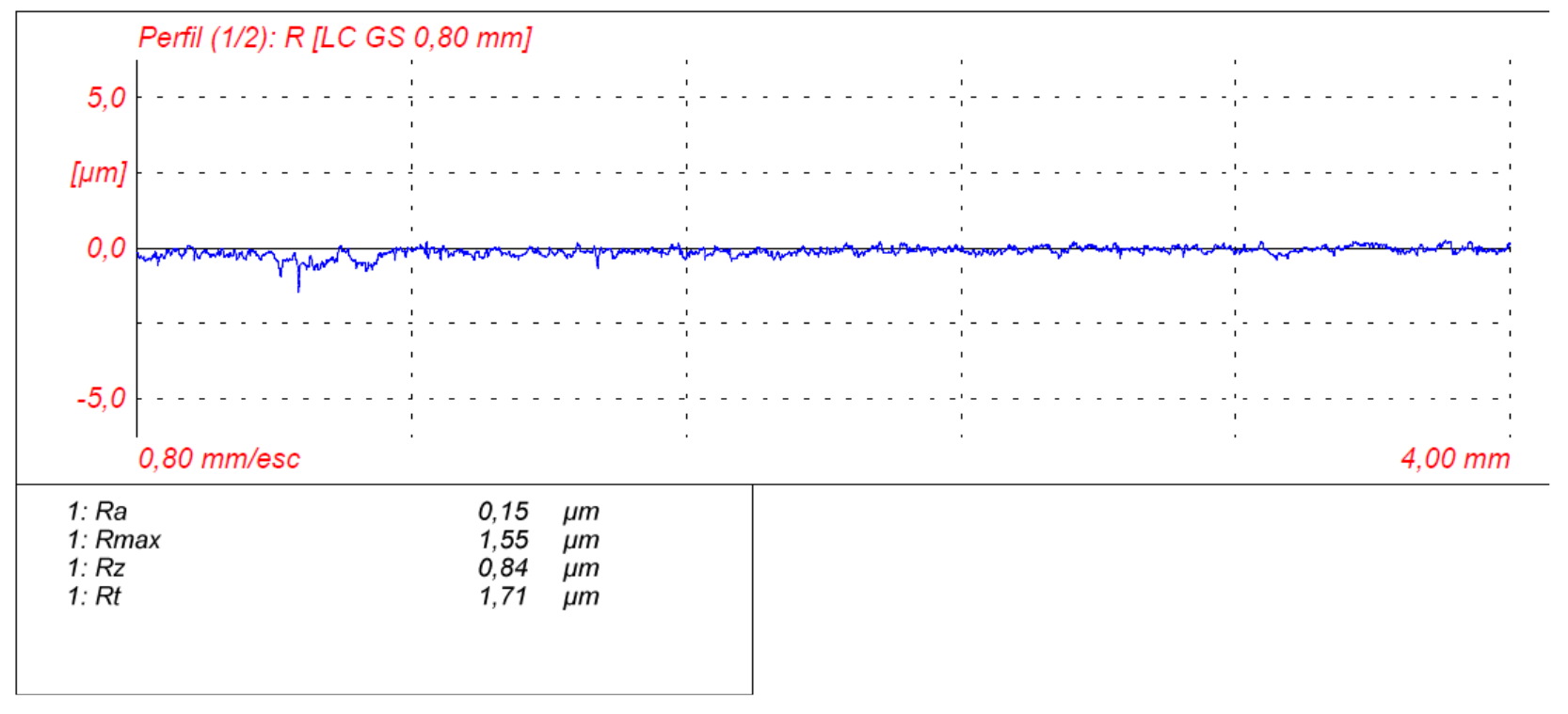

Figura 75 - Rugosidade superficial do corpo de prova após polimento.

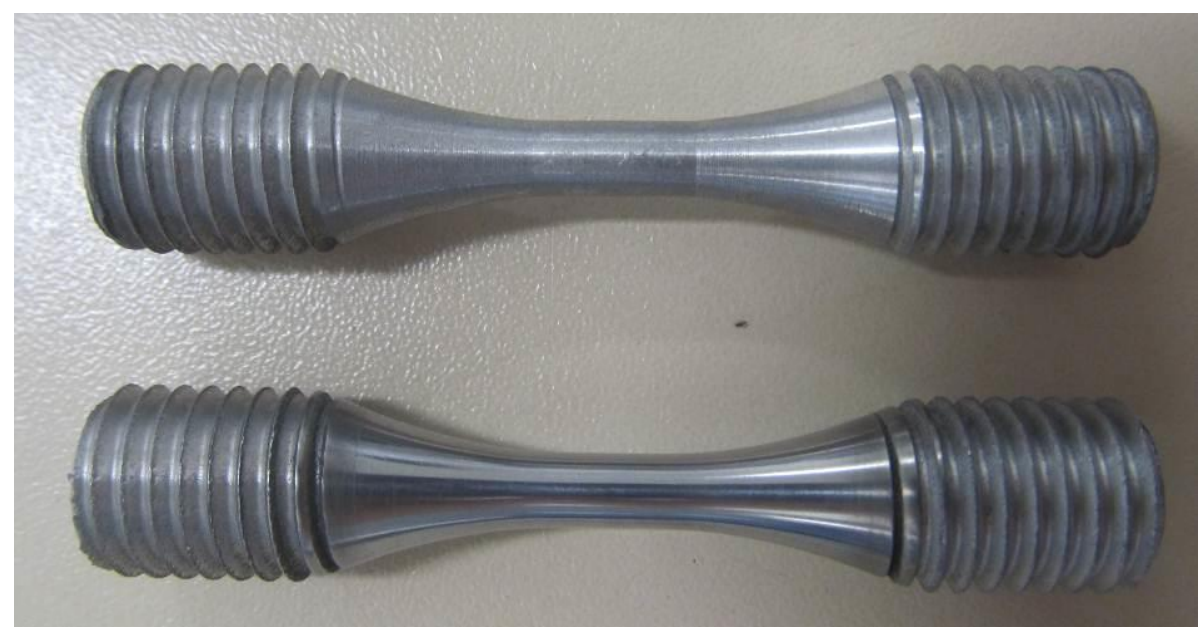

Figura 76 - Aspecto superficial do corpo de prova antes e após polimento.

Os ensaios de tração a quente foram realizados em um equipamento MTS 810 com forno MTS 653, conforme Figura 77. 


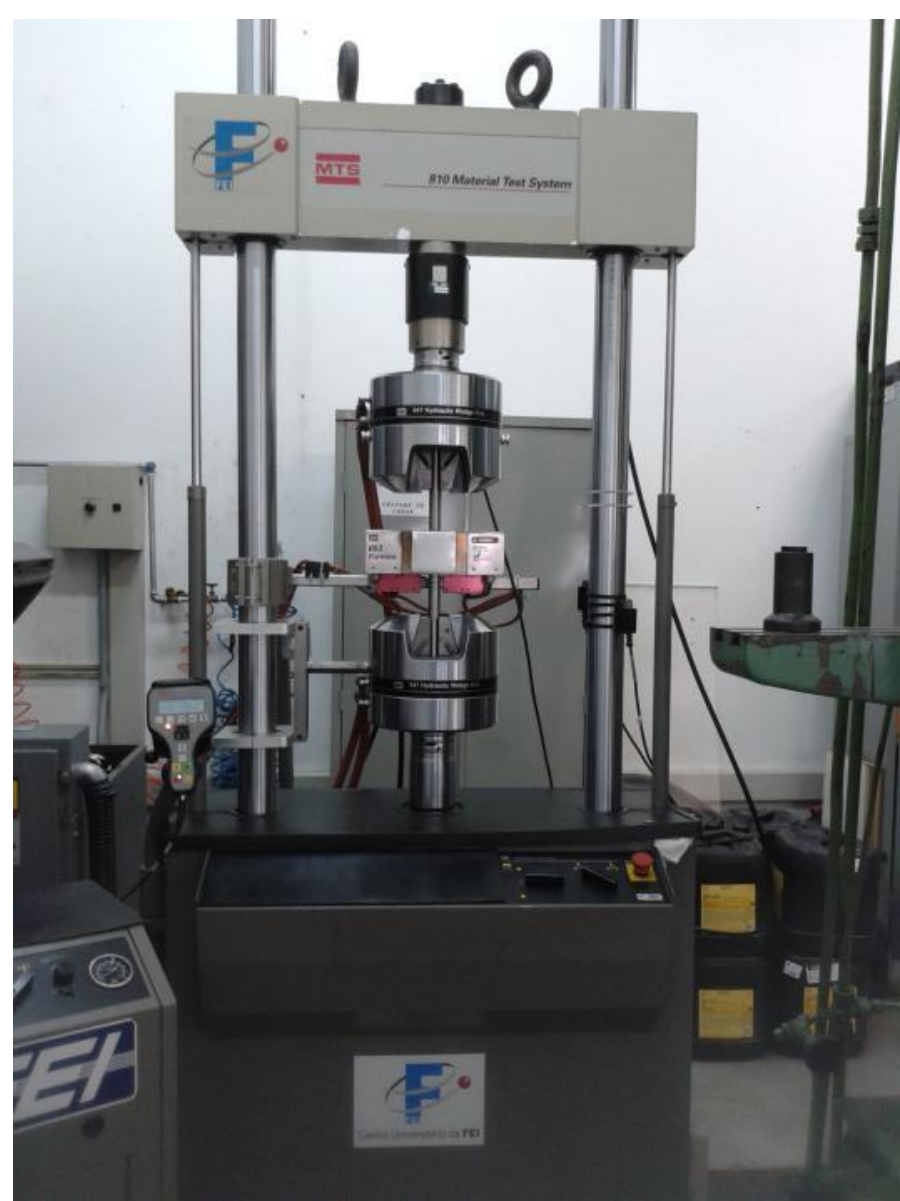

Figura 77 - Equipamento MTS810 com forno MTS653.

Antes do início dos ensaios, foi realizada a preparação da máquina e a temperatura foi homogeneizada por 20 minutos.

O tempo de 20 minutos foi determinado a partir de medições de temperatura superficial na peça realizado com termopar de contato (Figura 78). Foi constatado que a homogeneização ocorre com cerca de15 minutos. 


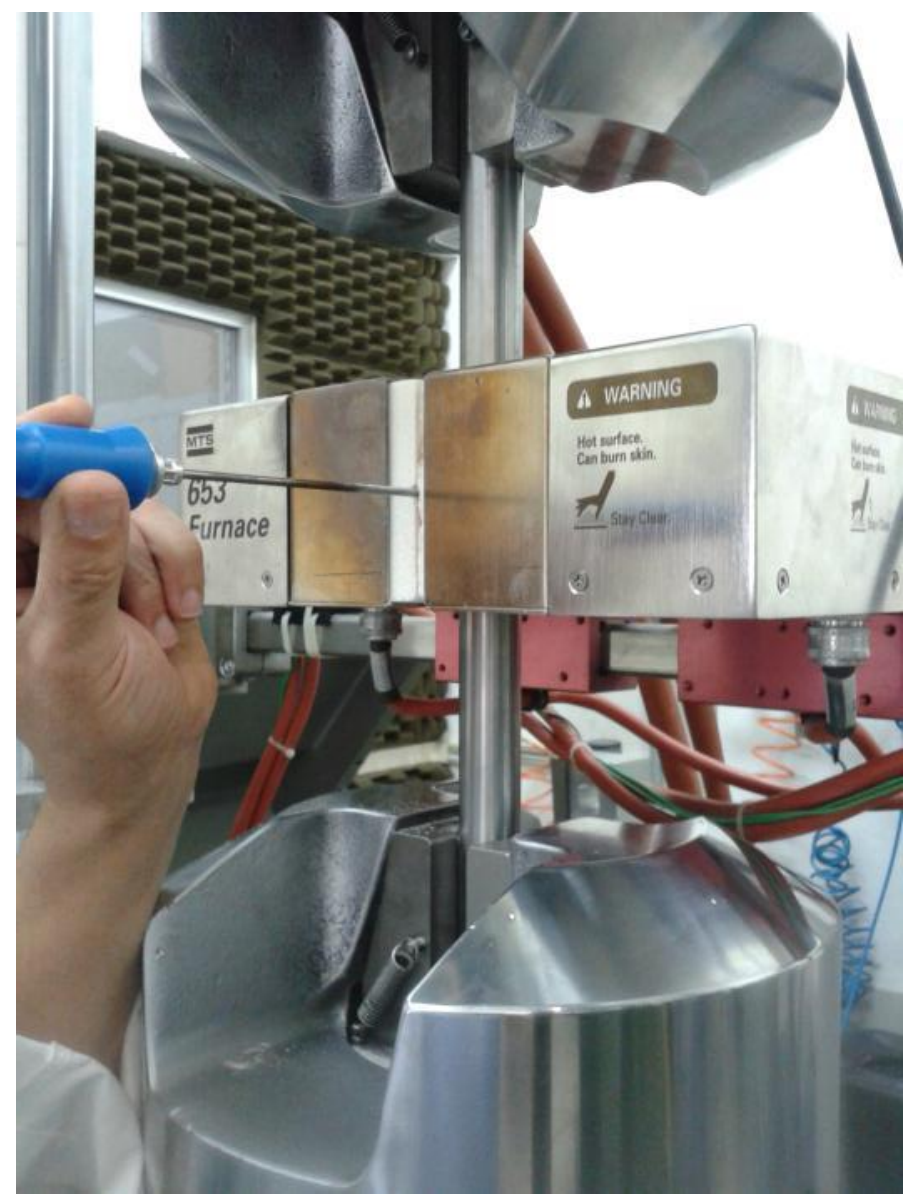

Figura 78 - Medição da temperatura da superfície do corpo de prova com termopar de contato.

Os ensaios de fadiga a quente foram realizados em um equipamento MTS servohidráulico, com quadro de carga de $250 \mathrm{KN}$ e célula de carga de $100 \mathrm{KN}$ com forno elétrico de resistência, conforme Figura 79. 


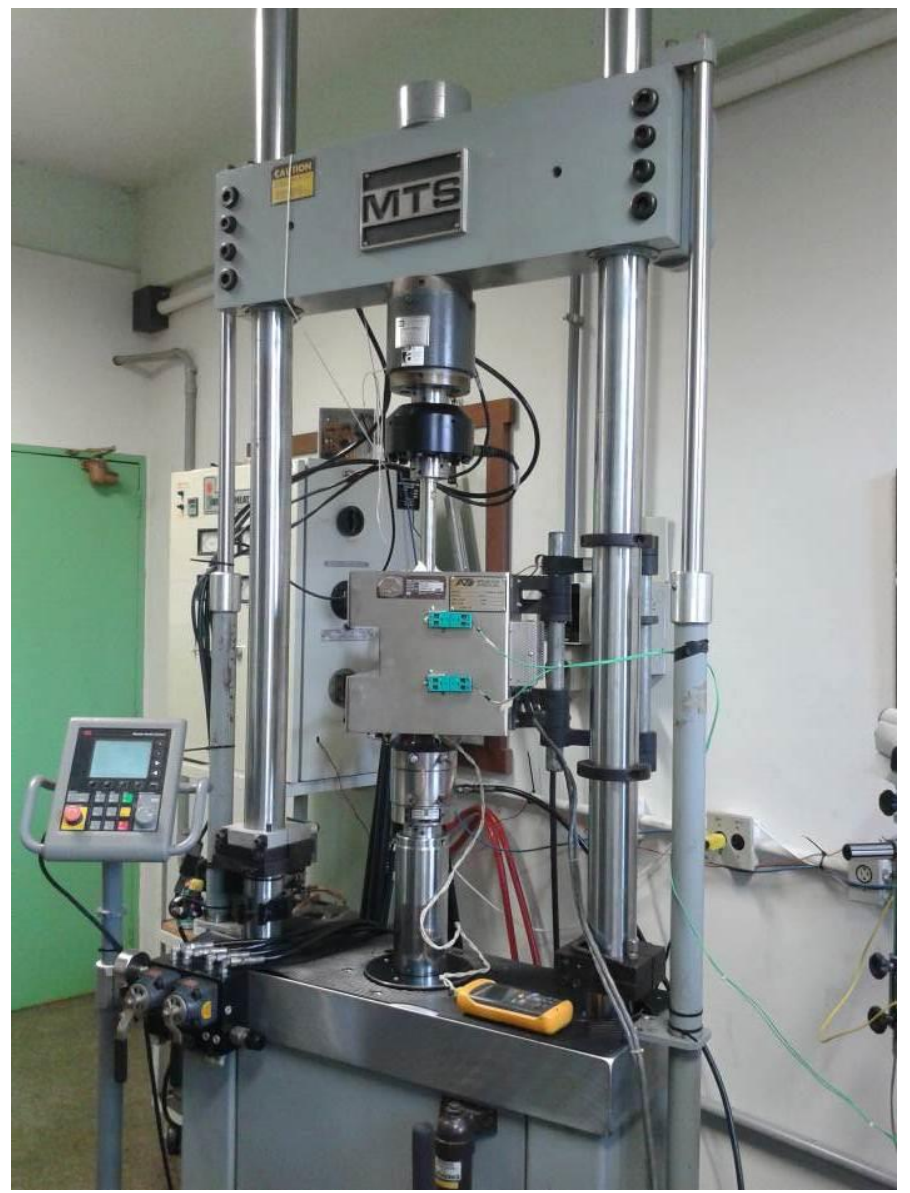

Figura 79 - Equipamento MTS com forno elétrico de resistência.

Um termopar de contato foi fixado a cada uma das amostras para garantir a temperatura do corpo de prova durante os ensaios (Figura 80). 


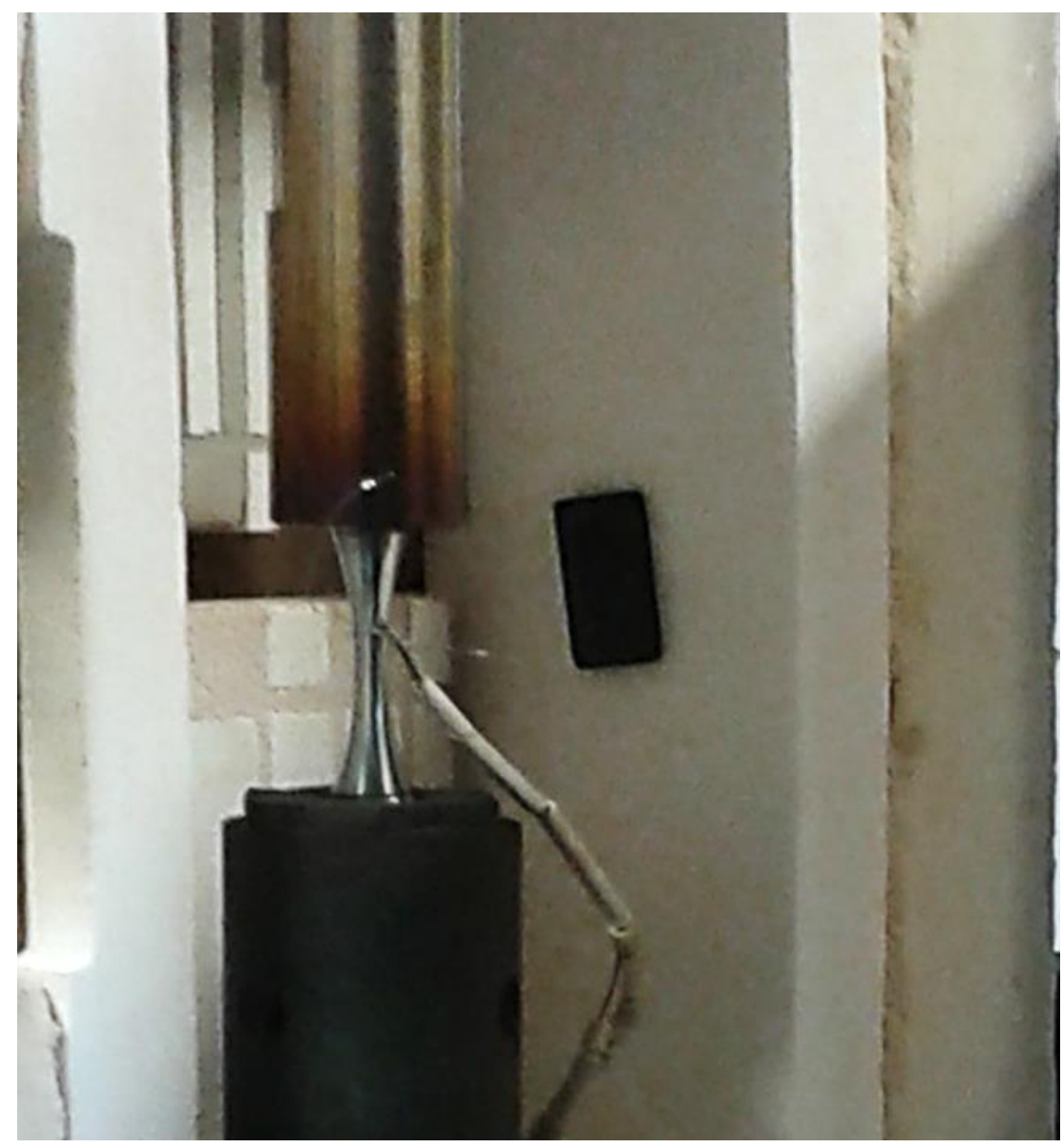

Figura 80 - Fixação do termopar ao corpo de prova.

Os ensaios de fadiga a quente foram realizados com amplitude de tensão $\left(\sigma_{a}\right)$ de $100 \mathrm{MPa}, 90 \mathrm{MPa}$, $80 \mathrm{MPa}$ e $72 \mathrm{MPa}, \mathrm{R}=-1$ e frequência de $30 \mathrm{~Hz}$.

Os ensaios de tração-compressão $(R=-1)$ são os que melhor representam 0 carregamento na borda de câmara dos pistões diesel, conforme Figura 81. 

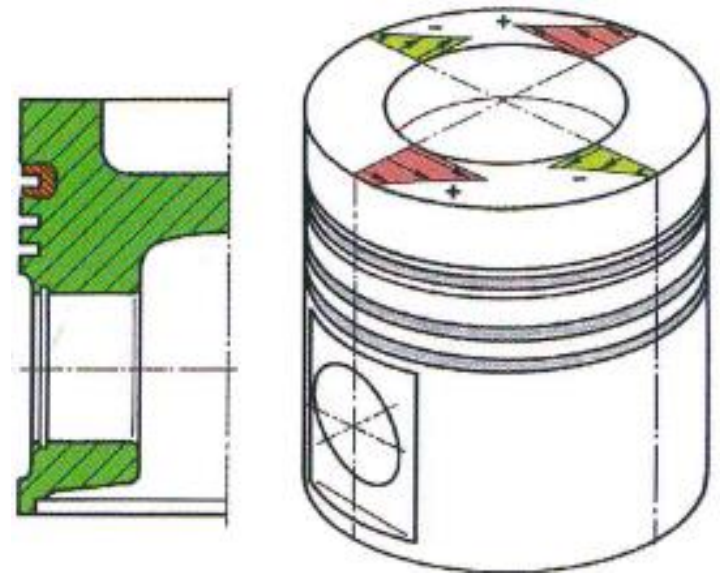

๑Esforços de tração $\Theta$ Esforços de compressão

Figura 81 - Esforços na borda de câmara de um pistão diesel. [Röhrle, 1995] 


\section{Resultados e discussões}

\subsection{Composição química}

A Tabela 11 mostra a composição química final das séries de amostras:

Tabela 11 - Composição química final das ligas.

\begin{tabular}{c|c|c|c|c|c|c|c|c|c|c}
\hline Série & $\mathbf{S i}$ & $\mathbf{C u}$ & $\mathbf{M g}$ & $\mathbf{N i}$ & $\mathbf{F e}$ & $\mathbf{P}$ & $\mathbf{Z r}$ & $\mathbf{V}$ & $\mathbf{T i}$ & $\mathbf{M n}$ \\
\hline $\begin{array}{c}\text { Referência } \\
\text { e R-TT }\end{array}$ & 12.74 & 0.97 & 0.99 & 0.907 & 0.169 & 0.0077 & 0.0006 & 0.0063 & 0.070 & 0.014 \\
\hline $\mathbf{R}-Z \mathbf{r}$ & 13.09 & 0.96 & 0.96 & 0.897 & 0.179 & 0.0075 & 0.1400 & 0.0076 & 0.010 & 0.017 \\
\hline $\mathbf{R}-Z r V$ & 13.06 & 1.05 & 1.04 & 0.948 & 0.212 & 0.0083 & 0.1300 & 0.1120 & 0.011 & 0.010 \\
\hline $\mathbf{R}-Z r V T i$ & 13.07 & 1.04 & 1.03 & 0.928 & 0.209 & 0.0082 & 0.1300 & 0.1210 & 0.125 & 0.011 \\
\hline $\mathbf{R}-Z r V T i M n$ & 13.04 & 1.04 & 1.01 & 0.999 & 0.215 & 0.0081 & 0.1280 & 0.1200 & 0.128 & 0.209
\end{tabular}

\subsection{Ensaios de fadiga a quente}

A princípio, foram realizados três ensaios de fadiga a quente para cada série, conforme apresentado na Tabela 13Error! Reference source not found.. Todos os ensaios foram realizados com amplitude de tensão de 80MPa.

A dureza de cada uma das séries foi medida após os ensaios de fadiga a quente (Tabela 12).

Tabela 12 - Resultados de dureza das séries após os ensaios de fadiga a quente.

\begin{tabular}{c|c}
\hline Série & Dureza (HB) \\
\hline Referência & 79,5 \\
\hline R-Zr & 74,7
\end{tabular}




\begin{tabular}{c|c} 
R-ZrV & 81,3 \\
\hline R-ZrVTi & 79,5 \\
\hline R-ZrVTiMn & 79,5 \\
\hline R-TT & 77,9
\end{tabular}

Tabela 13 - Resultados preliminares dos ensaios de fadiga a quente.

\begin{tabular}{c|c|c}
\hline Série & $\sigma_{\mathbf{a}}(\mathbf{M P a})$ & Ciclos \\
\hline Referência & 80 & 184254 \\
\hline Referência & 80 & 160262 \\
\hline Referência & 80 & 124937 \\
\hline $\mathrm{R}-\mathrm{Zr}$ & 80 & 163246 \\
\hline $\mathrm{R}-\mathrm{Zr}$ & 80 & 137066 \\
\hline $\mathrm{R}-\mathrm{Zr}$ & 80 & 197563 \\
\hline $\mathrm{R}-\mathrm{ZrV}$ & 80 & 208837 \\
\hline $\mathrm{R}-\mathrm{ZrV}$ & 80 & 75300 \\
\hline $\mathrm{R}-\mathrm{ZrV}$ & 80 & 148476 \\
\hline $\mathrm{R}-\mathrm{ZrVTi}$ & 80 & 169558 \\
\hline $\mathrm{R}-\mathrm{ZrVTi}$ & 80 & 190840 \\
\hline $\mathrm{R}-\mathrm{ZrVTi}$ & 80 & 207520 \\
\hline $\mathrm{R}-\mathrm{ZrVTiMn}$ & 80 & 204885 \\
\hline $\mathrm{R}-\mathrm{ZrVTiMn}$ & 80 & 244948 \\
\hline $\mathrm{R}-\mathrm{ZrVTiMn}$ & 80 & 131123 \\
\hline $\mathrm{R}-\mathrm{TT}$ & 80 & 270856 \\
\hline $\mathrm{R}-\mathrm{TT}$ & 80 & 170095 \\
\hline $\mathrm{R}-\mathrm{TT}$ & 80 & 281424
\end{tabular}

A Figura 82 mostra a comparação entre esses resultados, com as respectivas barras de erro associado. 


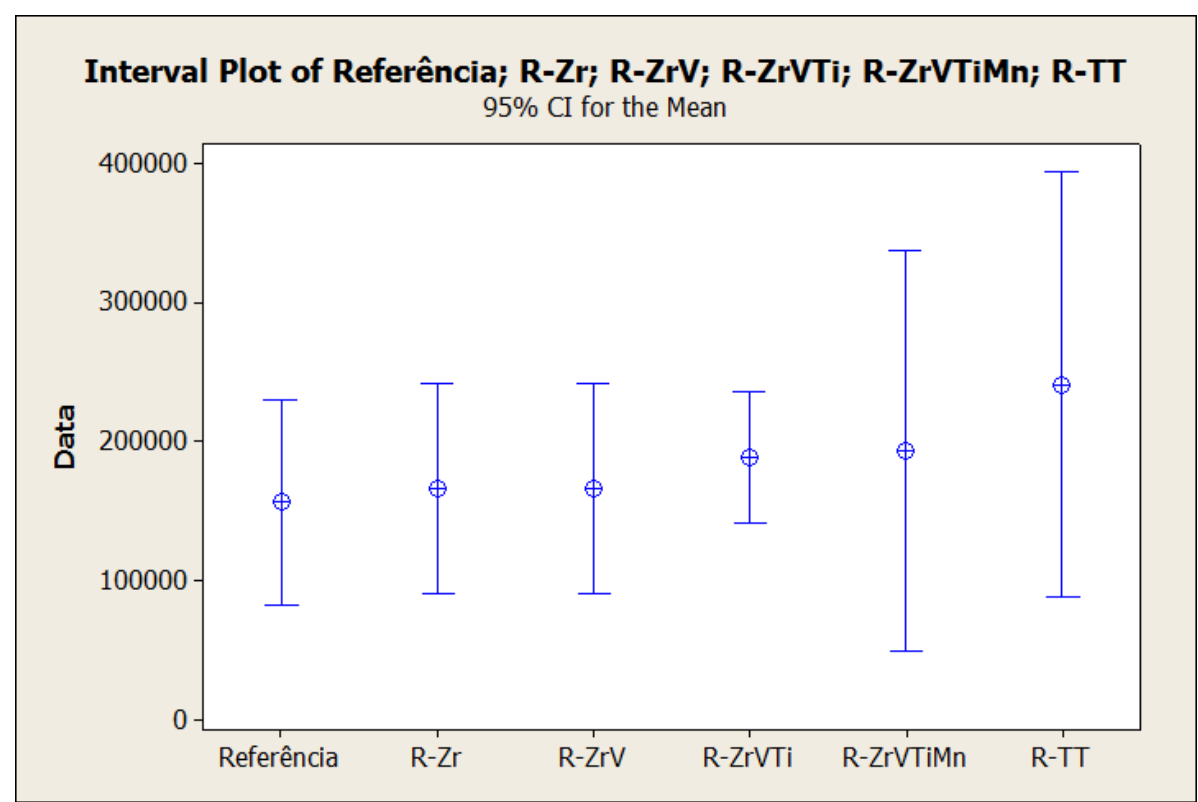

Figura 82 - Comparação entre os resultados preliminares de fadiga a quente.

Com apenas três resultados de fadiga a quente para cada série de material, não foi possível separar os resultados.

No entanto, foi possível definir alguns testes adicionais a fim de reduzir o erro associado a esses resultados.

A série $R-Z r$ foi interrompida por apresentar uma variabilidade pequena e, ainda assim, não mostrar sinais de melhoria com relação à série de referência.

A série R-ZrV foi interrompida devido à presença excessiva de feather crystals.

Uma nova bateria de ensaios foi realizada, aumentando o número de corpos de prova das séries de Referência, R-ZrVTi e R-TT para a mesma amplitude de tensão (80MPa). Os resultados obtidos estão apresentados na Tabela 14.

A Figura 83 mostra a comparação entre esses resultados, com as respectivas barras de erro associado.

Tabela 14 - Resultados dos ensaios de fadiga a quente $\left(\sigma_{a}=80 \mathrm{MPa}\right)$.

\begin{tabular}{c|c|c}
\hline Série & $\sigma_{\mathbf{a}}(\mathbf{M P a})$ & Ciclos \\
\hline Referência & 80 & 184254 \\
\hline Referência & 80 & 160262 \\
\hline Referência & 80 & 124937
\end{tabular}




\begin{tabular}{c|c|c} 
Referência & 80 & 139637 \\
\hline Referência & 80 & 79640 \\
\hline R-ZrVTi & 80 & 169558 \\
\hline R-ZrVTi & 80 & 190840 \\
\hline R-ZrVTi & 80 & 207520 \\
\hline R-ZrVTi & 80 & 103095 \\
\hline R-ZrVTi & 80 & 58814 \\
\hline R-ZrVTiMn & 80 & 204885 \\
\hline R-ZrVTiMn & 80 & 244948 \\
\hline R-ZrVTiMn & 80 & 131123 \\
\hline R-TT & 80 & 270856 \\
\hline R-TT & 80 & 170095 \\
\hline R-TT & 80 & 281424 \\
\hline R-TT & 80 & 318717 \\
\hline R-TT & 80 & 336842
\end{tabular}

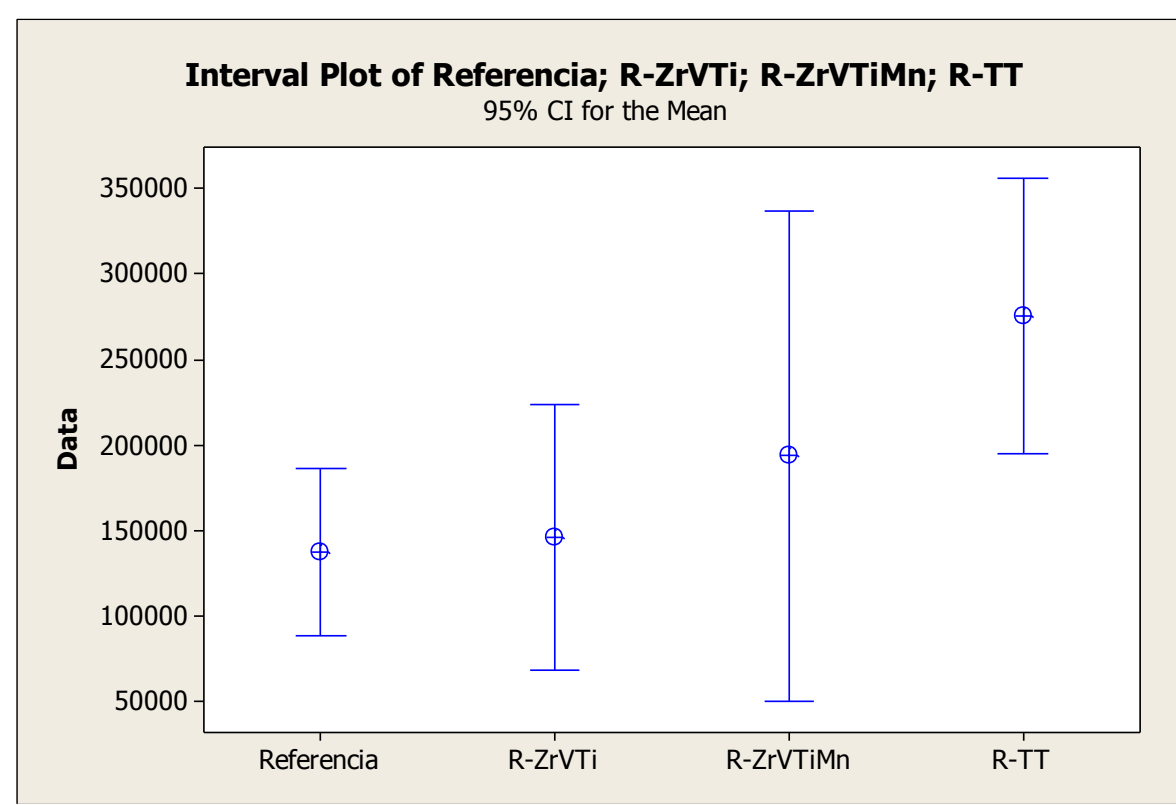

Figura 83 - Comparação entre os resultados de fadiga a quente $\left(\sigma_{a}=80 \mathrm{MPa}\right)$.

O boxplot, ou diagrama de caixa, é um gráfico que capta importantes aspectos de um conjunto de dados através do seu resumo dos cinco números, formado pelos seguintes valores: valor mínimo, primeiro quartil, mediana, terceiro quartil e valor máximo.

O gráfico boxplot dos resultados gerais de fadiga a quente com amplitude de tensão $80 \mathrm{MPa}$ é apresentado na Figura 84. 


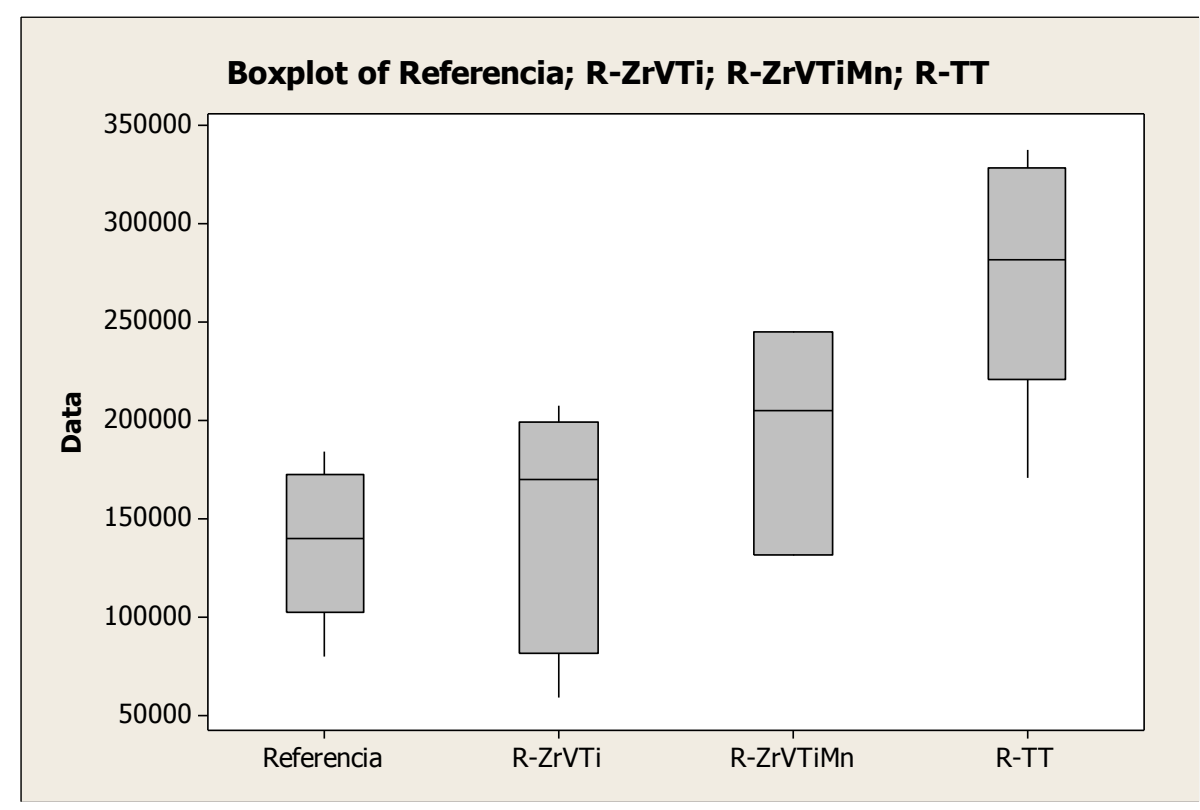

Figura 84 - Gráfico boxplot dos resultados de fadiga a quente $\left(\sigma_{\mathrm{a}}=80 \mathrm{MPa}\right)$ para as séries de referência, R-ZrVTi, R-ZrVTiMn e R-TT.

\subsubsection{Modelamento estatístico}

A fim de melhorar a análise dos resultados de fadiga, foi feito um modelamento estatístico dos dados.

No modelamento estatístico, assumiu-se que a variabilidade dos resultados dos ensaios de fadiga a quente é natural do material e não uma variável do ensaio.

Essa consideração leva a uma redução significativa dos erros residuais, isso é, as variações que não são explicadas pelo modelo proposto. Isso permite uma análise mais refinada, pois com um erro menor a capacidade de discernir diferenças aumenta, permitindo conclusões que não eram possíveis no início do trabalho (Figura 83). Para isso, algumas hipóteses foram feitas:

- A distribuição de vida pode ser bem representada por uma distribuição lognormal; 
- A curva de expectativa de vida em fadiga contra tensão alternada é uma reta no domínio log-log;

- As retas de expectativa de vida em fadiga possuem a mesma inclinação para as várias ligas e tratamentos discutidos nessa tese;

- As retas de expectativa de vida em fadiga (por exemplo B10 ou B90) são paralelas entre si, isso é, no domínio ensaiado a distribuição de vida é constante (Error! Reference source not found.).

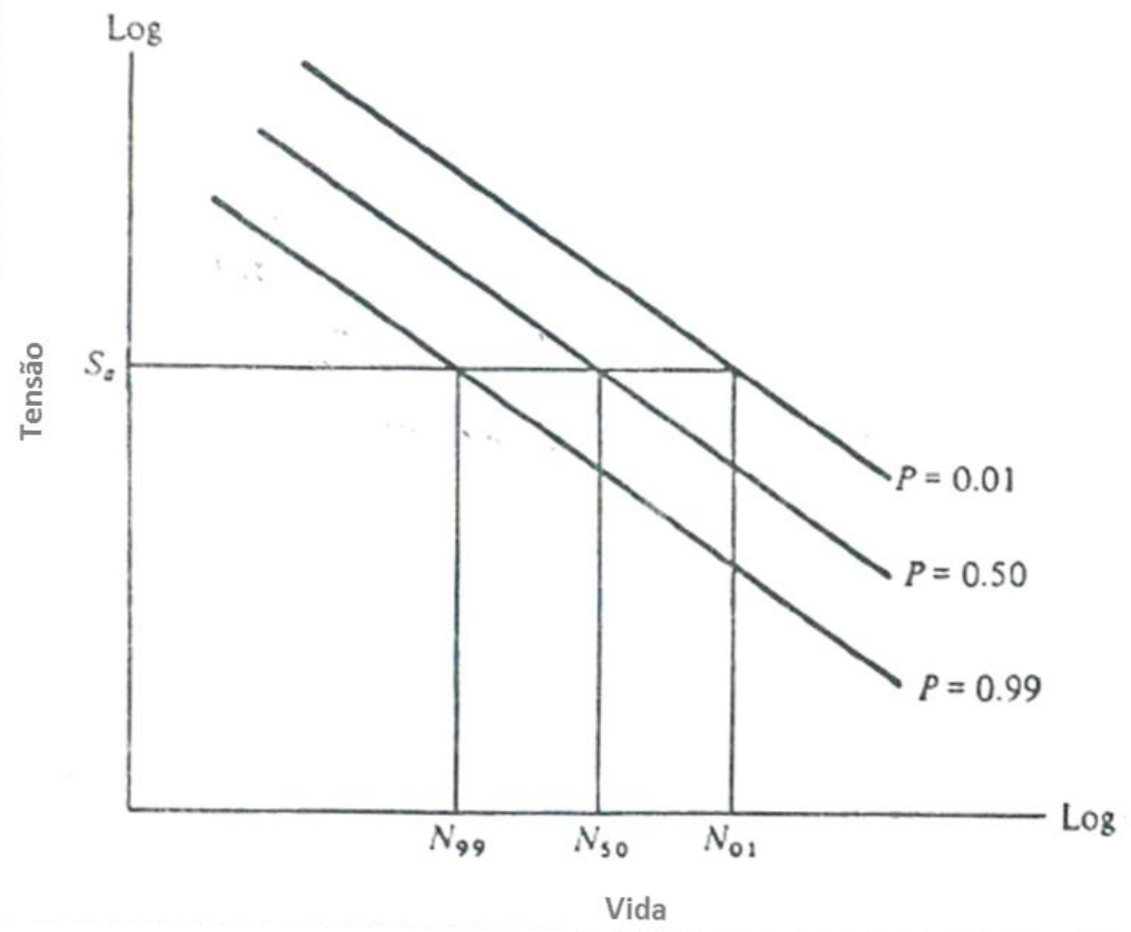

Figura 85 - Representação gráfica das retas de expectativa de vida em fadiga paralelas entre si [Lipson; Sheth, 1973].

Utilizando-se dessas hipóteses é possível criar um modelo matemático para explicar o comportamento das peças ensaiadas em fadiga. Esse modelo permite inclusive a utilização de amostras testadas em níveis de tensão diferentes.

$\mathrm{Na}$ tentativa de separar os resultados obtidos para cada série de material e determinar a inclinação da curva de expectativa de vida, alguns ensaios a 72MPa, $80 \mathrm{MPa}, 90 \mathrm{MPa}$ e 100MPa foram realizados. Os resultados são apresentados na Tabela 15. 
Tabela 15 - Resultados dos ensaios de fadiga a quente ( $\sigma_{a}=100 \mathrm{MPa}, 90 \mathrm{MPa}, 80 \mathrm{MPa}$ e $\left.72 \mathrm{MPa}\right)$.

\begin{tabular}{c|c|c|c}
\hline$\#$ & Série & $\sigma_{\mathbf{a}}$ & Ciclos \\
\hline $\mathbf{1}$ & Referência & 80 & 184254 \\
\hline $\mathbf{2}$ & Referência & 80 & 160262 \\
\hline $\mathbf{3}$ & Referência & 80 & 124937 \\
\hline $\mathbf{4}$ & Referência & 80 & 139637 \\
\hline $\mathbf{5}$ & Referência & 80 & 79640 \\
\hline $\mathbf{6}$ & Referência & 72 & 288595 \\
\hline $\mathbf{7}$ & Referência & 72 & 338368 \\
\hline $\mathbf{8}$ & R-Zr & 90 & 53000 \\
\hline $\mathbf{9}$ & R-Zr & 80 & 163246 \\
\hline $\mathbf{1 0}$ & R-Zr & 80 & 137066 \\
\hline $\mathbf{1 1}$ & R-Zr & 80 & 197563 \\
\hline $\mathbf{1 2}$ & R-ZrV & 100 & 18000 \\
\hline $\mathbf{1 3}$ & R-ZrV & 80 & 208837 \\
\hline $\mathbf{1 4}$ & R-ZrV & 80 & 75300 \\
\hline $\mathbf{1 5}$ & R-ZrV & 80 & 148476 \\
\hline $\mathbf{1 6}$ & R-ZrVTi & 80 & 169558 \\
\hline $\mathbf{1 7}$ & R-ZrVTi & 80 & 190840 \\
\hline $\mathbf{1 8}$ & R-ZrVTi & 80 & 207520 \\
\hline $\mathbf{1 9}$ & R-ZrVTi & 80 & 103095 \\
\hline $\mathbf{2 0}$ & R-ZrVTi & 80 & 58814 \\
\hline $\mathbf{2 1}$ & R-ZrVTiMn & 80 & 204885 \\
\hline $\mathbf{2 2}$ & R-ZrVTiMn & 80 & 244948 \\
\hline $\mathbf{2 3}$ & R-ZrVTiMn & 80 & 131123 \\
\hline $\mathbf{2 4}$ & R-ZrVTiMn & 72 & 377470 \\
\hline $\mathbf{2 5}$ & R-ZrVTiMn & 72 & 362491 \\
\hline $\mathbf{2 6}$ & R-ZrVTiMn & 72 & 390780 \\
\hline $\mathbf{2 7}$ & R-TT & 80 & 270856 \\
\hline $\mathbf{2 8}$ & R-TT & 80 & 170095 \\
\hline $\mathbf{2 9}$ & R-TT & 80 & 318717 \\
\hline $\mathbf{3 0}$ & R-TT & 80 & 336842 \\
\hline $\mathbf{3 1}$ & R-TT & 72 & \\
\hline $\mathbf{3 2}$ & R-TT & & \\
\hline & & 80729 \\
\hline
\end{tabular}

Ao ajustar os dados ao modelo estatístico existe uma parcela que não pode ser explicada pelo modelo, chamados residuais. Os residuais podem ser normalizados 
(divididos pela estimativa de desvio padrão dos próprios) e analisados quanto à normalidade, o que é útil para identificar resultados discrepantes e verificar a validade do modelo.

Peças que apresentaram alguma anomalia na superfície de fratura foram desconsideradas. As peças dos ensaios de número 12 e 14 apresentaram feather crystals e, portanto, seus residuais foram desconsiderados.

Devido à presença de feather crystals nas superfícies de fratura da liga R-ZrV, foi realizada uma análise macroestrutural das ligas. As macroestruturas encontradas estão apresentadas na Figura 86 à Figura 90.

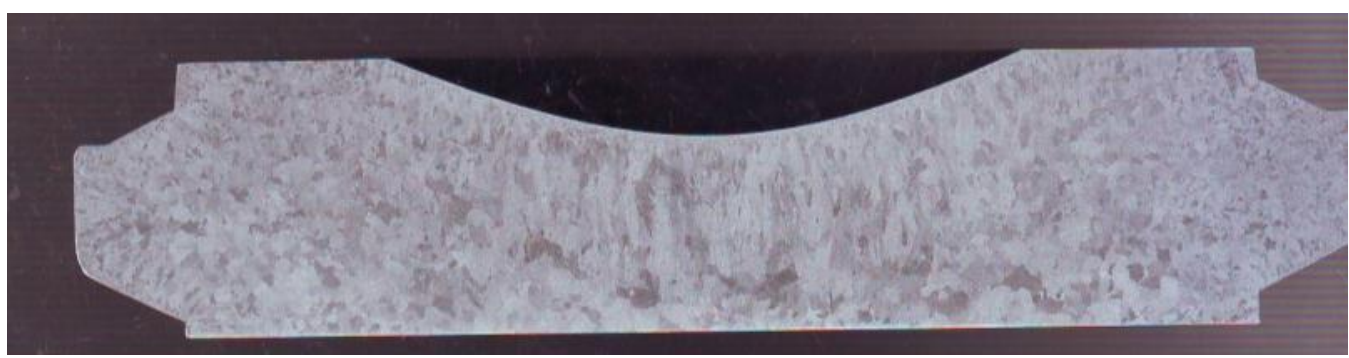

Figura 86 - Macrografia da liga de referência.

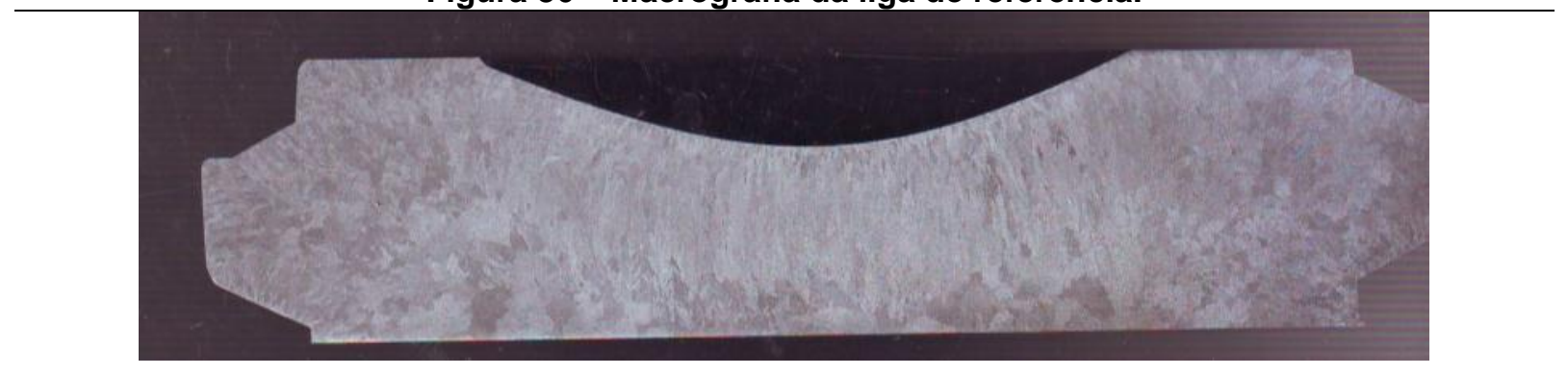

Figura 87 - Macrografia da liga R-Zr.

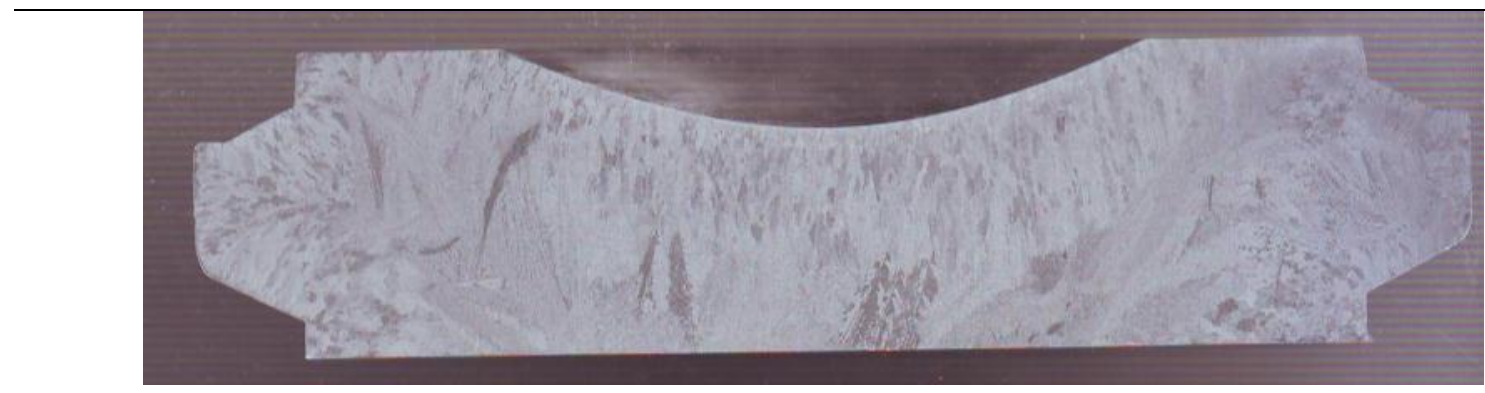

Figura 88 - Macrografia da liga R-ZrV. 


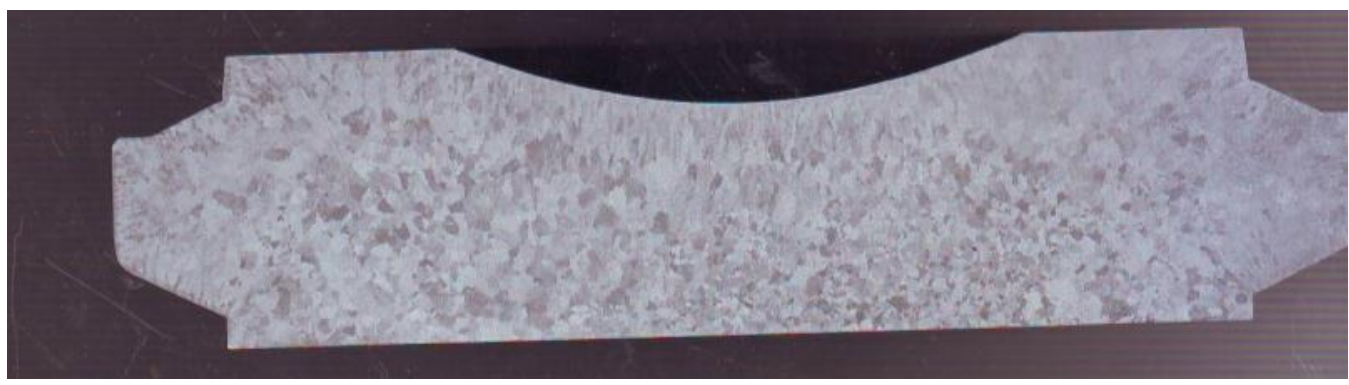

Figura 89 - Macrografia da liga R-ZrVTi.

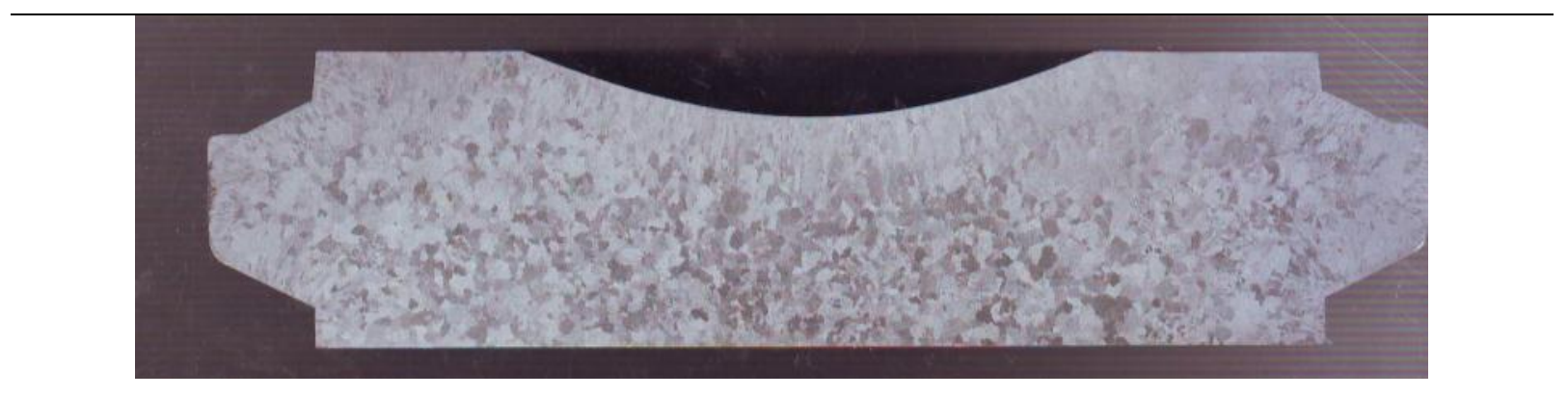

Figura 90 - Macrografia da liga R-ZrVTiMn.

De acordo com as macrografias, nota-se que a adição de zircônio aumenta o tamanho dos grãos equiaxiais e torna os grãos colunares mais finos e mais longos.

A adição de vanádio gera uma estrutura repleta de feather crystals.

A adição de titânio refina e o manganês não tem efeito sobre a macroestrutura da liga.

Em ligas de alumínio, feather crystals são um tipo de morfologia dos grãos de alumínio. Feather crystals são cristais de alumínio formados por dendritas macladas e podem resultar em uma redução das propriedades mecânicas do material. Sua nucleação e crescimento estão associados a determinadas condições de transferência e fluxo de calor e composição química da liga. [Turchin et al., 2007]

A Figura 91 apresenta o teste de verificação de normalidade dos residuais. 


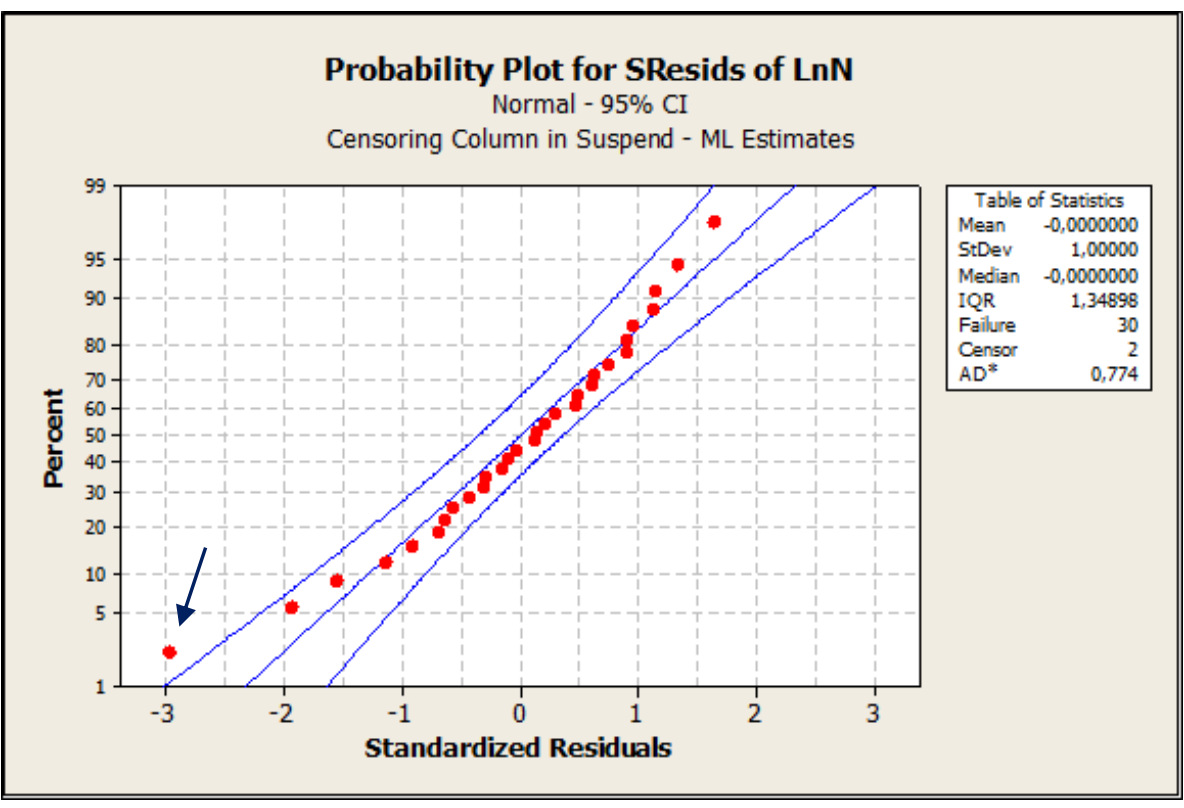

Figura 91 - Teste de normalidade dos residuais.

Nota-se que um ponto à esquerda na Figura 91 que foge ao modelo. Este ponto corresponde ao ensaio de número 20.

Excluindo-se este ensaio, pode-se considerar que todos os outros resultados são explicados pelo modelo proposto, conforme a Figura 92.

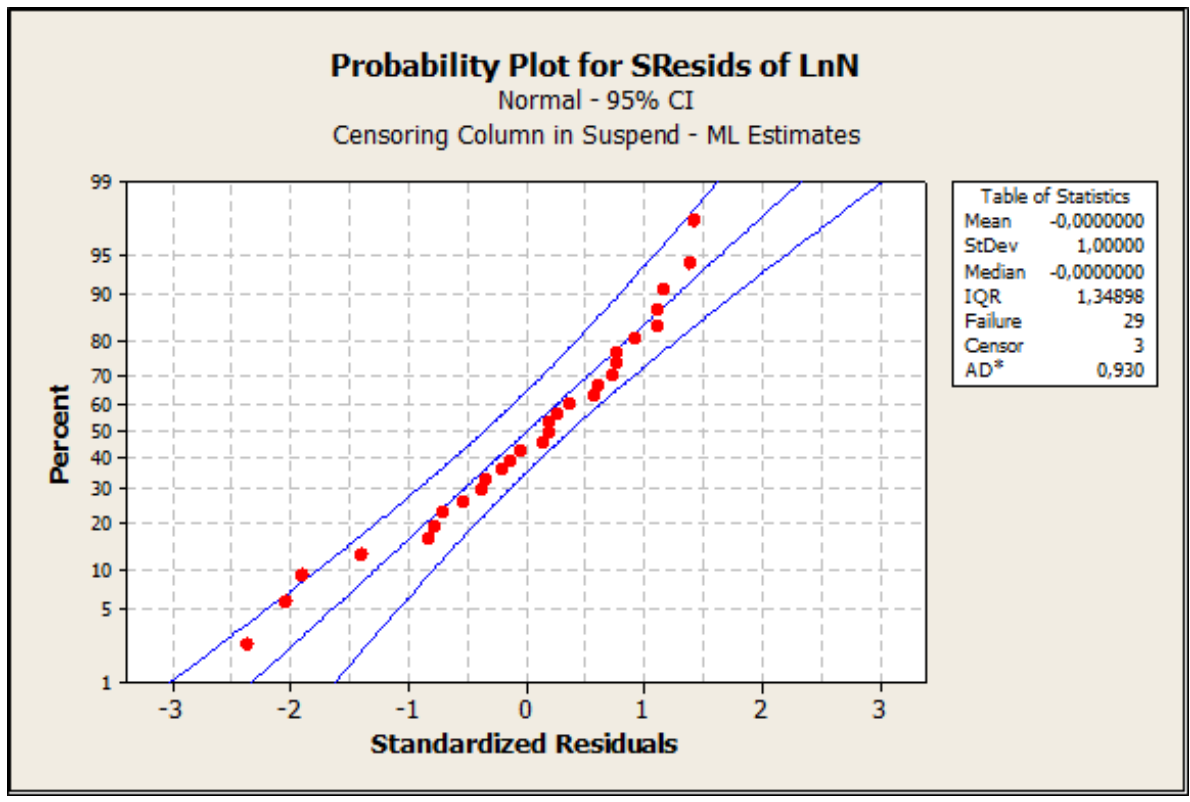

Figura 92 - Teste de normalidade dos residuais, excluindo-se resultados discrepantes. 
A Figura 93 apresenta o resultado do modelamento estatístico: a vida média em fadiga a $300^{\circ} \mathrm{C}$ com amplitude de tensão de $76 \mathrm{MPa}$ (média entre $72 \mathrm{MPa}$ e $80 \mathrm{MPa}$ ) e intervalo de confiança de 95\%. A altura das barras vermelhas representa o intervalo de confiança. Isso quer dizer que quando duas barras têm alturas distintas podemos afirmar que existe evidência estatística suficiente para considerar as vidas médias diferentes. Quando as barras tem uma região nas quais elas coexistem na altura não podemos concluir que os as médias são diferentes.

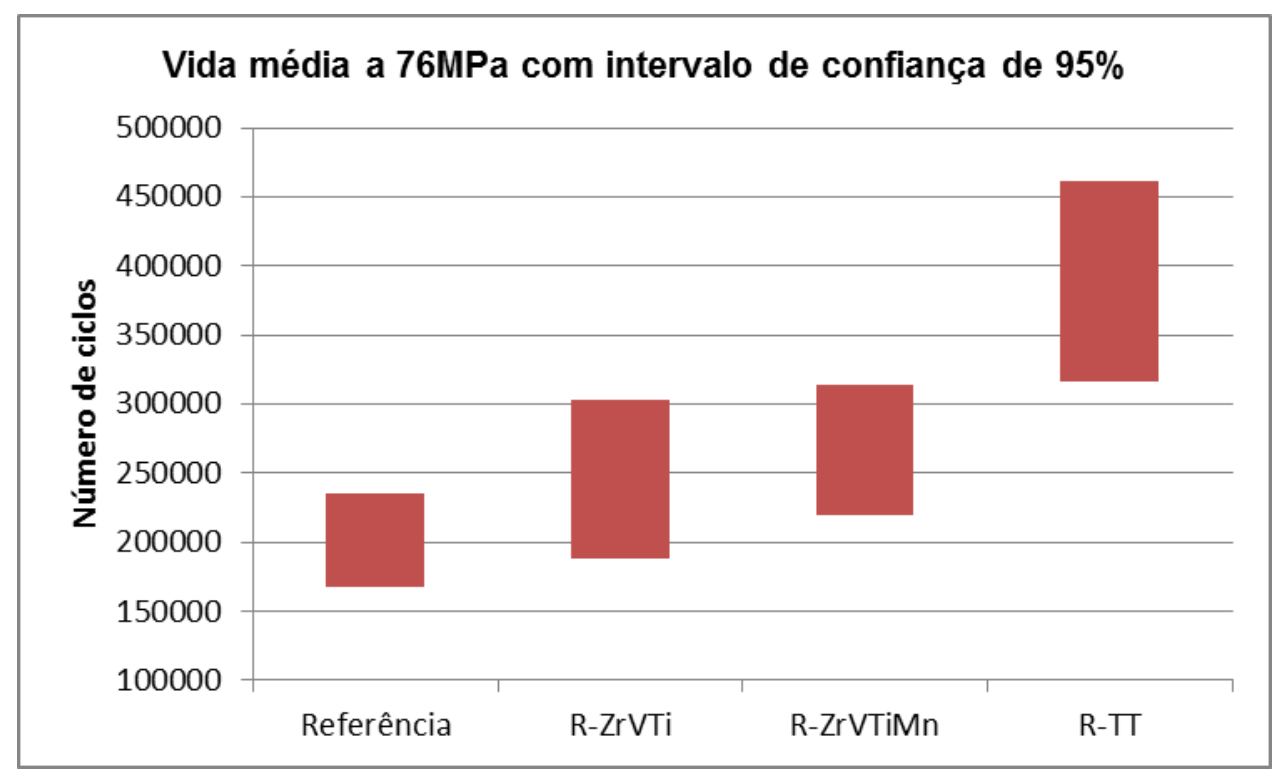

Figura 93 - Gráfico da vida média em fadiga com amplitude de tensão de $76 \mathrm{MPa}$ e intervalo de confiança de $95 \%$. 


\subsection{Efeito do tratamento térmico}

Quando foi definida a alteração do tratamento térmico de solubilização de $500^{\circ} \mathrm{C}$ por uma hora (Referência) para $525^{\circ} \mathrm{C}$ por quinze minutos (demais séries), visava-se exclusivamente a obtenção de um tratamento térmico economicamente viável para uma liga com adição de elementos de liga de baixa cinética de difusão no alumínio.

Excluindo-se a variável de composição química e comparando-se as séries de Referência e R-TT (com variação apenas no tratamento térmico), nota-se que há diferenças significativas no comportamento destes materiais (Figura 94).

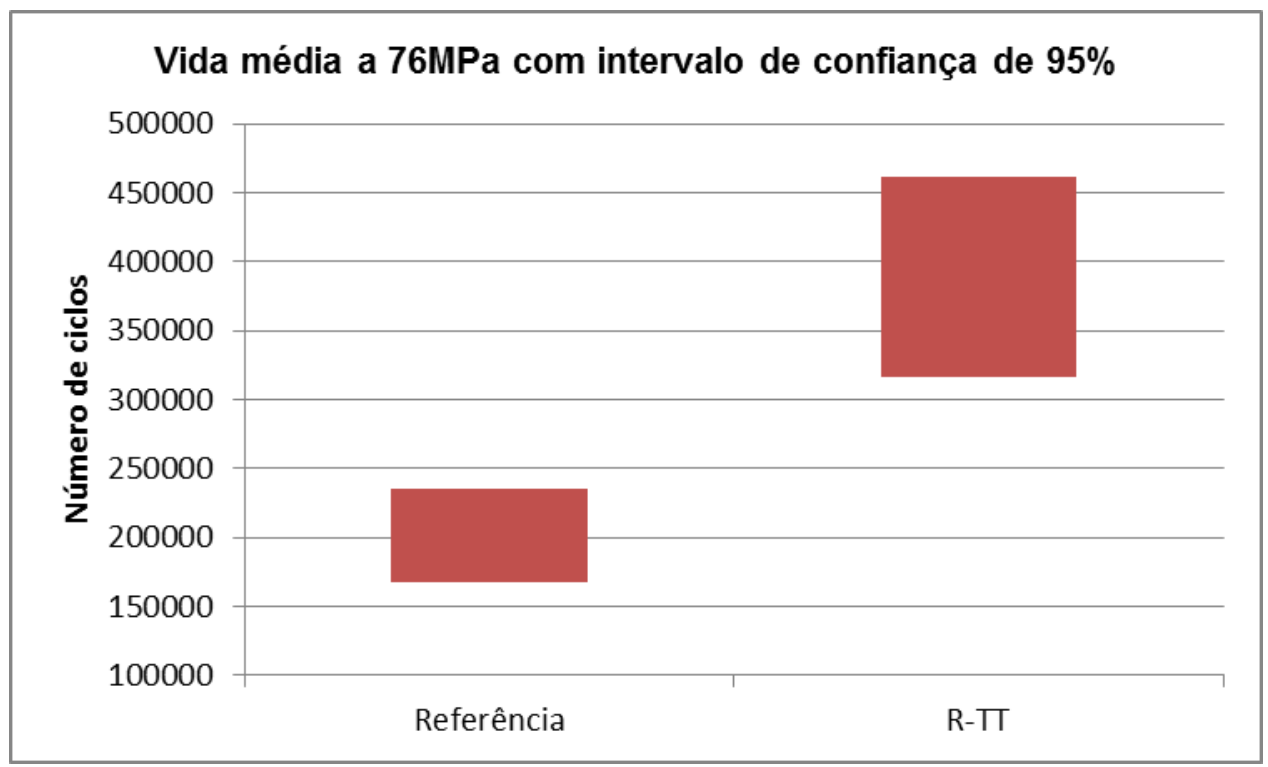

Figura 94 - Gráfico da vida média em fadiga com amplitude de tensão de 80MPa e intervalo de confiança de $95 \%$ para as séries de referência e R-TT.

Os resultados de vida média em fadiga a $300^{\circ} \mathrm{C}$ das séries de Referência e R-TT são estatisticamente diferentes entre si e a vida média da série R-TT é maior que a da série de Referência.

A fim de entender a diferença entre as séries de Referência e R-TT, foram comparadas as microestruturas, tanto por microscopia óptica (Figura 95 e Figura 96), quanto por microscopia eletrônica (Figura 97 a Figura 100). 


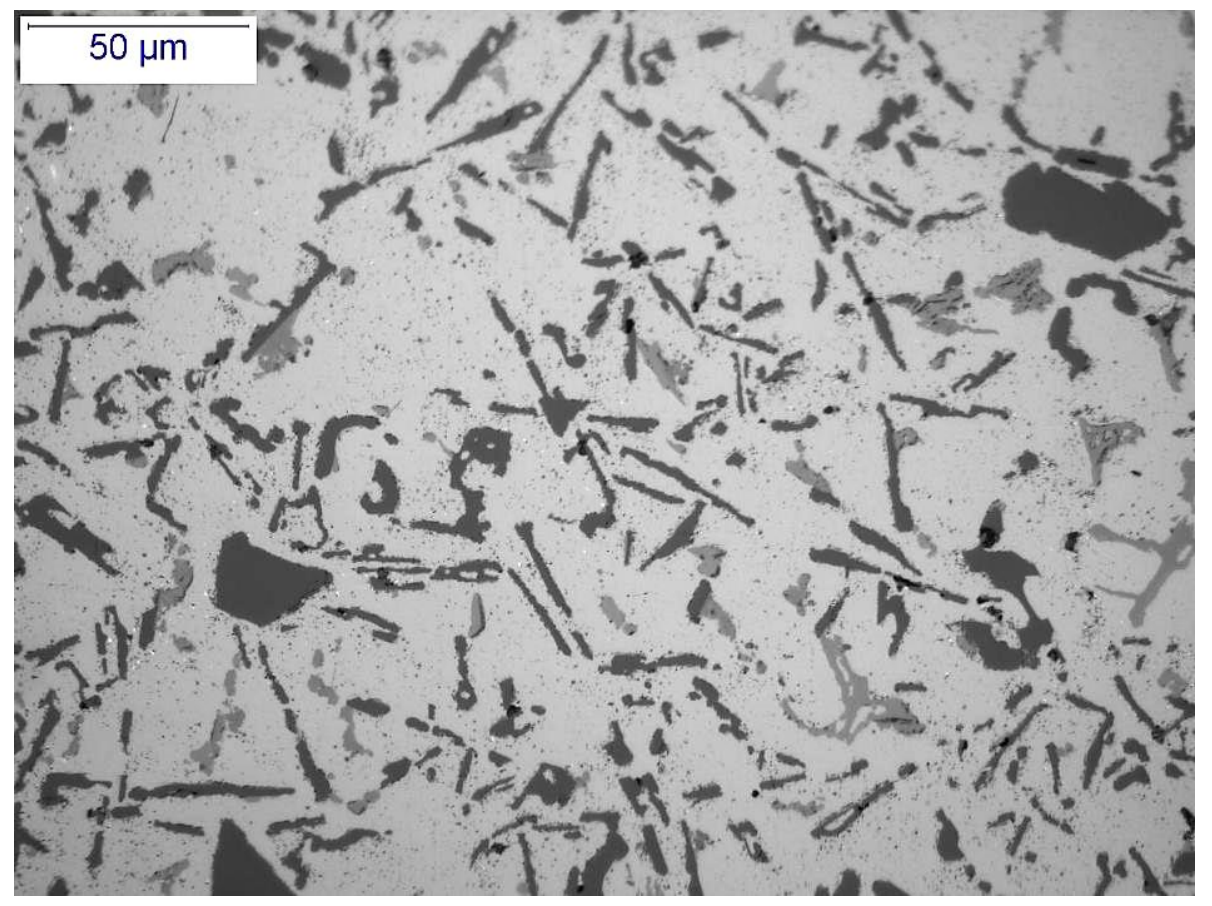

Figura 95 - Série de Referência (500x).

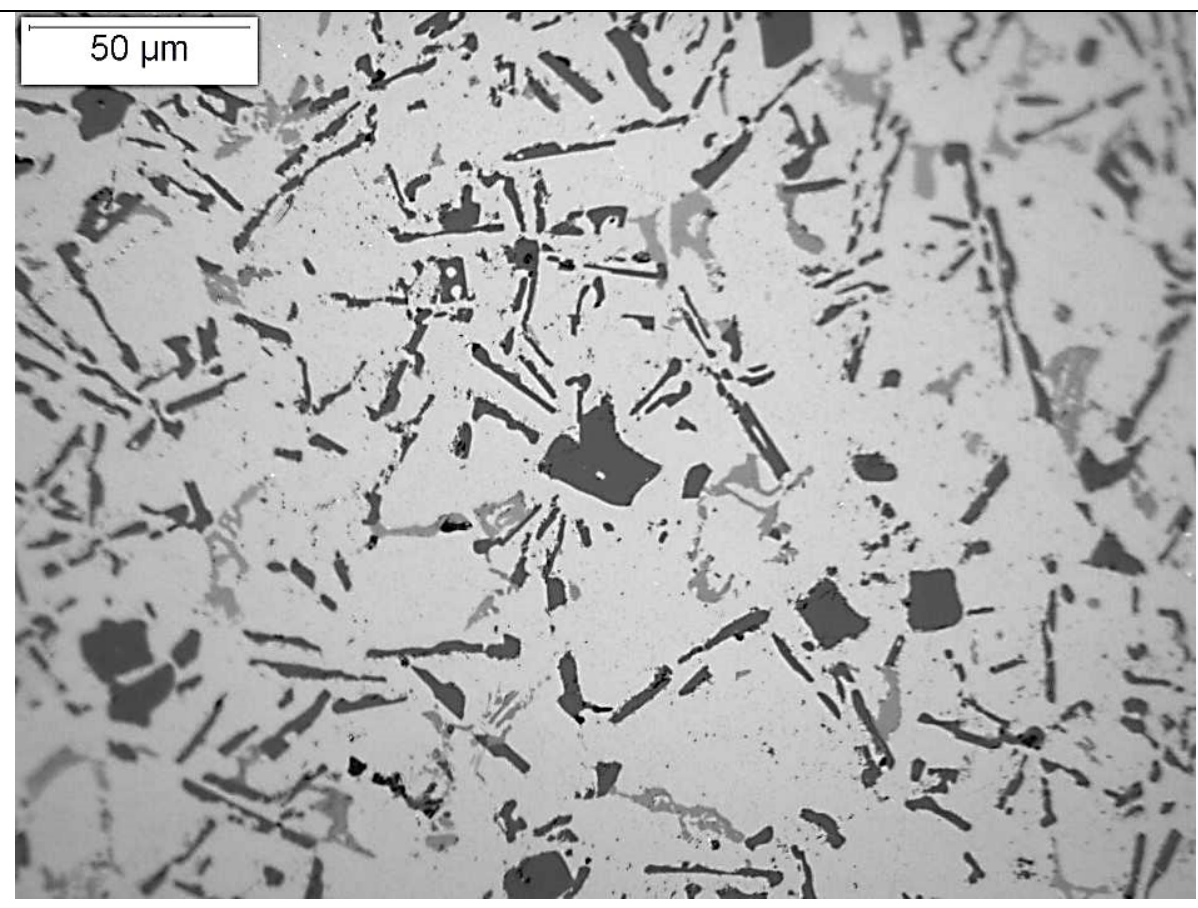

Figura 96 - R-TT (500x). 


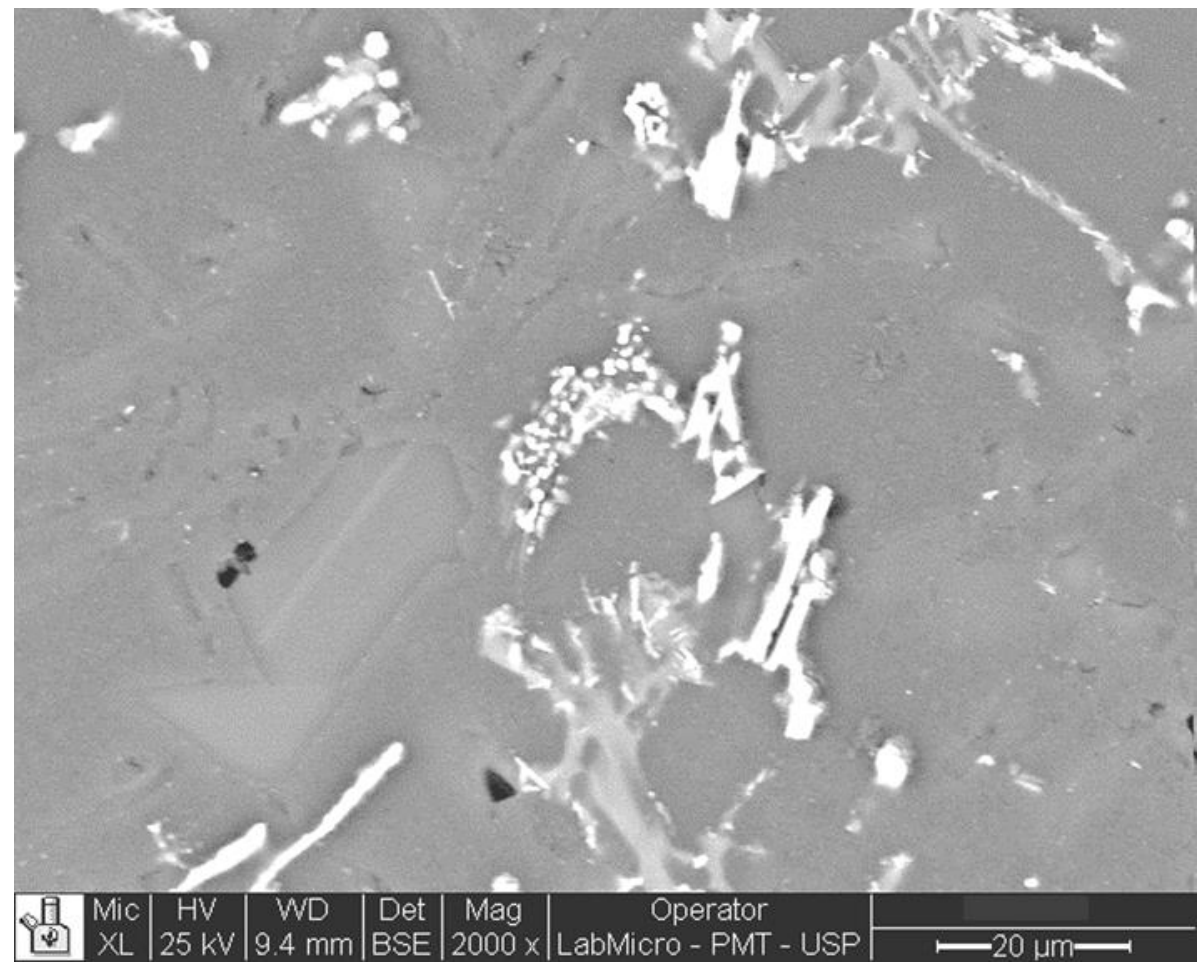

Figura 97 - Série de Referência (2000x).

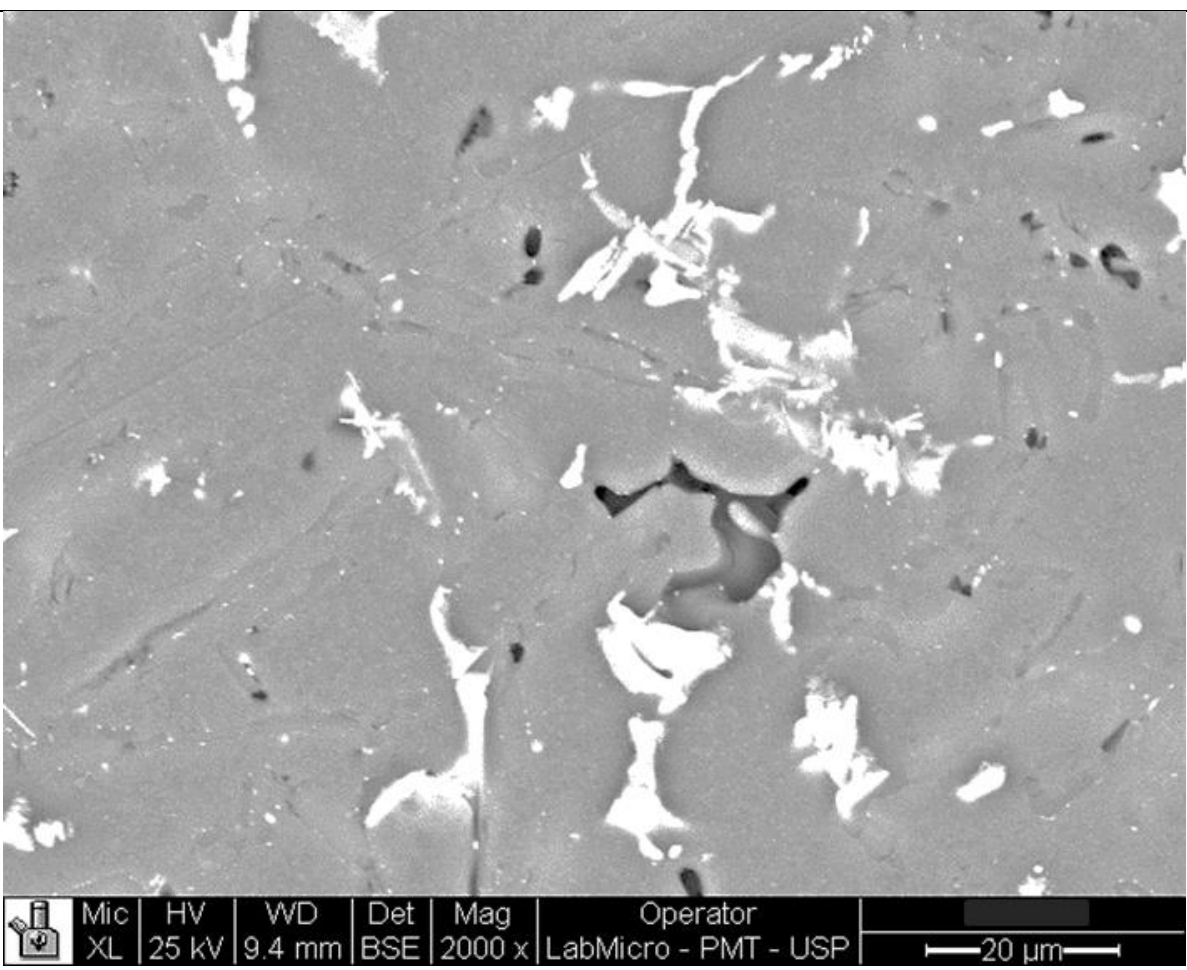

Figura 98 - Série de Referência (2000x). 


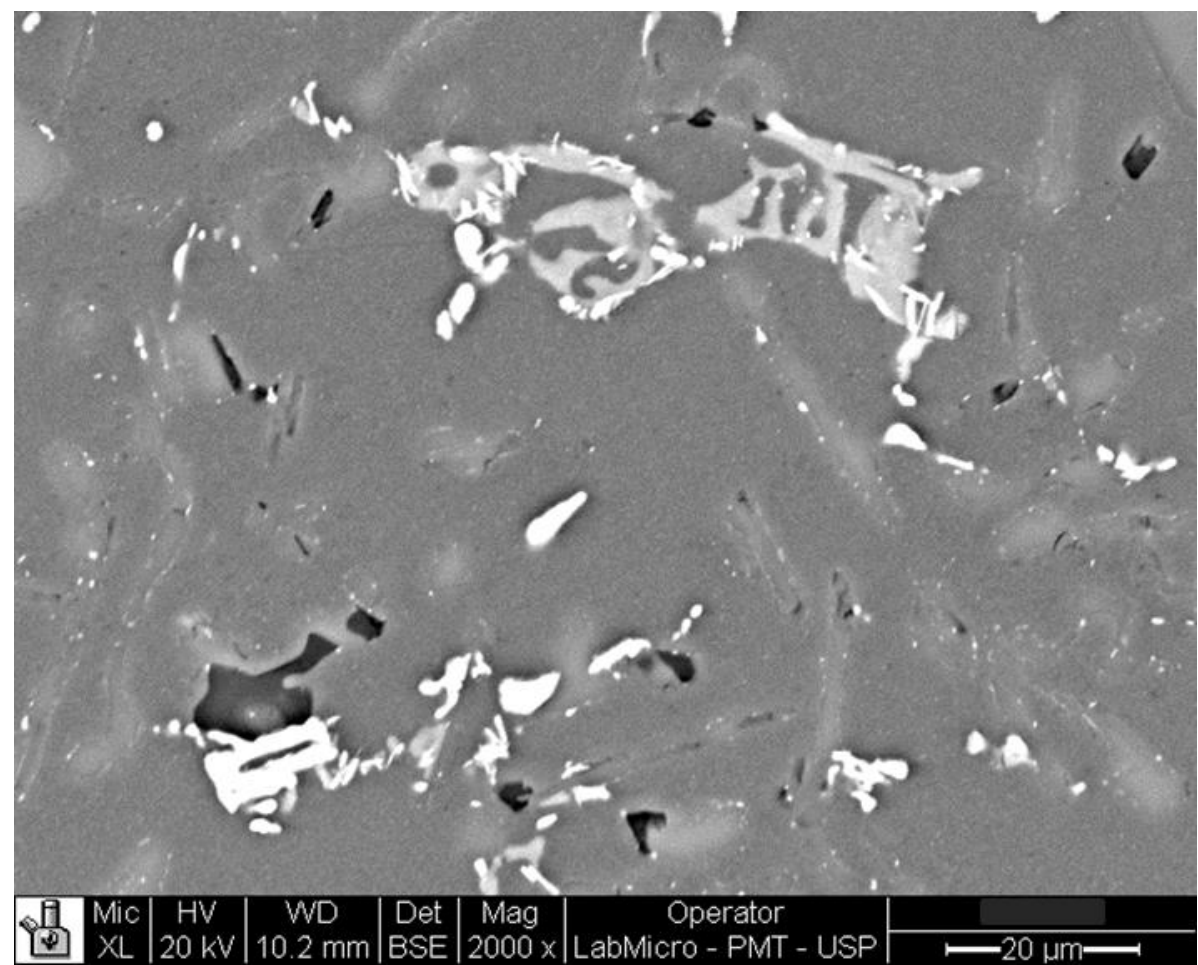

Figura 99 - Série de R-TT (2000x).

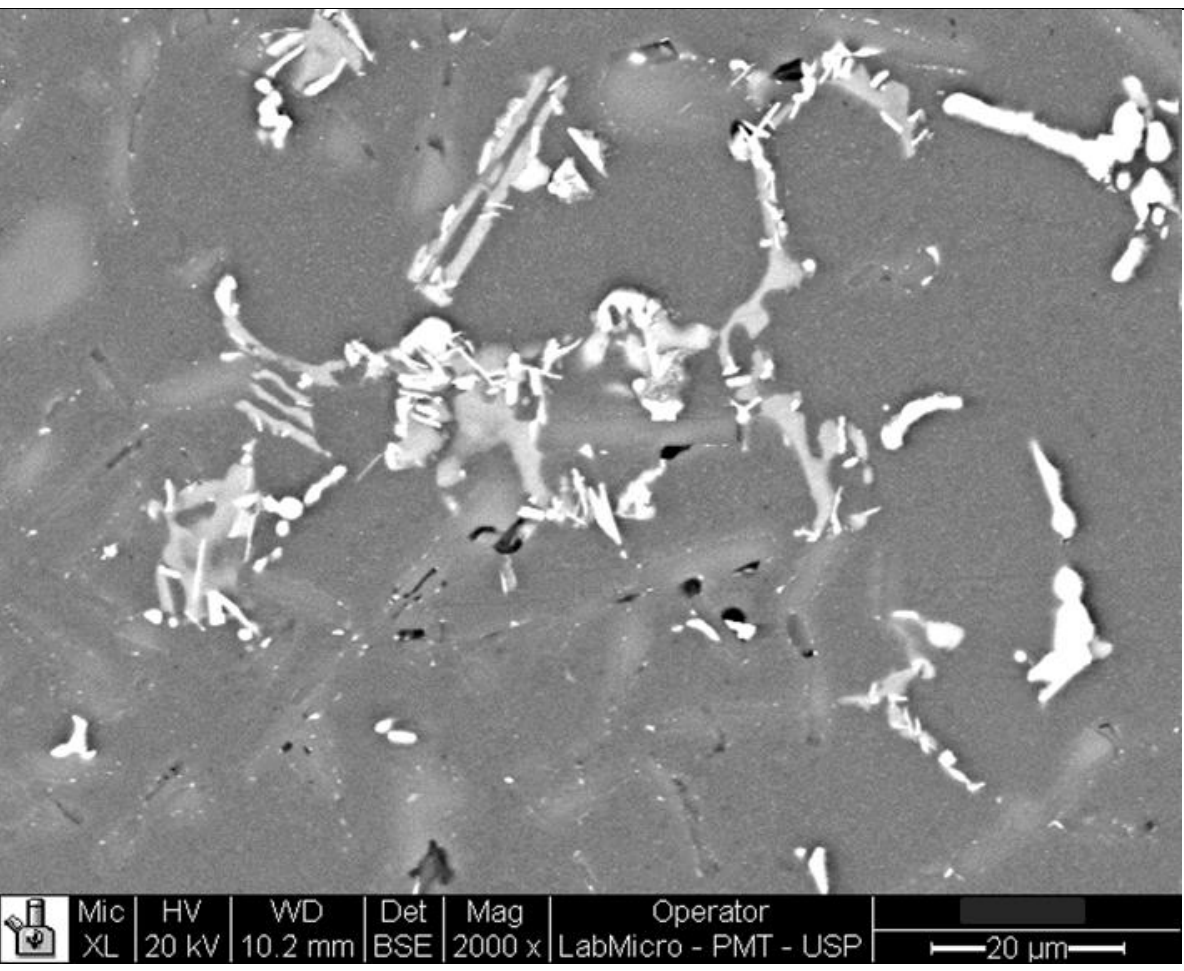

Figura 100 - Série de R-TT (2000x). 
Pela mera observação microestrutural, não é possível notar diferenças significativas entre as séries de Referência e R-TT.

As superfícies de fratura dos corpos de prova de fadiga foram analisadas a fim de identificar a presença de algum defeito de fundição que pudesse ter levado à falha prematura do material e identificar alguma anomalia no ponto de início da trinca, conforme a Tabela 16.

Em parte dos experimentos, após o rompimento do corpo de prova, o equipamento ainda concluiu mais um ciclo, amassando as superfícies e impossibilitando a análise.

Os demais corpos de prova foram analisados por microscopia eletrônica.

As amostras 1(série de referência), 9 (série R-Zr), 14 (R-ZrV), 17 (R-ZrVTi), 22 (RZrVTiMn) e 32 (R-TT) foram analisadas em microscopia óptica na região próxima ao ponto de início da trinca.

Defeitos de fundição não foram encontrados em nenhuma das amostras.

Analisando-se as superfícies de fratura dos corpos de prova de fadiga a $300^{\circ} \mathrm{C}$, nota-se que existe uma tendência de nucleação preferencial das trincas em partículas de silício primário de tamanho grande (Tabela 16). 
Tabela 16 - Avaliação da presença de anomalias no ponto de início da trinca.

\begin{tabular}{l|l|l}
\hline$\#$ & Série & Observações \\
\hline $\mathbf{1}$ & Referência & Partícula de silício no início da fratura \\
\hline $\mathbf{2}$ & Referência & Partícula de silício no início da fratura \\
\hline $\mathbf{3}$ & Referência & Nenhuma anomalia encontrada \\
\hline $\mathbf{4}$ & Referência & Amassamento superficial \\
\hline $\mathbf{5}$ & Referência & Amassamento superficial \\
\hline $\mathbf{6}$ & Referência & Amassamento superficial \\
\hline $\mathbf{7}$ & Referência & Amassamento superficial \\
\hline $\mathbf{8}$ & R-Zr & Amassamento superficial \\
\hline $\mathbf{9}$ & R-Zr & Partícula de silício no início da fratura \\
\hline $\mathbf{1 0}$ & R-Zr & Grão de alumínio no início da fratura \\
\hline $\mathbf{1 1}$ & R-Zr & Nenhuma anomalia encontrada \\
\hline $\mathbf{1 2}$ & R-ZrV & Amassamento superficial \\
\hline $\mathbf{1 3}$ & R-ZrV & Nenhuma anomalia encontrada \\
\hline $\mathbf{1 4}$ & R-ZrV & Presença de feather crystals \\
\hline $\mathbf{1 5}$ & R-ZrV & Amassamento superficial \\
\hline $\mathbf{1 6}$ & R-ZrVTi & Partícula de silício no início da fratura \\
\hline $\mathbf{1 7}$ & R-ZrVTi & Partícula de silício no início da fratura \\
\hline $\mathbf{1 8}$ & R-ZrVTi & Partícula de silício no início da fratura \\
\hline $\mathbf{1 9}$ & R-ZrVTi & Partícula de silício no início da fratura \\
\hline $\mathbf{2 0}$ & R-ZrVTi & Amassamento superficial \\
\hline $\mathbf{2 1}$ & R-ZrVTiMn & Nenhuma anomalia encontrada \\
\hline $\mathbf{2 2}$ & R-ZrVTiMn & Nenhuma anomalia encontrada \\
\hline $\mathbf{2 3}$ & R-ZrVTiMn & Partícula de silício no início da fratura \\
\hline $\mathbf{2 4}$ & R-ZrVTiMn & Amassamento superficial \\
\hline $\mathbf{2 5}$ & R-ZrVTiMn & Amassamento superficial \\
\hline $\mathbf{2 6}$ & R-ZrVTiMn & Amassamento superficial \\
\hline $\mathbf{2 7}$ & R-TT & Nenhuma anomalia encontrada \\
\hline $\mathbf{2 8}$ & R-TT & Partícula de silício no início da fratura \\
\hline $\mathbf{2 9}$ & R-TT & Partícula de silício no início da fratura \\
\hline $\mathbf{3 0}$ & R-TT & Partícula de silício no início da fratura \\
\hline $\mathbf{3 1}$ & R-TT & Amassamento superficial \\
\hline $\mathbf{3 2}$ & R-TT & Amassamento superficial \\
\hline
\end{tabular}

As superfícies de fratura que não sofreram amassamento superficial estão apresentadas na Figura 101 até a Figura 138. 


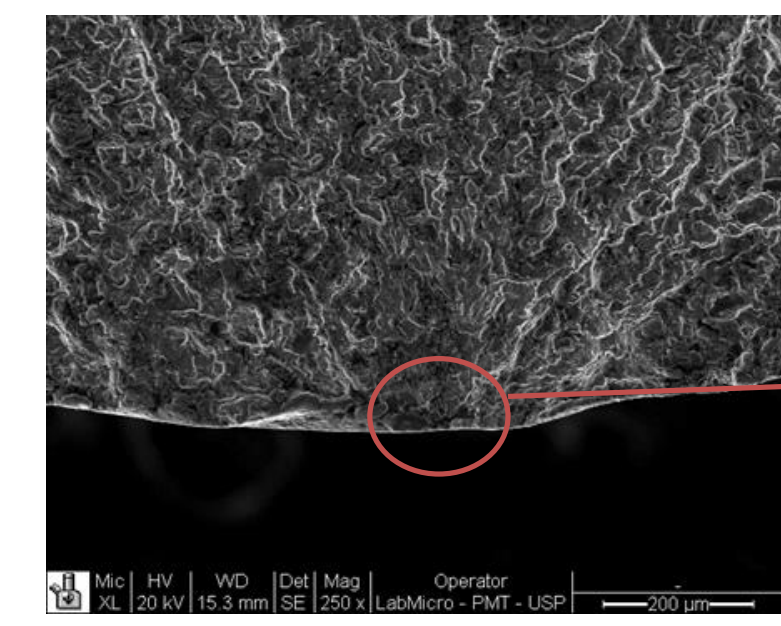

Figura 101 - Amostra 1: região de início da fratura (250x - SE).

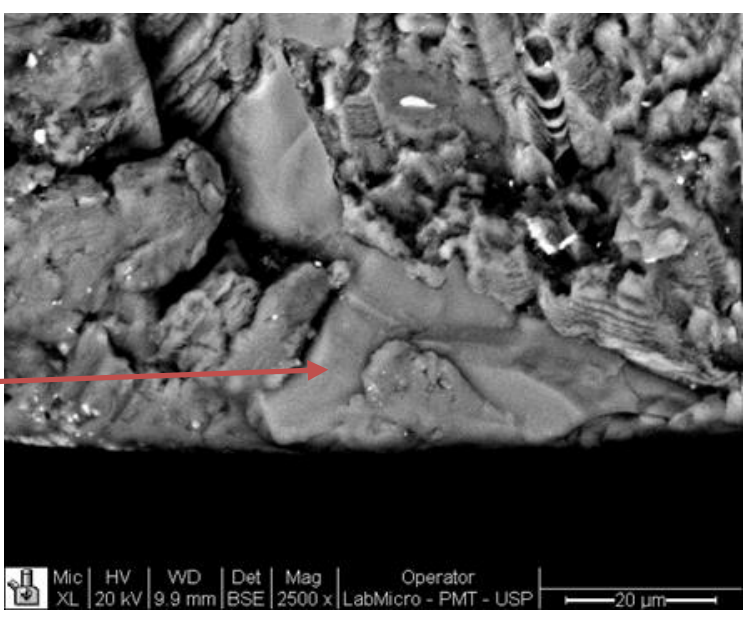

Figura 102 - Amostra 1: partícula de silício no início da fratura (2500x - BSE).
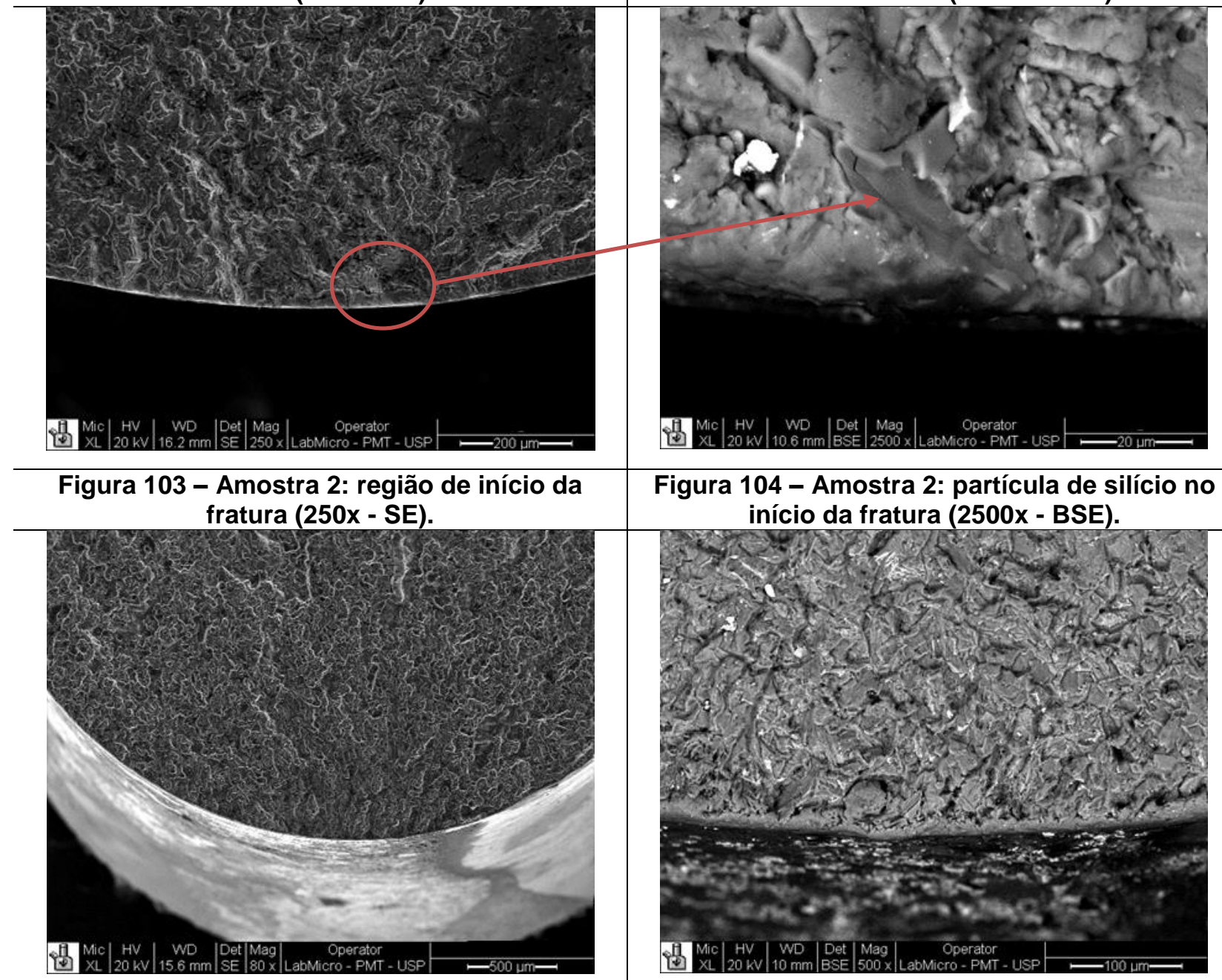

Figura 105 - Amostra 3: região de início da fratura $(80 x-S E)$.
Figura 104 - Amostra 2: partícula de silício no início da fratura (2500x - BSE).

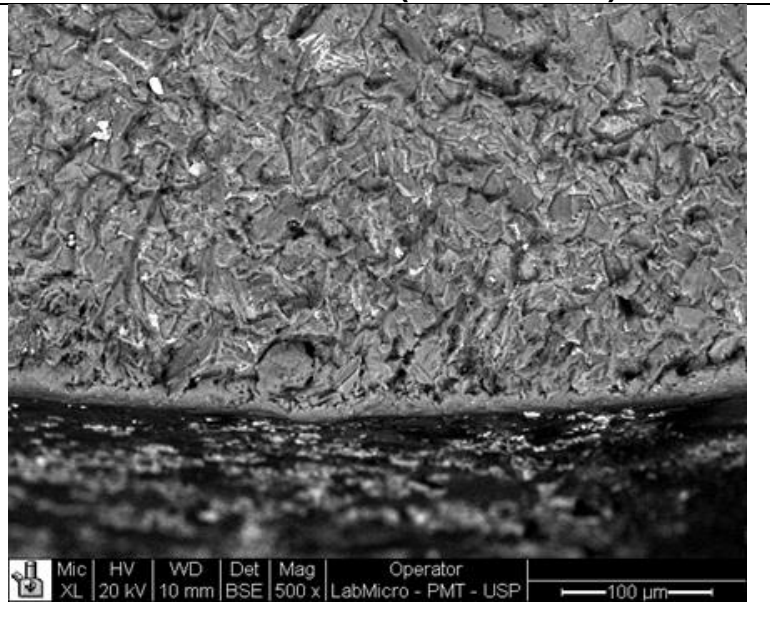

Figura 106 - Amostra 3: nenhuma anomalia no início da fratura (500x - BSE). 


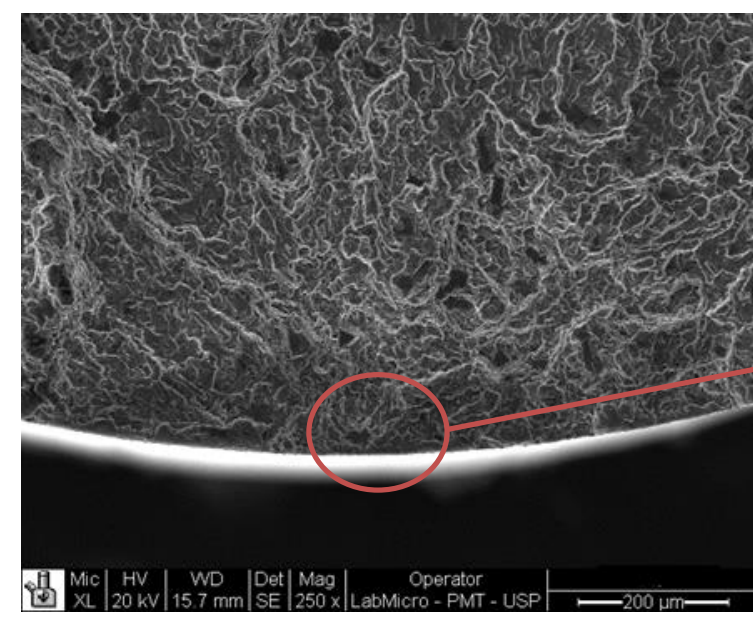

Figura 107 - Amostra 9: região de início da fratura (250x - SE).

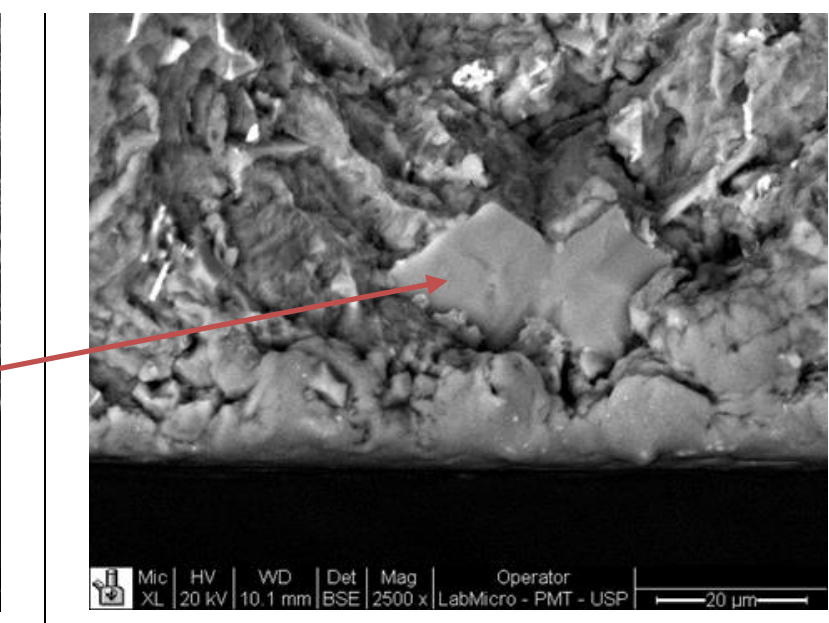

Figura 108 - Amostra 9: partícula de silício no início da fratura (2500x - BSE).

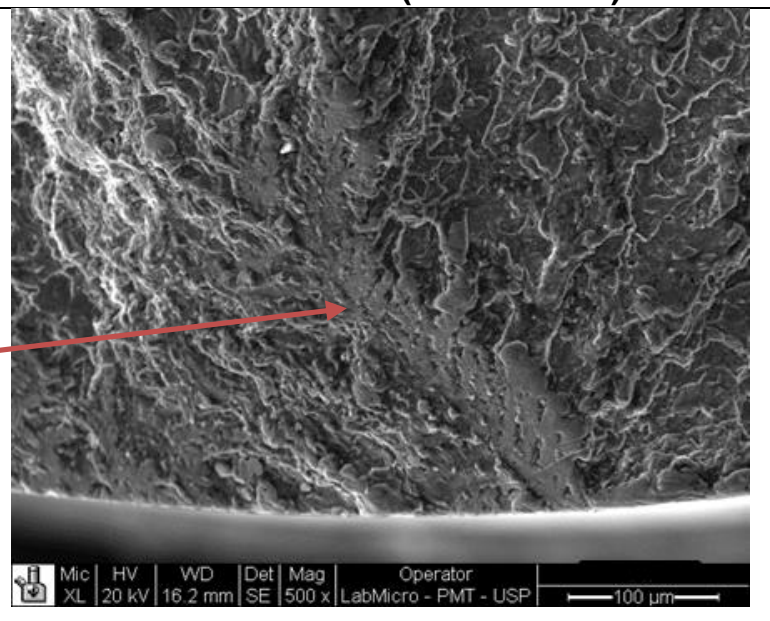

Figura 110 - Amostra 10: grão de alumínio no início da fratura (500x - SE).

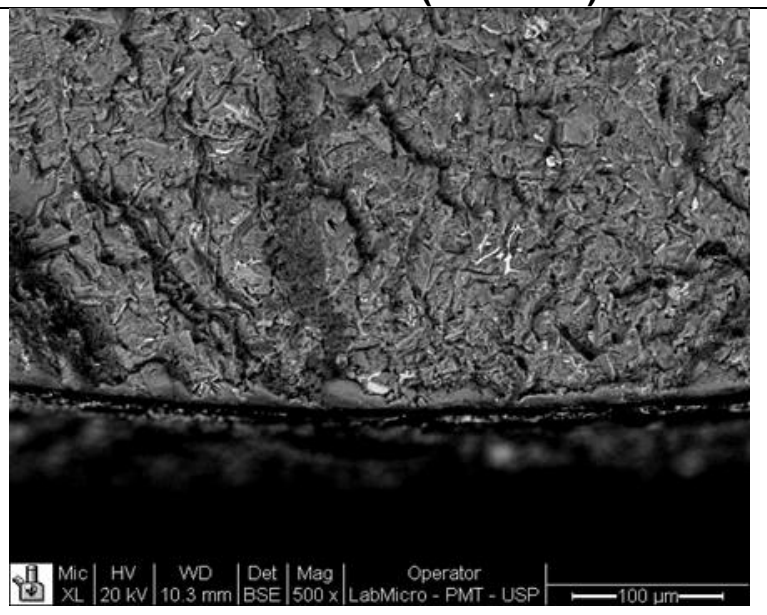

Figura 112 - Amostra 11: nenhuma anomalia no início da fratura (500x - BSE). 


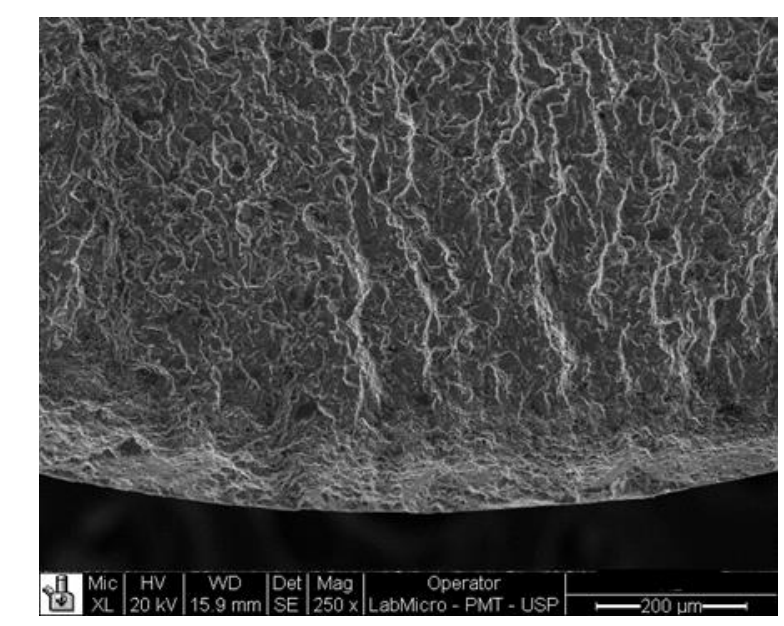

Figura 113 - Amostra 13: região de início da fratura (250x - SE).

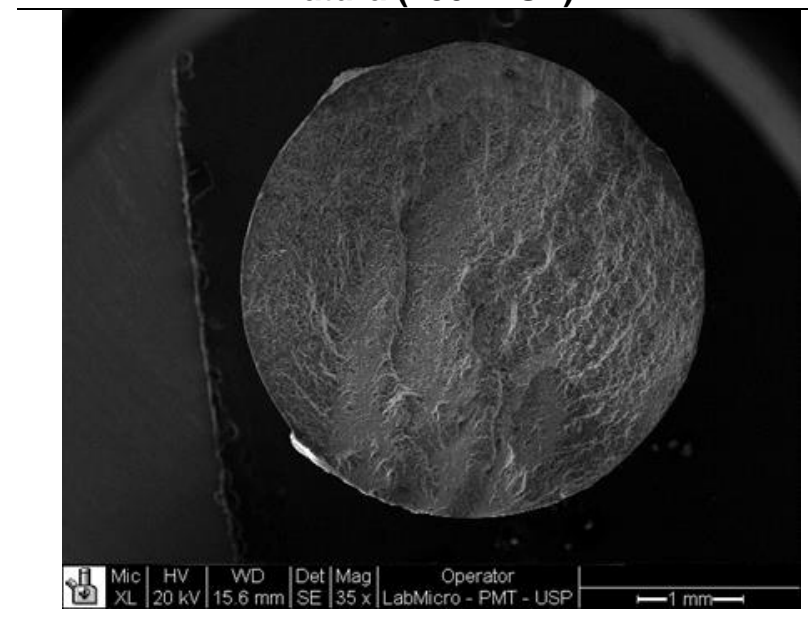

Figura 115 - Amostra 14: superfície de fratura com presença de feather crystals (35X - SE).

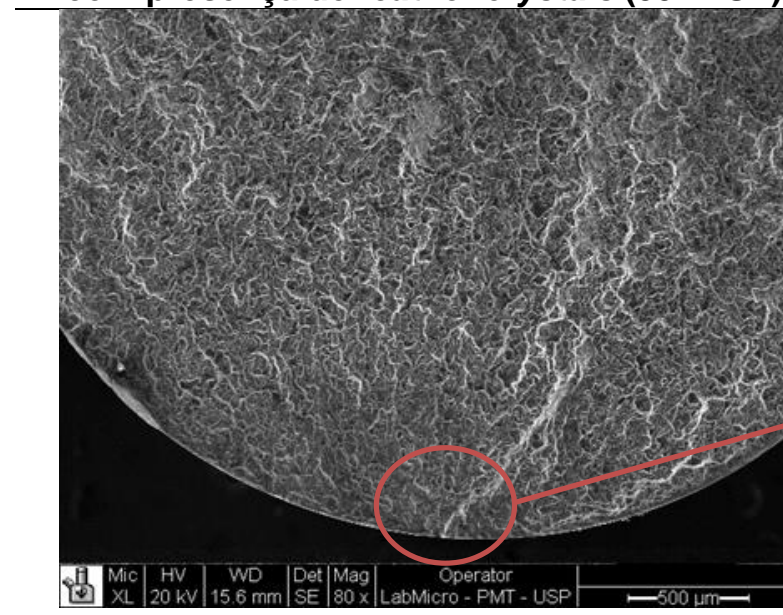

Figura 117 - Amostra 16: região de início da fratura $(80 x-S E)$.

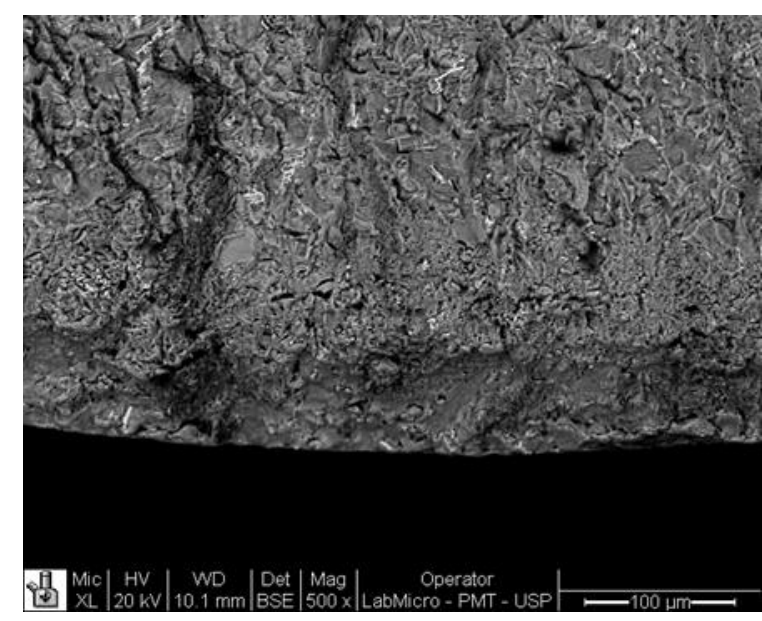

Figura 114 - Amostra 13: nenhuma anomalia no início da fratura (500x - BSE).

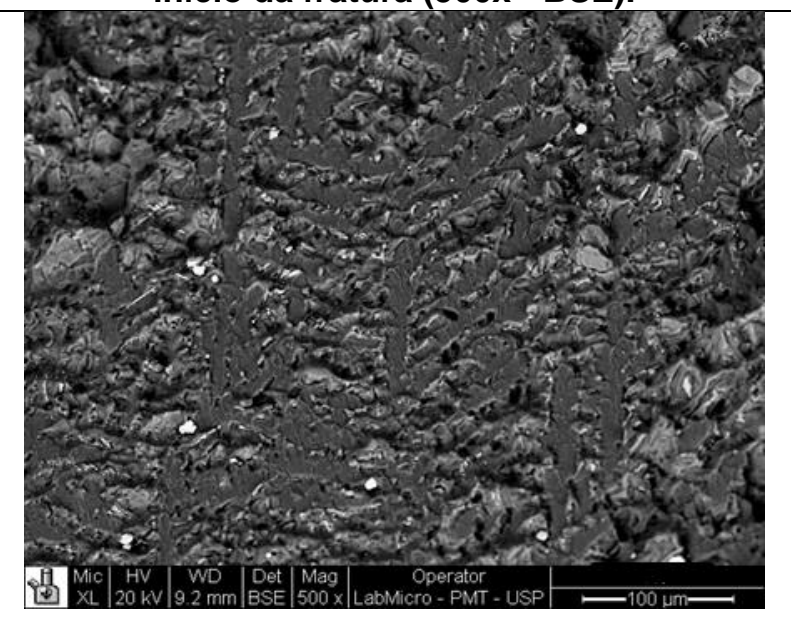

Figura 116 - Amostra 14: detalhe dos feather crystals (500x - SE).

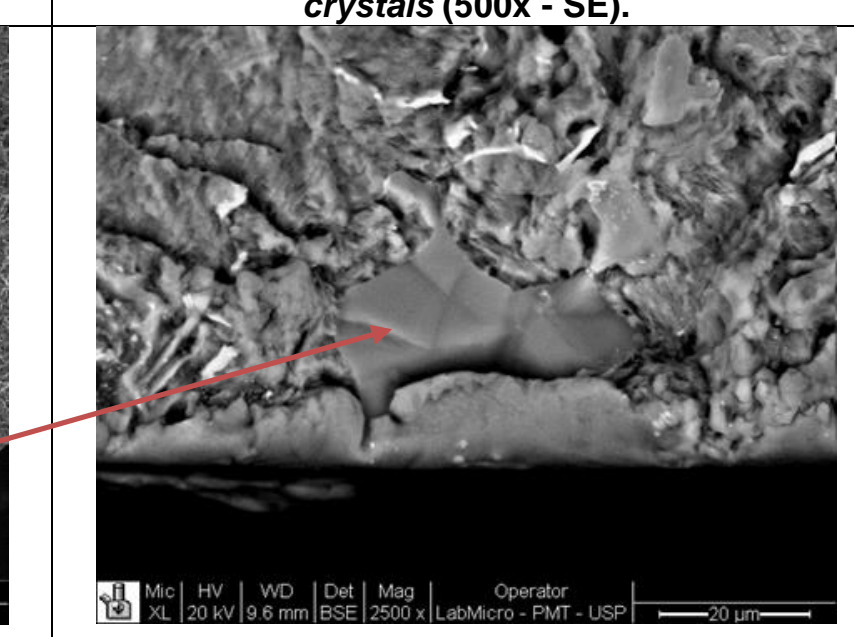

Figura 118 - Amostra 16: partícula de silício no início da fratura (2500x - BSE). 


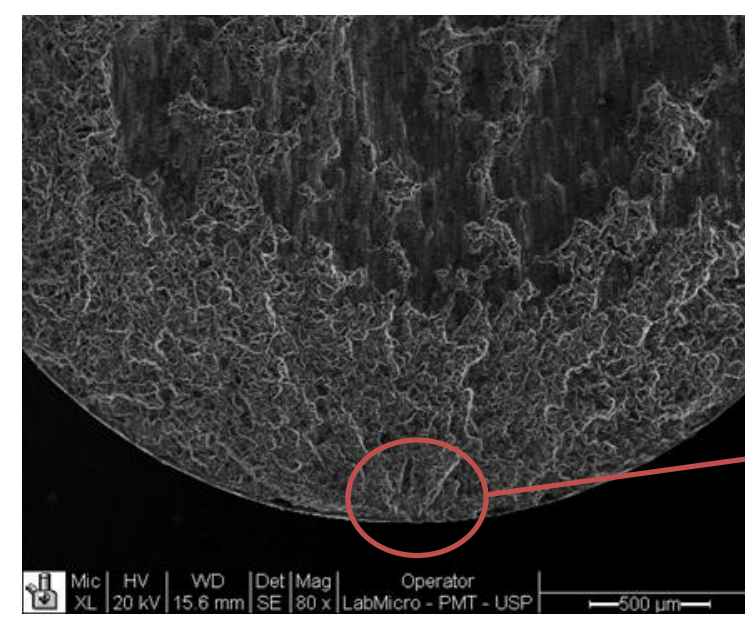

Figura 119 - Amostra 17: região de início da fratura $(80 x-S E)$.

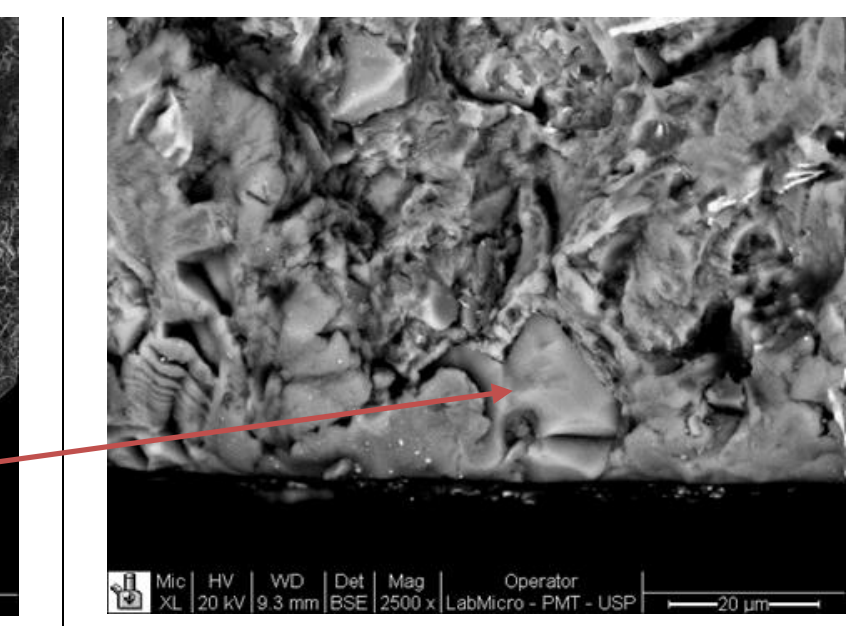

Figura 120 - Amostra 17: partícula de silício no início da fratura (2500x - BSE).

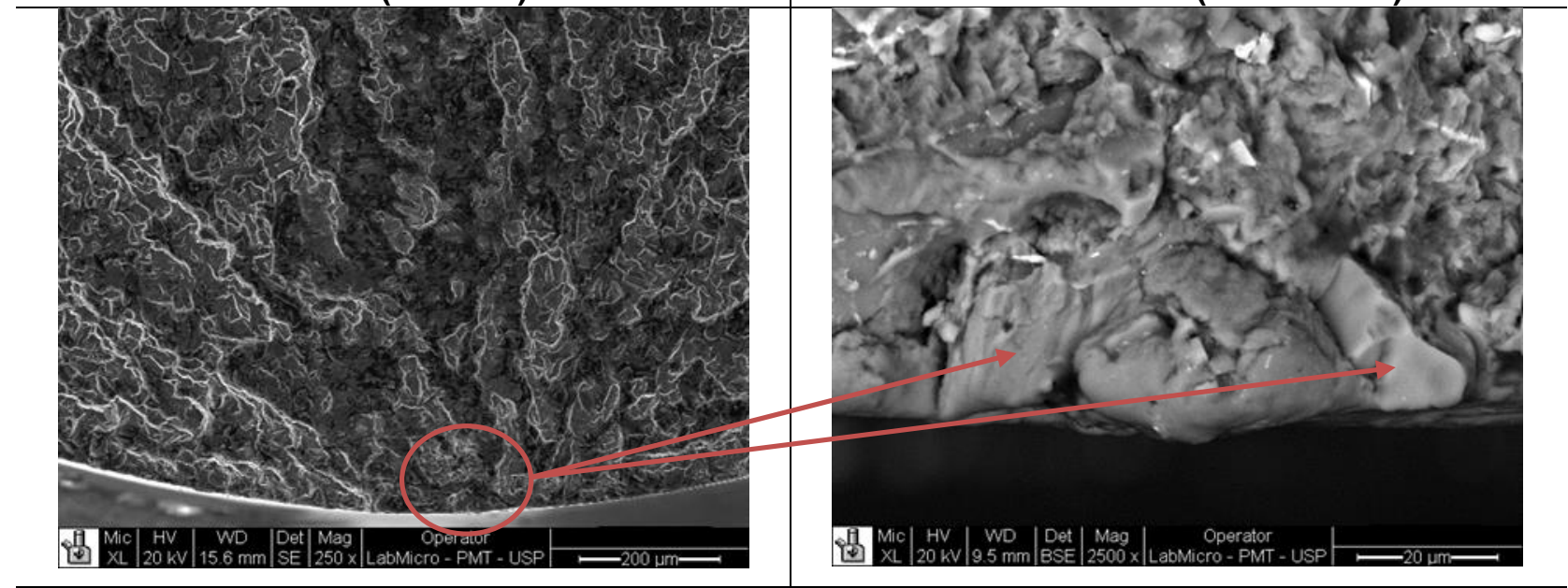

Figura 121 - Amostra 18: região de início da fratura (250x - SE).

Figura 122 - Amostra 18: partículas de silício no início da fratura (2500x - BSE).

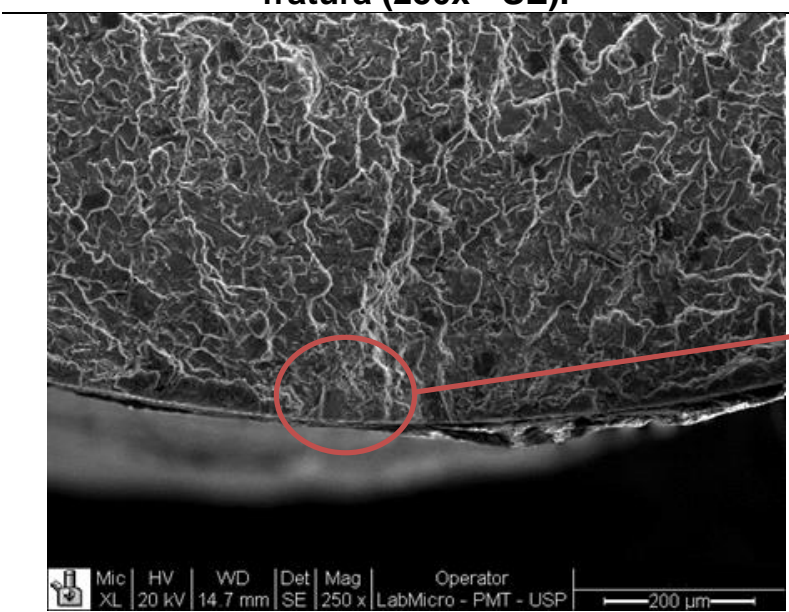

Figura 123 - Amostra 19: região de início da fratura (250x - SE).

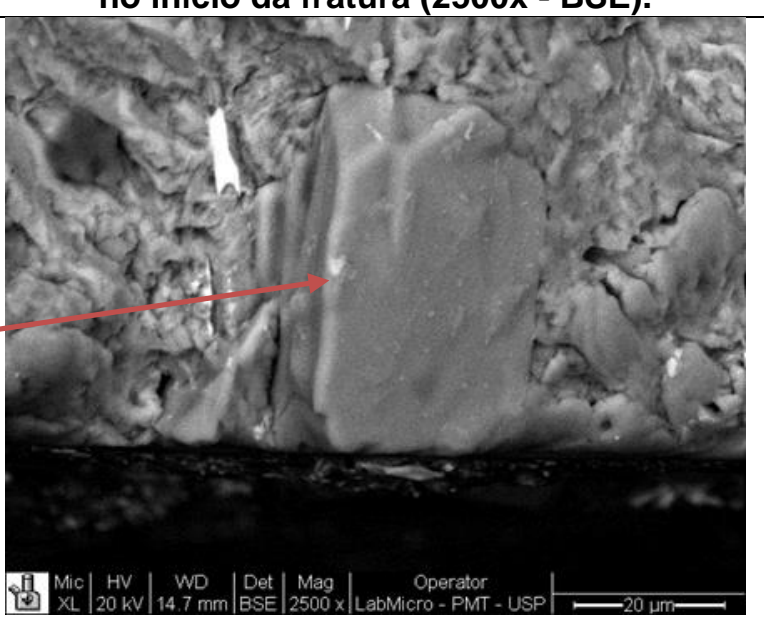

Figura 124 - Amostra 19: partícula de silício no início da fratura (2500x - BSE). 


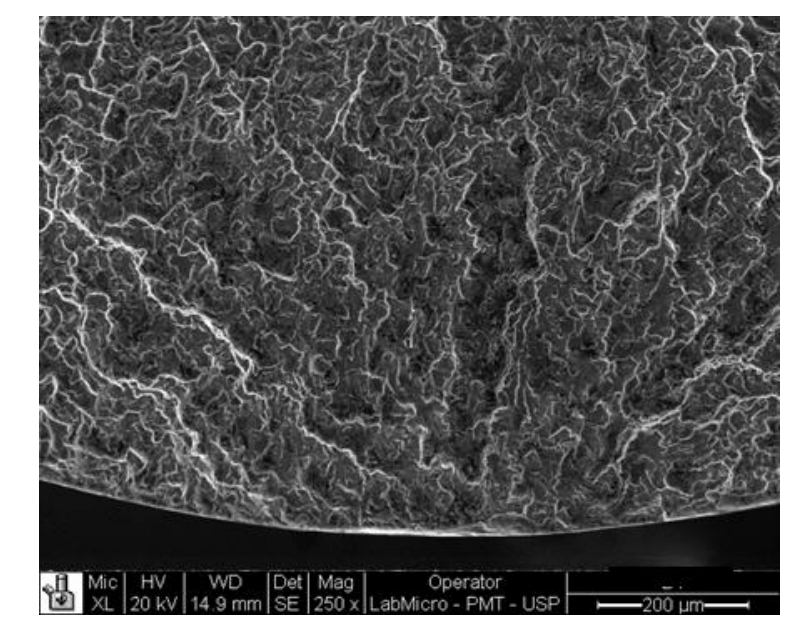

Figura 125 - Amostra 21: região de início da fratura (250x - SE).

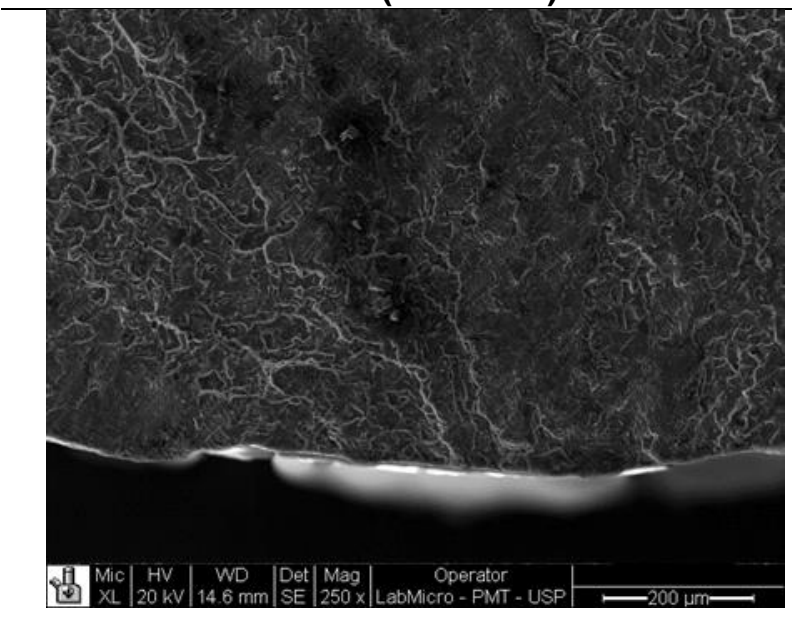

Figura 127 - Amostra 22: região de início da fratura (250x - SE).

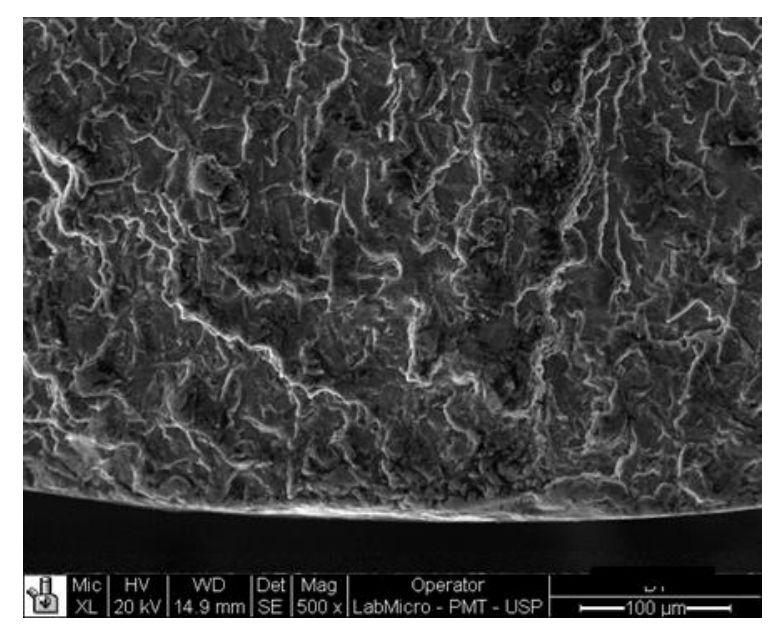

Figura 126 - Amostra 21: nenhuma anomalia no início da fratura (500x - SE).

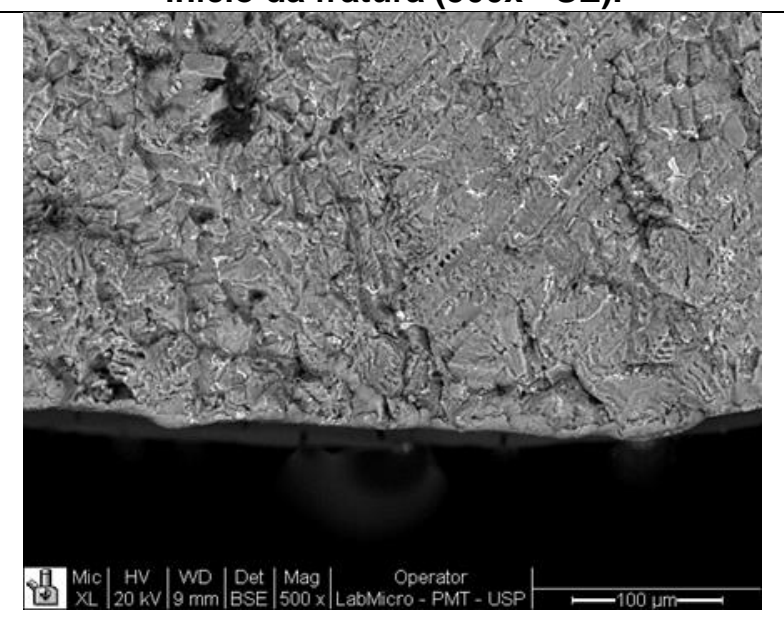

Figura 128 - Amostra 22: nenhuma anomalia no

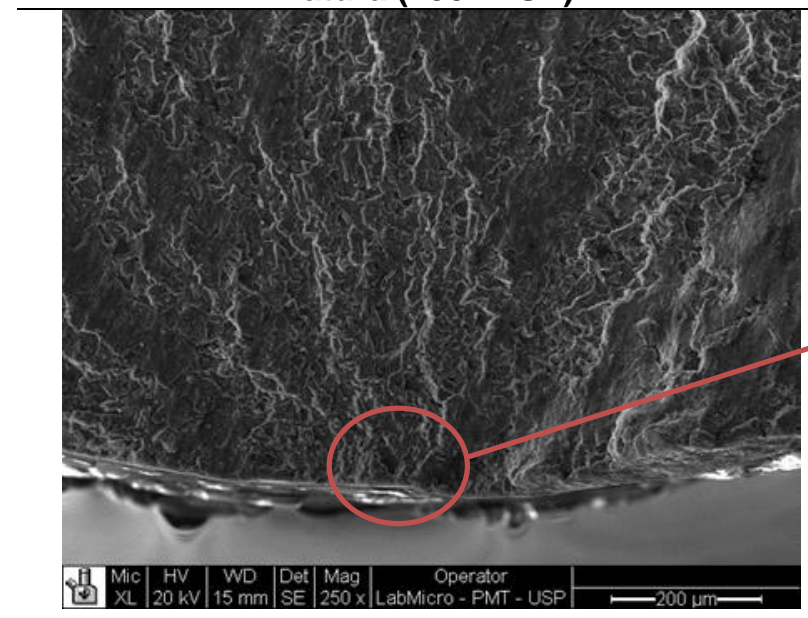

Figura 129 - Amostra 23: região de início da fratura (250x - SE). início da fratura (500x - BSE).

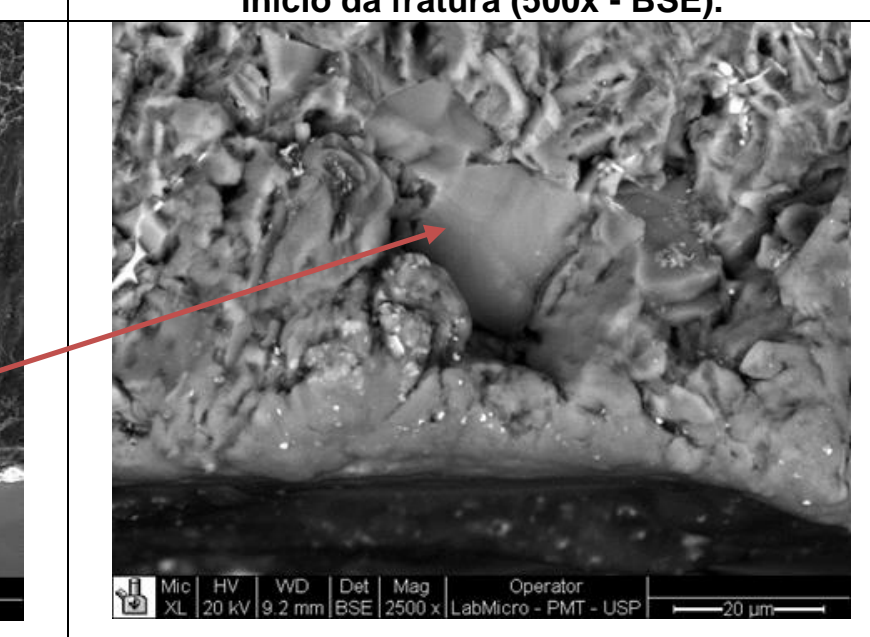

Figura 130 - Amostra 23: partícula de silício no início da fratura (2500x - BSE). 


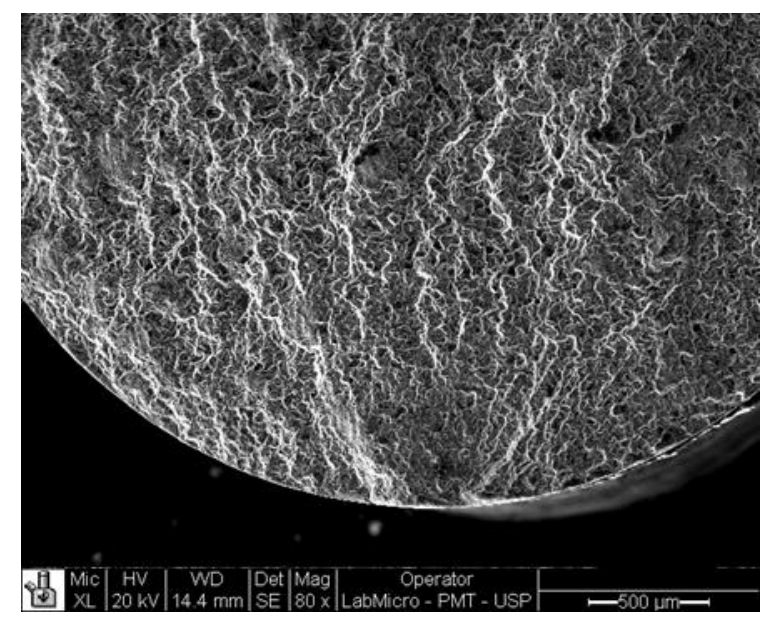

Figura 131 - Amostra 27: região de início da fratura $(80 x$ - SE).

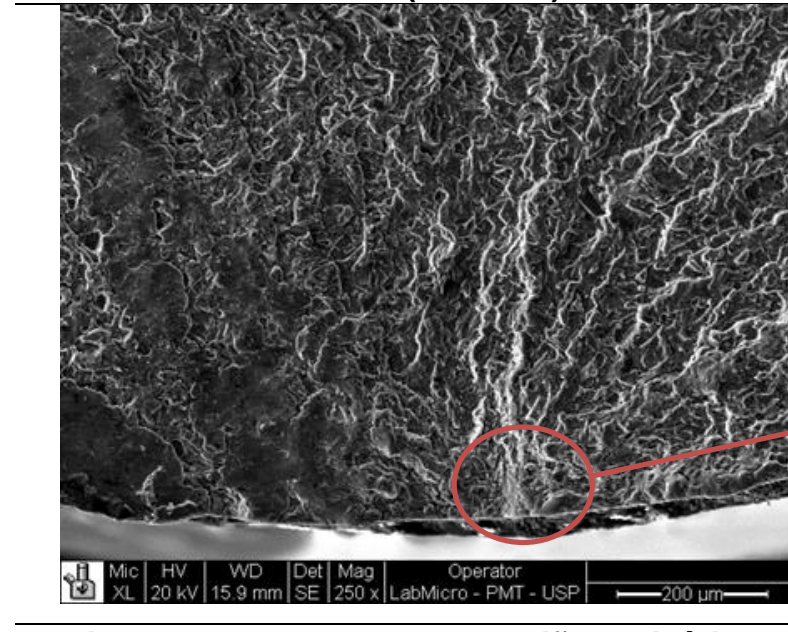

Figura 133 - Amostra 28: região de início da fratura (250X - SE).

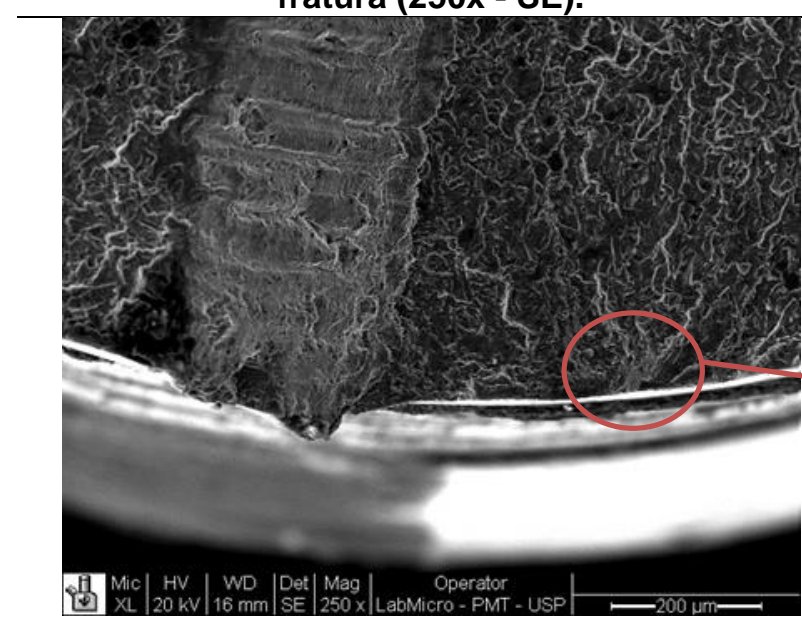

Figura 135 - Amostra 29: região de início da fratura (250x - SE).

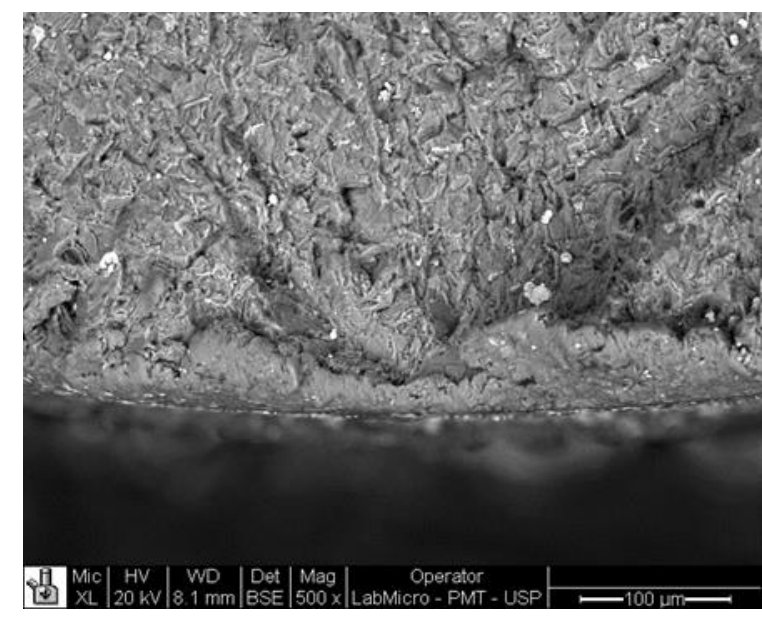

Figura 132 - Amostra 27: nenhuma anomalia no início da fratura (500x - BSE).

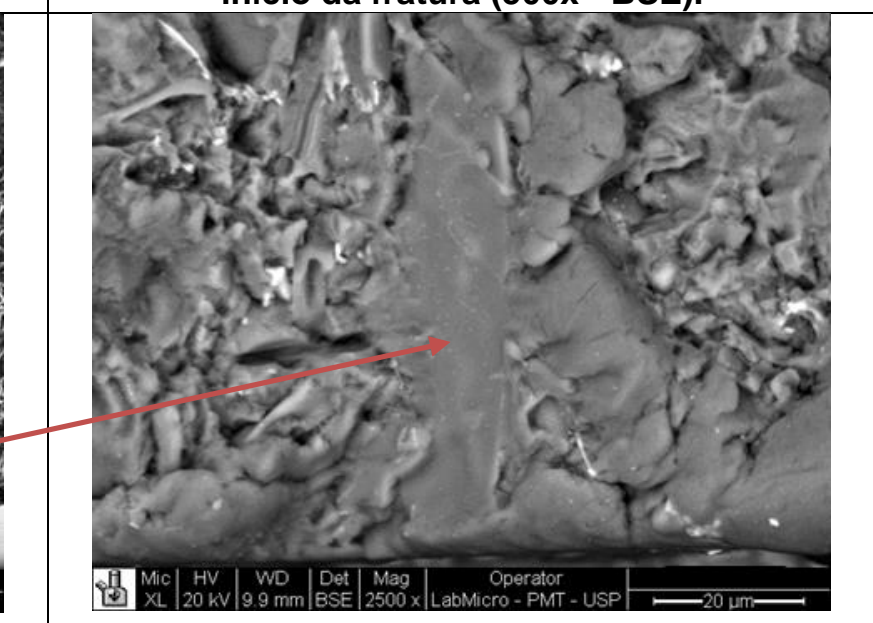

Figura 134 - Amostra 28: partícula de silício no início da fratura (2500x - BSE).
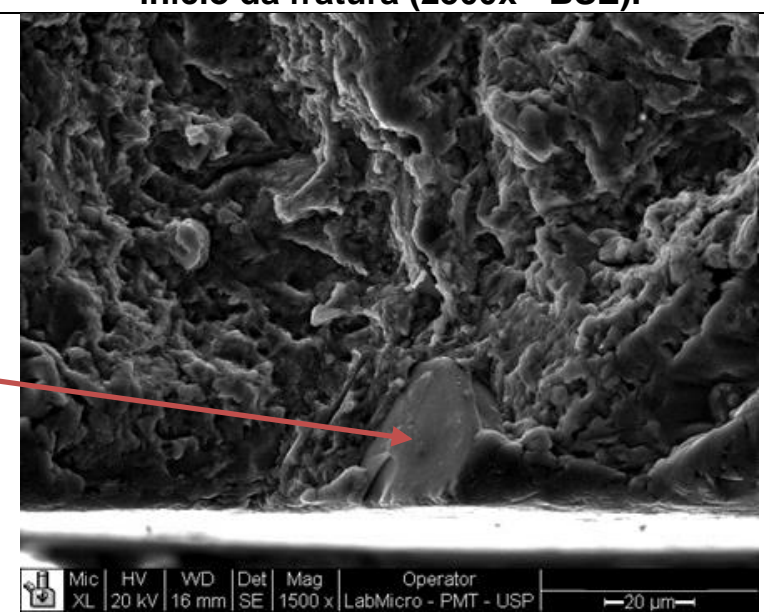

Figura 136 - Amostra 29: partícula de silício no início da fratura (1500x - SE). 


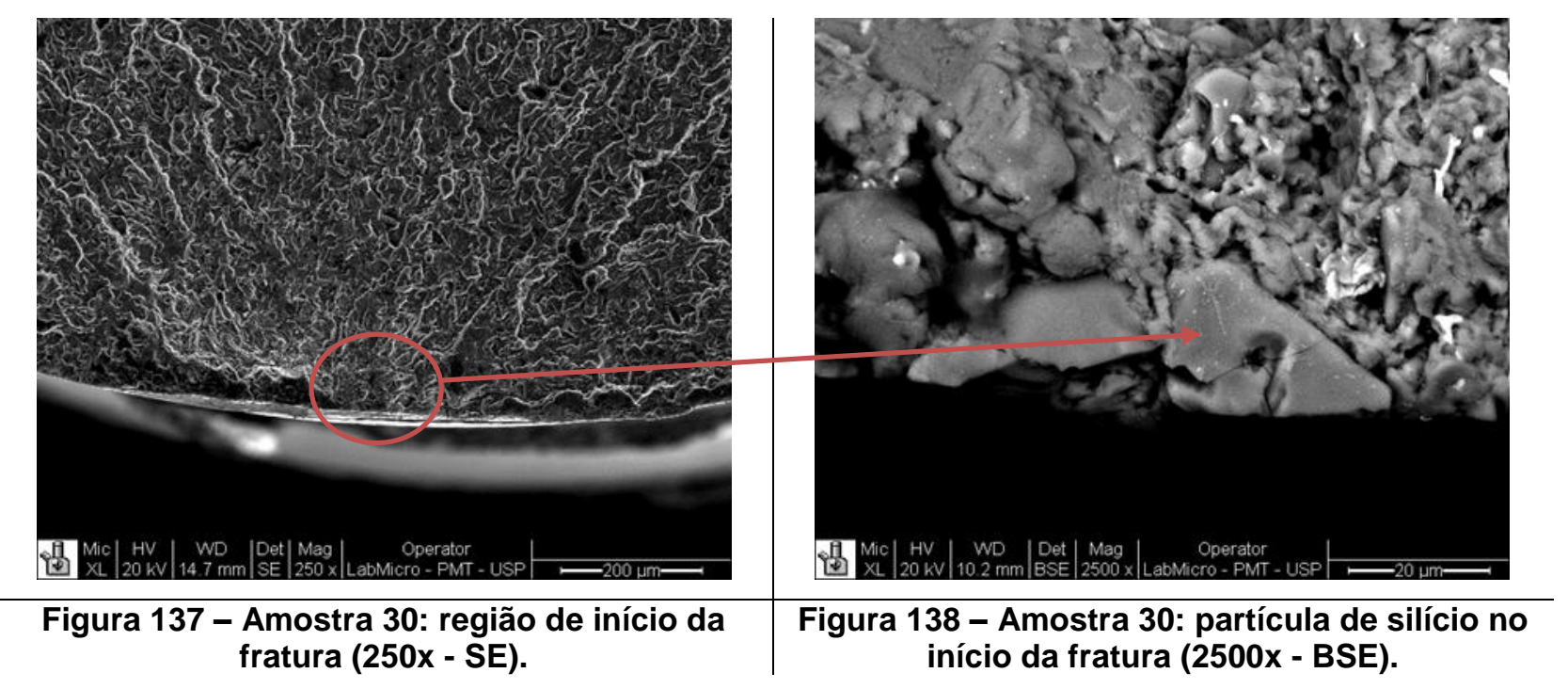

Com base nessas análises, pode-se assumir então que a nucleação das trincas é controlada por partículas de silício primário em todas as séries avaliadas.

Esses resultados são condizentes com os estudos realizados por [Murakami e Endo, 1994]. De acordo com esses estudos, inclusões não metálicas podem ser consideradas mecanicamente equivalentes a pequenos defeitos.

Medindo-se o tamanho das partículas de silício primário, pode-se assumir que elas apresentam a mesma distribuição de tamanho para todas as ligas testadas, conforme a Figura 139. 


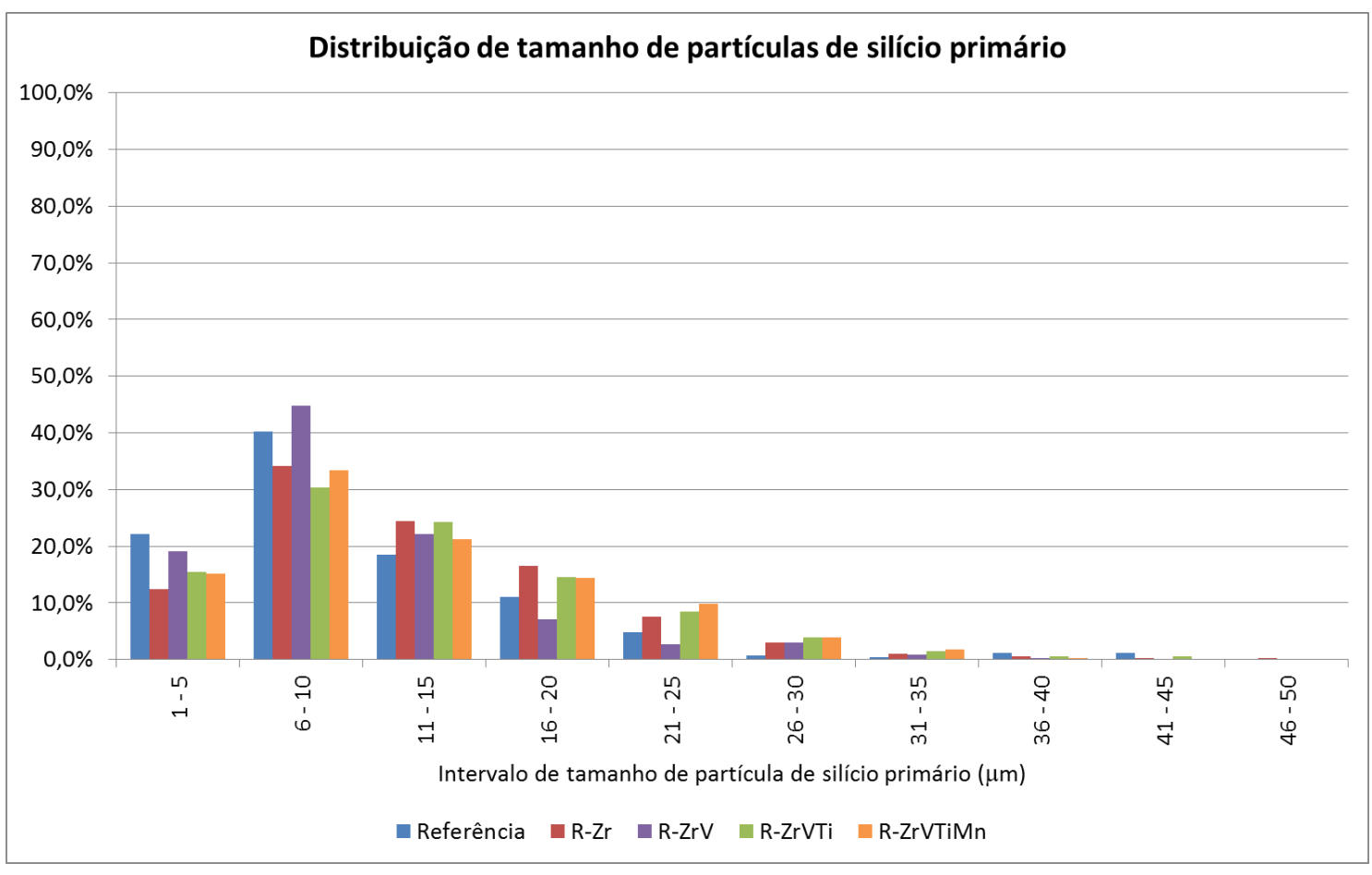

Figura 139 - Distribuição de tamanho de partículas de silício primário.

Comparando-se o fator de circularidade das partículas de silício primário (partículas maiores que $100 \mu \mathrm{m}^{2}$ - Figura 140), nota-se que não há diferenças entre as séries de Referência e R-TT. Ainda que tivessem sido encontradas diferenças de forma das partículas de silício primário, de acordo com [Murakami e Endo, 1994], a forma da partícula não influencia no aumento da vida em fadiga do material. Apenas a área das partículas não metálicas é importante. 


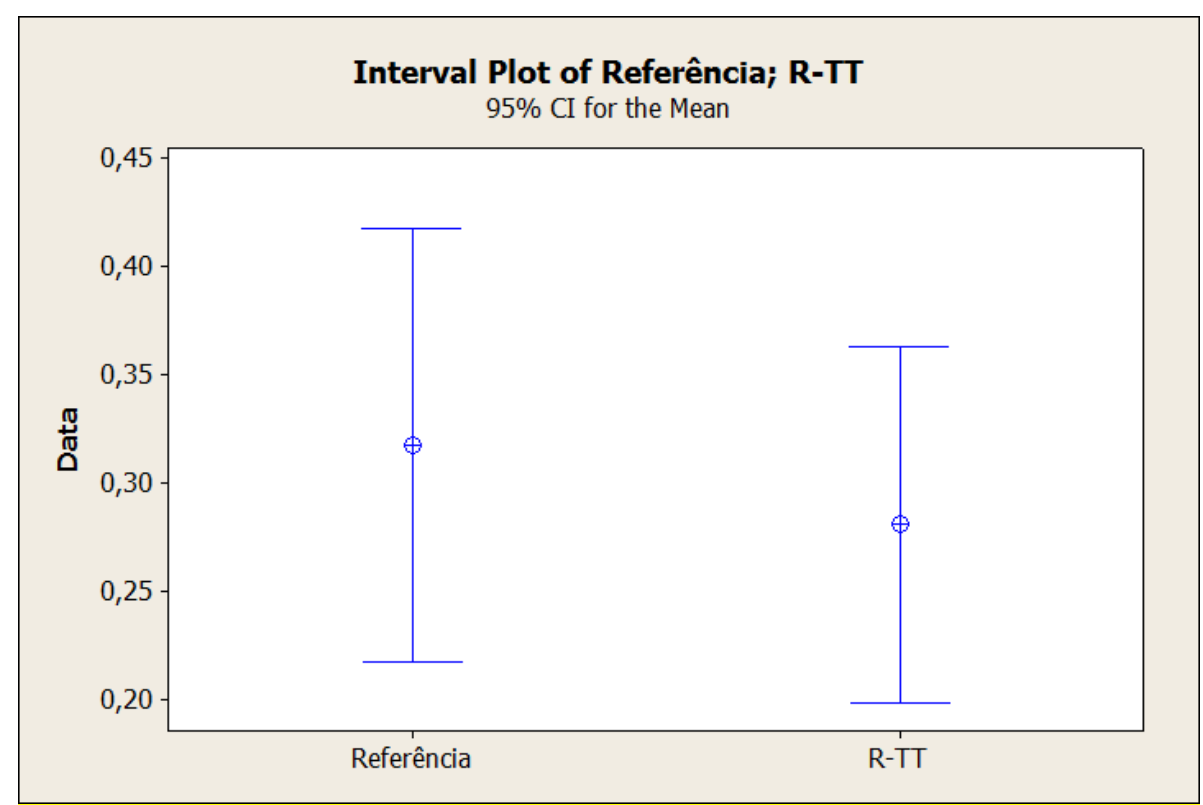

Figura 140 - Comparação do fator de circularidade das partículas de silício grandes (maiores que $100 \mu \mathrm{m}^{2}$ ) das séries de Referência e R-TT.

Com base nos resultados apresentados acima, a nucleação das trincas por fadiga das séries de Referência e R-TT ocorreu em partículas de silício primário (Tabela 16). As partículas de silício primário de ambas as séries são de igual tamanho (Figura 139) e igual fator de circularidade (Figura 140).

Pode-se concluir então que a nucleação da trinca não tem influência sobre a diferença da vida em fadiga encontrada entre as séries de Referência e R-TT. A diferença de vida média em fadiga a $300^{\circ} \mathrm{C}$ está somente na propagação da trinca.

A Figura 141 até a Figura 144 apresentam o caminho de propagação da trinca na região próxima ao ponto de início da trinca. Nota-se que as trincas por fadiga tendem a propagar por partículas frágeis como silício primário e eutético e partículas de intermetálicos. 


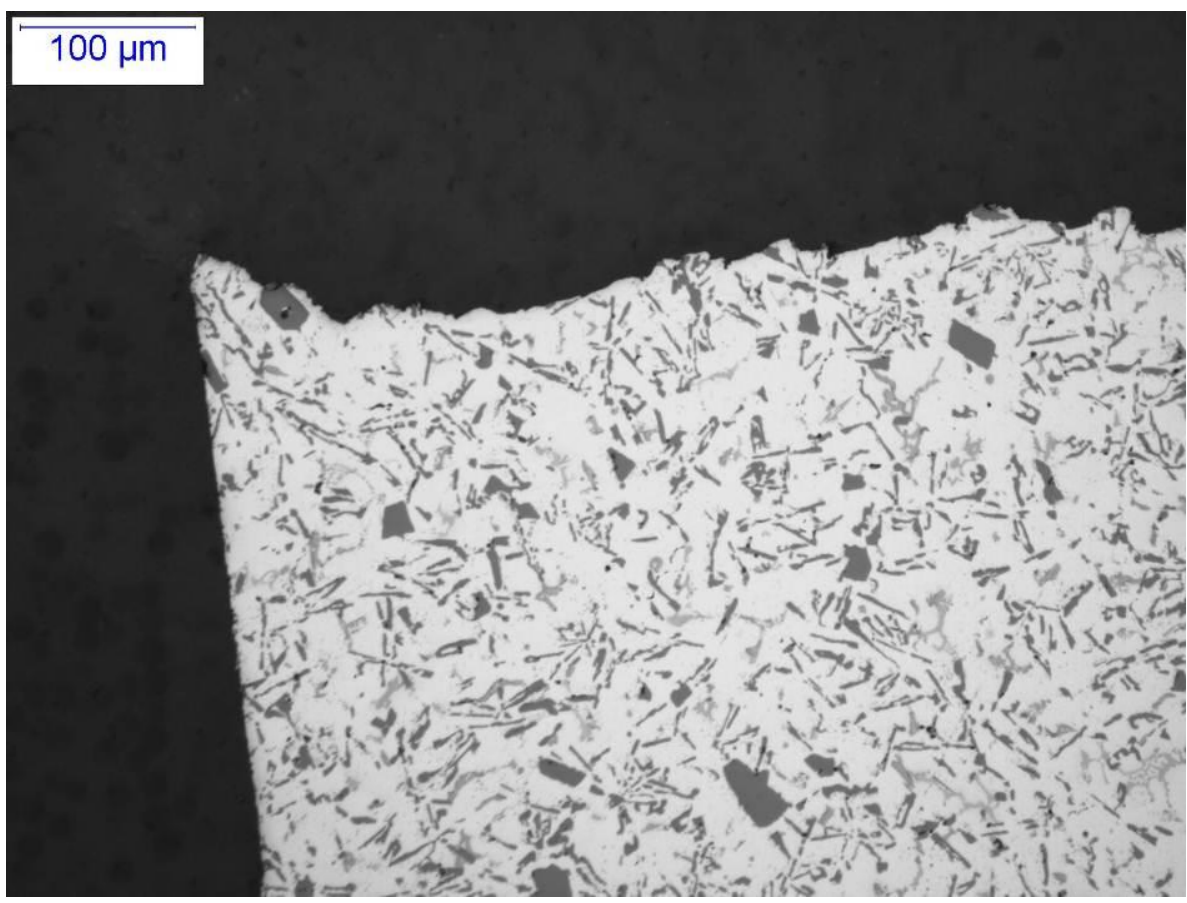

Figura 141 - Série de Referência (Amostra 1): superfície de fratura (200x).

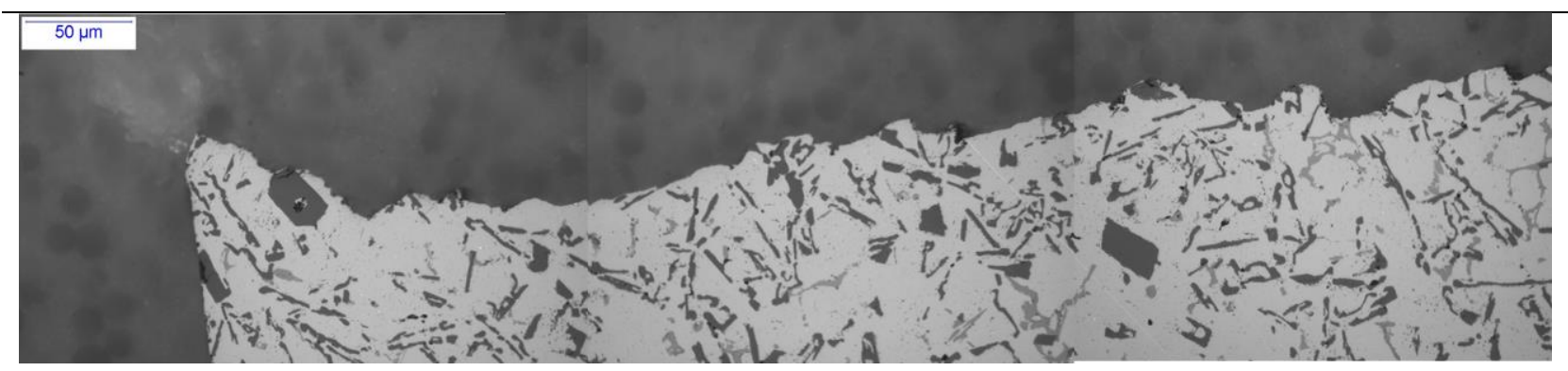

Figura 142 - Série de Referência (Amostra 1): superfície de fratura (500x). 


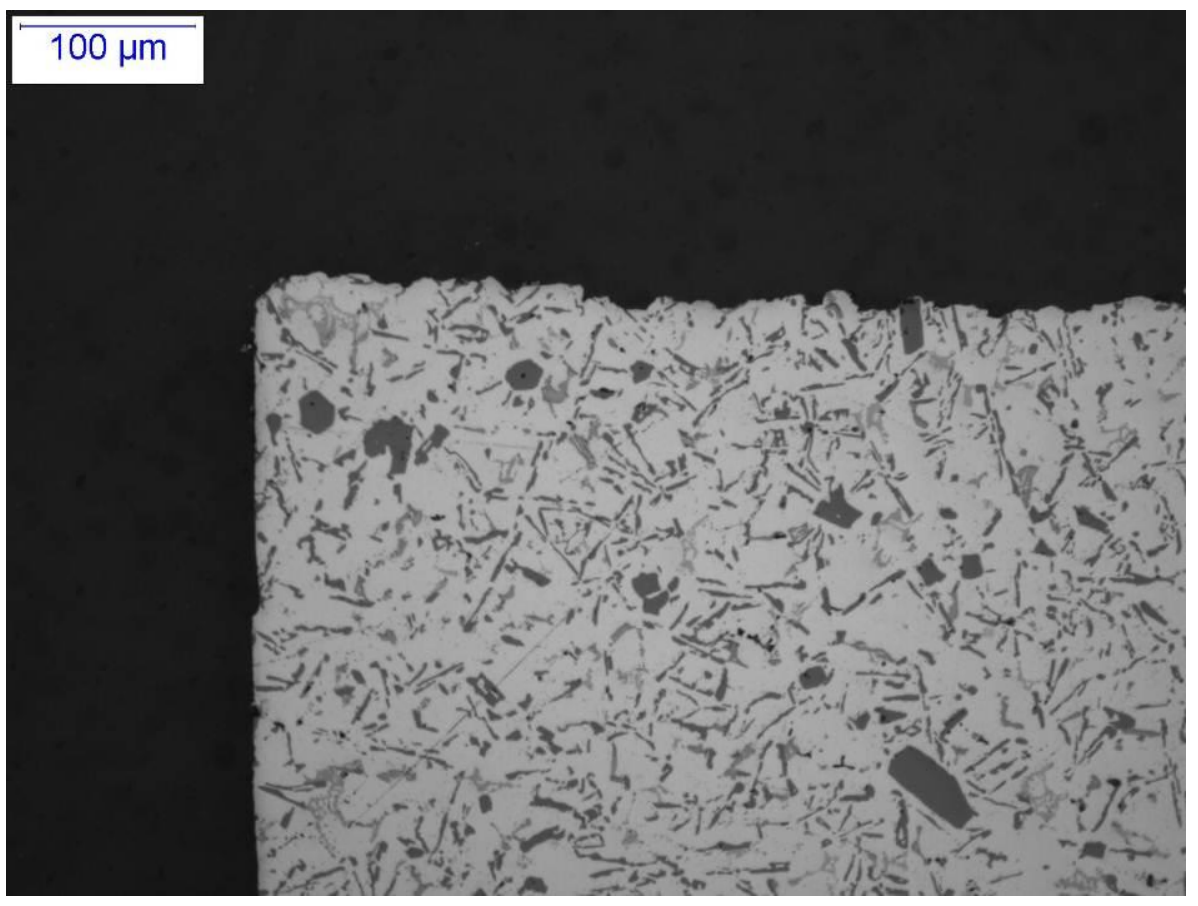

Figura 143 - Série R-TT (Amostra 32): superfície de fratura (200x).

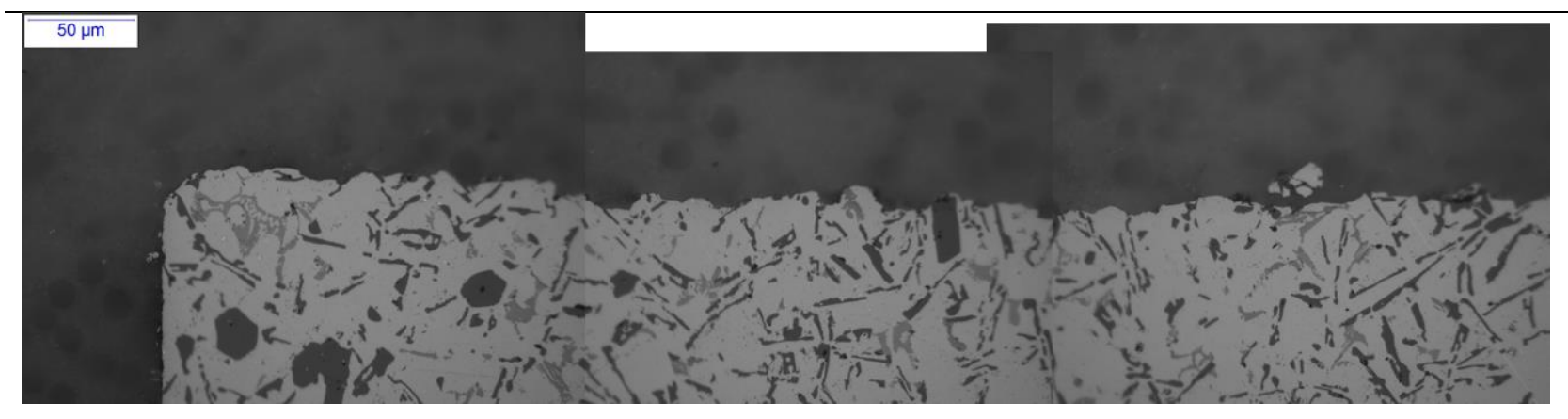

Figura 144 - Série R-TT (Amostra 32): superfície de fratura (500x).

No entanto, quando se compara o fator de circularidade das séries de Referência e RTT antes do tratamento térmico (Referência BF) e após o tratamento térmico (Referência e R-TT), nota-se que existe uma tendência de maior arrendondamento tanto das partículas de silício primárias e eutéticas (Figura 145), quanto do total de partículas (Figura 146) na série R-TT. 


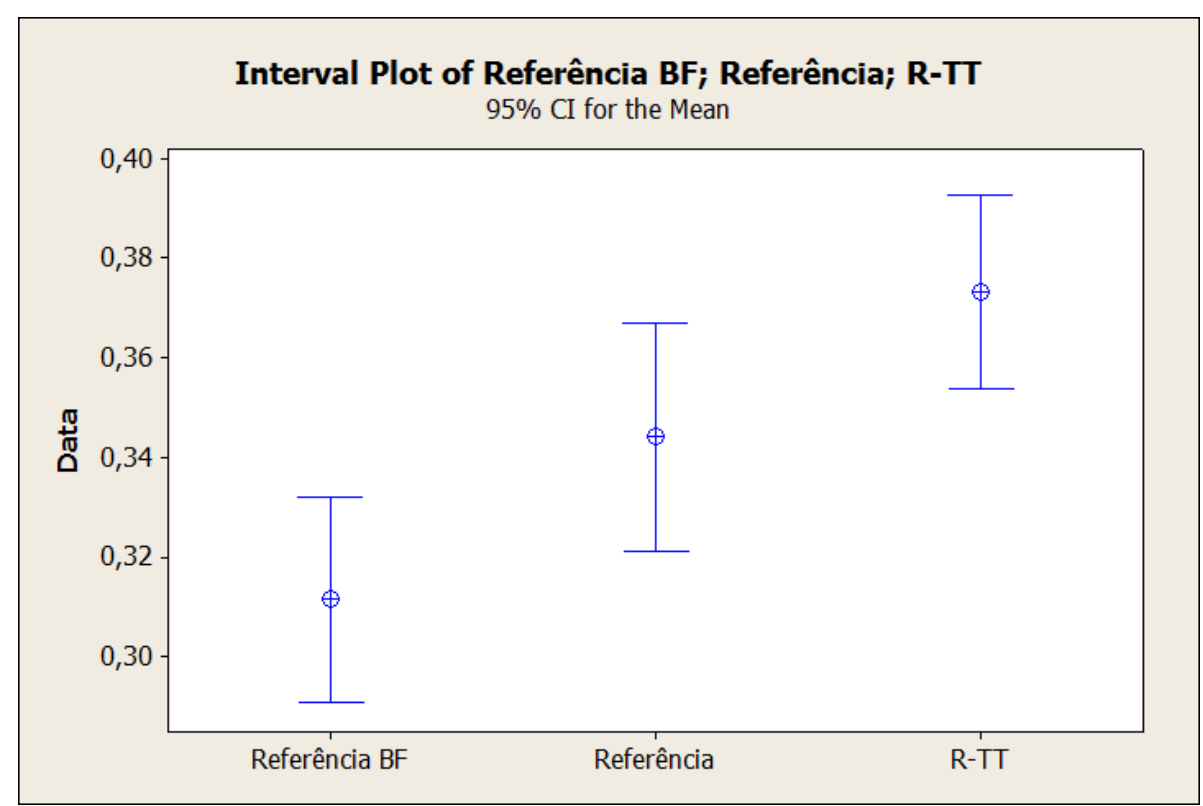

Figura 145 - Comparação do fator de circularidade das partículas de silício das séries de referência antes do tratamento térmico (Referência BF) e após o tratamento térmico (Referência e R-TT).

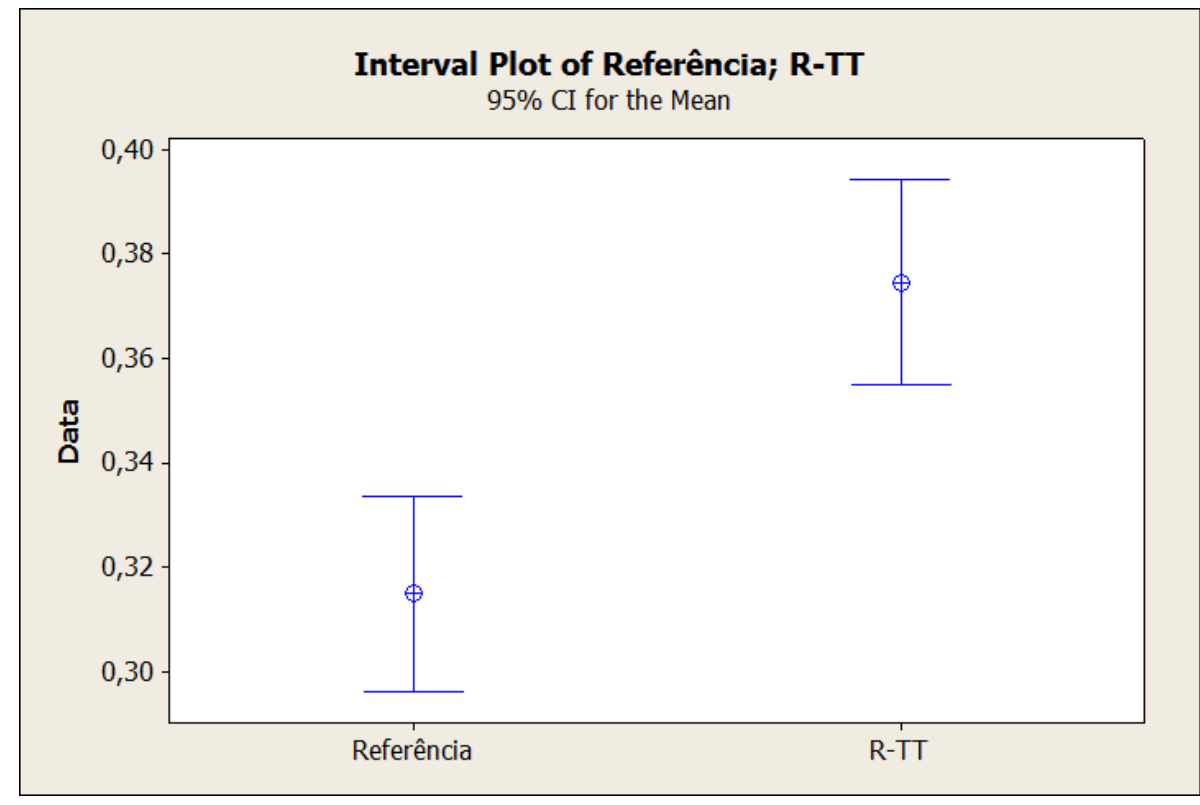

Figura 146 - Fator de circularidade total das séries de Referência e R-TT. 
De acordo com a Figura 142 e a Figura 144, a propagação das trincas de fadiga não é absolutamente plana, sofrendo diversos desvios devido à presença de partículas, tanto de silício (primário e eutético) quanto de intermetálicos, que são mais frágeis que a matriz de alumínio.

O fator de circularidade das partículas de silício e o fator de circularidade total das partículas explica a diferença de velocidade de propagação, já que partículas mais redondas têm menor área por volume e, assumindo-se que o volume de partículas é igual, há menor área de partículas disponível para facilitar a propagação das trincas.

Além disso, partículas arredondadas tendem a concentrar menos tensões que partículas com ângulos agudos nas bordas, contribuindo para a menor velocidade de propagação de trincas.

É importante ressaltar que a vida média em fadiga encontrada para a série R-TT é de cerca de $100 \%$ maior que a vida média em fadiga encontrada para a série de Referência.

Este resultado é de grande importância comercial não só pelo aumento significativo nas propriedades mecânicas, mas também pela redução de custo com tratamento térmico e redução de tempo de processamento das peças em um quarto do tempo utilizado no processo atual.

\subsection{Efeito da adição de elementos de liga}

Excluindo-se a variável de tratamento térmico e considerando que a literatura está correta e que a adição combinada de zircônio, vanádio, titânio e manganês é a melhor, podemos comparar as séries de R-ZrVTiMn e R-TT. Essas duas séries passaram pelo mesmo ciclo de tratamento térmico e a única variável é a composição química.

A comparação de vida média em fadiga a $300^{\circ} \mathrm{C}$ entre essas séries está apresentada na Figura 147. 


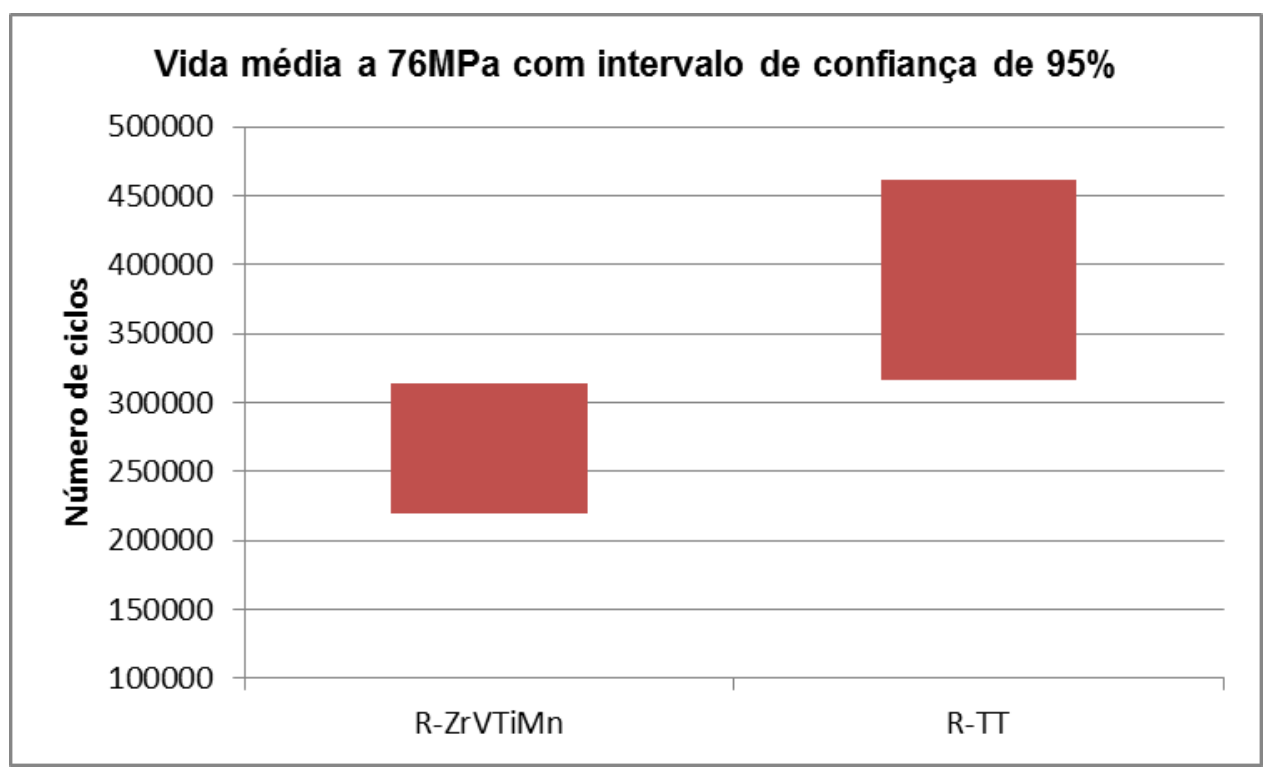

Figura 147 - Gráfico da vida média em fadiga com amplitude de tensão de 76MPa e intervalo de confiança de $95 \%$ para as séries R-ZrVTiMn e R-TT.

De acordo com os resultados apresentados na Figura 147, as séries R-ZrVTiMn e R-TT são estatisticamente diferentes e a vida média da série R-ZrVTiMn é cerca de $30 \%$ menor que a da série R-TT.

As microestruturas das duas séries foram comparadas por microscopia óptica (Figura 148 e Figura 149) e eletrônica (Figura 150 a Figura 153). Comparando-se a Figura 148 com a Figura 149, nota-se um aparente aumento na quantidade de intermetálicos na série R-ZrVTiMn. 


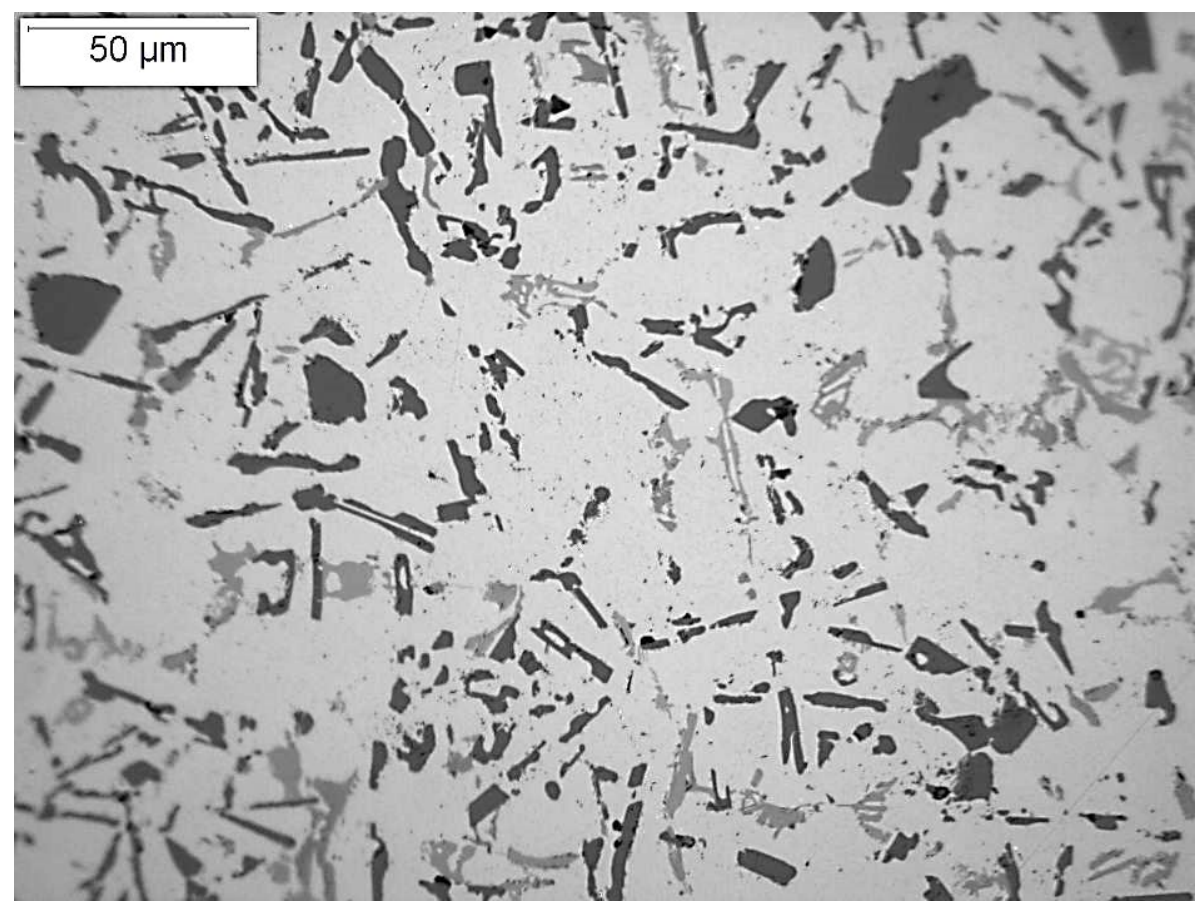

Figura 148 - Série R-ZrVTiMn (500x).

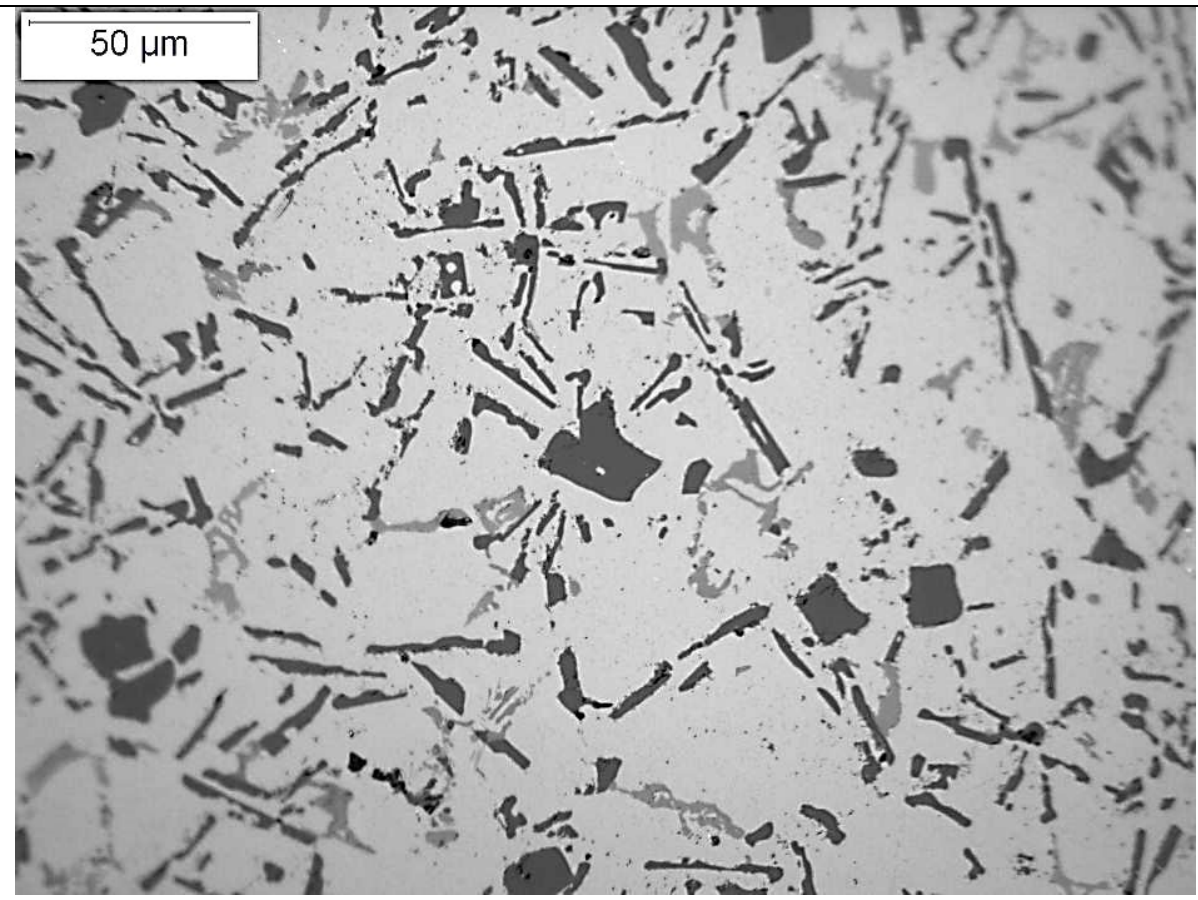

Figura 149 - R-TT (500x). 


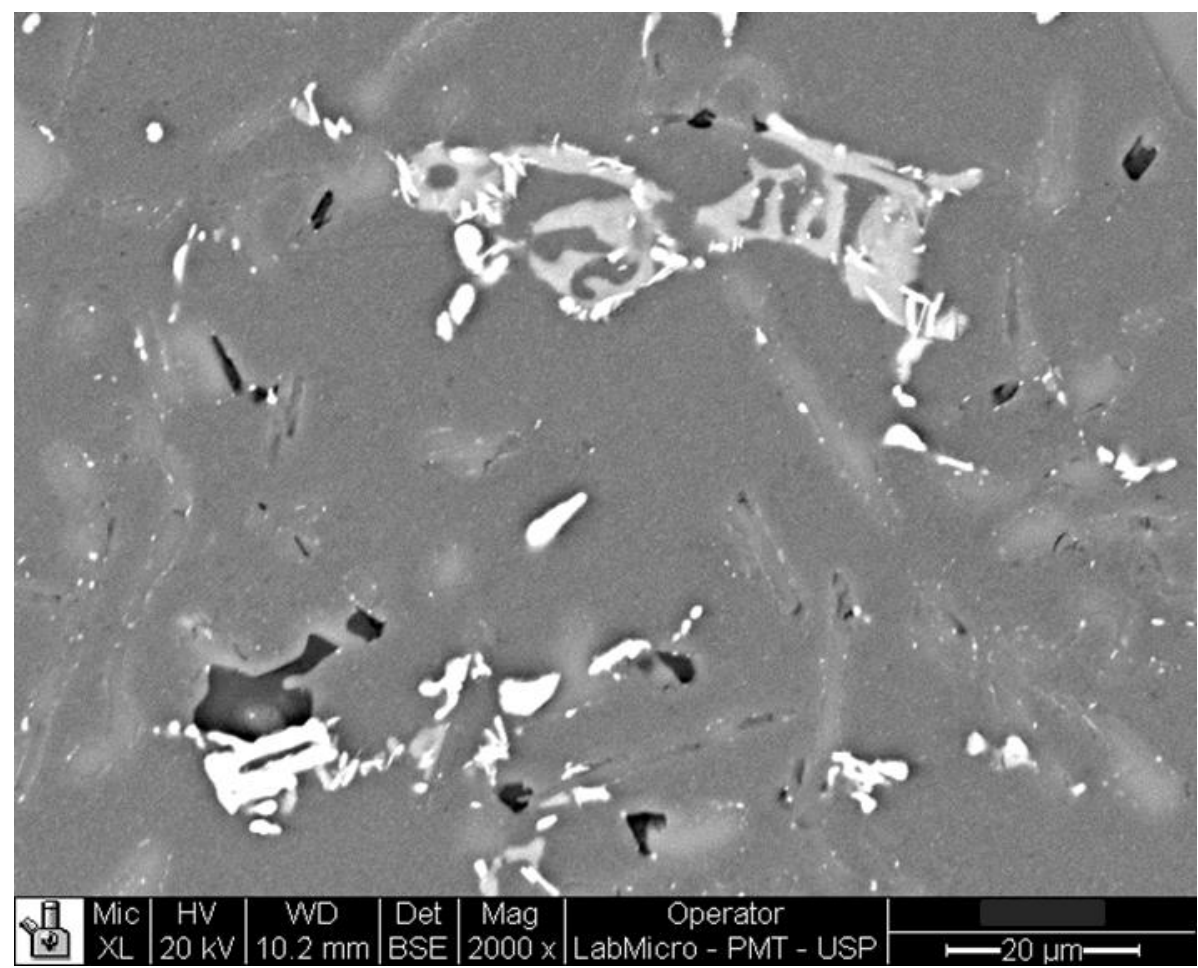

Figura 150 - Série de R-TT (2000x).

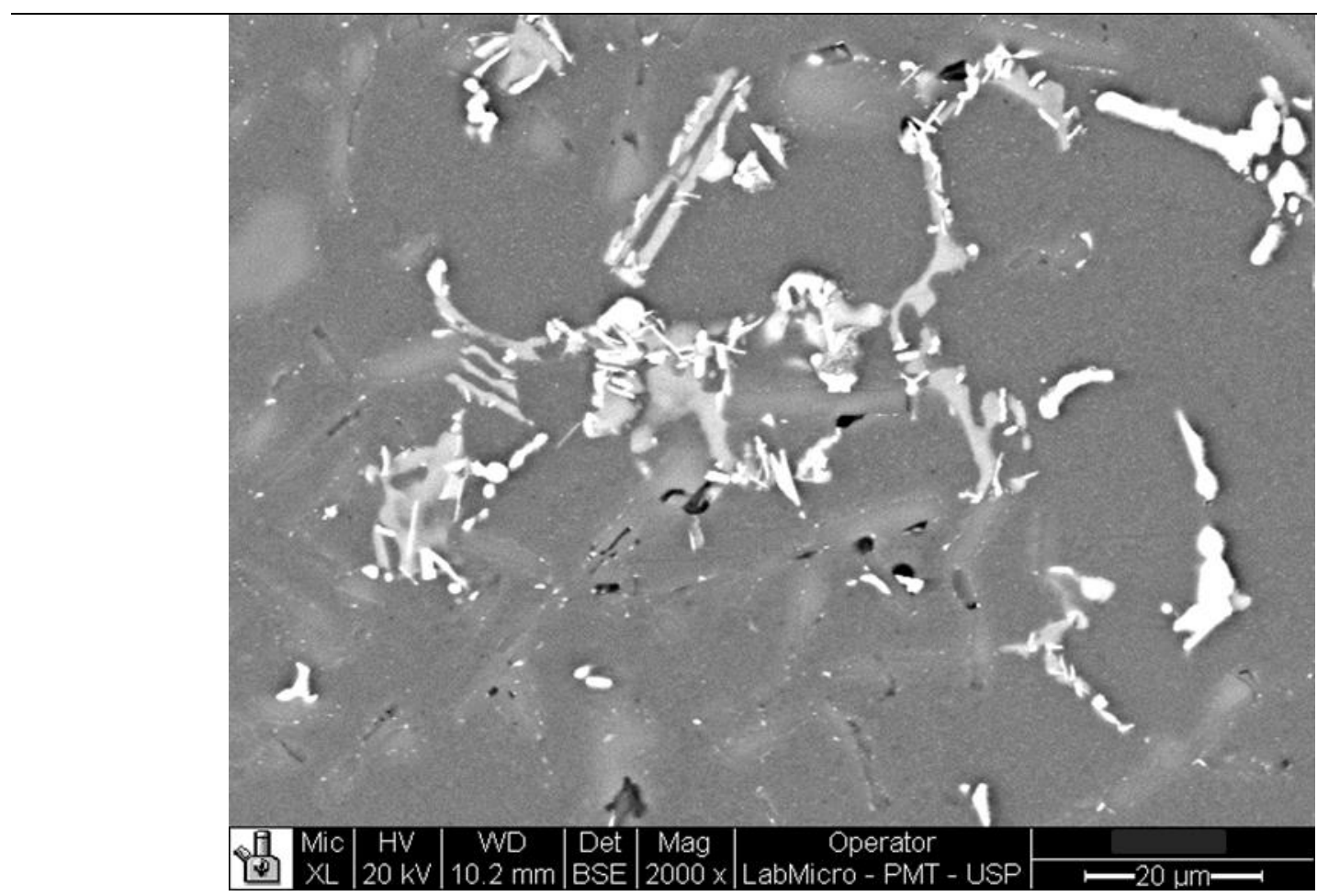

Figura 151 - Série de R-TT (2000x). 


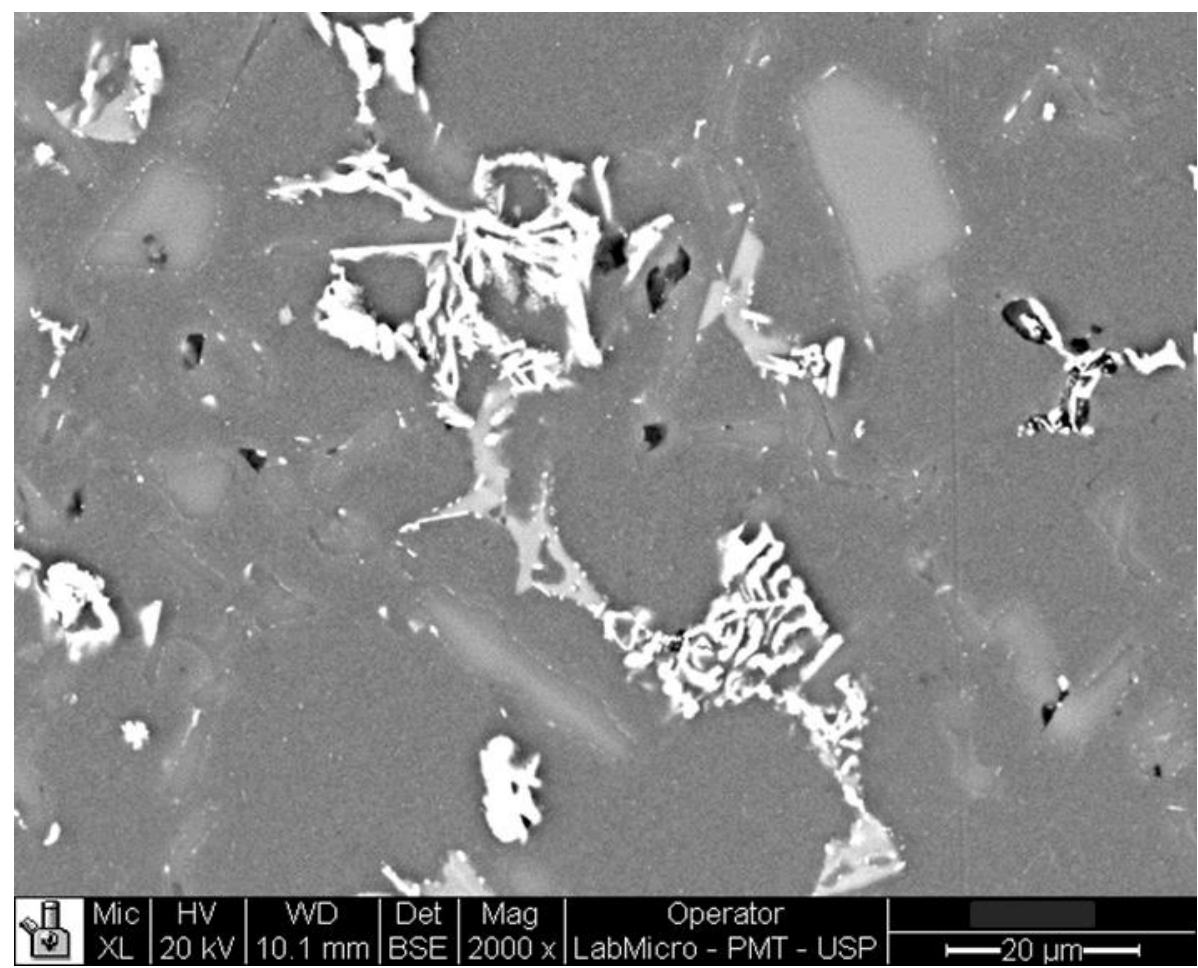

Figura 152 - Série de R-ZrVTiMn (2000x).

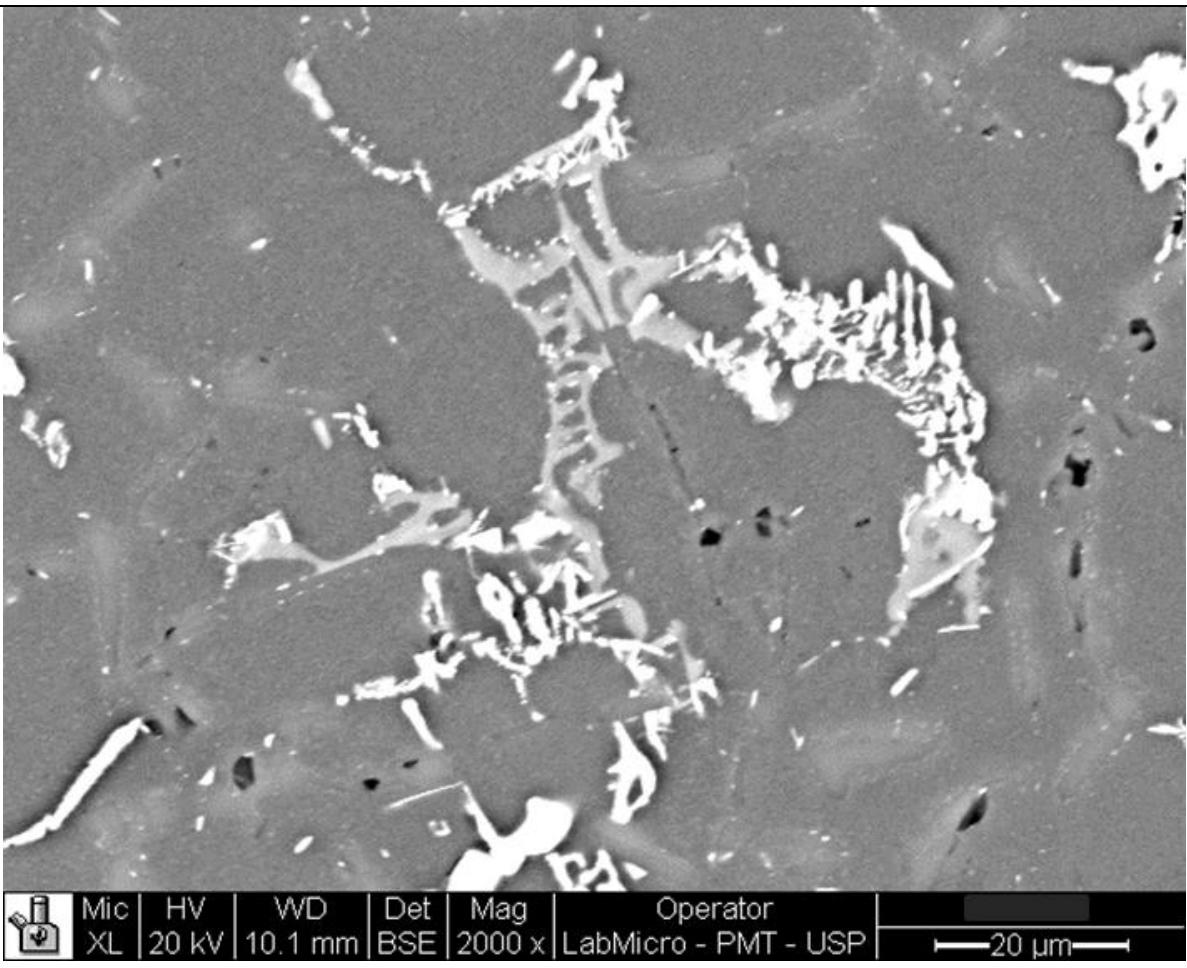

Figura 153 - Série de R-ZrVTiMn (2000x). 
Quando se compara a composição química dos intermetálicos presentes na série R-TT (Figura 154) e R-ZrVTiMn (Figura 155), nota-se que na série R-ZrVTiMn há o aparecimento de um intermetálico de morfologia tipo espinha de peixe contendo zircônio.

A presença de vanádio e titânio não foi identificada nos intermetálicos analisados. $O$ manganês foi detectado nos intermetálicos contendo ferro.

Foi notado também o aparecimento de vazios nas imagens de microscopia eletrônica de todas as séries. Quando analisados, esses vazios apresentam alto teor de magnésio. Como esses vazios também foram notados na série de Referência (Figura 97 e Figura 98), não se atribuiu sua formação à fusão incipiente devido ao aumento na temperatura de tratamento térmico.

Como os vazios também não foram identificados nas regiões próximas ao início das fraturas de fadiga, pode-se concluir que sua presença não influenciou as propriedades mecânicas dos materiais avaliados.

É possível que alguma fase solúvel em água tenha se formado e, durante a preparação das amostras, essa fase tenha deixado um vazio na peça. 


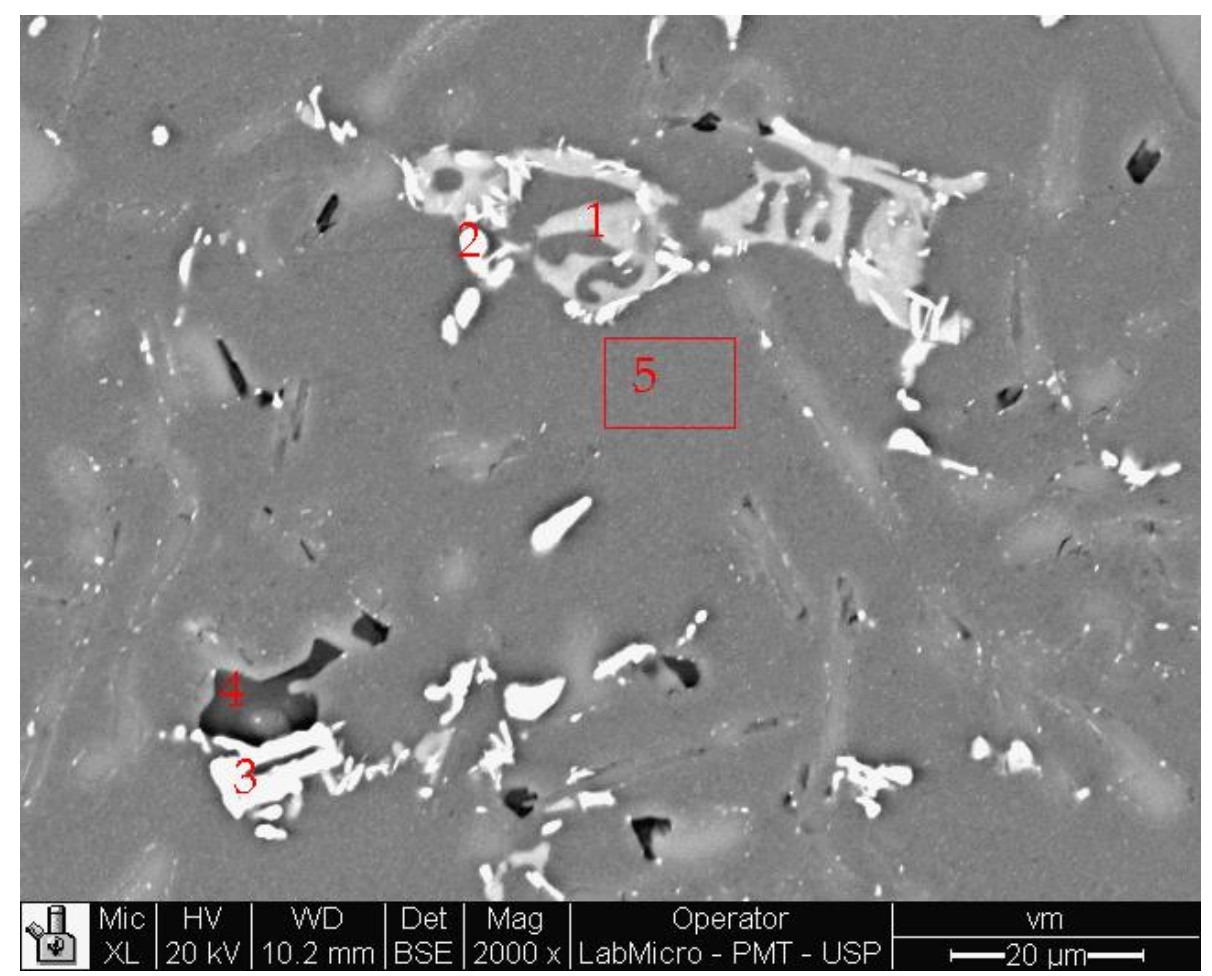

\begin{tabular}{|c|c|c|c|c|c|c|c|c|}
\hline & Al & Si & Cu & Ni & Mg & Fe & Mn & O \\
\hline Ponto 1 & 58,95 & 22,41 & 0,00 & 3,42 & 10,48 & 4,73 & 0,00 & 0,00 \\
\hline Ponto 2 & 79,09 & 0,17 & 1,90 & 16,69 & 0,54 & 1,61 & 0,00 & 0,00 \\
\hline Ponto 3 & 59,85 & 1,85 & 4,65 & 32,64 & 1,01 & 0,00 & 0,00 & 0,00 \\
\hline Ponto 4 & 20,73 & 39,62 & 0,00 & 0,00 & 35,31 & 0,00 & 0,00 & 4,34 \\
\hline Ponto 5 & 98,52 & 0,00 & 1,11 & 0,00 & 0,37 & 0,00 & 0,00 & 0,00 \\
\hline
\end{tabular}

Figura 154 - Análise de composição química em EDS das fases presentes na microestrutura da série R-TT. Dados de composição química em peso\%. 


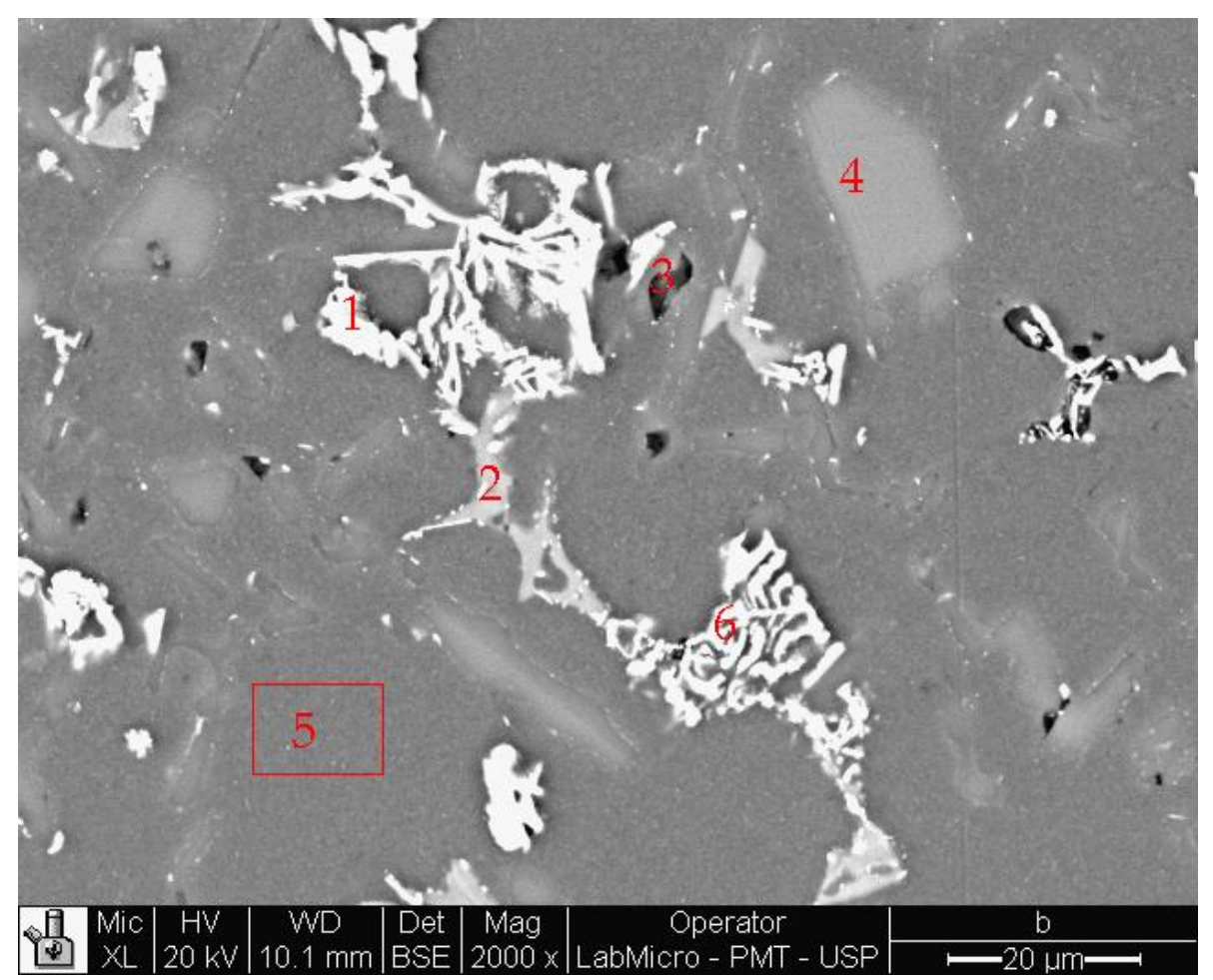

\begin{tabular}{|l|c|c|c|c|c|c|c|c|c|}
\hline & $\mathbf{A l}$ & $\mathbf{S i}$ & $\mathbf{C u}$ & $\mathbf{N i}$ & $\mathbf{M g}$ & $\mathbf{F e}$ & $\mathbf{M n}$ & $\mathbf{0}$ & $\mathbf{Z r}$ \\
\hline Ponto 1 & 59,31 & 0,90 & 17,55 & 22,24 & 0,00 & 0,00 & 0,00 & 0,00 & 0,00 \\
\hline Ponto 2 & 77,12 & 10,90 & 0,00 & 2,85 & 5,27 & 2,70 & 1,16 & 0,00 & 0,00 \\
\hline Ponto 3 & 33,88 & 31,00 & 0,00 & 1,85 & 27,22 & 1,26 & 1,26 & 3,54 & 0,00 \\
\hline Ponto 4 & 0,00 & 100,00 & 0,00 & 0,00 & 0,00 & 0,00 & 0,00 & 0,00 & 0,00 \\
\hline Ponto 5 & 98,48 & 0,00 & 1,52 & 0,00 & 0,00 & 0,00 & 0,00 & 0,00 & 0,00 \\
\hline Ponto 6 & 75,82 & 3,23 & 2,35 & 14,23 & 0,37 & 1,13 & 0,95 & 0,00 & 1,92 \\
\hline
\end{tabular}

Figura 155 - Análise de composição química em EDS das fases presentes na microestrutura da série de R-ZrVTiMn. Dados de composição química em peso\%.

Comparando-se o fator de circularidade das partículas de silício (Figura 156) e o fator de circularidade do total de partículas incluindo intermetálicos (Figura 157), nota-se que os valores são estatisticamente iguais e que a presença de zircônio, vanádio, titânio e manganês não afeta o fator de circularidade do silício. 


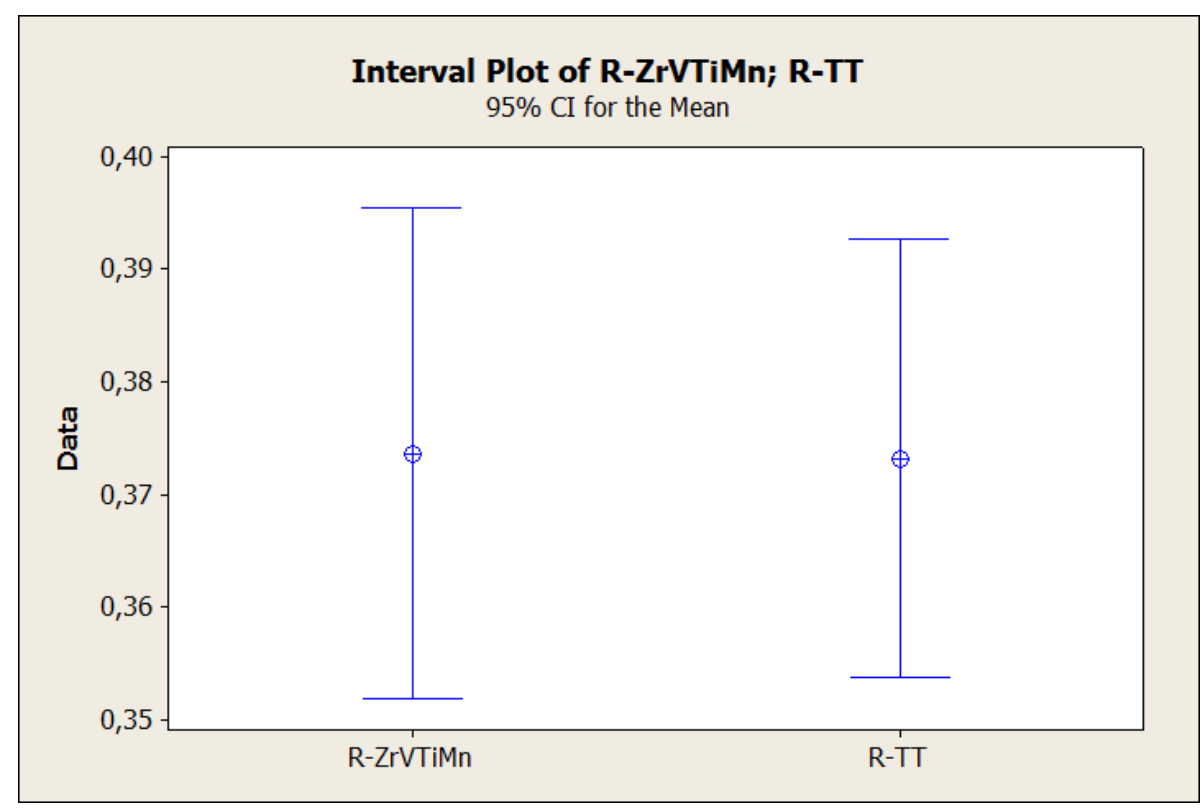

Figura 156 - Comparação de fator de circularidade das partículas de silício entre as séries RZrVTiMn e R-TT.

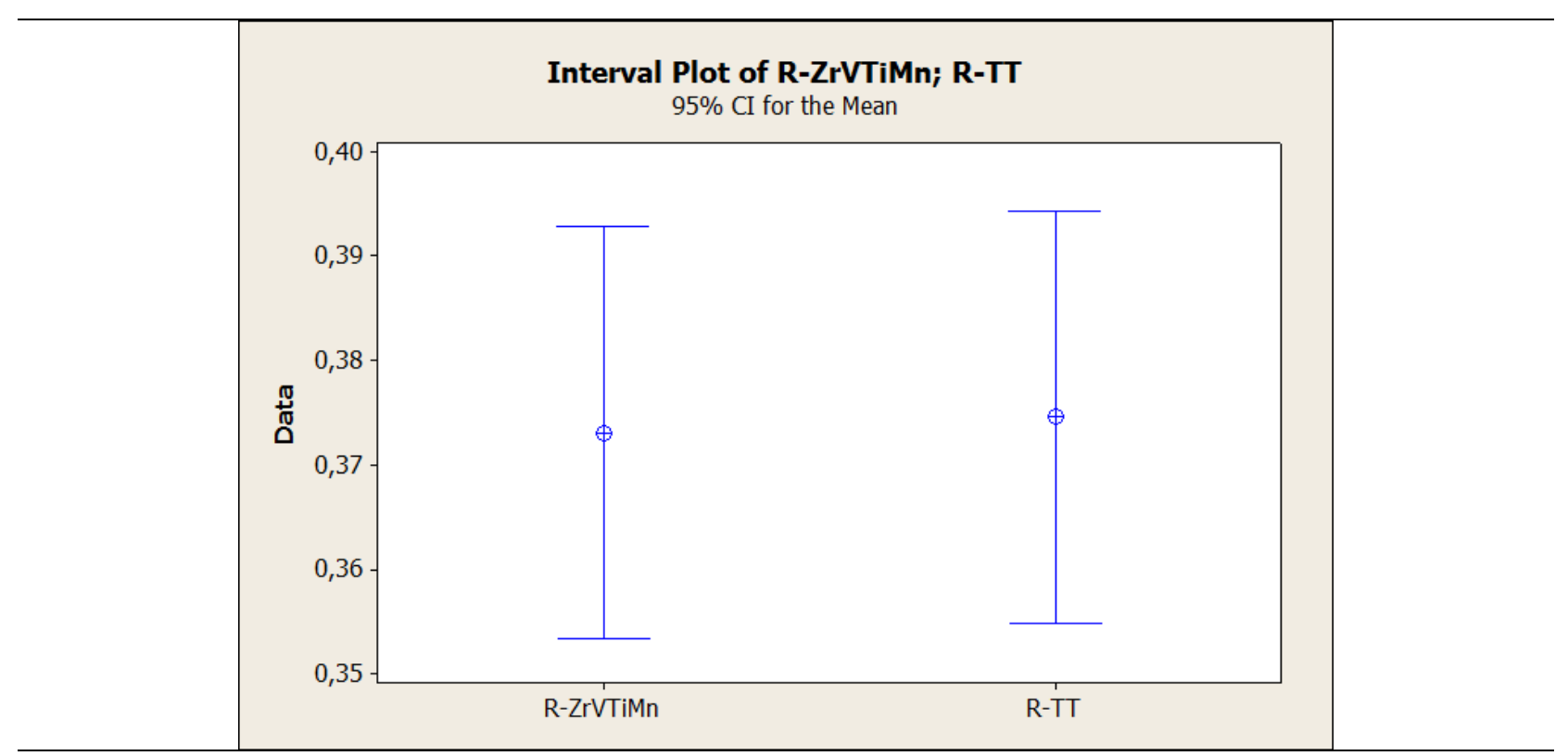

Figura 157 - Fator de circularidade total das séries de R-ZrVTiMn e R-TT.

Nos ensaios de tração a quente, os resultados de limite de resistência e limite de escoamento (Figura 158) se mostraram aproximadamente iguais para as séries R-TT e R-ZrVTiMn. No entanto, a adição de elementos de liga resultou na queda do alongamento da série R-ZrVTiMn quando comparada à série R-TT. 
Comparando-se as durezas após os ensaios de tração e fadiga a quente (Figura 158 e Tabela 12), pode-se dizer que as adições realizadas não tiveram efeito significativo sobre o endurecimento da matriz de alumínio.

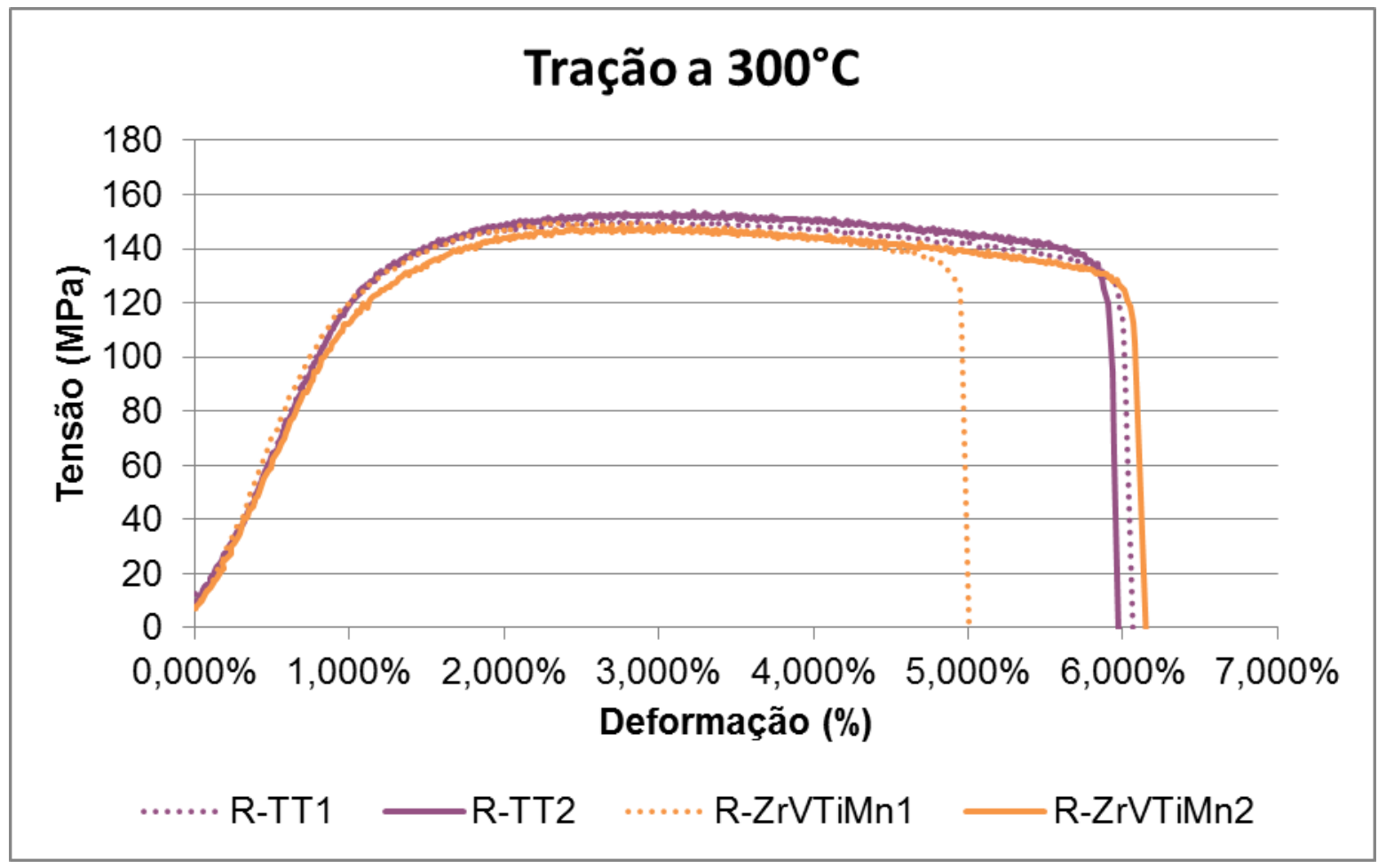

\begin{tabular}{c|c|c|c|c}
\hline & LE (MPa) & LR (MPa) & Dureza final (HB) & $\begin{array}{c}\text { Dureza da matriz de } \\
\text { alumínio (HV) }\end{array}$ \\
\cline { 1 - 3 } R-TT 1 & 126 & 150 & \multirow{2}{*}{83,0} & 62,9 \\
\hline R-TT 2 & 125 & 148 & \multirow{2}{*}{83,0} & \multirow{2}{*}{63,3} \\
\hline R-ZrVTiMn 1 & 129 & 151 & 148 & \\
\hline
\end{tabular}

Figura 158 - Dados de Tensão-Deformação a $300^{\circ} \mathrm{C}$.

Seguindo a mesma linha de raciocínio apresentada na análise do efeito do tratamento térmico, existe uma tendência de nucleação preferencial das trincas em partículas de silício primário de tamanho maior que a média da população de partículas (Tabela 16). Se a nucleação da trinca e a matriz de alumínio são iguais para as séries R-TT e RZrVTiMn, assume-se então que a propagação da trinca esteja influenciando a menor vida em fadiga encontrada na série R-ZrVTiMn. 
Foi realizada uma medição da área ocupada por intermetálicos nas ligas R-TT e RZrVTiMn, sendo que a diferença encontrada foi de apenas $0,4 \%(9,28 \%$ da área é ocupada por intermetálicos na série R-TT, enquanto $9,66 \%$ da área é ocupada por intermetálicos na série R-ZrVTiMn). No entanto, a medição da quantidade de intersecções entre linhas paralelas sobrepostas à imagem da microestrutura mostra um aumento de $50 \%$ de intersecções na liga R-ZrVTiMn quando comparada à liga R-TT. As imagens da superfície da trinca do corpo de prova de fadiga, apresentadas na Figura 159 à Figura 162, mostram que a propagação da trinca tende a ocorrer através de partículas frágeis (silício e partículas intermetálicas).

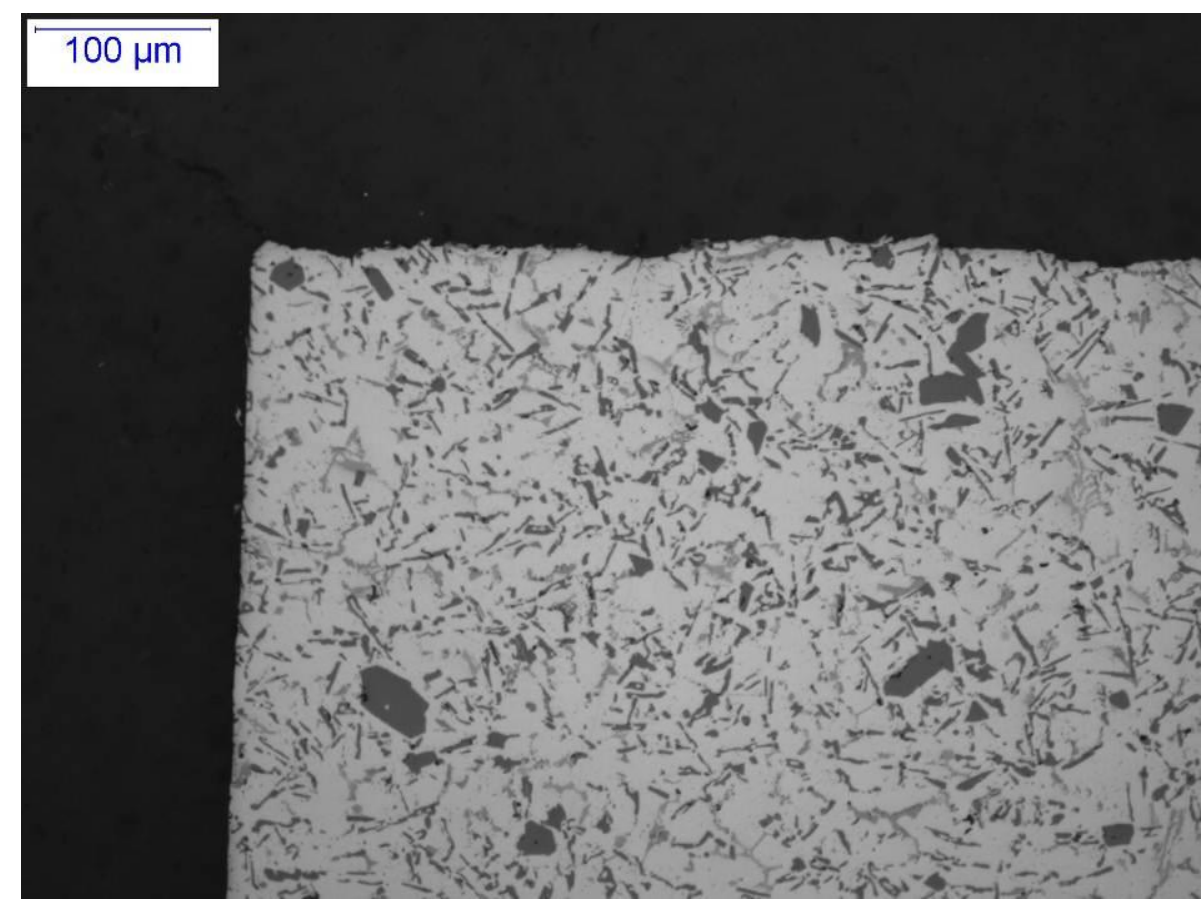

Figura 159 - Série R-ZrVTiMn (Amostra 22): superfície de fratura (200x).

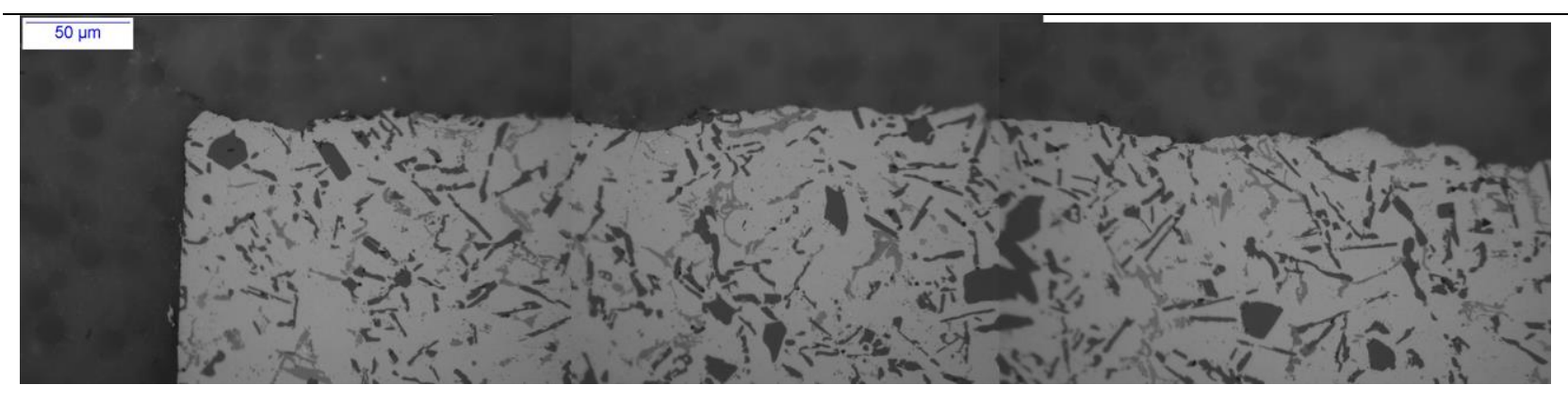

Figura 160 - Série R-ZrVTiMn (Amostra 22): superfície de fratura (500x). 


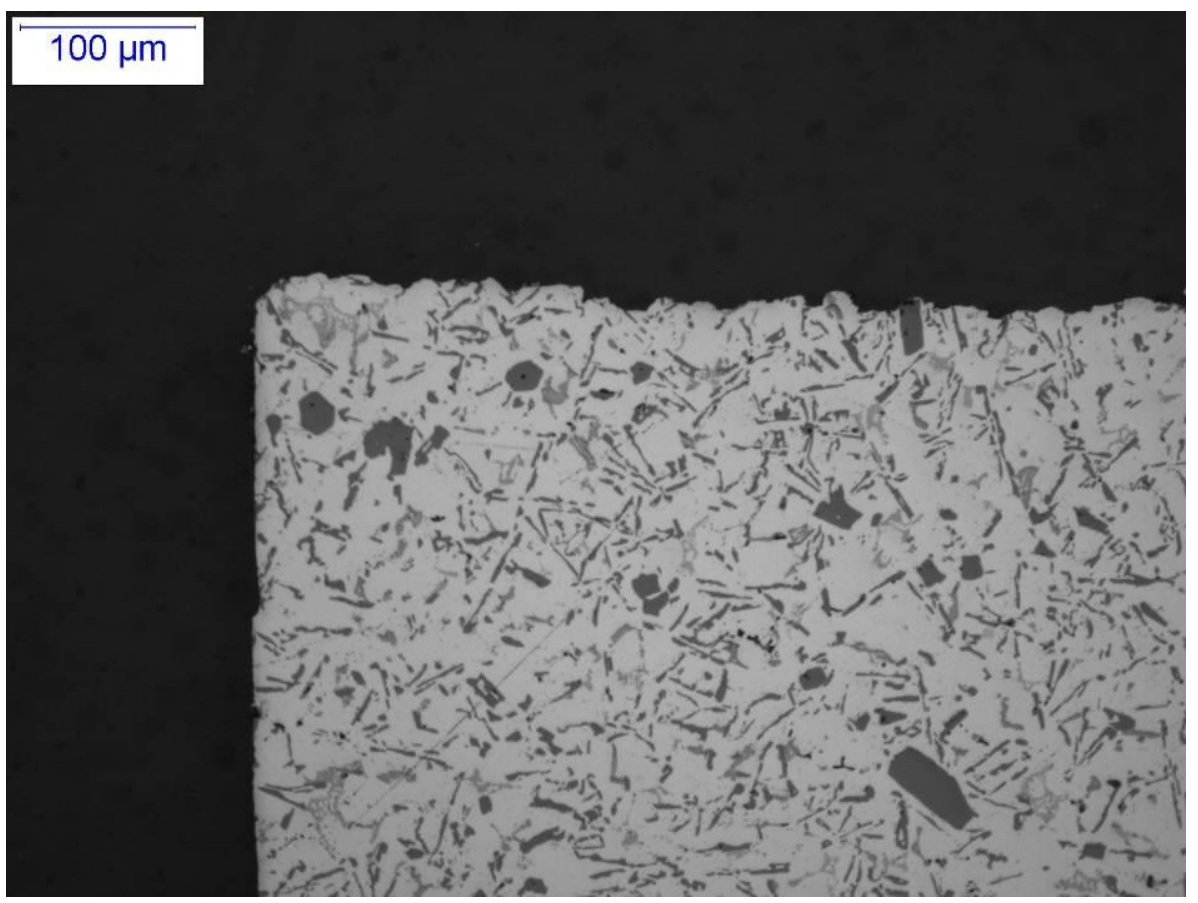

Figura 161 - Série R-TT (Amostra 32): superfície de fratura (200x).

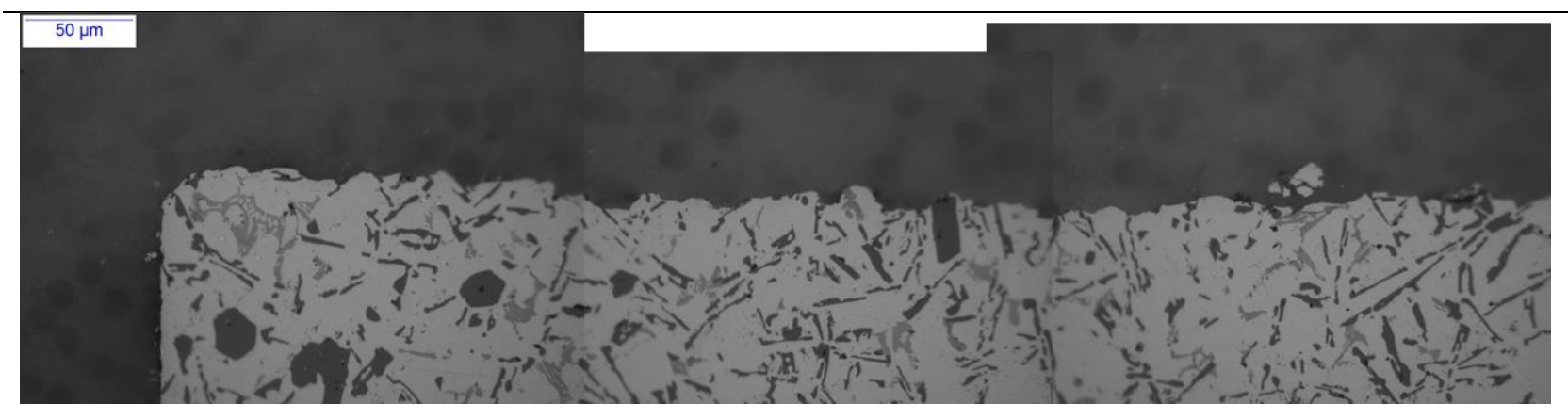

Figura 162 - Série R-TT (Amostra 32): superfície de fratura (500x).

Quando se compara as superfícies de fratura dos corpos de prova de tração, nota-se que na série R-TT, a fratura passa predominantemente por partículas de silício (Figura 163 à Figura 181). 


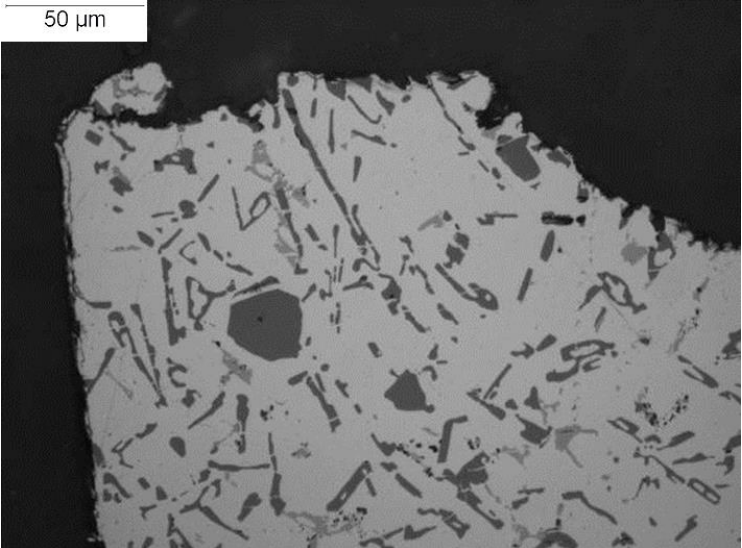

Figura 163 - Superfície de fratura do corpo de prova de tração a quente da série R-TT. Parte 1. (500x)

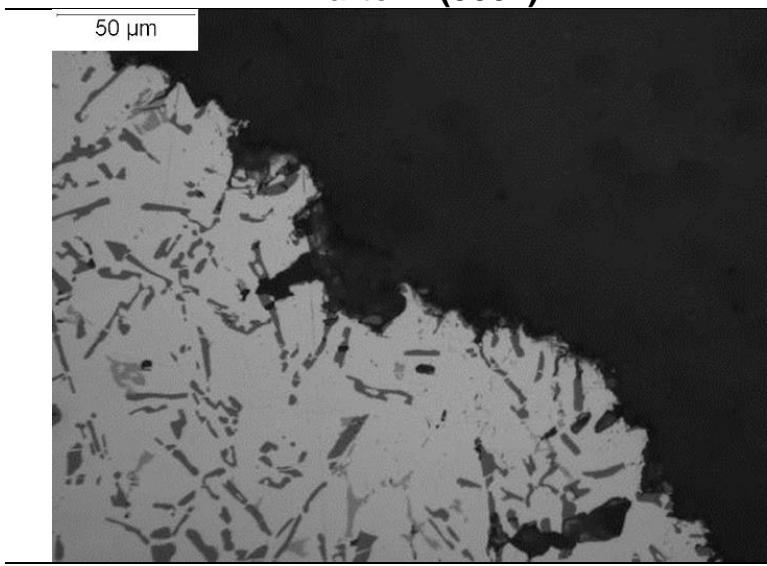

Figura 165 - Superfície de fratura do corpo de prova de tração a quente da série R-TT. Parte 3. (500x)

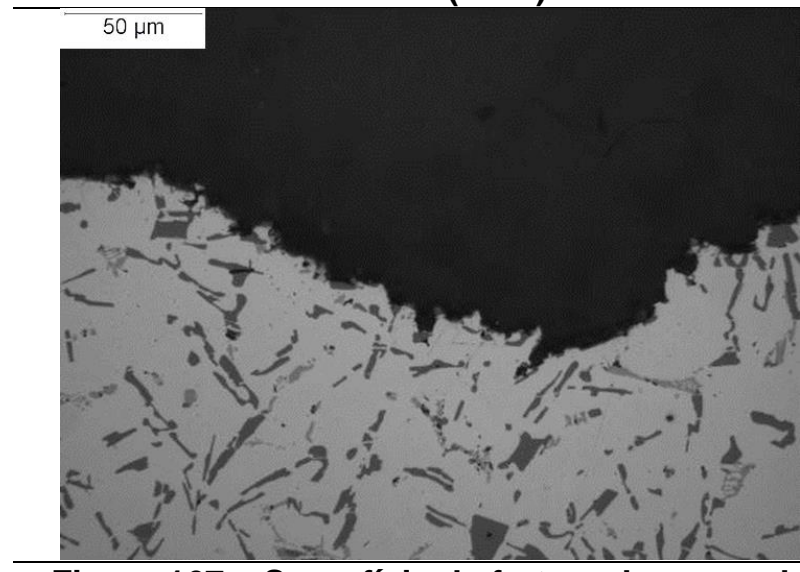

Figura 167 - Superfície de fratura do corpo de prova de tração a quente da série R-TT. Parte 5. (500x)

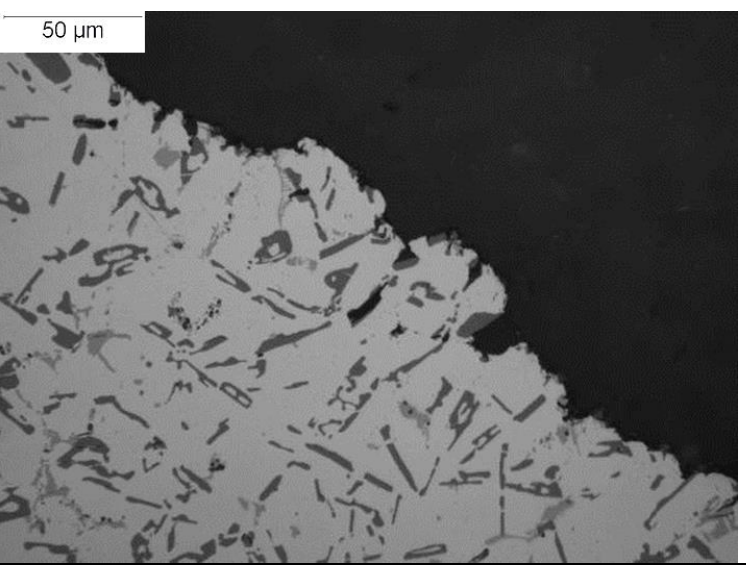

Figura 164 - Superfície de fratura do corpo de prova de tração a quente da série R-TT. Parte 2. (500x)

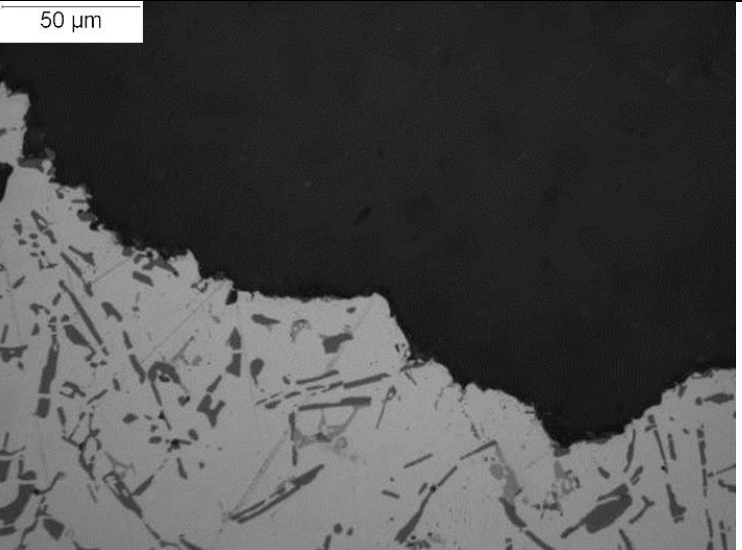

Figura 166 - Superfície de fratura do corpo de prova de tração a quente da série R-TT. Parte 4. (500x)

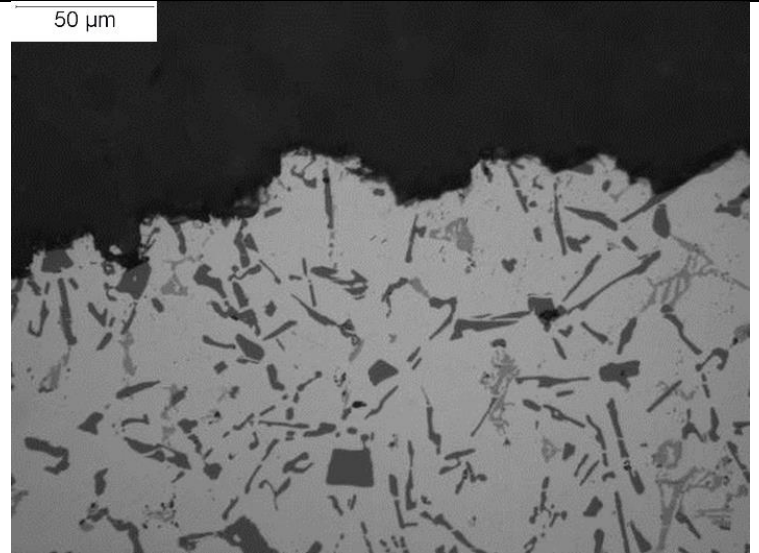

Figura 168 - Superfície de fratura do corpo de prova de tração a quente da série R-TT. Parte 6. (500x) 


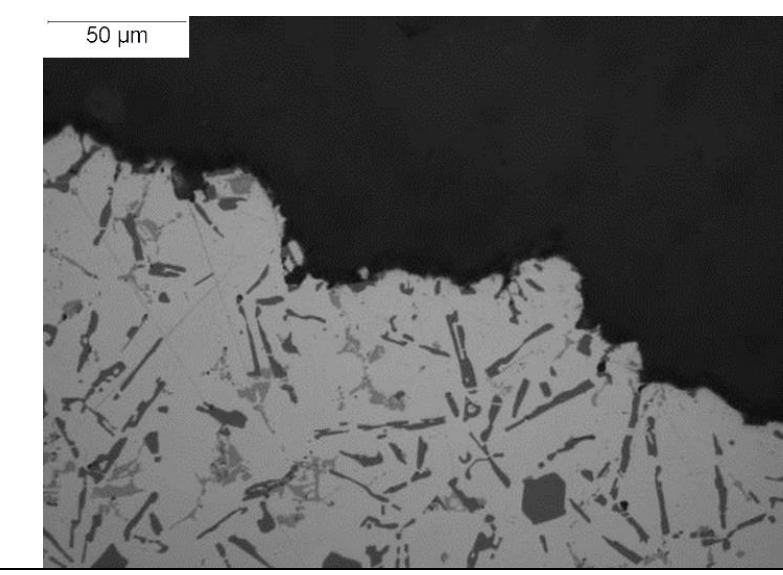

Figura 169 - Superfície de fratura do corpo de prova de tração a quente da série R-TT. Parte 7. (500x)

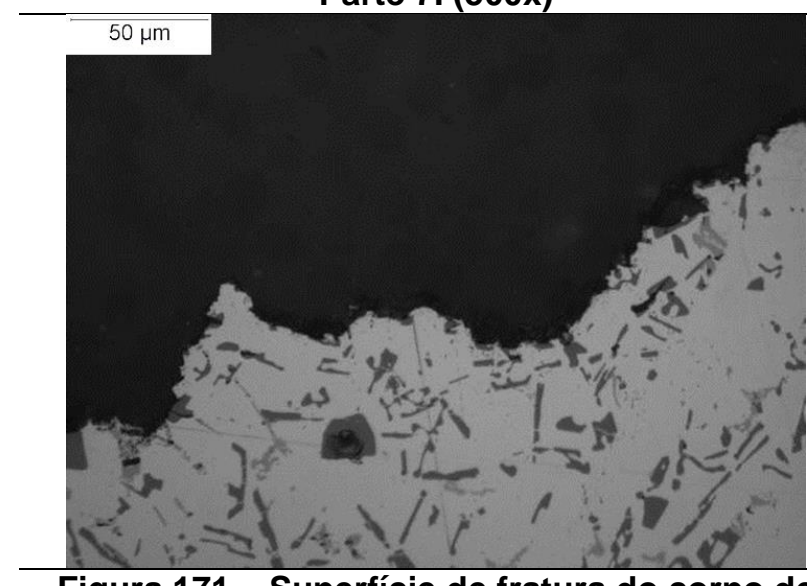

Figura 171 - Superfície de fratura do corpo de prova de tração a quente da série R-TT. Parte 9. (500x)

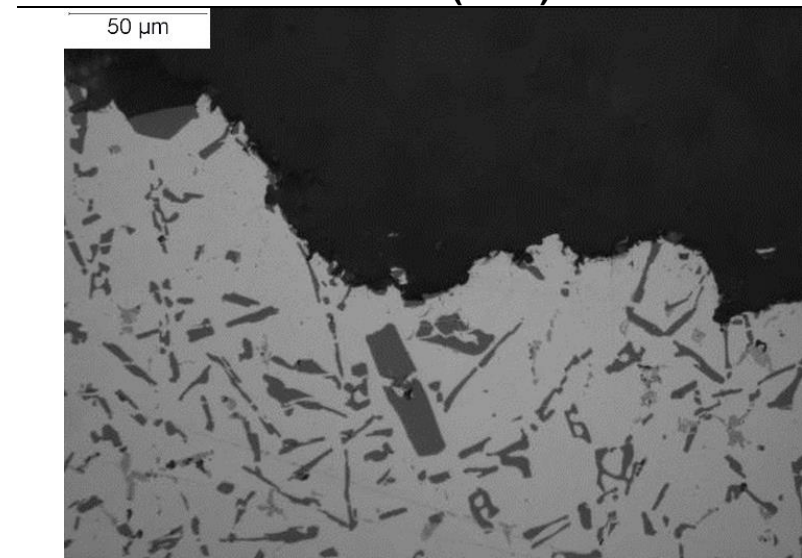

Figura 173 - Superfície de fratura do corpo de prova de tração a quente da série R-TT. Parte 11. (500x)

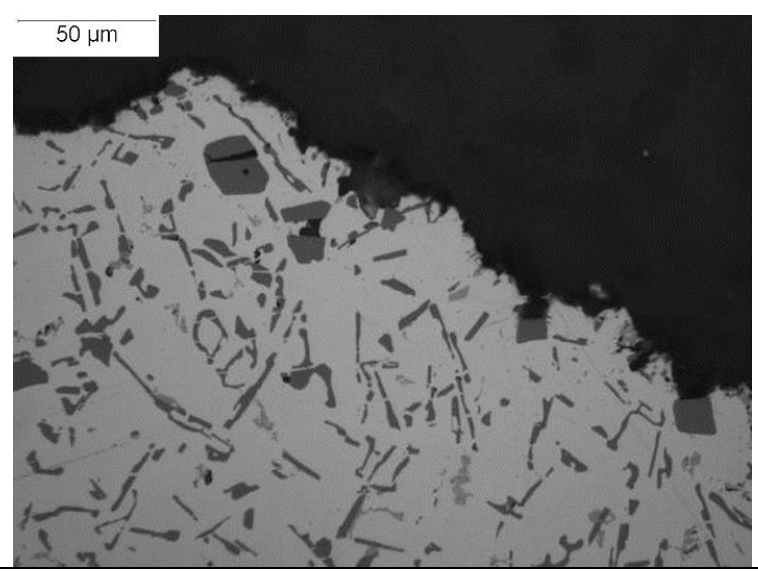

Figura 170 - Superfície de fratura do corpo de prova de tração a quente da série R-TT. Parte 8. (500x)

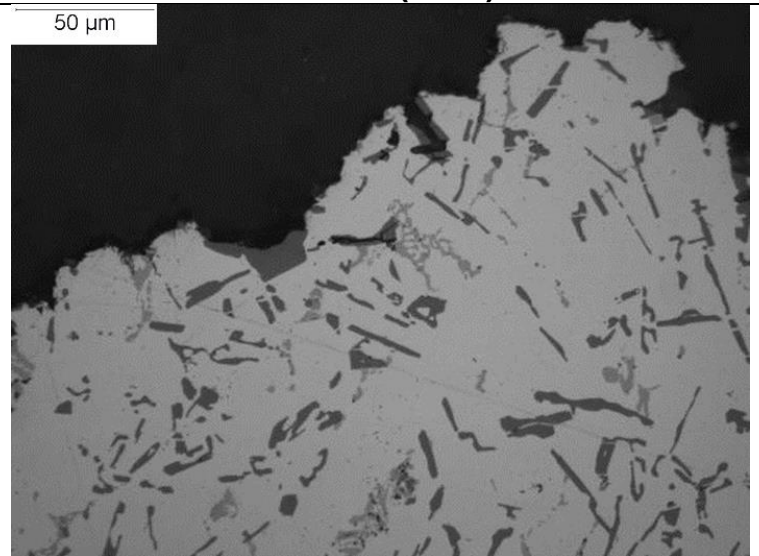

Figura 172 - Superfície de fratura do corpo de prova de tração a quente da série R-TT. Parte 10. (500x)

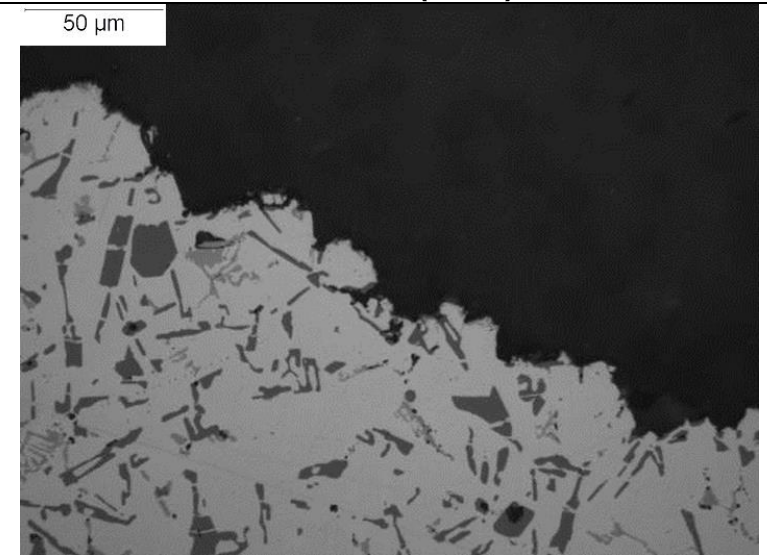

Figura 174 - Superfície de fratura do corpo de prova de tração a quente da série R-TT. Parte 12. (500x) 


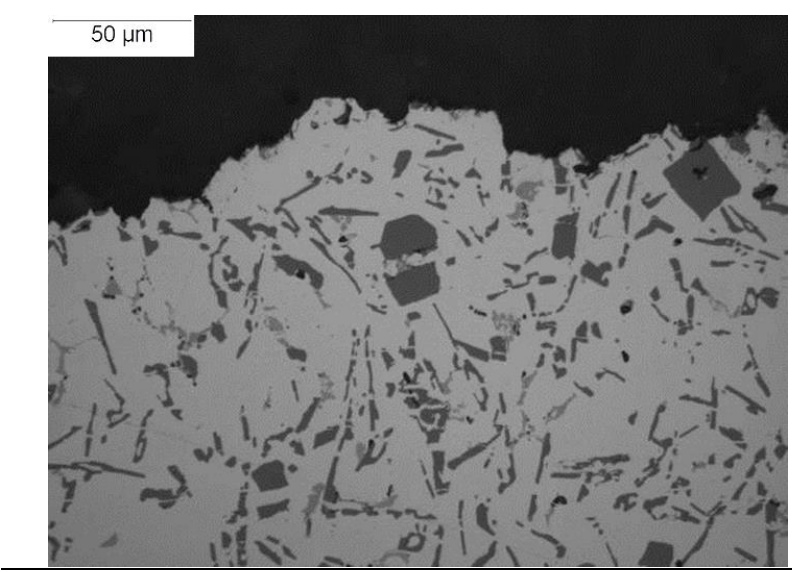

Figura 175 - Superfície de fratura do corpo de prova de tração a quente da série R-TT. Parte 13. (500x)

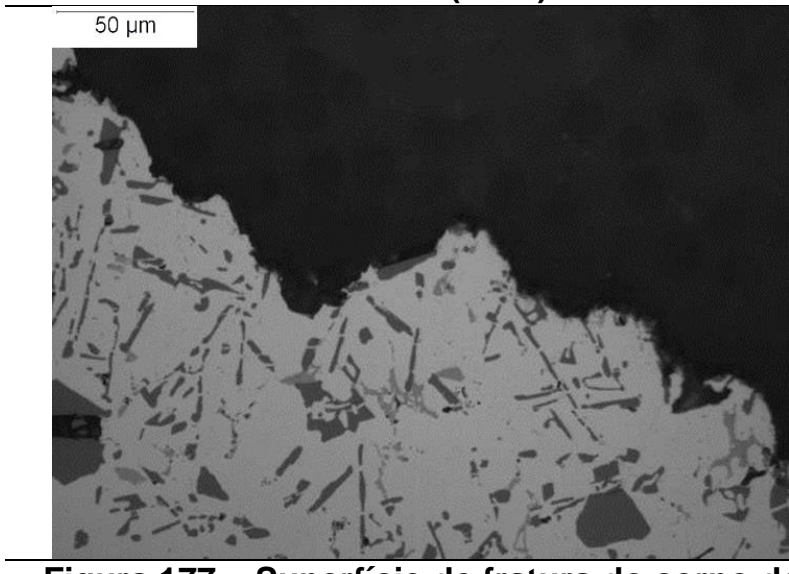

Figura 177 - Superfície de fratura do corpo de prova de tração a quente da série R-TT.

Parte 15. (500x)

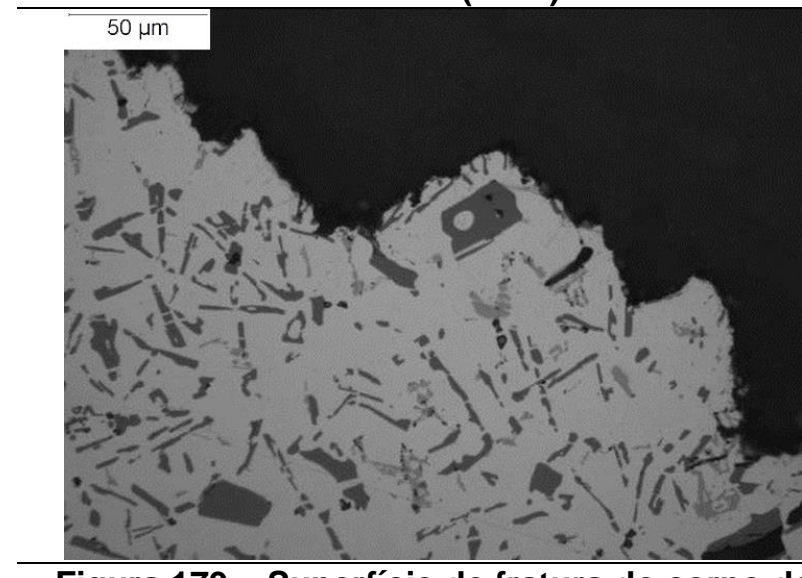

Figura 179 - Superfície de fratura do corpo de prova de tração a quente da série R-TT. Parte 17. (500x)

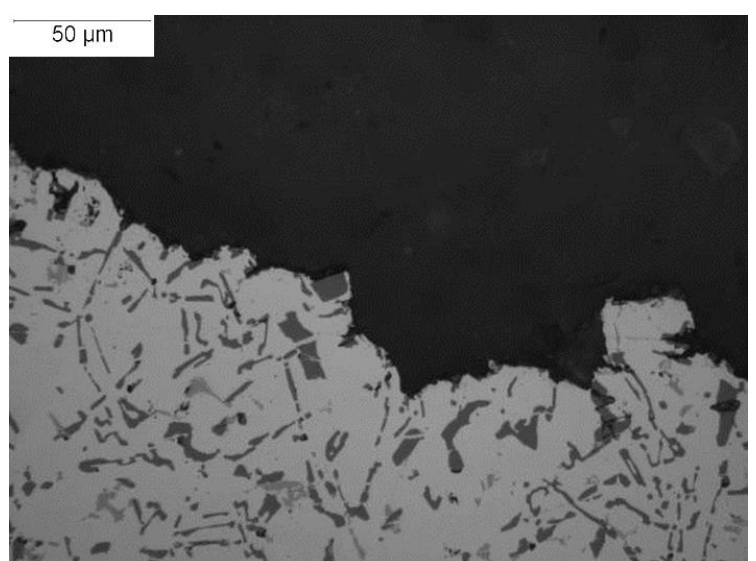

Figura 176 - Superfície de fratura do corpo de prova de tração a quente da série R-TT. Parte 14. (500x)

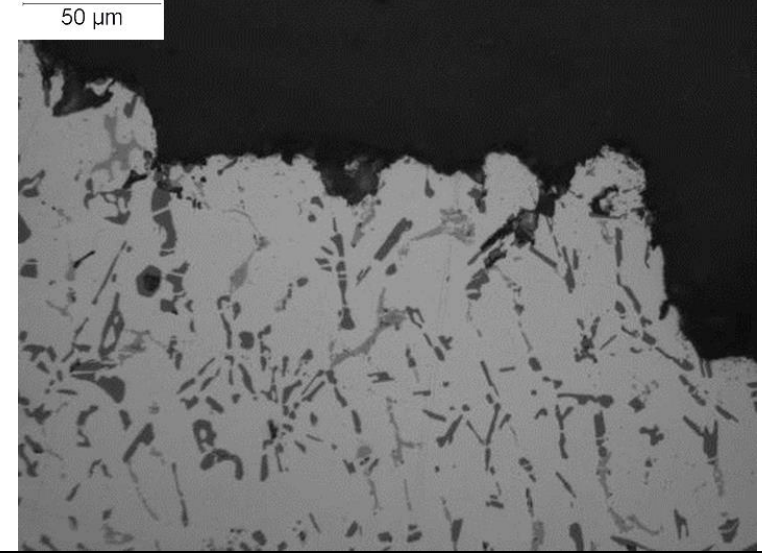

Figura 178 - Superfície de fratura do corpo de prova de tração a quente da série R-TT. Parte 16. (500x)

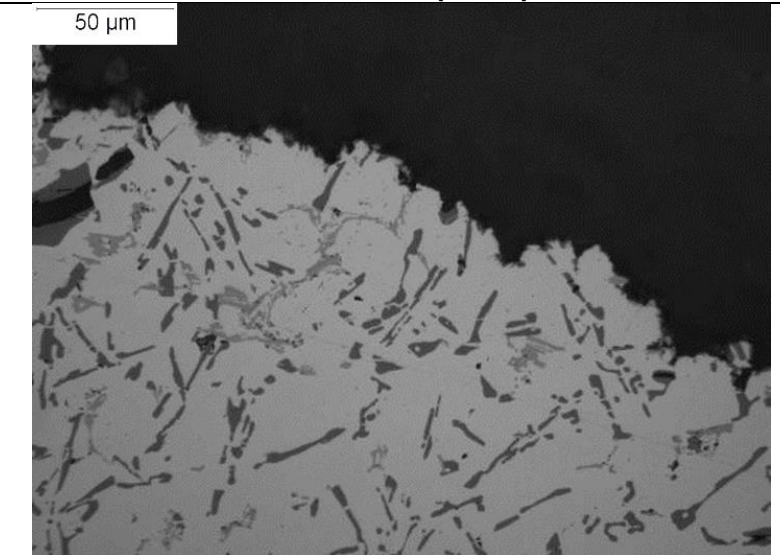

Figura 180 - Superfície de fratura do corpo de prova de tração a quente da série R-TT. Parte 18. (500x) 


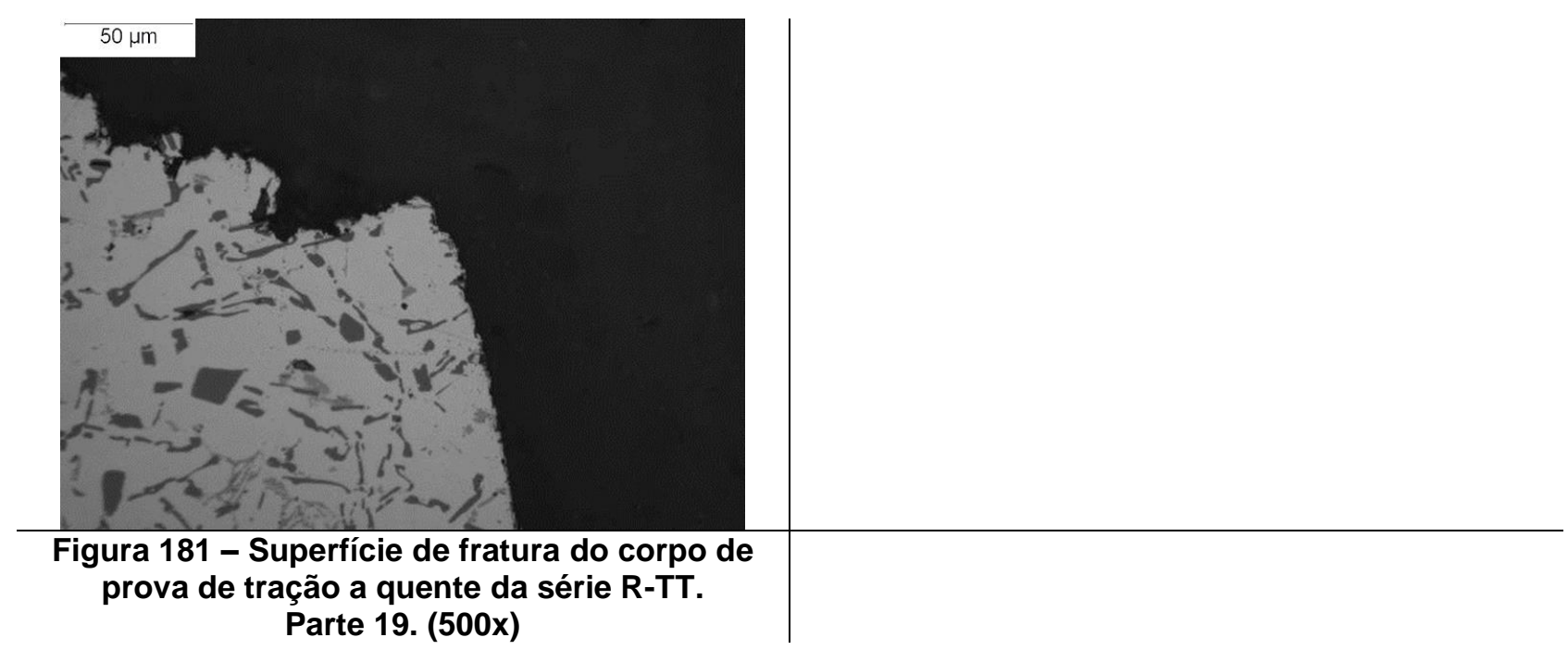

Na série R-ZrVTiMn, a fratura passa tanto por partículas de silício, quanto por partículas de intermetálicos (Figura 182 à Figura 201).

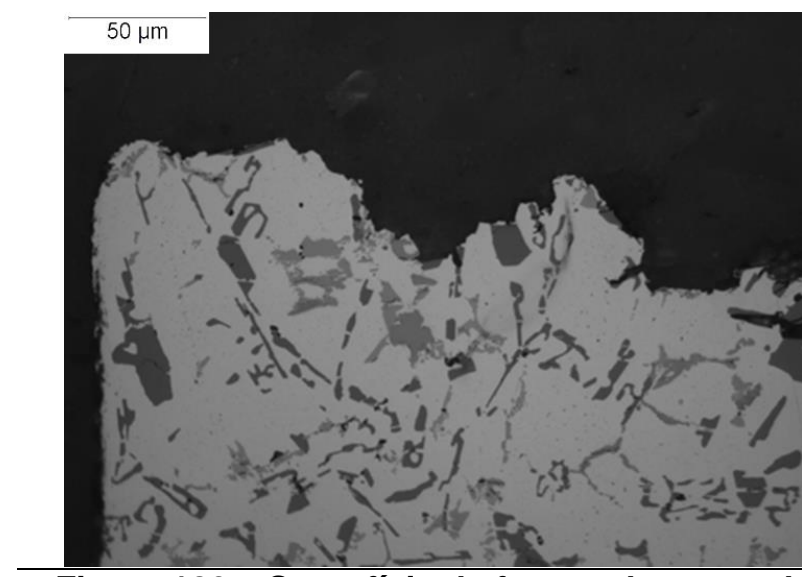

Figura 182 - Superfície de fratura do corpo de prova de tração a quente da série R-ZrVTiMn.

Parte 1. (500x)

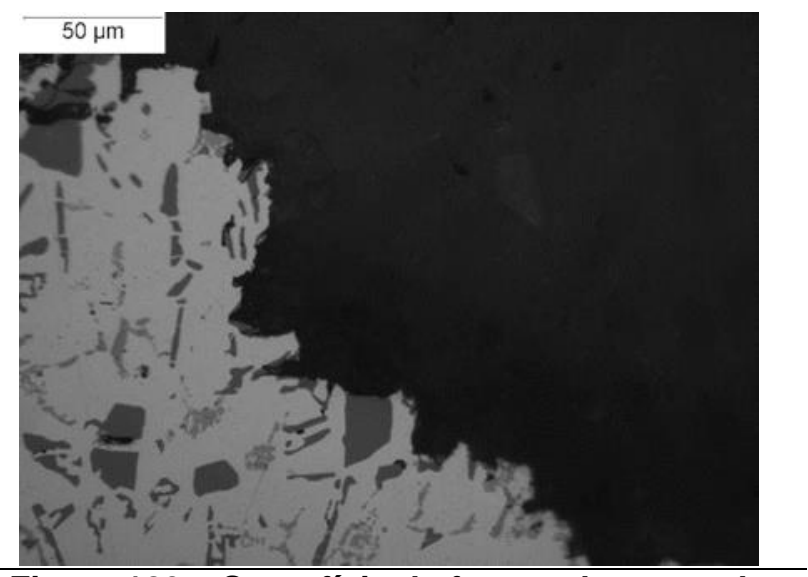

Figura 183 - Superfície de fratura do corpo de prova de tração a quente da série R-ZrVTiMn.

Parte 2. (500x) 


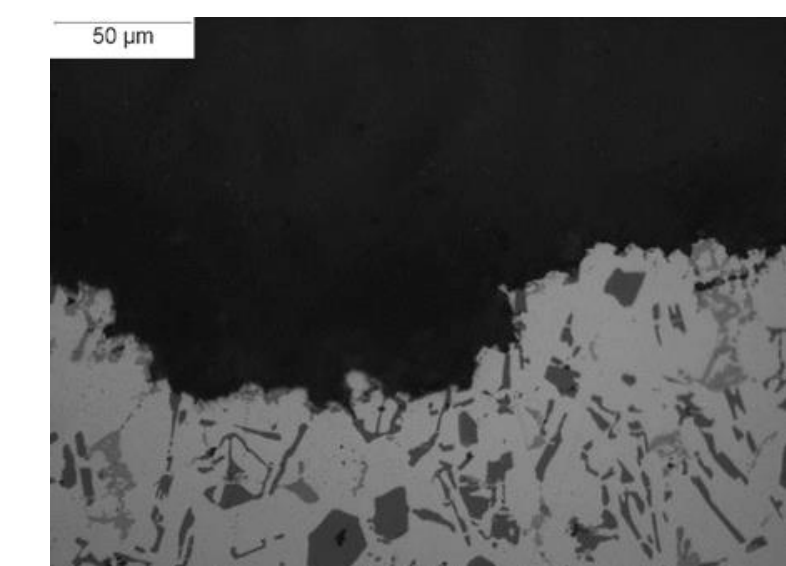

Figura 184 - Superfície de fratura do corpo de prova de tração a quente da série R-ZrVTiMn.

Parte 3. (500x)

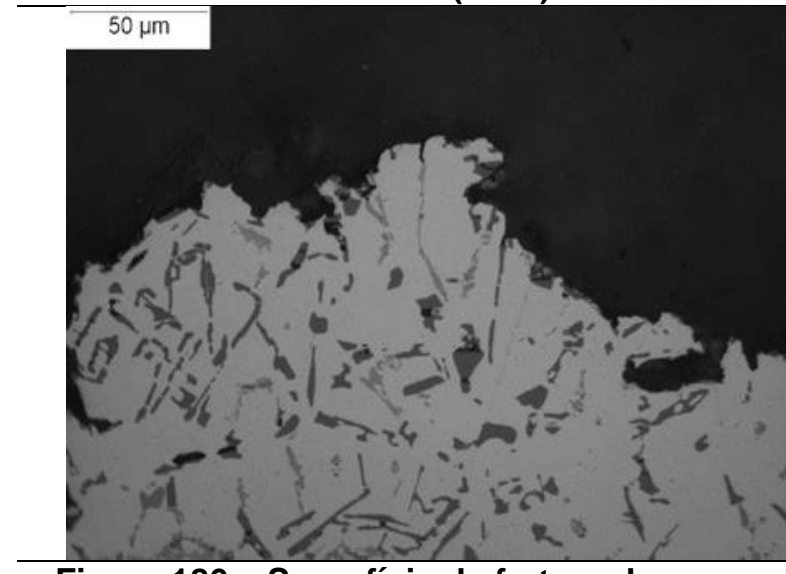

Figura 186 - Superfície de fratura do corpo de prova de tração a quente da série R-ZrVTiMn. Parte 5. (500x)

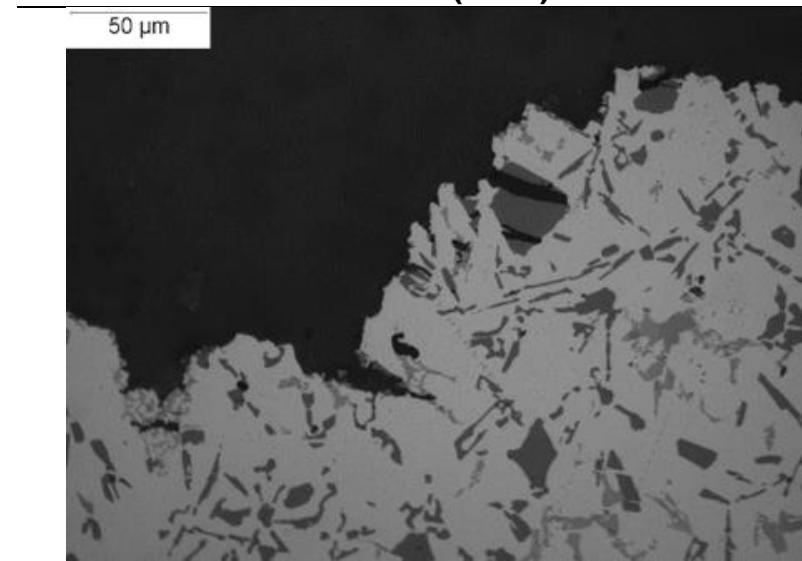

Figura 188 - Superfície de fratura do corpo de prova de tração a quente da série R-ZrVTiMn. Parte 7. (500x)

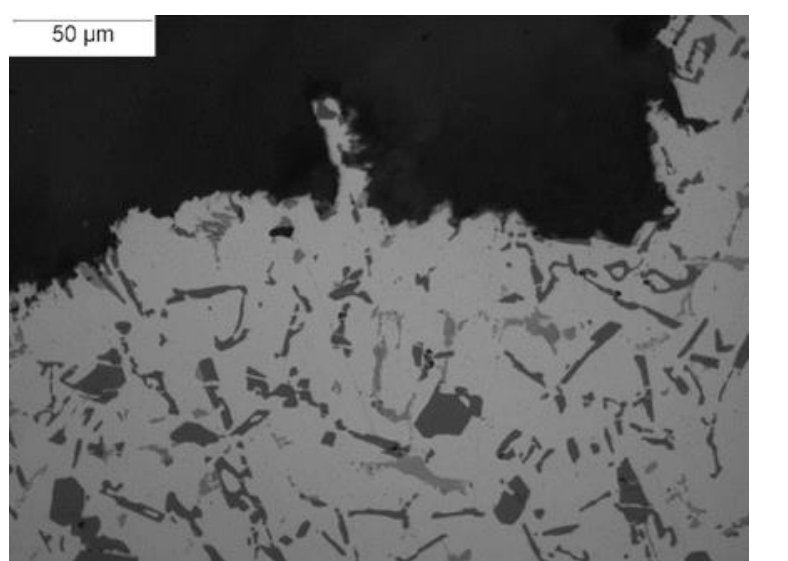

Figura 185 - Superfície de fratura do corpo de prova de tração a quente da série R-ZrVTiMn.

Parte 4. (500x)

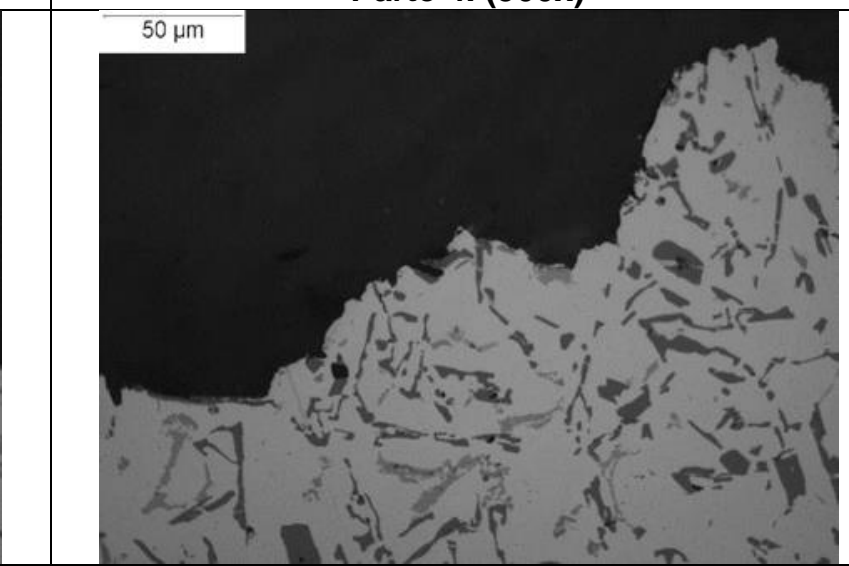

Figura 187 - Superfície de fratura do corpo de prova de tração a quente da série R-ZrVTiMn.

Parte 6. (500x)

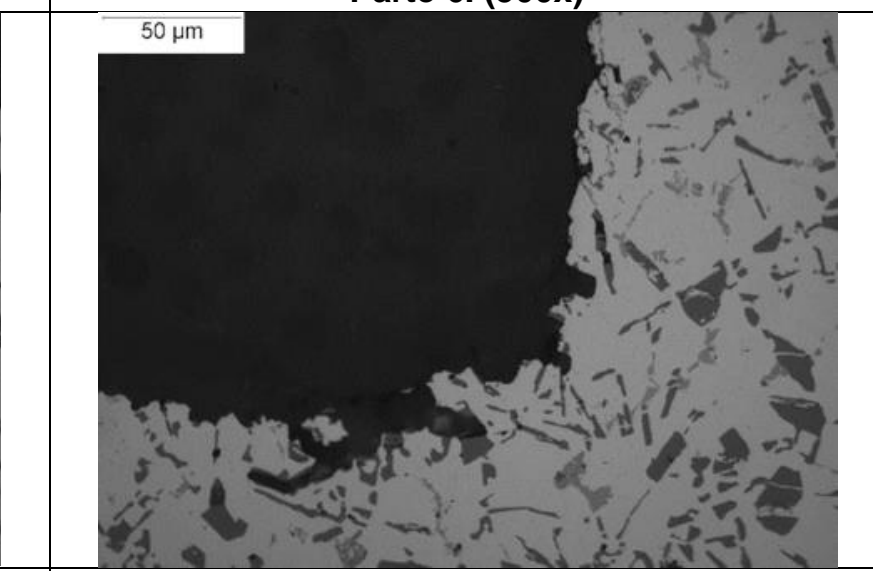

Figura 189 - Superfície de fratura do corpo de prova de tração a quente da série R-ZrVTiMn.

Parte 8. (500x) 


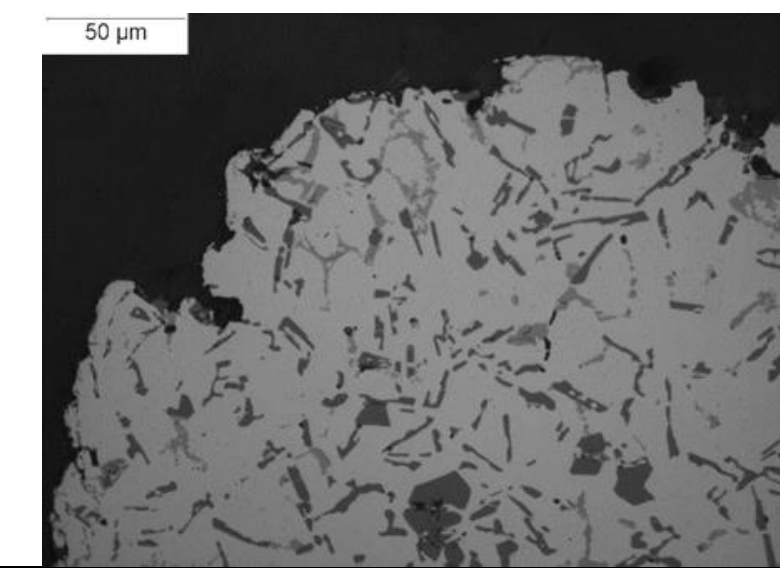

Figura 190 - Superfície de fratura do corpo de prova de tração a quente da série R-ZrVTiMn.

Parte 9. (500x)

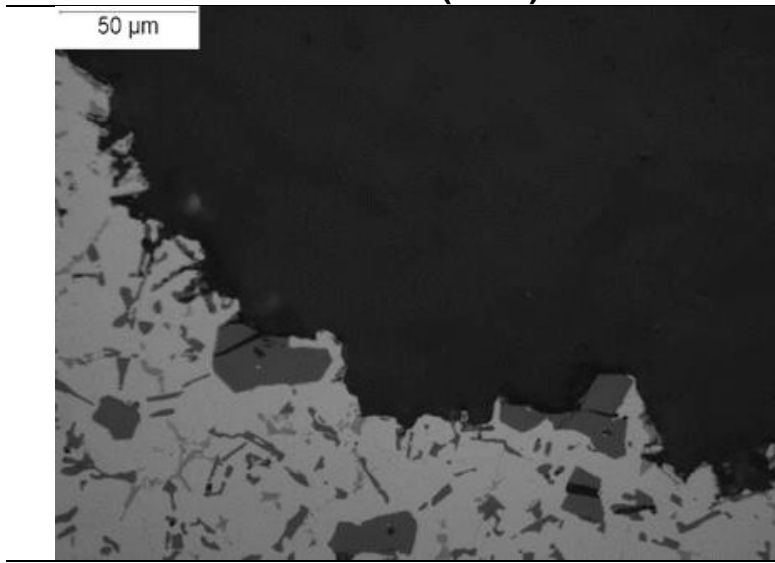

Figura 192 - Superfície de fratura do corpo de prova de tração a quente da série R-ZrVTiMn.

Parte 11. (500x)

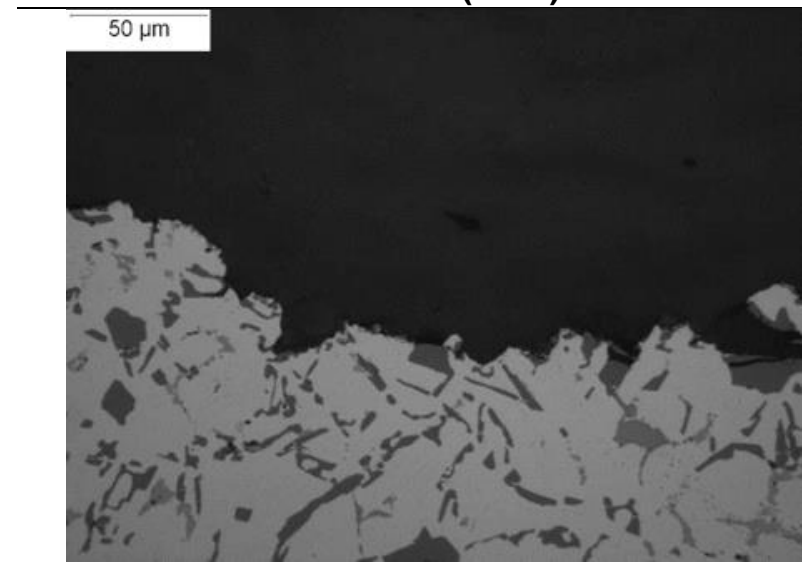

Figura 194 - Superfície de fratura do corpo de prova de tração a quente da série R-ZrVTiMn. Parte 13. (500x)

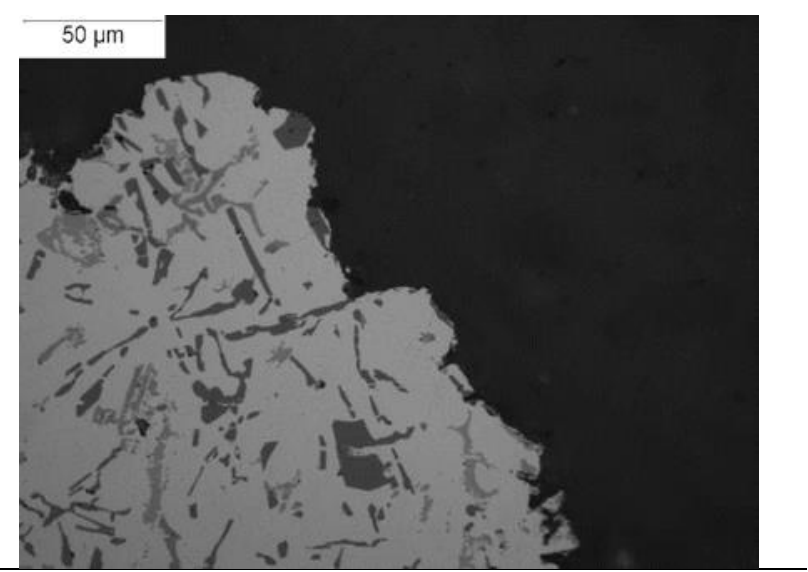

Figura 191 - Superfície de fratura do corpo de prova de tração a quente da série R-ZrVTiMn. Parte 10. (500x)

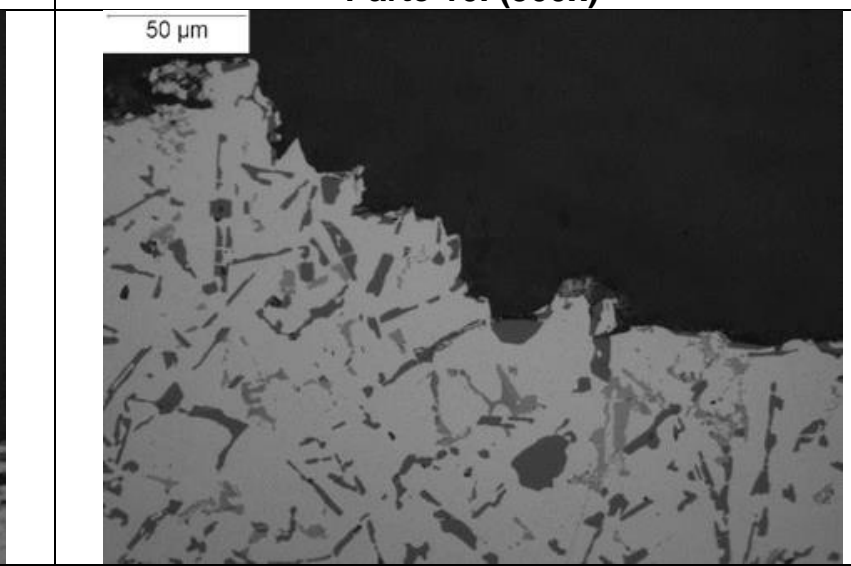

Figura 193 - Superfície de fratura do corpo de prova de tração a quente da série R-ZrVTiMn.

Parte 12. (500x)

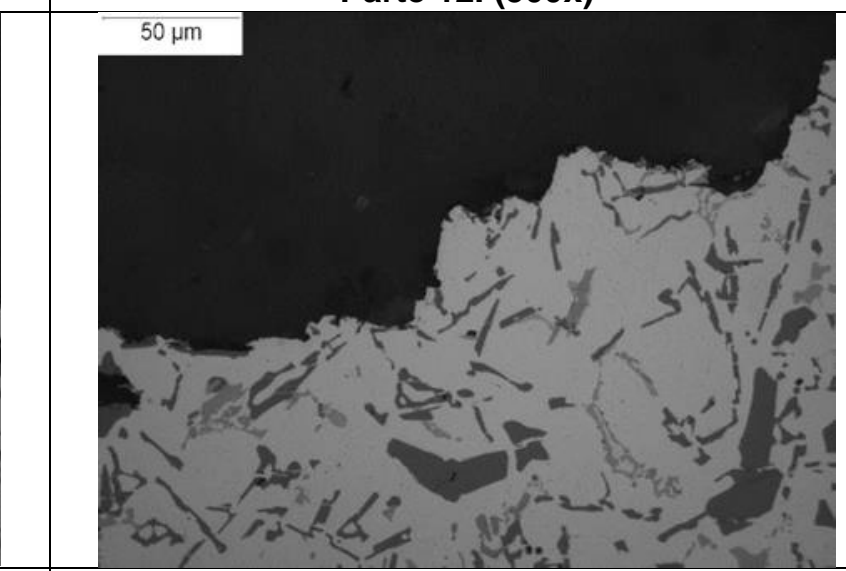

Figura 195 - Superfície de fratura do corpo de prova de tração a quente da série R-ZrVTiMn.

Parte 14. (500x) 


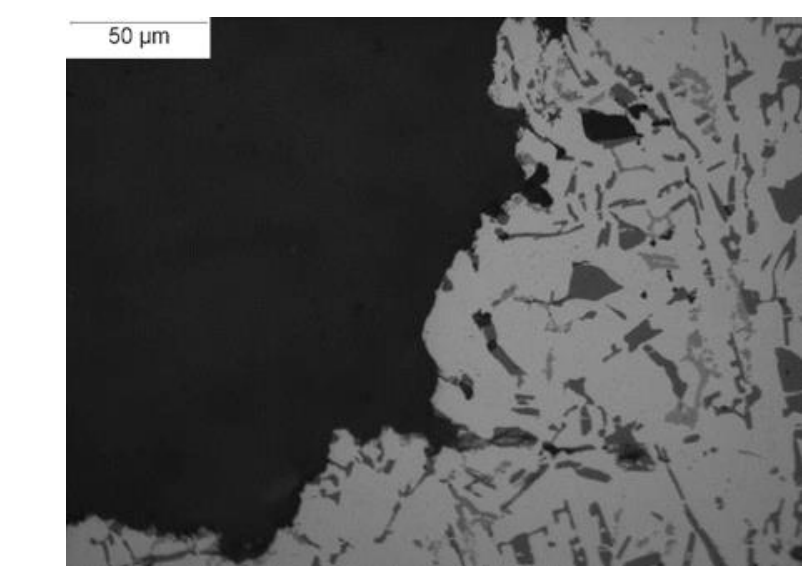

Figura 196 - Superfície de fratura do corpo de prova de tração a quente da série R-ZrVTiMn.

Parte 15. (500x)

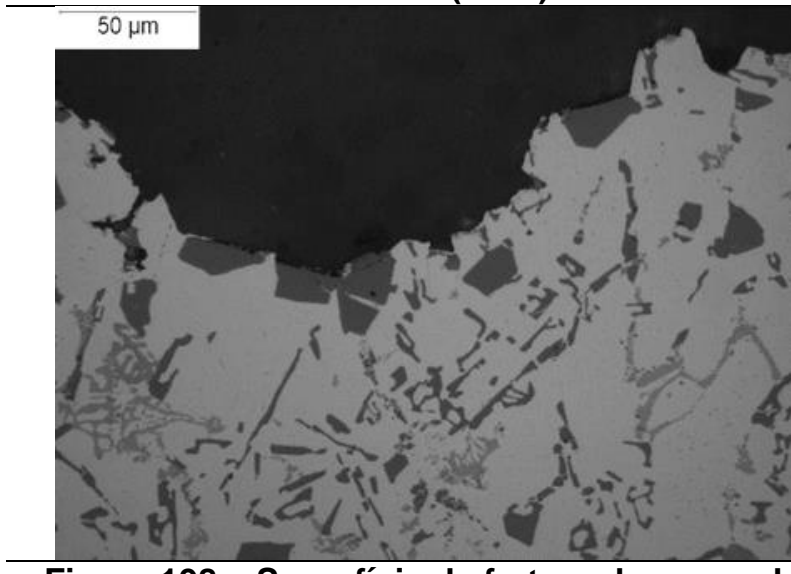

Figura 198 - Superfície de fratura do corpo de prova de tração a quente da série R-ZrVTiMn.

Parte 17. (500x)

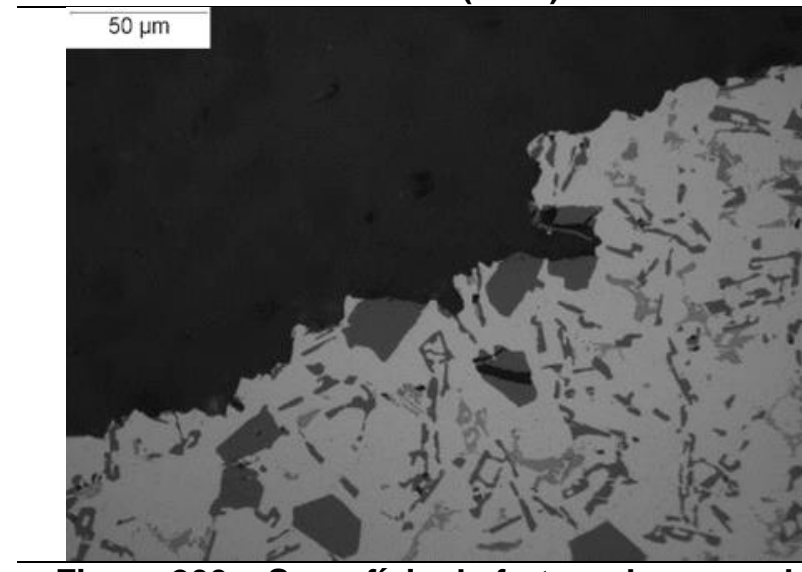

Figura 200 - Superfície de fratura do corpo de prova de tração a quente da série R-ZrVTiMn.

Parte 19. (500x)

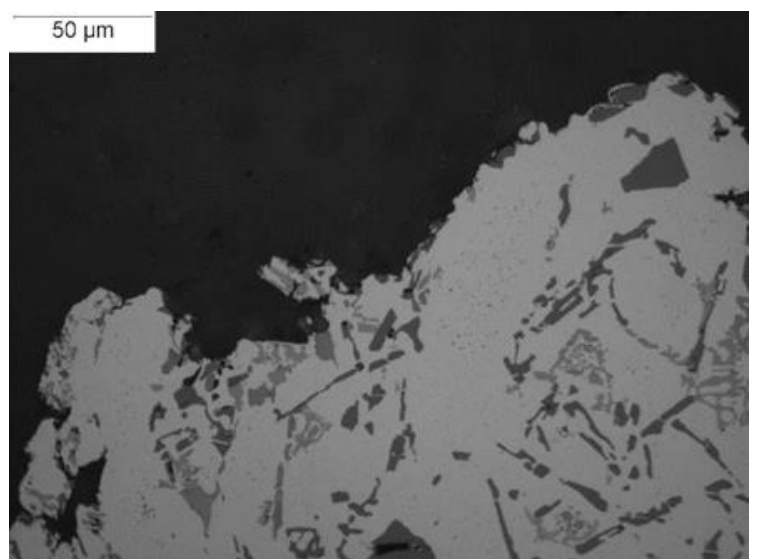

Figura 197 - Superfície de fratura do corpo de prova de tração a quente da série R-ZrVTiMn.

Parte 16. (500x)

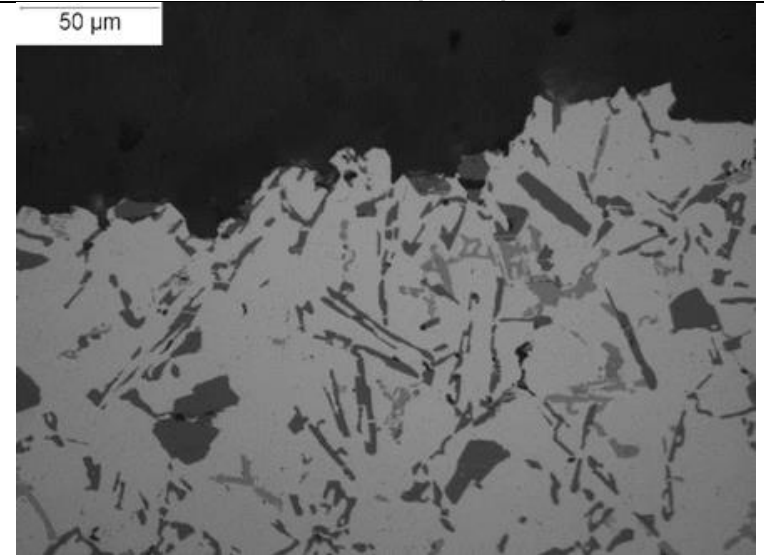

Figura 199 - Superfície de fratura do corpo de prova de tração a quente da série R-ZrVTiMn.

Parte 18. (500x)

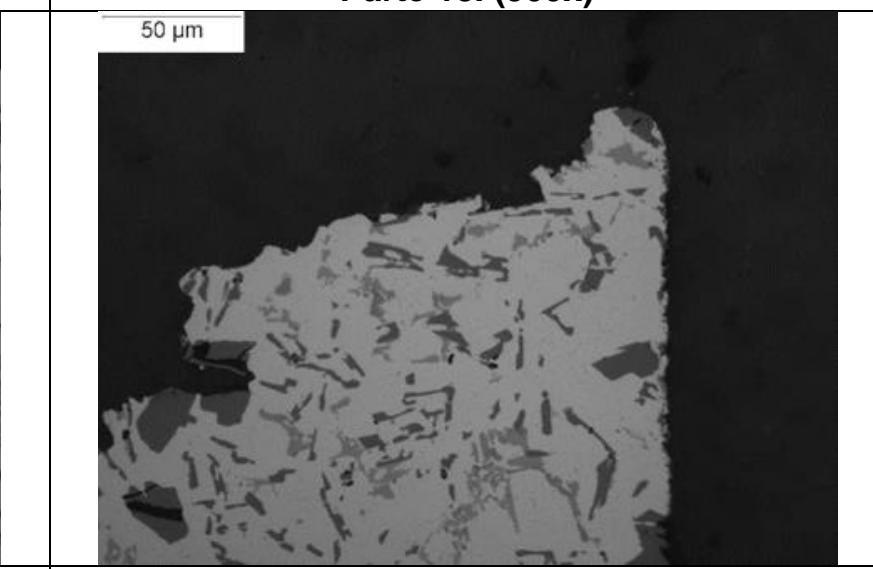

Figura 201 - Superfície de fratura do corpo de prova de tração a quente da série R-ZrVTiMn.

Parte 20. (500x) 
$O$ aumento na quantidade de intermetálicos encontrado na liga R-ZrVTiMn justifica tanto a redução de alongamento nos ensaios de tração (Figura 158), quanto à redução da vida média em fadiga devido à maior velocidade de propagação da trinca.

Os resultados de redução de alongamento são similares aos resultados obtidos por [Garat; Laslaz, 2002] e [Joyce et al., 2003].

No entanto, a redução da vida em fadiga não era um resultado esperado, já que toda a literatura encontrada indicava que a adição do zircônio, vanádio, titânio e manganês seria benéfica para o material.

A principal diferença entre as ligas utilizadas neste estudo e nos trabalhos publicados por [Garat; Laslaz, 2002] e [Garat, 2011] é o teor de silício. Enquanto neste estudo foram utilizadas ligas hipereutéticas com presença de partículas de silício primário, nos dois trabalhos que motivaram este estudo, foram utilizadas ligas hipoeutéticas modificadas.

Na discussão de resultados, ficou claro que as partículas de silício primário exercem um papel decisivo na nucleação das trincas de fadiga, o que explica os valores consideravelmente mais baixos encontrados nas ligas hipereutéticas.

No artigo publicado por [Joyce et. al., 2003], a quantidade de partículas de silício primário ao longo de uma trinca por fadiga foi contada e comparada à quantidade de partículas de silício aleatoriamente distribuídas na liga e chegou-se à conclusão de que há cerca de $30 \%$ mais partículas de silício primário na superfície de fratura que no restante da microestrutura.

Isso mostra que as partículas de silício primário influenciam não só na nucleação das trincas de fadiga, mas também em seu crescimento.

Sendo assim, pode-se esperar que ligas de alumínio hipoeutéticas apresentem comportamento diferente das ligas de alumínio hipereutéticas. 


\section{Conclusões}

- A alteração do tratamento térmico de solubilização de $500^{\circ} \mathrm{C}$ por uma hora para $525^{\circ} \mathrm{C}$ por quinze minutos resulta em um aumento de vida média em fadiga a $300^{\circ} \mathrm{C}$ de cerca de $100 \%$ para uma liga AlSi12CuMgNi. O aumento da vida em fadiga foi atribuído a um maior arredondamento das partículas de silício e intermetálicos, reduzindo a área de partículas frágeis que facilitam a propagação de trincas e reduzindo a concentração de tensões em ângulos agudos nas bordas das partículas.

- A adição combinada de zircônio, titânio, vanádio e manganês a uma liga AISi12CuMgNi gera uma redução de cerca de 30\% na vida média em fadiga a $300^{\circ} \mathrm{C}$. Esta redução na vida média em fadiga é resultado da fragilização do material pela presença de maior quantidade de intermetálicos que facilitam a propagação das trincas.

- As trincas por fadiga, nas condições em que foram realizados os ensaios, iniciam predominantemente em partículas de silício primário de tamanho maior que a média da população de partículas. Sendo assim, o controle do tamanho das partículas de silício primário é o fator de maior importância no aumento da vida em fadiga deste material.

- A adição de zircônio, vanádio, titânio e manganês reduz o alongamento de uma liga AISi12CuMgNi sem aumentar o limite de escoamento e o limite de resistência em ensaios de tração a $300^{\circ} \mathrm{C}$ devido ao aumento da quantidade de intermetálicos na liga.

- Ligas hipoeutéticas e hipereutéticas com adição de zircônio, vanádio, titânio e manganês apresentam comportamentos mecânicos diferentes em ensaios de fadiga a quente.

- A adição de vanádio a uma liga AISi12CuMgNi resulta no crescimento de feather crystals que reduzem consideravelmente a vida em fadiga a $300^{\circ} \mathrm{C}$. 


\section{Sugestões de trabalhos futuros}

- Existe uma tendência de mercado de eliminação do tratamento de solubilização. Seria interessante entender o efeito do zircônio, vanádio, titânio e manganês em ligas sem tratamento de solubilização.

- Ensaios de fadiga em $10^{7}$ ciclos ajudariam a separar melhor o efeito de nucleação e propagação de trincas de fadiga e, consequentemente, aumentariam a distinção de resultados entre as séries.

- Estudar a microestrutura de forma a entender a influência da interconectividade entre partículas em ensaios de fadiga. A literatura atual se concentra em ensaios de tração e compressão.

- Estudar a presença e a distribuição de intermetálicos contendo zircônio, vanádio, titânio e manganês na matriz de alumínio via microscopia de transmissão. A literatura analisada durante a revisão bibliográfica sugere que esses intermetálicos são responsáveis pelo aumento de propriedades mecânicas, em particular, a fluência.

- Estudar a alteração de morfologia e as propriedades mecânicas dos intermetálicos após a adição de zircônio, vanádio, titânio e manganês. 


\section{REFERÊNCIAS}

[Apelian et al., 1989] Apelian, D.; Shibkumar, S.; Sigworth, G.; Fundamental aspects of heat treatment of cast Al-Si-Mg; AFS Transactions; V.97; 1989; pp.727742.

[Arnold, 1961] Arnold, F.L.; Prestley, J.S.; Hypereutectic aluminum-silicon casting alloys phosphorus refinement; AFS Transactions; v.69; 1961; pp.129-137.

[Asghar et al., 2009] Asghar, Z.; Requena, G.; Degischer, H.P.; Cloetens, P.; Threedimensional study of Ni aluminides in an AlSi12 alloy by means of light optical and synchroton microtomography; Acta Materialia, v.57; 2009; pp. 4125-4132.

[Asghar et al., 2014] Asghar, Z.; Requena, G.; Zahid, G.H.; Effect of thermally stable interpenetrating networks of aluminudes and $\mathrm{Si}$ on the high temperature strength of an AISi12CuMgNi alloy; Unpublished article; 2014; 14p.

[ASM Metals Handbook, 1993]METALS HANDBOOK; American Society for Metals; v.3; Alloy Phase Diagrams; 10a ed.; 1993.

[Bäckerud et al., 1991] Bäckerud, L.; Gustafson, P.; Johnsson; Grain refining mechanisms in aluminum as a result of additions of titanium and boron, Part II; Aluminium, v.67; No.9; 1991; pp.910-915.

[Bäckerud, 1990] Bäckerud, L.; Chai, G.; Tamminem, J.; Solidification characteristics of aluminum alloys - volume 2: Foundry alloys; AFS/Skanaluminium; 1990.

[Baradarani; Raiszadeh, 2011] Baradarani, B.; Raiszadeh, R.; Precipitation hardening of cast Zr-containing A356 aluminum alloy; Materials and design; v.32; 2011; pp.935-940.

[Belov et al., 2005] Belov., N.A.; Eskin, D.G.; Avxentieva, N.N.; Constituent phase diagram of the Al-Cu-Fe-Mg-Ni-Si system and their application to the analysis of aluminum piston alloys; Acta Materialia; v.53; 2005; pp.4709-4722. 
[Callister; Rethwisch, 1998] Callister, W.D.; Rethwisch, D.G.; Materials Science and Engineering: An introduction; John Wiley and Sons; University of Minnesota; 4ed.; 1998.

[Cárceres et al., 1999a] Cárceres, C.H.; Djurdjevic, M.B.; Stockwell, T.J.; Sokolowski, K.H.; The effect of Cu content on the level of microporosity in Al-Si-CuMg casting alloys; Scripta Materialia; v.40; no.5; 1999; pp.631-637.

[Cárceres et al., 1999b] Cárceres, C.H.; Davidson, C.J.; Griffiths, J.R.; Wang, Q.G; The effect of $\mathrm{Mg}$ on the microstructure and mechanical behavior of Al-Si-Mg casting alloys; Metallurgical and materials transactions A; v.30A; 1999; pp.2611-2618.

[Chan, 2010] Chan, K.S.; Roles of microstructure in fatigue crack initiation; International Journal of Fatigue; v.32; 2010; pp.1428-1447.

[Chen et al., 2006] Chen, C.L.; West, G.; Thomson, R.C.; Characterization of intermetallic phases in multicomponent $\mathrm{Al}-\mathrm{Si}$ casting alloys for engineering applications; Materials Science Forum, v. 359, 2006, pp.519-52.

[Closset; Gruzleski, 1982] Closset, B.; Gruzleski, J.E.; Structure and properties of hypoeutectic Al-Si-Mg alloys modified with pure strontium; Metallurgical Transactions A; v.13A; June; 1982; pp.945-951.

[Crosley; Mondolfo, 1966] Crosley, P.B.; Mondolfo, L.F.; The modification of aluminum-silicon alloys; AFS Transactions; v.74; 1966; pp.89-100.

[Davies; Bakken, 1966] Davies, L.V.; Bakken, K.; High temperature low cycle fatigue of an extruded aluminum-silicon-magnesium-nickel alloy; Journal of nuclear materials; v.18; 1699; pp.226-230.

[Dieter, 1988] Dieter, G.E.; Mechanical Metallurgy; McGraw-Hill Book Company; Singapura; 1988.

[Dons et al., 2005] Dons, A.L.; Heiberg, G.; Voje, J.; Maeland, J.S.; Loland, J.O.; Prestmo, A.; On the effect of additions of $\mathrm{Cu}$ and $\mathrm{Mg}$ on the ductility of AISi foundry alloys cast with cooling rate of approximately $3 \mathrm{~K} / \mathrm{s}$; Materials Science and Engineering A; v.413-414; 2005; pp.561-566. 
[Dowling, 1998] Dowling, N.E.; Mechanical Behavior of Materials; 2ed.; Prentice Hall; New Jersey; 1998.

[Edwards et al., 1998] Edwards, G.A.; Stiller, K.; Dunlop, G.L.; Couper, M.J.; The precipitation sequence in Al-Mg-Si alloys; Acta Materialia, 46; No. 11; 1998; pp. 3893-3904.

[Feikus, 1998] Feikus, F.J.; Optimization of Al-Si cast alloys for cylinder head applications; AFS Transactions, v.106; 1998; pp. 225-231.

[Floweday et al., 2011] Floweday, G.; Petrov, S.; Tait, R.B.; Press, J.; Thermomechanical fatigue damage and failure of modern high performance diesel pistons; Engineering Failure Analysis; v.18; 2011; pp.1664-1674.

[Forbord et al., 2008] Forbord, B.; Hallem, H., Royset, J.; Marthisen, K.; Thermal stability of $\mathrm{Al}_{3}\left(\mathrm{Sc}_{x}, \mathrm{Zr}_{1-x}\right)$-dispersoids in extruded aluminum alloys; Materials Science and Engineering A; v.475; 2008; pp.241-248.

[Furlan, 2007] Furlan, T.S.; Influência do teor de estrôncio na modificação da liga A356; Dissertação (Mestrado); Escola Politécnica da Universidade de São Paulo; São Paulo; 2007.

[Garat, 2011] Garat, M.; Optimization of an aluminum cylinder head alloy of the AlSi7Cu3MnMg type reinforced by additions of peritectic elements; International Journal of Metalcasting; Summer 2011; pp.17-24.

[Garat; Laslaz, 2002] Garat, M.; Laslaz, G.; Improved aluminum alloys for common rail diesel cylinder heads; AFS Transactions; v.110; 2002; pp.89-96.

[Granger et al., 1986] Granger, D.A.; Truckner, W.G.; Rooy, E.L.; Aluminum alloys for elevated temperatura application; AFS Transactions; v.94; 1986; pp.777-784.

[Guillot et al., 2002] Guillot, I.; Barlas, B.; Cailletaud, G.; clavel, M.; Massinon, D.; Thermomechanical fatigue and aging of cast aluminum alloy: a link between numerical modeling and microstructural approach; Temperature-fatigue interaction; 2002; pp.75-84. 
[Haque et al., 1983] Haque, M.M.; Bennett, G.H.; Kondic, V.; Effects of silicon and magnesium additions on strontium modification of aluminum-silicon eutectic base alloys; Foundry Trade Journal; March 24; 1983; pp.387-190.

[Heusler et al., 2001] Heusler, L.; Feikus, F.J.; Otte, M.O.; Alloy and casting process optimization for engine block application; AFS Transactions; v.109; 2001; pp.443452.

[Heywood, 1998] Heywood, J.B.; Internal Combustion Engine Fundamentals; McGraw-Hill International Editions; Singapura; 1998; 930p.

[Hoskin et al, 1988] Hoskin, G.A.; Provan, J.W.; Gruzleski, J.E.; The in-situ fatigue testing of a cast aluminum-silicon alloy; Theoretical and Applied Fracture Mechanics; v.10; 1988; pp.27-41.

[Joenoes; Gruzleski, 1991] Joenoes, A.T., Gruzleski, J.E.; Magnesium effects on the microstructure of unmodified and modified Al-Si alloys; Cast metals, v.4 No2; 1991.

[Jorstad, 1996] Jorstad, J.L.; Hypereutectric Al-Si casting alloys: 25 yars, what's next?; Silver anniversary paper; AFS Transactions; v.104; paper 96-18; pp.669-671; 1996.

[Jorstad, 2009] Jorstad, J.L.; The progress of 390 alloy: from inception until now. AFS Transactions; v. 117; paper 09-152; pp.241-249; 2009.

[Joyce et. al., 2003] Joyce, M.R.; Styles, C.M.; Reed, P.A.S.; Elevated temperature short crack fatigue behaviour in near eutecti Al-Si alloys; International Journal of Fatigue; v.25; 2003; pp.863-869.

[Kim et al., 2006] Kim, H.Y.; Han, S.W.; Lee, H.M.; The influence of $\mathrm{Mn}$ and $\mathrm{Cr}$ on the tensile properties of A356-0,20Fe alloy; Materials Letters, v.60; 2006; pp. 18801883.

[Knipling et al., 2006] Knipling, K.E.; Dunand, D.C.; Seidman, D.N.; Criteria for developing castable, creep-resistant aluminum-based alloys - A review; Z. Metallkd.; v.97; 2006; pp.246-265. 
[Kobayashi et al., 1997] Kobayashi, T.; Kim, H.J.; Niinomi, M.; Effect of calcium on mechanical properties of recycled aluminum casting alloys; Materials Science and Technology; v. 13; Junho, 1997; pp.497-502.

[Kumari et al., 2008] Kumari, S.S.S.; Pillai, R.M.; Pai, B.C.; A study on the structural, age hardening and mechanical characteristics of $\mathrm{Mn}$ and $\mathrm{Ca}$ added $\mathrm{Al}-\mathrm{TSi}-0.3 \mathrm{Mg}$ 0.6Fe alloy; Journal of alloys and compounds; v.453; 2008; pp.167-173.

[Lang, G., 1972] LANG, G., Giesseigenschaften and Oberflachenspannung von Aluminium und binâren Aluminiumiegierungen; Part I; Aluminium; v.48; No.10; 1972; p. 664-672.

[Lasa; Rodriguez-lbabe, 2002] Lasa, L.; Rodriguez-Ibabe, J.M.; Characterization of the $\mathrm{Al} 2 \mathrm{Cu}$ phase in two Al-Si-Cu-Mg casting alloys using calorimetry; Materials Characterization; v.48; 2002; pp.371-378.

[Lasagni et al., 2007] Lasagni, F.; Lasagni, A.; Marks, E.; Holzapfel, C.; Mücklich, F.; Degischer, H.P.; Three dimensional characterization of 'as-cast' and solution treated AISi12(Sr) alloys by high resolution FIB tomography; Acta Materialia; v.55; 2007; pp.3875-3882.

[Lehmann et al., 2002] Lehmann, U.; Scholz, J.; Goller, J.; Calculation and simulation: pitson calculations. Em: van Basshuesen R. Schafer F, editors. Internal combustion engines handbook; basic componentes, systems and perpectives; 1a ed.; Warrendale, PA, EUA; Springer Verlag Wien \& SAE; 2006; pp.170-187.

[Li et al., 2003] Li, Z.; Samuel, F.H.; Samuel,A.M.; Ravindran, C.; Valtierra, S.; Effect of alloying elements on the segregation and dissolution of Al2Cu phase in AlSi-Cu 319 alloys; Journal of Materials Science; v.38; 2003; pp.1203-1218.

[Li et al., 2010] Li, Y.; Yang, Y.; Wu, Y.; Wang, L.; Liu, X.; Quantitative comparison of three Ni-containing phases to the elevated-temperature properties of Al-Si piston alloys; Materials Science and Engineering A; v. 527; 2010; pp.7132-7137.

[Lipson e Sheth, 1973] Lipson, C.; Sheth, N.J.; Statistical design and analysis of engineering experiments; McGraw-Hill Book Company; EUA; 518p;1973. 
[Loper, 2000] Loper Jr., C.R.; Cho, J.I.; Influence of trace amounts of phosphorus in Al casting alloys - A review of the literature; AFS Transactions; v.108; 2000; pp.667-672.

[Mahmudi et al., 2006] Mahmudi, R.; Sepehrband, P.; Ghasemi, H.M.; Improved properties of A319 aluminum casting alloy modified with Zr; Materials Letters; v.60; 2006; pp.2606-2610.

[Major, 1989] Major, J.F.; Rutter, J.W.; Effect of strontium and phosphorus on solid/liquid interface of Al-Si eutectic; Materials Science and Technology; v.5; Julho 1989; pp.645-656

[Manasijevic et al., 2011] Manasijevic, S.; Radisa, R.; Markovic, S.; Pavlovic, Z.A.; Raic, K.; Thermal analysis and microscopic characterization of the piston alloy AISi13Cu4Ni2Mg; Intermetallics; v.19; 2011; pp.486-492.

[Mbuya et al., 2011] Mbuya, T.O.; Sinclair, I.; Moffat, A.J.; Reed, P.A.S.; Analysis of fatigue crack initiation and S-N response model cast aluminum piston alloys; Materials Science and Engineering A; v.528; 2011; pp.7331-7340.

[Meyers; Chawla, 1982] Meyers, M.A.; Chawla, K.K.; Mechanical Metallurgy: Principles and applications; Prentice-Hall; New York; 1ed.; 1982.

[Misra; Oswalt, 1982] Misra, M.S.; Oswalt, K.J.; Aging characteristics of titaniumrefined A356 and A357 aluminum castings; AFS Transactions; v.90; 1982; pp.1-10.

[Moffat et al., 2005] Moffat, A.J.; Barnes, S.; Mellor, B.G.; Reed, P.A.S.; The effect of silicon content on long crack fatigue behaviour of aluminum-silicon piston alloys at elevated temperature; International Journal of Fatigue; v.27; 2005; pp.1564-1570.

[Moffat et al., 2006] Moffat, A.J., Mellor, B.G., Chen, C.L., Thomson, R.C.; Reed, P.A.S.; Microstructural analysis of fatigue initiation in Al-Si casting alloys; Aluminium Alloys 2006: Innovation Through Research and Technology. 10th International Conference on Aluminum Alloys Switzerland, Trans Tech; 2006; pp.1083-1088.

[Mondolfo, 1976] Mondolfo, L.F.; Aluminum Alloys: structure and properties; Butterworth \& Co Ltd.; 1976. 
[Moustafa et al., 2002] Moustafa, M.A.; Samuel, F.H.; Doty, H.W.; Valtierra, S.; Effect of $\mathrm{Mg}$ and $\mathrm{Cu}$ additions on the microstructural characteristics and tensile properties of Sr-modified Al-Si eutectic alloys; International Journal of Cast Metals Research; v.14; 2002; pp.235-253.

[Murakami e Endo, 1994] Murakami, Y.; Endo, M.; Effect of defects, inclusions and inhomogeneities on fatigue strength; Fatigue; v.16; 1004; pp.163-182.

[Ogris et al., 2002] Ogris, E.; Wahlen, A.; Lüchinger, H.; Uggowitzer, P.J.; On the silicon spheroidization in Al-Si alloys; Journal of Light Metals; v.2; 2002; pp.263-269.

[Paray; Gruzleski, 1994] Paray, F.; Gruzleski, J.E.; Factors to consider in modification, in: Transactions AFS; v.102; pp. 883-842; 1994.

[Qian et al., 2008] Qian, Z.; Liu, X.; Zhao, D.; Zhang, G.; Effects of trace Mn addition on the elevated temperature tensile strength and microstructure of a low iron Al-Si piston alloy; Materials Letters; v.62; 2008; pp.2146-2149.

[Qiao, 2005] Qiao, J; Liu, X; Liu, X.; Bian, X.; Relationship between microstructures and contents of $\mathrm{Ca} / \mathrm{P}$ in near-eutectic piston alloys; Materials Letters; v.59; 2005; pp.1790-1794.

[Ravi et al., 2008] Ravi, K.R.; Pillai, R.M.; Amaranathan, K.R.; Pai, B.C.; Chakraborty, M.; Fluidity of aluminum alloys and composites: a review. Journal of alloys and compounds. 4562008 pp.201-210.

[Requena et al., 2009] Requena, G.; Garcés, G.; Rodríquez, M; Pirling, T.; Cloetens, P.; 3D architecture and load partition in eutectic Al-Si alloys; Advaced Engineering Materials, v.11; No.12; pp.1007-1014.

[Robson; Prangnell, 2001] Robson, J.D.; Prangnell, P.B.; Dispersoid precipitation and process modelling in zirconium containing commercial aluminium alloys; Acta Materialia; v.49; 2001; pp.599-613.

[Röhrle, 1995] Röhrle, M.D.; Pistons for internal combustion engines; Verlag Moderne Industrie; Landsberg/Lech; 1995. 
[Ryum, 1969] Ryum, N.; Precipitation and recrystallization in an Al-0,5wt\%Zr alloy; Acta Metallurgica; v.17; March; 1969; pp. 269-278.

[Samuel et al., 1998] Samuel, F.H.; Ouellet, P.; Samuel, A.M.; Doty, H.W.; Effect of $\mathrm{Mg}$ and $\mathrm{Sr}$ additions on the formation of intermetallics in Al-6 Wt Pct Cu-(0.45) to (0.8) Wt Pct Fe 319-type alloys; Metallurgical and Materials Transactions A; v.29A; December; 1998; 2871-2884.

[Samuel; Samuel, 1997] Samuel F.H.; Samuel, A.M.; Modification of Iron Intermetallics by Magnesium; Int J Cast Metals research; v. 10; 1997; pp.147-157.

[Santos et al., 2006] Santos, J.C.; Angeloni, M.; Maluf, O.; Milan, M.T.; Spinelli, D.; Efeito da adição de magnésio sobre as propriedades de fadiga em altas temperaturas de ligas de Al-Si fundidas sob pressão em molde permanente; $17^{\circ}$ CBCIMat; Foz do Iguaçu; 2006.

[Sepehrband et al., 2005] Sepehrband, P; Mahmudi, R.; Khomamizadeh, F.; Effect of $\mathrm{Zr}$ addition on the aging behavior of A319 aluminum cast alloy; Scripta Materialia; v.52; 2005; pp.253-257.

[Shivanath, 1977] R. Shivanath, P.K. Sengupta and T.S.. Eyre, Wear of aluminum silicon alloys,. Foundryman 70 349-356,1977

[Sigworth, 1983] Sigworth, G.K.; Theoretical and practical aspects of the modification of AI-Si alloys; AFS Transactions, v.91; 1983; pp.7-16.

[Sigworth, 1987] Sigworth, G.K.; Refinement of hypereutectic Al-Si-alloys; AFS Transactions, v.95; 1987; pp.303-314.

[Silva, 2006] Silva, F.S.; Fatigue on engine pistons - A compendium of case studies; Engineering Failure Analysis, v.13; 2006; pp.480-492.

[Sjölander; Seifeddine, 2010] Sjölander, E.; Seiffedine, S.; The heat treatment of AlSi-Cu-Mg casting alloys; Journal of Materials Processing Technology; v.210; 2010; pp.1249-1259. 
[Styles; Reed, 2000] Styles, C.M. and Reed, P.A.S.; Fatigue of an Al-Si gravity die casting alloy; Aluminium Alloys: Their Physical and Mechanical Properties; 7th International Conference ICAA7 Switzerland, Trans Tech, 2000; pp.1457-1462.

[Suresh, 1998] Suresh, S.; Fatigue of Materials; Cambridge University Press; Cambridge; 1998; 678p.

[Tash et al., 2007] Tash, M.; Samuel, F.H.; Mucciardi, F.; Doty, H,W,; Effect of metallurgical parameters on the hardness and microstructural characterization of as-cast and heat-treated 356 and 319 aluminum alloys; Materials Science and Engineering A; v. 443; 2007; pp.185-201.

[Taylor, 1995] Taylor, J.A.; The effect of iron in Al-Si casting alloys; International Journal of Cast Metals Research; 1995; pp.225-252.

[Tenekedjiev et al., 1989] Tenekedjiev, N.; Argo, D.; Gruzleski, J.E.; Sodium, strontium and phosphorus effects in hypereutectic Al-Si alloys; AFS Transactions; v.97; 1989; pp.127-136.

[Tenekedjiev, 1989] Tenekedjiev, N.; Strontium treatment of Aluminum-17\% silicon casting alloys; Dissertação (Mestrado); McGill University; Montreal, Québec; 1989.

[Tiryakioglu; Staley, 2003] Tiryakioglu, M.; Staley, J.T.; Aluminum Handbook v.1; pp.81-209.

[Turchin et al., 2007] Turchin, A.N.; Zuijderwijk, M.; Pool, J.; Eskin, D.G.; Katgerman, L.; Acta Materialia; v.55; 2007; pp.3795-3801.

[Wang et al., 2001] Wang, Q.G.; Apelian, D.; Lados, D.A.; Fatigue behavior of A356T6 aluminum cast alloys. Part I. Effect of casting defects; Journal of Light Metals; v. $1 ; 2001 ;$ pp.73-84.

[Wang et al., 2001b] Wang, Q.G.; Apelian, D.; Lados, D.A.; Fatigue behavior of A356-T6 aluminum cast alloys. Part II. Effect of microstructural constituents; Journal of Light Metals; v.1; 2001; pp.85-97.

[Weiss, 1987] Weiss, J.C.; Loper, C.R.; Primary silicon in hypereutectic aluminum- 
silicon casting alloys; AFS Transactions; v.95; 1987; pp.51-62.

[Yang et al., 2012] Yang, Y.; Yu, K.; Li, Y.; Zhao, D.; Liu, X.; Evolution of nickel-rich phases in Al-Si-Cu-Ni-Mg piston alloys with diferente $\mathrm{Cu}$ additions; Materials and Design; v.33; 2012; pp.220-225.

[Yu et al., 2007] Yu, L.; Liu, X.; Ding, H.; Bian, X.; A new nucleation mechanism of primary Si by peritectic-like coupling of AIP and TiB2 in near eutectic Al-Si alloy; Journal of alloys and compounds; v.432; 2007; pp.156-162.

[Zeren et al., 2011] Zeren, M.; Karakulak, E.; Gümüs, S.; Influence of Cu addition on microstructure and hardness of near-eutectic Al-Si-xCu-alloys; Transactions of Nonferrous Metals Society of China; v.21; 2011; pp.1698-1702.

[Zeren, 2007] Zeren, M.; The effect of heat treatment on aluminum-based piston alloys; Materials and Design; v.28; 2007; pp.2511-2517.

[Zolotorevsky et al., 2007 ] Zolotorevsky, V.S.; Belov, N.A.; Glazoff, M.V.; Casting aluminum aloys; Elsevier; Oxford-UK; 2007.

[Zuo et al., 2009] Zuo, M., Liu, X., Sun, Q.; Effects of processing parameters on the refinement of primary silicon in A390 alloys with a new Al-Si-P master alloy; Journal of Materials Science; v.44; 2009; pp.1952-1958

[Zuo et al., 2009] Zuo, M.; Liu, X.; Dai, H.; Liu, X.; Al-Si-P master alloy and its modification and refinement performance on Al-Si alloys; Rare Metals, v.28; n.4; Aug 2009; pp.412-417. 